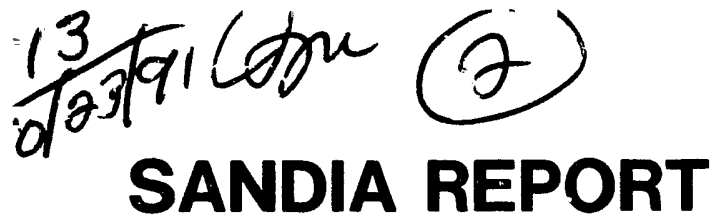

SAND $90-2138 \cdot \mathrm{UC}-523$

Unlimited Release

Printed August 1991

\section{Experimental Results of Direct Containment Heating by High-Pressure Melt Ejection Into the Surtsey Vessei: The DCH-3 and DCH-4 Tests}

Michael D. Allen, Martin Pilch, Robert T. Nichols, John E. Brockmann, David W. Sweet, William W. Tarbell

Prepared by

Sandia National Laboratories

Albuquerque, New Mexico 87185 and Livermore, California 94550

for the United States Department of Energy

under Contract DE-AC04-76DP00789 
Issued by Sandia National Laboratories, operated for the United States Department of Energy by Sandia Corporation.

NOTICE: This report was prepared as an account of work sponsored by an agency of the United States Government. Neither the United States Government nor any agency thereof, nor any of their employees, nor any of their contractors, subcontractors, or their employees, makes any warranty, express or implied, or assumes any legal liability or responsibility for the accuracy, completeness, or usefulness of any information, apparatus, product, or process disclosed, or represents that its use would not infringe privately owned rights. Reference herein to any specific commercial product, process, or service by trade name, trademark, manufacturer, or otherwise, does not necessarily constitute or imply its endorsement, recommendation, or favoring by the United States Government, any agency thereof or any of their contractors or subcontractors. The views and opinions expressed herein do not necessarily state or reflect those of the United States Government, any agency thereof or any of their contractors.

Printed in the United States of America. This report has been reproduced directly from the best available copy.

Available to DOE and DOE contractors from

Office of Scientific and Technical Information

PO Box 62

Oak Ridge, TN 37831

Prices available from (615) 576-8401, FTS 626-8401

Available to the public from

National Technical Information Service

US Department of Commerce

5285 Port Royal Rd

Springfield, VA 22161

NTIS price codes

Printed copy: A11

Microfiche copy: A01 
SAND90-2138

Unlimited Release

Printed August 1991

SAND- $-90-2138$

DE92 001670

\begin{abstract}
EXPERIMENTAL RESULTS OF DIRECT CONTAINMENT HEATING BY HIGH-PRESSURE MELT EJECTION INTO THE SURTSEY VESSEL: THE DCH-3 AND DCH-4 TESTS
\end{abstract}

\author{
Michael D. Allen \\ Martin Pilch \\ Robert T. Nichols* \\ John F. Brockmann \\ David W. Sweet\$ \\ William W. Tarbell
}

Severe Accident Phenomenology Division

Sandia National Laboratories

Albuquerque, NM 87185

\begin{abstract}
Two experiments, $\mathrm{DCH}-3$ and $\mathrm{DCH}-4$, were performed at the surtsey test facility to investigate phenomena associated with a highpressure melt ejection (HPME) reactor accident sequence resulting in direct containment heating (DCH). These experiments were performed using the same experimental apparatus with identical initial conditions, except that the Surtsey test vessel contained air in $\mathrm{DCH}-3$ and argon in $\mathrm{DCH}-4$. Inerting the vessel with argon eliminated chemical reactions between metallic debris and oxygen. Thus, a comparison of the pressure responses in $\mathrm{DCH}-3$ and $\mathrm{DCH}-4$ gave an indication of the $\mathrm{DCH}$ contribution due to metal/oxygen reactions.
\end{abstract}

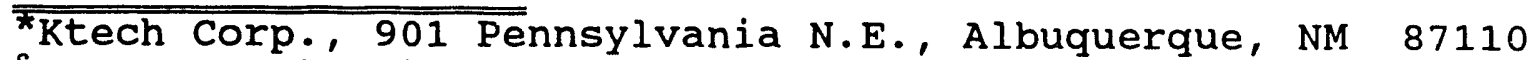
§Attache, Winfrith, Atomic Energy Authority, United Kingdom 


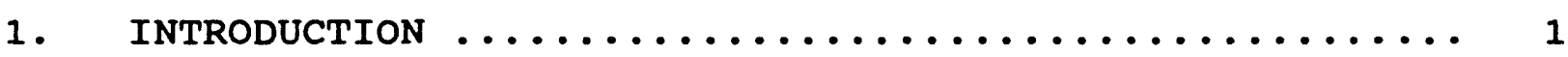

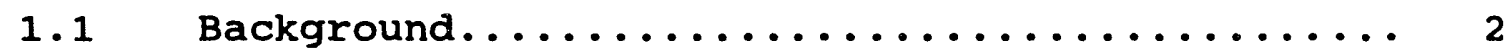

1.2 objectives........................ 3

$1.3 \quad \mathrm{DCH}-3$ Experiment........................ 4

$1.4 \quad \mathrm{DCH}-4$ Experiment................... 5

2. EXPERIMENT DESCRIPTION .................... 6

2.1 Experiment Apparatus ................. 6

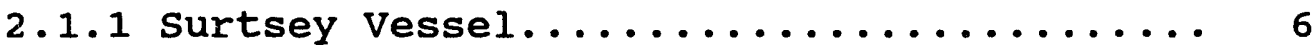

2.1 .2 Melt Generator....................... 7

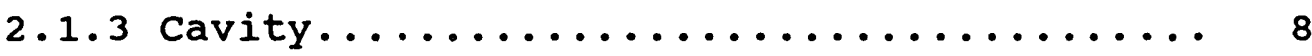

2.2 Instrumentation...................... 8

2.2.1 Pressure Measurements.............. 13

2.2.2 Temperature Measurements............ 14

2.2.3 Data Acquisition system............... 15

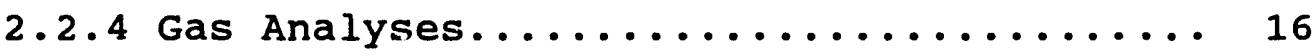

2.2 .5 Aerosol Instrumentation............ 17

2.3 Initial conditions.................. 22

2.4 Experiment Procedures................. 24

3. EXPERIMENTAL RESULTS........................ 49

3.1 Pressure and Temperature Measurements

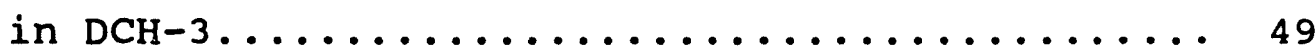

3.2 Pressure and Temperature Measurements in $\mathrm{DCH}-4 \ldots \ldots \ldots \ldots \ldots \ldots \ldots \ldots . \ldots \ldots \ldots . \ldots \ldots$

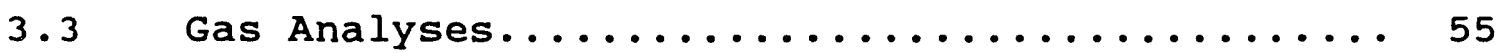

3.4 Debris Recovery and Mass Balance........... 58

3.5 Aerosol Measurements................... 62

3.5.1 Aerosol Mass Release............... 63

3.5.2 Aerosol Mass Distribution and Particle Morphology............... 69

3.5.3 Aerosol Release Fractions............ 70 
CONTENTS (continued)

3.6 Observations from Film Records............ 87

3.6 .1 video Observations................ 87

3.6 .2 Real Time X-ray Imaging system........ 88

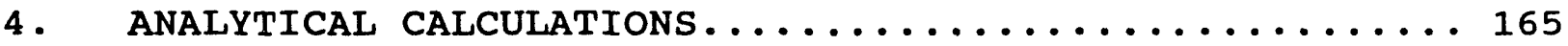

4.1 The CONTAIN-DCH Analysis............... 166

4.1 .1 DCH-3 CONTAIN Model.............. 167

4.1 .2 Discussion.................... 168

4.2 The Kiva-DCH Analysis.................. 169

4.2.1 Model Assumptions and Initial

Conditions.......................... 171

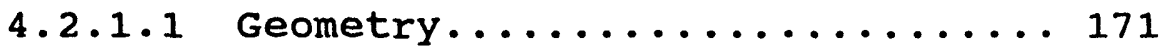

4.2.1.2 Debris and Gas Injection....... 174

4.2.1.3 Debris-Surface Interactions.... 178

4.2.1.4 Initial Conditions......... 179

4.2 .2 Kiva-DCH Results................. 179

4.2.2.1 Pressure...................179

4.2.2.2 Iron oxidation............ 184

4.2.2.3 Gas Analysis.............. 189

4.2.2.4 Debris Mass Variations........ 192

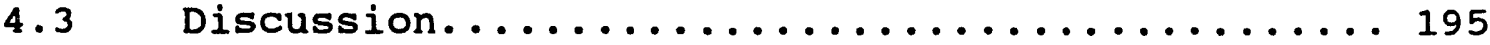

4.3.1 Pressure Histories................ 195

4.3.1.1 Initial Pressure Peak........ 195

4.3.1.2 Second Pressure Peak.......... 196

4.3 .2 Iron oxidation.................. 200

4.3 .3 oxygen Depletion.................. 202

4.3.4 Trapping and Dripping Parameters.......203

4.3 .5 sensitivity studies.............. 204

4.3.5.1 Debris Sensitivity studies..... 204

4.3.5.2 Blowdown Gas.............. 208

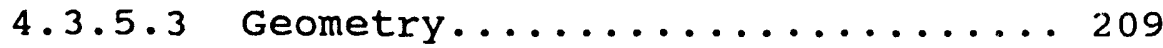




\section{CONTENTS (concluded)}

Section

Page

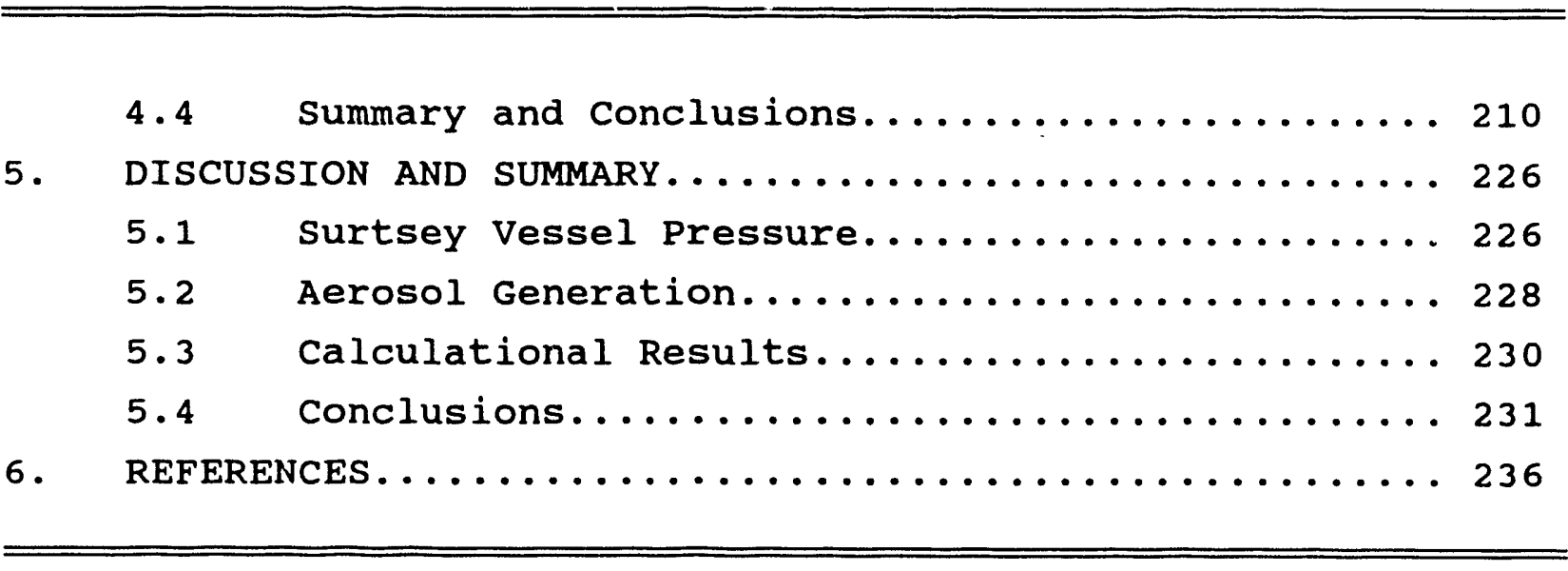




\section{LIST OF FIGURES}

\section{Figure}

2-1. Schematic diagram of the melt generator and cavity in the surtsey vessel...................... 30

2-2. Schematic diagram of the melt generator assembly.... 31

2-3. Photograph of the melt generator in $\mathrm{DCH}-3 \ldots \ldots \ldots 32$

2-4. Schematic drawing of the scaled zion cavity....... 33

2-5. Photograph of the pyrometer box............. 34

2-6. Schematic diagram of the gas sampling system...... 35

2-7. Gas grab sample manifold pressure versus experiment

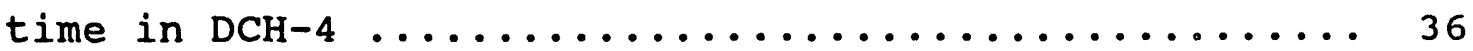

2-8. Cross-sectional view of the surtsey vessel showing the internal structures, melt generator, scaled $\mathrm{Zion}$ cavity, and aerosol instrumentation............ 37

2-9. Photograph of the aerosol sampling loop with the assembled aerosol sampling equipment............ 38

2-10. Schematic drawing of the gooseneck nozzle for

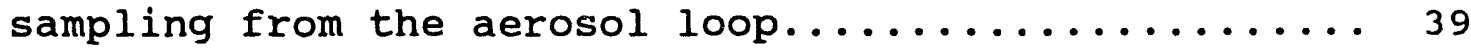

2-11. Schematic diagram of the $D C H$ aerosol sampling instrumentation....................... 40

2-12. Schematic diagram of the aerosol flow dilutor...... 41

2-13. Photograph of a disassembled Andersen Mark III cascade impactor........................ 42

2-14. Photograph of the assembled cascade impactor bank... 43 2-15. Photograph of a disassembled Gelman filter holder... 44 2-16. Photograph of the assembled filter bank......... 45 


\section{LIST OF FIGURES (continued)}

Figure

Page

2-17. Photograph of a disassembled sierra cyclone

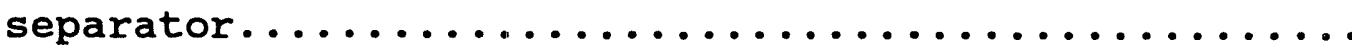

2-18. Schematic diagram of the Dynatron opacity monitor....

2-19. Photograph of the programmer and controller used to control the sampling scheme for the aerosol

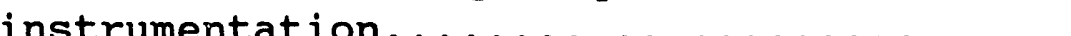

3-1. Signal from the photodiode below the melt plug in

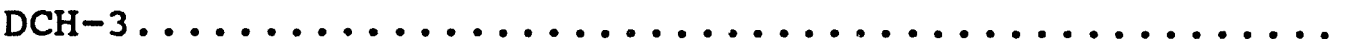

3-2. Ignitor timing signal in $\mathrm{DCH}-3 \ldots \ldots \ldots \ldots \ldots \ldots$

3-3. Pressure measured by transducer PMG-29 inside the melt generator in $\mathrm{DCH}-3 \ldots \ldots \ldots \ldots \ldots \ldots \ldots \ldots \ldots$

3-4. Pressure measured by transducer PMG-30 inside the

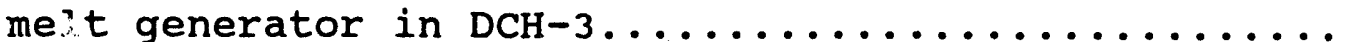

3-5. Pressure measured by transducer PMG-29 inside the

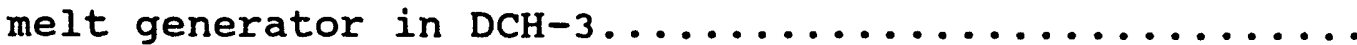

3-6. Pressure measured by transducer PMG-30 inside the

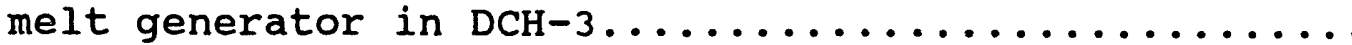

3-7. Temperature measured by thermocouple HMGSID located on the side of the melt generator in $\mathrm{DCH}-3 \ldots \ldots \ldots \ldots$

3-8. Pressure response for transducer PL1-20 located at level 1 of the surtsey vessel in $\mathrm{DCH}-3 \ldots \ldots \ldots \ldots \ldots . . .$.

3-9. Pressure response for transducer PL1-21 located at level 1 of the surtsey vessel in $\mathrm{DCH}-3 \ldots . . \ldots \ldots \ldots . .$.

3-10. Pressure response for transducer PL1-22 located at level 1 of the surtsey vessel in $\mathrm{DCH}-3 \ldots \ldots \ldots \ldots \ldots . . . .98$

3-11. Pressure response for transducer PL3-23 located at level 3 of the surtsey vessel in $\mathrm{DCH}-3 \ldots \ldots \ldots \ldots \ldots$ 


\section{LIST OF FIGURES (continued)}

Figure

Page

3-12. Pressure response for transducer PL3-24 located at level 3 of the surtsey vessel in $\mathrm{DCH}-3 \ldots \ldots \ldots \ldots \ldots . \ldots 100$

3-13. Pressure response for transducer PL3-25 located at level 3 of the surtsey vessel in $\mathrm{DCH}-3 \ldots \ldots \ldots \ldots \ldots 101$

3-14. Pressure response for transducer PL5-26 located at level 5 of the surtsey vessel in DCH-3........... 102

3-15. Pressure response for transducer PL5-27 located at level 5 of the surtsey vessel in $\mathrm{DCH}-3 \ldots \ldots \ldots \ldots \ldots . \ldots 103$

3-16. Temperature response for thermocouple HL1-01 located at level 1 of the surtsey vessel in $\mathrm{DCH}-3 \ldots \ldots \ldots \ldots \ldots 104$

3-17. Temperature response for thermocouple HL1-02 located at level 1 of the surtsey vessel in $\mathrm{DCH}-3 \ldots \ldots \ldots \ldots . . \ldots 5$

3-18. Temperature response for thermocouple HL1-03 located at level 1 of the surtsey vessel in $\mathrm{DCH}-3 \ldots \ldots \ldots \ldots \ldots 106$

3-19. Temperature response for thermocouple HL1-04 located at level 1 of the Surtsey vessel in DCH-3......... 107

3-20. Temperature response for thermocouple HL1-05 located at level 1 of the surtsey vessel in $D C H-3 \ldots \ldots \ldots \ldots \ldots 108$

3-21. Temperature response for thermocouple HL1-06 located at level 1 of the surtsey vessel in $\mathrm{DCH}-3 \ldots \ldots \ldots \ldots . . .109$

3-22. Temperature response for thermocouple HL3-07 located at level 3 of the surtsey vessel in $\mathrm{DCH}-3 \ldots \ldots \ldots \ldots . . .110$

3-23. Temperature response for thermocouple HL3-08 located at level 3 of the surtsey vessel in $\mathrm{DCH}-3 \ldots \ldots \ldots \ldots \ldots 111$

3-24. Temperature response for thermocouple HL3-09 located at level 3 of the surtsey vessel in $D C H-3 \ldots \ldots \ldots \ldots 112$

3-25. Temperature response for thermocouple HL3-10 located at level 3 of the surtsey vessel in $\mathrm{DCH}-3 \ldots \ldots \ldots \ldots \ldots 113$ 


\section{LIST OF FIGURES (continued)}

Figure.

3-26. Temperature response for thermocouple HL3-11 located at level 3 of the surtsey vessel in $\mathrm{DCH}-3 \ldots \ldots \ldots \ldots \ldots 114$

3-27. Temperature response for thermocouple HL3-12 located at level 3 of the surtsey vessel in $\mathrm{DCH}-3 \ldots \ldots \ldots \ldots \ldots 115$

3-28. Temperature response for thermocouple HL5-13 located at level 5 of the surtsey vessel in DCH-3......... 116

3-29. Temperature response for thermocouple HL5-15 located at level 5 of the surtsey vessel in $\mathrm{DCH}-3 \ldots \ldots \ldots \ldots \ldots 117$

3-30. Temperature response for thermocouple HL5-16 located at level 5 of the surtsey vessel in $\mathrm{DCH}-3 \ldots \ldots \ldots \ldots \ldots 118$

3-31. Temperature response for thermocouple HL5-17 located at level 5 of the surtsey vessel in DCH-3......... 119

3-32. Temperature response for thermocouple HL5-18 located at level 5 of the surtsey vessel in $\mathrm{DCH}-3 \ldots \ldots \ldots \ldots . \ldots 120$

3-33. Temperature response for thermocouple HL5-19 located at level 5 of the surtsey vessel in $\mathrm{DCH}-3 \ldots \ldots \ldots \ldots \ldots 121$

3-34. Signal from the photodiode (EPD-75) below the melt

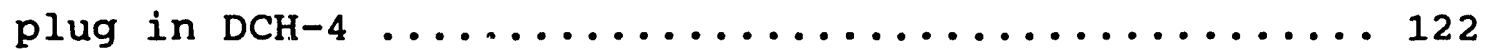

3-35. Ignitor timing signal $(E I G-76)$ in $\mathrm{DCH}-4 \ldots \ldots \ldots \ldots$

3-36. Pressure measured by transducer inside the melt

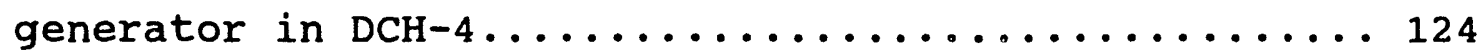

3-37. Pressure response for transducer PL1-10 located at level 1 of the surtsey vessel in DCH-4........... 125

3-38. Pressure response for transducer PL1-11 located at level $i$ of the surtsey vessel in $\mathrm{DCH}-4 \ldots \ldots \ldots \ldots \ldots . \ldots 126$

3-39. Pressure response for transducer PL1-12 located at level 1 of the surtsey vessel in DCH-4.......... 127 


\section{LIST OF FIGURES (continued)}

Figure

Page

3-40. Pressure response for transducer PL3-13 located at level 3 of the surtsey vessel in $\mathrm{DCH}-4 \ldots \ldots \ldots \ldots \ldots \ldots 128$

3-41. Pressure response for transducer PL1-14 located at level 3 of the surtsey vessel in $\mathrm{DCH}-4 \ldots \ldots \ldots \ldots \ldots \ldots 129$

3-42. Pressure response for transducer PL1-15 located at level 3 of the surtsey vessel in $\mathrm{DCH}-4 \ldots \ldots \ldots \ldots \ldots \ldots 130$

3-43. Pressure response for transducer PL1-17 located at level 5 of the surtsey vessel in $\mathrm{DCH}-4 \ldots \ldots \ldots \ldots \ldots \ldots 131$

3-44. Pressure response for transducer PL1-18 located at level 5 of the surtsey vessel in $\mathrm{DCH}-4 \ldots \ldots \ldots \ldots \ldots \ldots 132$

3-45. Temperature response for thermocouple \#1 located at level 1 of the surtsey vessel in $\mathrm{DCH}-4 \ldots \ldots \ldots \ldots \ldots \ldots 133$

3-46. Temperature response for thermocouple \#2 located at level 1 of the surtsey vessel in $\mathrm{DCH}-4 \ldots \ldots \ldots \ldots \ldots . . .134$

3-47. Temperature response for thermocouple \#3 located at level 1 of the surtsey vessel in $\mathrm{DCH}-4 \ldots \ldots \ldots \ldots \ldots \ldots 135$

3-48. Temperature response for thermocouple \#4 located at level 1 of the surtsey vessel in DCH-4.......... 136

3-49. Temperature response for thermocouple \#5 located at level 1 of the surtsey vessel in $\mathrm{DCH}-4 \ldots \ldots \ldots \ldots \ldots \ldots 137$

3-50. Temperature response for thermocouple \#6 located at level 1 of the Surtsey vessel in DCH-4........... 138

3-51. Temperature response for thermocouple \#7 located at level 3 of the surtsey vessel in $\mathrm{DCH}-4 \ldots \ldots \ldots \ldots \ldots . . . .139$

3-52. Temperature response for thermocouple \#8 located at level 3 of the surtsey vessel in $D C H-4 \ldots \ldots \ldots \ldots \ldots \ldots 140$

3-53. Temperature response for thermocouple \#9 located at level 3 of the surtsey vessel in $\mathrm{DCH}-4 \ldots \ldots \ldots \ldots \ldots \ldots 141$ 
LIST OF FIGURES (continued)

Figure

Page

3-54. Temperature response for thermocouple \#10 located at level 3 of the surtsey vessel in DCH-4............ 142

3-55. Temperature response for thermocouple \#11 located at level 3 of the surtsey vessel in DCH-4........... 143

3-56. Temperature response for thermocouple \#12 located at level 3 of the surtsey vessel in DCH-4........... 144

3-57. Temperature response for thermocouple \#13 located at level 5 of the surtsey vessel in $\mathrm{DCH}-4 \ldots \ldots \ldots \ldots \ldots \ldots 145$

3-58. Temperature response for thermocouple \#14 located at level 5 of the surtsey vessel in $\mathrm{DCH}-4 \ldots \ldots \ldots \ldots \ldots \ldots 146$

3-59. Temperature response for thermocouple \#15 located at level 5 of the surtsey vessel in $\mathrm{DCH}-4 \ldots \ldots \ldots \ldots \ldots \ldots 147$

3-60. Temperature response for thermocouple \#16 located at level 5 of the surtsey vessel in DCH-4........... 148

3-61. Temperature response for thermocouple \#17 located at level 5 of the surtsey vessel in $\mathrm{DCH}-4 \ldots \ldots \ldots \ldots \ldots \ldots 149$

3-62. Photograph of three aspirated thermocouple assemblies

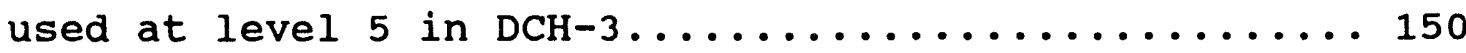

3-63. Temperature history from optical pyrometer measurements in $\mathrm{DCH}-3 \ldots \ldots \ldots \ldots \ldots \ldots \ldots \ldots \ldots 151$

3-64. Temperature history from the two-color pyrometer

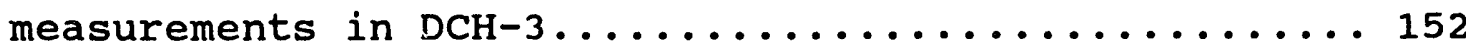

3-65. Temperature history from optical pyrometer

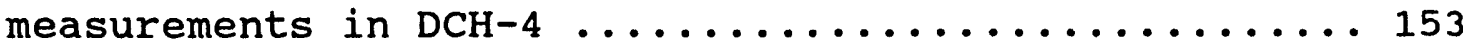

3-66. Temperature history from the two-color pyrometer

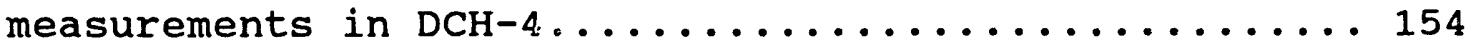




\section{LIST OF FIGURES (continued)}

Figure

Page

3-67. Posttest photograph showing an aerosol coating on the meit generator, cavity chute, and a mixing fan after

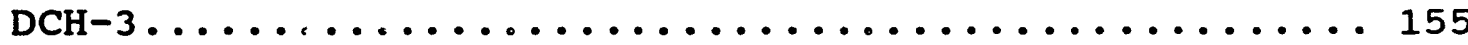

3-68. Photograph of the lower head of the surtsey vessel prior to $\mathrm{DCH}-3 \ldots \ldots \ldots \ldots \ldots \ldots \ldots \ldots \ldots \ldots \ldots \ldots$

3-69. Pnotograph of the lower head of the surtsey vessel after DCH-3, showing an aerosol coating.......... 157

3-70. DCH-3 aerosol mass concentration comparison of filter data to opacity monitor output............... 158

3-71. DCH-4 aerosol mass concentration comparison of filter data to opacity monitor output............... 159

3-72. Aerosol mass distribution in $\mathrm{DCH}-1 \ldots \ldots \ldots \ldots \ldots \ldots$

3-73. Aerosol mass distribution in $\mathrm{DCH}-2 \ldots \ldots \ldots \ldots \ldots \ldots$

3-74. Aerosol mass distribution in $\mathrm{DCH}-3 \ldots \ldots \ldots \ldots \ldots \ldots$

3-75. Aerosol mass distribution in $\mathrm{DCH}-4 \ldots \ldots \ldots \ldots \ldots$

3-76. Electron photomicrograph of aerosol collecied in

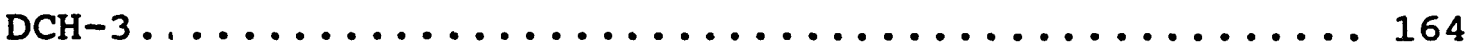

4-1. CONTAIN pressure prediction for one- and three-cell

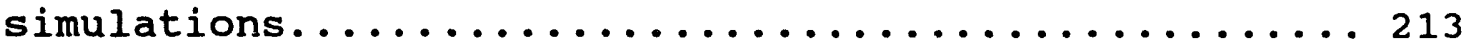

4-2. Three-cell CONTAIN-DCH representation of the surtsey vessel............................... 214

4-3. DCH-3 calculated and measured pressure histories $\left(P_{\text {trap }}=0.9, P_{\text {drip }}=0.22\right) \ldots \ldots \ldots \ldots \ldots \ldots \ldots \ldots \ldots \ldots \ldots \ldots \ldots$

4-4. DCH-3 calculated and measured pressure histories

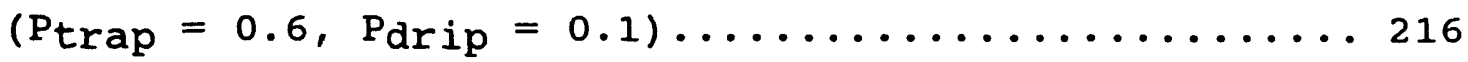




\section{LIST OF FIGURES (concluded)}

Figure

Page

4-5. DCH-4 calculated and measured pressure histories $\left(P_{\text {trap }}=0.90, P_{\text {drip }}=0.22\right) \ldots \ldots \ldots \ldots \ldots \ldots \ldots \ldots \ldots \ldots \ldots$

4-6. DCH-4 calculated and measured pressure histories

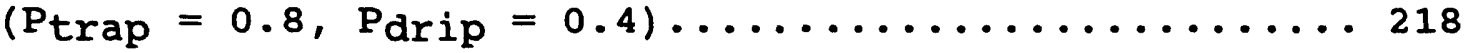

4-7. Effect of oxidation on pressure for Kiva DCH-3 (Ptrap $=0.9,{ }^{2}$ drip $\left.=0.22\right) \ldots \ldots \ldots \ldots \ldots \ldots \ldots \ldots \ldots \ldots \ldots \ldots \ldots$

4-8. Effect of oxidation on pressure for Kiva DCH-4 (Ptrap $\left.=0.9, P_{\text {drip }}=0.41\right) \ldots \ldots \ldots \ldots \ldots \ldots \ldots \ldots \ldots \ldots . \ldots \ldots$

4-9. Effect of oxidation on pressure for Kiva DCH-3 (Ptrap

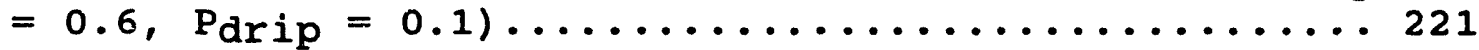

4-10. Effect of oxidation on pressure for Kiva DCH-4 (Ptrap $=0.8, \operatorname{Pdrip}=0.4) \ldots \ldots \ldots \ldots \ldots \ldots \ldots \ldots \ldots \ldots \ldots$

4-11. Effect of varying the debris mass on DCH-4 Kiva

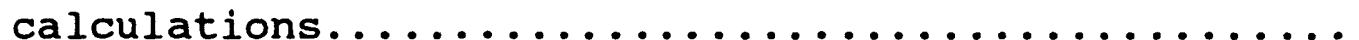

4-12. Measured pressure histories for $\mathrm{DCH}-3$ and $\mathrm{DCH}-4 \ldots \ldots 224$

4-13. Comparison of $\mathrm{Kiva} \mathrm{DCH}-3$ and $\mathrm{DCH}-4$ pressure histories with $\mathrm{P}_{\text {trap }}=0.90 \ldots \ldots \ldots \ldots \ldots \ldots \ldots$

5-1. Pressure histories inside the surtsey vessel for the four $\mathrm{DCH}$ experiments measured by level 3 pressure

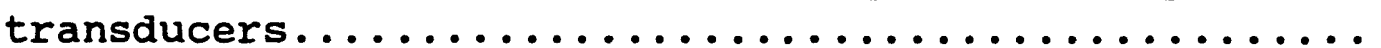

5-2. Comparison of CONTAIN-DCH pressure prediction and experimental results for $\mathrm{DCH}-1 \ldots \ldots \ldots \ldots \ldots \ldots \ldots \ldots \ldots$ 
LIST OF TABLES

Table

Page

2.1. DCH-3 Instrumentation..................... 9

$2.2 \quad \mathrm{DCH}-4$ Instrumentation..................... 11

2.3 Aerosol Instrumentation Used in $\mathrm{DCH}-3$ and $\mathrm{DCH}-4 \ldots \ldots 19$

2.4 Initial conditions for the DCH Experiments.........23

2.5 Melt Constituents by Element $(\mathrm{kg}) \ldots \ldots \ldots \ldots \ldots \ldots \ldots$

2.6 DCH-3 Initial Conditions................... 25

2.7 Initial Melt simulant Mass in $\mathrm{DCH}-3 \ldots \ldots \ldots \ldots \ldots \ldots$

2.8 DCH-4 Initial Conditions.................. 27

2.9 Initial Melt simulant Mass in $\mathrm{DCH}-4 \ldots \ldots \ldots \ldots \ldots \ldots$

3.1 Gas Grab Sample Results from DCH-3............. 56

3.2 Gas Grab Sample Results from DCH-4............. 57

3.3 Mass, Location, and Oxidation of Recovered Debris.... 59

3.4 Estimated Mass Balance.................... 62

$3.5 \quad$ DCH-3 Filter Data...................... 65

$3.6 \quad$ DCH -4 Filter Data....................... 66

3.7 Calculated Aerosol Release Fractions for Each Element

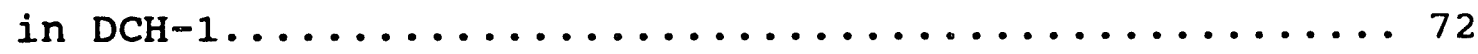

3.8 Calculated Aerosol Release Fractions for Each Element

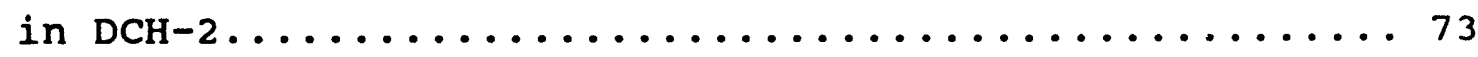

3.9 Calculated Aerosol Release Fractions for Each Element

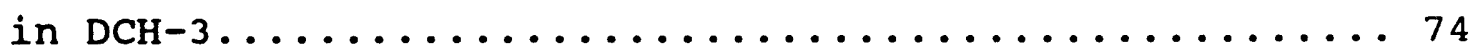


List of Tables (continued)

Table

Page

3.10 Calculated Aerosol Release Fractions for Each Element

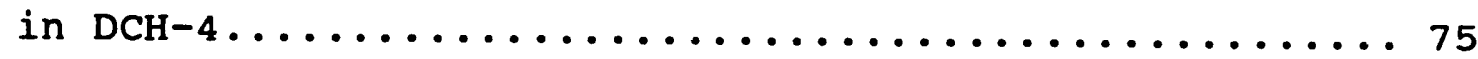

3.11 Elemental Analysis of DCH-1 Filter Samples ........76

3.12 Elemental Analysis of DCH-2 Filter Samples.........77

3.13 Elemental Analysis of DCH-3 Filter Samples.........78

3.14 Elemental Analysis of $\mathrm{DCH}-4$ Filter Samples......... 79

3.15 Elemental Analysis of Size classified Aerosol Collected with a Cyclone in $\mathrm{DCH}-1 \ldots \ldots \ldots \ldots \ldots \ldots$

3.16 Elemental Analysis of Size classified Aerosol Collected with a Cyclone in $\mathrm{DCH}-2 \ldots \ldots \ldots \ldots \ldots \ldots . \ldots . \ldots 8$

3.17 Elemental Analysis of Size classified Aerosol Collected with a Cyclone in $\mathrm{DCH}-3 \ldots \ldots \ldots \ldots \ldots . \ldots . \ldots 8$

3.18 Elemental Analysis of Size Classified Aerosol Collected with a Cyclone in $\mathrm{DCH}-4 \ldots \ldots \ldots \ldots \ldots . \ldots . \ldots 8$

3.19 Elemental Release Fractions from Relocated Mass in DCH Experiments............................ 85

4.1 Comparison of Surtsey Vessel and Kiva Code Model

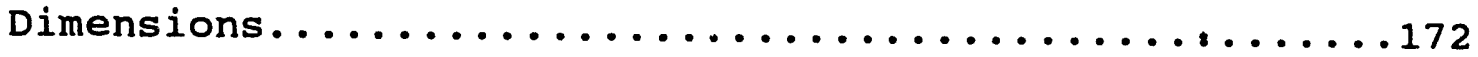

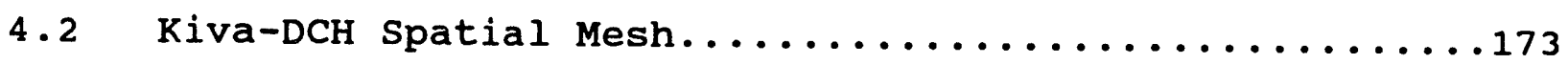

4.3 Debris and Gas Injection Parameters..............175

4.4 Derivation of Debris Data Used for the Analysis.....176

4.5 Trapping and Dripping probabilities in Kiva and

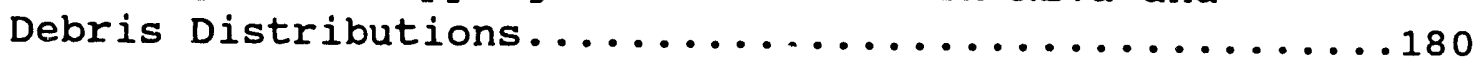

4.6 DCH-3 and $\mathrm{DCH}-4$ Initial Conditions.............. 
List of Tables (concluded)

Table

Page

4.7 Measured and Calculated Peak Pressures for DCH-3

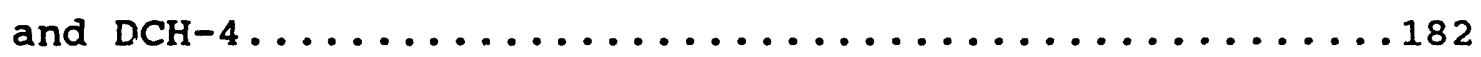

4.8 Comparison of Peak Pressures Calculated by Kiva with Values Estimated from Debris/Atmosphere Thermal

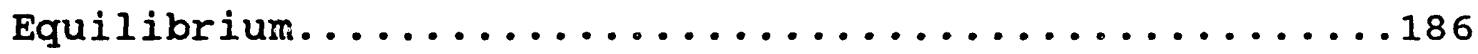

4.9 Calculated and Measured oxygen Depletion in DCH-3

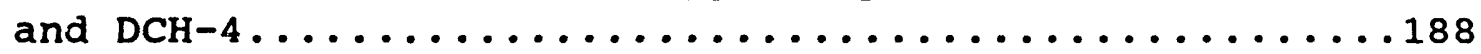

4.10 DCH-3 and DCH-4 Experiment Gas Samples.............190

4.11 Estimated Impurity Gas Qualities for $\mathrm{DCH}-3$ and

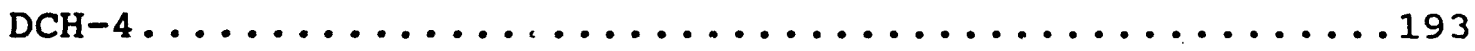

4.12 Comparison of Kiva and Simple Equilibrium

Calculations of Pressure Rises for A Range of

Debris Masses with DCH-4 Conditions................ 194

4.13 Comparison of Gas oxidation Energy with Energy

Required for Second Pressure Peak................... 01

4.14 Sensitivity of $\mathrm{DCH}-3$ and $\mathrm{DCH}-4$ Kiva Calculations

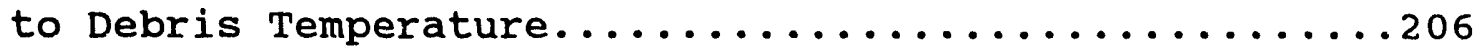

4.15 Summary of Kiva Sensitivity Calculations..........207 


\section{Acknowledgments}

The authors express their gratitude to Michael s. Oliver, who was the electronics and instrumentation engineer for the DCH-3 and DCH-4 experiments, and to James $W$. Ross, who was the senior mechanical technician. The authors are grateful to Daniel A. Lucero who assembled the aerosol instrumentation and made all of the aerosol measurements, and to Richard Gomez who performed the gas analyses. The CONTAIN-DCH calculations were performed by $\mathrm{Dr}$. Kenneth Washington, and the early Kiva-DCH analyses were performed by Dr. Kenneth Marx. The authors appreciate the technical review of this report provided by Drs. David Gardner, Richara Griffith, and Dana Powers. Editorial review was providea by Daryl Isbell.

This work was funded by the Accident Evaluation Branch of the United states Nuclear Regulatory Commission. 


\subsection{INTRODUCTION}

Reactor safety studies [NRC 1975; ZPSS 1981] have shown tha' during a light water reactor (LWR) core-melt accident an incore instrument guide tube penetration in the lower head of the reactor pressure vessel (RPV) may fail while the primary system is pressurized. The aperture formed in the vessel by tube ejection can lead to the rapid discharge of molten core debris into the reactor cavity, followed by entrainment of the core debris by the blowdown of the reactor coolant system (RCS) [Pilch and Tarbell 1985]. This sequencs of events is called a high pressure melt ejection (HPME).

Experiments and analyses [Tarbell et al. 1984, 1986; Tutu et al. 1988; Nichols and Tarbell 1988; Tarbell 1988c] have shown that blowdown of the RCS into the cavity may entrain core debris in the gas flow and disperse it from the cavity. As molten debris is expelled into the reactor containment building $(\mathrm{RCB})$, several processes may lead to a rapid increase in the pressure and temperature of the containment atmosphere: direct debris/gas heat transfer between the airborne corium particles and the containment atmosphere, (2) exothermic reactions between oxygen and metallic debris, and (3) combustion of hydrogen formed by the reaction of metallic debris with steam. The rapid discharge of molten debris and the subsequent physical and chemical processes that lead to containment pressurization are collectively known as direct containment heating $(\mathrm{DCH})$.

The results from early calculations [NRC 1985; Bergeron and Williams 1985; Pilch and Tarbell 1986] indicated that the potential loads imposed on the RCB are significant and demonstrated the need for refined analyses and appropriate experimental data. In response to the need for test results, the United States Nuclear Regulatory Commission (NRC) sponsored the development of the surtsey Direct containment Heating Test Facility at Sandia National Laboratories. The Surtsey facility is used to perform scaled experiments to investigate DCH due to a HPME accident scenario. The concern over DCH also motivated the development of the CONTAIN-DCH containment response code [Bergeron et al. 1987] and the Kiva-DCH experiment analysis 
code [Amsden et al. 1985; Marx 1988; Marx 1989]. The data from the $\mathrm{DCH}-3$ and $\mathrm{DCH}-4$ experiments performed in the surtsey Direct Heating Test Facility and the analyses of these experiments with CONTAIN-DCH and Kiva-DCH are the subjects of this report.

\subsection{Background}

The risk significance of direct containment heating was identified as one of the eight major areas of technical uncertainties in NUREG-0956, "Reassessment of the Technical Bases for Estimating Source Terms" [Silberberg et al. 1986]. The NUREG-1150 study [NRC 1989] implies that the contribution of HPME/DCH to the mean risk of early fatalities from the PWR reference plants is between $8 \%$ and $17 \%$, and the mean risk of latent cancer fatalities is between $7 \%$ and $23 \%$. Thus, the risk is considered to be significant, though not dominant. In addition, the direct containment heating safety issue is identified in NUREG-1265, "Uncertainty Papers on severe Accident source Terms" [NRC 1987] and in SECY-88-147, "Integration Plan for Closure of Severe Accident Issues" [NRC 1988].

simple upper bound analyses using single-cell, adiabatic, thermodynamic models of $\mathrm{DCH}$ in reactor HPME accident scenarios predict pressures that threaten the integrity of the containment [NRC 1985]. Early DCH analysis efforts employed simple energy balances between the gas and a single debris field [NRC 1985; Pilch and Tarbell 1986]. More detailed analyses have been performed using the multiple-cell, ratelimiting, mechanistic models incorporated in the CoNTAIN code [Bergeron et al. 1987]. The conTAIN code is a system-level, lumped-parameter code for computing containment response in severe reactor accidents. In cONTAIN, the containment is divided into cells; $\mathrm{DCH}$-related models have been integrated into CONTAIN and this developmental version of the code is called CONTAIN-DCH [Williams et al 1987; Murata et al. 1989]. CONTAIN-DCH uses mechanistic models for debris/gas heat transfer and chemical reactions, and parametric models for poorly understood phenomena such as debris/structure interactions. The code currently predicts significantly lower containment pressures than previous simplistic models by accounting for heat sinks, the complex structure of real 
containments, and kinetic limitations to heat and mass transfer processes. Despite these technical advancements, this stateof-the-art analysis tool continues to predict containmentthreatening pressures for some plants [Williams et al. 1987]. Further $D C H$ experimental research is needed to validate the models being used to make these predictions.

\section{2 objectives}

A primary objective of the NRC DCH research program is to reduce the uncertainties in the predicted containment pressure due to $\mathrm{DCH}$. Several unknowns remain concerning the threat to containment integrity posed by $\mathrm{DCH}$, the most critical of which are
1. Initial conditions
2. Amount of debris dispersed from the cavity
3. Generation and combustion of hydrogen
4. Containment loads over a range of initial conditions
5. Debris/gas heat transfer
6. Debris oxidation reactions
7. Effect of structures on debris dispersal
8. Effect of water

The overall focus of the sandia experimental program is to reduce the uncertainty in the predicted containment loads over a range of initial conditions. To partially accomplish this goal, the $\mathrm{DCH}-3$ and $\mathrm{DCH}-4$ experiments were performed in the surtsey test facility to investigate the mechanisms of debris dispersal and direct containment heating. Another goal of these experiments was to characterize the potentially significant aerosol source term that may be generated by a HPME/DCH transient.

The results of the $\mathrm{DCH}-3$ and $\mathrm{DCH}-4$ experiments are used to guide the development of phenomenological models that can be incorporated into containment response codes, such as CONTAIN-DCH. The experiments aiso provide the data base for validation of the models and codes. The initial conditions of the DCH-3 and $\mathrm{DCH}-4$ experiments were not determined from a rigorous scaling analysis, and therefore, the experimental results are not intended to be extrapolated directly to nuclear 
power plant (NPP) scale for predicting accident consequences. only fully scaled integral experiments or system-level computer codes can make meaningful predictions of the complex phenomena taking place in NPP accidents.

The Kiva code [Amsden et al. 1985], which was developed to analyze the behavior of fuel droplets in internal combustion engines, has been modified to analyze the surtsey DCH experiments [Marx 1988; Marx 1989]. The Kiva code is a two or three dimensional hydrodynamic code that allows detailed analyses of chemical reactions, the aerodynamic behavior of particles, and interictions of particles with structures. Kiva-DCH is used strictly as an experjment analysis tool; it is not suitable for full-scale NPP accident calculations. However, information derived from the Kiva-DCH analyses can be used to develop models for CONTAIN-DCH. The suitability of the models will be validated by comparison of CONTAIN-DCH calculations to the results of experiments. CONTAIN-DCH can then be used with some confidence to predict DCH phenomena in reactor accidents.

\subsection{DCH-3 Experiment}

The purpose of $\mathrm{DCH}-3$ was to perform a HPME experiment to investigate $\mathrm{DCH}$ using a large melt mass and a longer unobstructed flight path for the ejected debris than had been used in previous surtsey DCH experiments [Tarbell et al. 1987 ; 1988a]. In the $\mathrm{DCH}-3$ experiment, $80 \mathrm{~kg}$ of molten debris was ejected by high-pressure nitrogen into a 1:10 linear scale model of the zion reactor cavity modified with a vertical exit chute to direct the debris plume along the axial centerline of the surtsey vessel.

The $\mathrm{DCH}-3$ experiment was performed with the same geometry as the DCH-1 experiment. However, there were four major differences between $\mathrm{DCH}-3$ and $\mathrm{DCH}-1$ : (1) in $\mathrm{DCH}-3$, the debris flight path to the upper head of the vessel was unobstructed, whereas in $\mathrm{DCH}-1$, the debris plume impacted a structure in its path which dispersed the plume and made the energy transfer to the atmosphere very efficient [Pilch et al. 1988]; (2) in $\mathrm{DCH}-3,80 \mathrm{~kg}$ of thermite melt simulant was used instead of the 
$20 \mathrm{~kg}$ used in $\mathrm{DCH}-1 ;$ (3) in $\mathrm{DCH}-3$, a larger volume of driving gas $\left(0.267 \mathrm{~m}^{3}\right)$ was used than in $\mathrm{DCH}-1\left(0.1 .1 \mathrm{~m}^{3}\right) ;$ and (4) in $\mathrm{DCH}-3$, the gas driving pressure was higher (6.1 MPa) than in $\mathrm{DCH}-1 \quad(2.6 \mathrm{MPa})$.

DCH-3 and DCH-2 were performed with similar initial conditions, except that in $\mathrm{DCH}-2$ a vertical exit chute was not used. Thus, the debris plume exited the cavity at an angle of about $26^{\circ}$, impacted the side wall of the surtsey vessel, and rebounded to the upper head of the vessel. In addition, in $\mathrm{DCH}-2$ the driving gas volume was smaller $\left(0.11 \mathrm{~m}^{3}\right)$ than in $\mathrm{DCH}-3$.

The DCH-3 experiment was primarily designed to investigate debris/gas heat transfer and debris oxidation. However, because it was performed early in the surtsey DCH test series, DCH-3 is considered to be a developmental test for instrumentation and procedures and a scoping test for $\mathrm{DCH}$ phenomena. The results of this experiment expanded the data base on HPME and $\mathrm{DCH}$ and provided important insight into the process identification and ranking phase of $D C H$ issue resolution.

\subsection{DCH-4 Experiment}

The DCH-4 experiment was designed primarily to investigate debris/gas heat transfer by excluding metal/oxidation reactions. It was conducted using the same experimental setup as the DCH-3 test. Melt $(80 \mathrm{~kg})$ generated by a thermite reaction was ejected by nitrogen into a 1:10 linear scale model of the zion reactor cavity with a vertical exit chute. However, in $\mathrm{DCH}^{-4} 4$ the surtsey vessel was inerted with argon, in contrast to the air atmosphere used in $\mathrm{DCH}-3$. The purpose of the argon was to eliminate oxidation reactions, and thus be able to determine how much of the pressure increase in the surtsey atmosphere was due to exothermic metal/oxygen reactions.

This report includes a description of the test apparatus, initial conditions, experiment observations, test results, and the results of analyses of the $\mathrm{DCH}-3$ and $\mathrm{DCH}-4$ experiments. 


\subsection{EXPERIMENT DESCRIPTION}

The $\mathrm{DCH}^{-3}$ and $\mathrm{DCH}-4$ experiments were part of a test series designed to identify and quantify the phenomena important in HPME/DCH accidents. Experiments that are partially integral scoping tests, such as $\mathrm{DCH}-3$ and $\mathrm{DCH}-4$, aid in identifying key phenomena in the $\mathrm{DCH}$ process so that these phenomena receive proper attention in any experimental or analytical effort.

\subsection{Experimental Apparatus}

A schematic drawing of the surtsey test facility is shown in Figure 2-1. The same experimental apparatus was used in both the $\mathrm{DCH}-3$ and $\mathrm{DCH}-4$ experiments. Three major components were used to simulate a HPME/DCH accident at a nuclear power plant: (1) the surtsey vessel, which simulated a reactor containment building (RCB); (2) the melt generator, which simulated a reactor pressure vessel (RPV); and (3) the cavity, which was a 1:10 linear scale model of the zion reactor cavity. These components are described individually in the sections below.

\subsection{1 surtsey Vessel}

The Surtsey vessel is an ASME-approved steel pressure vessel with an internal volume of $103 \mathrm{~m}^{3}$, which makes it slightly over-scaled (for a 1:10 linear scale) compared to most nuclear reactor containment buildings. It has a cylindrical shape with removable, dished heads attached to both ends and is approximately $4 \mathrm{~m}$ in diameter by $11 \mathrm{~m}$ high. The surtsey vessel has a maximum allowable working pressure of $1 \mathrm{MPa}$ at $260^{\circ} \mathrm{C}$, but has a burst diaphragm installed to limit the pressure in the vessel to less than $0.9 \mathrm{MPa}$. It is supported approximately $2 \mathrm{~m}$ off the ground by a structural steel framework with its longitudinal axis oriented vertically. The interior of the vessel has four equally spaced I-beams welded vertically along the length of the body of the vessel. Structural steel has been welded to these I-beams for adding removable scaffolding to facilitate instrumenting and cleaning the vessel. The internal steel framework also supports an overhead bridge crane to facilitate loading and unloading the melt generator, 
crucible, and cavity. Near the bottom of the vessel, steel I-beams were welded in place to support the melt generator and scaled reactor cavity. A total cf twenty $30.5 \mathrm{~cm}$ (12 inch) and $61 \mathrm{~cm}(24 \mathrm{inch})$ instrument penetration ports exist at six different levels around the perimeter of the vessel. The Surtsey vessel has two manways at level 1 to allow personnel access.

\subsubsection{Melt Generator}

The melt generator and cavity were located near the bottom of the surtsey vessel (Figure 2-1) and were situated so that the cavity exit was near the vertical centerline. A schematic drawing of the melt generator assembly is shown in Figure 2-2. It had an internal volume $\left(0.267 \mathrm{~m}^{3}\right)$ that was approximately $1 / 10^{\text {th }}$ linear scale of the volume of the primary coolant system of a typical nuclear power plant $\left(\approx 300 \mathrm{~m}^{3}\right)$. The outside wall of the melt generator, which acted as the pressure barrier, was comprised of a seamless, schedule 140 (1.75-inch vall thickness) pipe section having a $50.8 \mathrm{~cm}(20$ inch) outside diameter; it had $4000 \mathrm{~N}(900 \mathrm{lb})$ slip-on flanges welded to both ends (Figure 2-3). The melt generator was oriented with its longitudinal axis vertical and had blind flanges bolted to both ends. Inside the melt generator was a crucible that contained the molten debris until melt ejection occurred. The lower blind flange was machined to accept an o-ring seal and seat for the crucible; the lower flange was bolted to the scale model of the zion cavity. The upper flange was drilled and tapped for instrumentation.

The crucible was designed to contain $80 \mathrm{~kg}$ of iron oxide/aluminum thermite. It consisted of a base and an inside and outside wall. The outside crucible wall was made from a schedule 20 seamless steel pipe section that was $0.76 \mathrm{~m}$ long ( 30 inches) and had a nominal outside diameter of $0.3 \mathrm{~m}$ (12 inches). The inside wall was made from rolled and spot welded 14 gauge sheet steel that had an inside diameter of $0.27 \mathrm{~m}$ (10.76 inches). The crucible base was a $30.5-\mathrm{cm}$ (12 inch) diameter by $5-\mathrm{cm}$ ( 2 inch) thick steel plate that had its center drilled and tapped to accept a $3.8-\mathrm{cm}(1-1 / 2$ inch) NPT brass pipe plug. The steel walls of the crucible were centered on the steel base and were welded into place. The 
annular space between the steel walls was packed with wet ram Mgo and baked for 24 hours prior to the test to drive off moisture. The crucible was destroyed during each test, and consequently, had to be replaced for each test.

In these experiments, when the thermite reaction front contacted the brass plug in the base of the crucible, the plug vaporized quickly. Failure of the brass plug initiated the high pressure melt ejection into the scaled reactor cavity.

\subsubsection{Cavity}

A schematic of the scale model of the zion cavity is shown in Figure 2-4. The model of the zion cavity was constructed of $1.3-\mathrm{cm}(0.5-i n c h)$ thick steel plates and lined with $5 \mathrm{~cm}$ ( 2 inches) of sand and limestone concrete. The internal geometry of the model cavity was scaled (1:10) to the dimensions of the zion reactor cavity. The upward slunted section was a model of the passageway for the instrument guide tubes to the seal table room. In these tests, a 0.9-m tall chute was added to the cavity exit to force the debris to be ejected vertically upward. This allowed the debris to have the longest uninterupted flight path possible in the vessel.

\subsection{Instrumentation}

The instrumentation used in the $\mathrm{DCH}-3 / 4$ experiments was designed to measure quantities that are important in a HPME/DCH accident. These quantities include the pressure and temperature of the surtsey atmosphere, the temperature of the debris exiting the cavity, the time-of-flight of the debris, gas composition, heat flux to the vessel walls, and aerosol characteristics. A list of the instrumentation used in $\mathrm{DCH}-3$ is given in Table 2.1 and the instrumentation for $\mathrm{DCH}-4$ is listed in Table 2.2; also included are the functiors of each instrument. Instrumentation details such as range, location, and dynamic characteristics can be found in Tarbell et al. [1987; 1988a]. In addition to the instrumentation listed in Tables 2.1 and 2.2 , high-speed cameras were used in these tests to film the HPME inside the surtsey vessel. The $\mathrm{DCH}-4$ 
Table 2.1

DCH-3 Instrumentation

\begin{tabular}{|c|c|c|c|}
\hline Instrument (Label) & Location & Range & Purpose \\
\hline $\begin{array}{l}\text { Pressure Transducer } \\
\text { (PMG-29) }\end{array}$ & $\begin{array}{l}\text { Melt } \\
\text { generator }\end{array}$ & $0-1000$ psi & $\begin{array}{l}\text { Melt generator } \\
\text { pressure }\end{array}$ \\
\hline $\begin{array}{l}\text { Pressure Transducer } \\
\text { (PMG-30) }\end{array}$ & $\begin{array}{l}\text { Melt } \\
\text { generator }\end{array}$ & $0-1000$ psi & $\begin{array}{l}\text { Melt generator } \\
\text { pressure }\end{array}$ \\
\hline $\begin{array}{l}\text { Pressure Transducer } \\
(\text { PL1-20) }\end{array}$ & Level 1 & $0-100$ psi & Vessel pressure \\
\hline $\begin{array}{l}\text { Pressure Transducer } \\
(\mathrm{PLI}-21)\end{array}$ & Level 1 & $0-100 \mathrm{psi}$ & Vessel pressure \\
\hline $\begin{array}{l}\text { Pressure Transducer } \\
(\operatorname{PL} 1-22)\end{array}$ & Level & $0-100 \mathrm{psi}$ & Vessel pressure \\
\hline $\begin{array}{l}\text { Pressure Transducer } \\
(\mathrm{PL} 3-23)\end{array}$ & Level 3 & $0-100 \mathrm{psi}$ & Vessel pressure \\
\hline $\begin{array}{l}\text { Pressure Transducer } \\
\text { (PL3-24) }\end{array}$ & Level 3 & $0-100 \mathrm{psi}$ & Vessel pressure \\
\hline $\begin{array}{l}\text { Pressure Transducer } \\
\text { (PL3-25) }\end{array}$ & Level 3 & $0-100 \mathrm{psi}$ & Vessel pressure \\
\hline $\begin{array}{l}\text { Pressure Transducer } \\
\text { (PL5-26) }\end{array}$ & Level 5 & $0-100 \mathrm{psi}$ & Vessel pressure \\
\hline $\begin{array}{l}\text { Pressure Transducer } \\
\text { (PL5-27) }\end{array}$ & Level 5 & $0-100 \mathrm{psi}$ & Vessel pressure \\
\hline $\begin{array}{l}\text { Pressure Transducer } \\
\text { (PL5-28) }\end{array}$ & Level 5 & $0-100 \mathrm{psi}$ & Vessel pressure \\
\hline $\begin{array}{l}\text { Ignitor signal } \\
\text { (EIG-76) }\end{array}$ & $-\infty$ & $0-3 \mathrm{~V}$ & $\begin{array}{l}\text { To signal } \\
\text { thermite ignition }\end{array}$ \\
\hline $\begin{array}{l}\text { Photodiode } \\
(\text { EPD-75) }\end{array}$ & $\begin{array}{l}\text { Below melt } \\
\text { plug }\end{array}$ & $0-3 \mathrm{~V}$ & $\begin{array}{l}\text { To signal melt } \\
\text { ejection from the } \\
\text { pressure vessel }\end{array}$ \\
\hline
\end{tabular}


Table 2.1 (continued)

DCH-3 Instrumentation

\begin{tabular}{|c|c|c|c|c|}
\hline Instrument (Label) & Location & Range & & Purpose \\
\hline $\begin{array}{l}6 \text { Type } \mathrm{K} \\
\text { Thermocouples } \\
\text { (HL1-01 through } \\
\text { HL1-06) }\end{array}$ & Level 1 & $300-1643$ & $\mathbf{K}$ & Vessel temperature \\
\hline $\begin{array}{l}6 \text { Type K } \\
\text { Thermocouples } \\
\text { (HL3-07 through } \\
\text { HL3-012) }\end{array}$ & Level 3 & $300-1643$ & $\mathbf{K}$ & Vessel temperature \\
\hline $\begin{array}{l}6 \text { Type } \mathrm{K} \\
\text { Thermocouples } \\
\text { (HL5-13 and HL5-15 } \\
\text { through HL5-19) }\end{array}$ & Level 5 & $300-1643$ & $\mathbf{K}$ & Vessel temperature \\
\hline $\begin{array}{l}\text { Type K Thermocouple } \\
\text { (HMGTOP) }\end{array}$ & $\begin{array}{l}\text { Top of melt } \\
\text { generator }\end{array}$ & $300-1643$ & $\mathbf{K}$ & $\begin{array}{l}\text { Melt generator } \\
\text { temperature }\end{array}$ \\
\hline $\begin{array}{l}\text { Type K Thermocouple } \\
\text { (HMGS10) }\end{array}$ & $\begin{array}{l}\text { Side of } \\
\text { melt } \\
\text { generator }\end{array}$ & $300-1643$ & $\mathrm{~K}$ & $\begin{array}{l}\text { Melt generator } \\
\text { temperature }\end{array}$ \\
\hline $\begin{array}{l}\text { Radiometer } \\
\text { (K53714) }\end{array}$ & Level 5 & & & \\
\hline $\begin{array}{l}\text { Calorimeter } \\
\text { (K3590) }\end{array}$ & Level 5 & & & \\
\hline $\begin{array}{l}\text { Pyrometer } \\
(\mathrm{K} 11 \times 20)\end{array}$ & $\begin{array}{l}\text { Focused at } \\
\text { chute exit }\end{array}$ & & & Debris temperature \\
\hline $\begin{array}{l}\text { Pyrometer } \\
\text { (K2 coLO) }\end{array}$ & $\begin{array}{l}\text { Focused at } \\
\text { chute exit }\end{array}$ & & & Debris temperature \\
\hline
\end{tabular}


Table 2.2

DCH-4 Instrumentation

\begin{tabular}{|c|c|c|c|}
\hline Instrument (Label) & Location & Range & Purpose \\
\hline Pressure Transducer & $\begin{array}{l}\text { Melt } \\
\text { generator }\end{array}$ & $0-1000 \mathrm{psi}$ & $\begin{array}{l}\text { Melt generator } \\
\text { pressure }\end{array}$ \\
\hline Pressure Transducer & $\begin{array}{l}\text { Melt } \\
\text { generator }\end{array}$ & $0-1000$ psi & $\begin{array}{l}\text { Melt generator } \\
\text { pressure }\end{array}$ \\
\hline $\begin{array}{l}\text { Pressure Transducer } \\
(\text { PL1-10) }\end{array}$ & Level 1 & $0-100 \mathrm{psi}$ & Vessel pressure \\
\hline $\begin{array}{l}\text { Pressure Transducer } \\
\text { (PL1-11) }\end{array}$ & Level 1 & $0-100 \mathrm{psi}$ & Vessel pressure \\
\hline $\begin{array}{l}\text { Pressure Transducer } \\
\text { (PL1-12) }\end{array}$ & Level 1 & $0-100 \mathrm{psi}$ & Vessel pressure \\
\hline $\begin{array}{l}\text { Pressure Transducer } \\
\text { (PL3-13) }\end{array}$ & Level 3 & $0-100 \mathrm{psi}$ & Vessel pressure \\
\hline $\begin{array}{l}\text { Pressure Transducer } \\
\text { (PL3-14) }\end{array}$ & Level 3 & $0-100 \mathrm{psi}$ & Vessel pressure \\
\hline $\begin{array}{l}\text { Pressure Transducer } \\
\text { (PL3-15) }\end{array}$ & Level 3 & $0-100 \mathrm{psi}$ & Vessel pressure \\
\hline $\begin{array}{l}\text { Pressure Transducer } \\
\text { (PL5-16) }\end{array}$ & Level 5 & $0-100 \mathrm{psi}$ & Vessel pressure \\
\hline $\begin{array}{l}\text { Pressure Transducer } \\
\text { (PL5-17) }\end{array}$ & Level 5 & $0-100 \mathrm{psi}$ & Vessel pressure \\
\hline $\begin{array}{l}\text { Pressure Transducer } \\
\text { (PL5-18) }\end{array}$ & Level 5 & $0-100 \mathrm{psi}$ & Vessel pressure \\
\hline $\begin{array}{l}\text { Ignitor Signal } \\
\text { (EIG-76) }\end{array}$ & -- & $0-3 \mathrm{~V}$ & $\begin{array}{l}\text { To signal } \\
\text { thermite ignition }\end{array}$ \\
\hline Photodiode & $\begin{array}{l}\text { Below melt } \\
\text { plug }\end{array}$ & $0-5 \mathrm{~V}$ & $\begin{array}{l}\text { To signal melt } \\
\text { ejection from the } \\
\text { pressure vessel }\end{array}$ \\
\hline $\begin{array}{l}6 \text { Type } K \\
\text { Thermocouples } \\
\text { (TC1 through TC6) }\end{array}$ & Level 1 & $300-1643 \mathrm{~K}$ & Vessel temperature \\
\hline
\end{tabular}


Table 2.2 (continued)

DCH-4 Instrumentation

Instrument (Label)

6 Type $\mathrm{K}$

Thermocouples

(TC7 through TC12)

6 Type $\mathrm{K}$

Thermocouples

(TC13 through TC18)

Pyrometer

(K2COLO)

Pyrometer

(K11X20)

Radiometer

(K53714)

Calorimeter

(K3590)

$\begin{array}{lll}\text { Location } & \text { Range } & \\ \text { Level } 3 & 300-1643 \mathrm{~K} & \text { Purpose } \\ \text { Level } 5 & 300-1643 \mathrm{~K} & \text { Vessel temperature } \\ & & \\ \begin{array}{l}\text { Focused at } \\ \text { chute exit }\end{array} & \text { Debris temperature } \\ \begin{array}{l}\text { Focused at } \\ \text { chute exit }\end{array} & \text { Debris temperature }\end{array}$

Level 5

Level 5 
experiment also incorporated a real time $x$-ray system to obtain information on debris particle size leaving the cavity exit.

\subsubsection{Pressure Measurements}

The instruments used to measure pressures in the $\mathrm{DCH}-3$ and DCH-4 experiments were semiconductor strain gauge-type pressure transducers (Kulite model XT-190, Kulite semiconductor Products Inc., Ridgefield, NJ). Nine transducers, three each at levels 1,3 , and 5, were used. The transducers were mounted in tapped holes in instrument penetration ports in the sides of the Surtsey vessel and had their sensing ends protected with steel turnings.

All pressure transducers were factory calibrated by the manufacturer and were recalibrated at regular intervals against standards traceable to the National Bureau of standards (NBS) by the Sandia Calibrations Laboratory. The data acquisition system recorded data from the pressure transducers at a rate of 1400 data points per second during the HPME transient.

The pressure of the accumulator driving gas was measured with two Kulite model number XT-190-1000A transducers. The driving gas pressure was also monitored by a device that was a combination Bourdon tube and signal generator (model number 2279, Ashcroft Dresser Instrument Division, Newtown, CT). The Kulite pressure transducers were installed through the accumulator shell; the tapped holes were filled with stainless steel turnings to protect the pressure gauges from hot particles that might splash from the molten thermite pool. The Ashcroft gauge was mounted on the outside of the surtsey vessel. The gauge was connected to the melt generator by a steel tube that passed through one of the ports via a pressure fitting. A television camera focused on the gauge allowed the accumulator pressiure to be observed from a monitor in the control center. This allowed test personnel to monitor the pressure in the accumulator during the experiment. 


\subsubsection{Temperature Measurements}

Temperatures in the $\mathrm{DCH}-3$ and $\mathrm{DCH}-4$ experiments were measured with type $\mathrm{K}$ thermocouples. The location and purpose of each thermocouple are given in Table 2.1 for $\mathrm{DCH}-3$ and in Table 2.2 for $\mathrm{DCH}-4$. The gas temperatures in the surtsey vessel were measured following the HPME transient with six aspirated thermocouple assemblies. Three bare type $K$ thermocouples (wire diameter $=0.005$ in.) were mounted in an anodized aluminum tube, and two of each of these assemblies were installed through instrumentation ports at levels 1,3 , and 5 . Just after the HPME, the solenoid valves behind the aspirated thermocouple assemblies were opened and hot gas in the vessel flowed through the tubes and over the thermocouples. This configuration was chosen because it reduced the radiant heat transfer to the thermocouples. The tube surrounding the thermocouples was used to shield the thermocouples from the radiant heat flux.

The temperature of the driving gas was measured using two type $\mathrm{K}$ thermocouples. They were installed in the melt generator shell using pressure-tight fittings adjacent to the pressure sensors. Standard calibration tables were used to interpret the signals generated by these thermocouples.

Two pyrometers were used to measure the temperature of the debris as it emerged from the cavity chute. An optical pyrometer (Series 1100, Type 11x20, Ircon Inc., Niles, IL) and a two-color pyrometer (Modline $R$ series, Model Number $R-35 \mathrm{C} 10$, Ircon Inc., stokie, IL) were focused at the cavity exit. The optical pyrometer had a response time of $1.5 \mathrm{~ms}$ to $95 \%$ of its full range; it was capable of measuring temperatures between 1700 and $2800^{\circ} \mathrm{C}$ with a specified accuracy of 18 of the fullscale temperature. The two-color pyrometer (wavelengths 0.7 and $1.05 \mu \mathrm{m}$ ) had a temperature range of 1500 to $3500^{\circ} \mathrm{C}$ and a calibrated accuracy of $1 \%$ of the full-scale temperature. The response time of the two-color pyrometer was $0.1 \mathrm{~s}$ at the sensing head. In a transient event such as a HPME experiment, the accuracy of the pyrometer measurements were expected to be no better than $\pm 25^{\circ} \mathrm{C}$. 
The pyrometers were mounted at the cavity exit in a mild steel box with fused silica windows for viewing the melt, as shown in Figure 2-5. The pyrometers were factory calibrated and were also recalibrated by the Sandia Calibrations Laboratory. Data points from the thermocouples and the pyrometers were recorded by the data acquisition system at a rate of 10 per second prior to thermite ignition, and then just prior to thermite ignition the data acquisition system was switched to the fast mode, in which data points were recorded at a rate of 1400 per second.

Heat flux measurements to the vessel wall were performed with a radiometer and calorimeter mounted side by side in ports at levels 2 and 5. This configuration allowed a distinction to be made between the amount of radiant heat flux and the sum of radiant plus convective heat flux to the vessel wall. The data from these measurements could be used to infer an emissivity of the debris cloud during ejection. The radiant heat flux measurements were taken with a Hy-Cal water-cooled radiometer (model number R-8101-F-140-072, Hy-Cal Engineering, El Monte, $C A)$. The radiant plus convective heat flux measurements were taken with a water-cooled probe calorimeter (model number 1000-30, Thermogage, Inc., Frostburg, MD), which was a circular foil-type heat flux gage.

\subsubsection{Data Acquisition system}

The data acquisition system was based on a Hewlett Packard model 1000 series A-600 minicomputer. Four analog-to-digital converters were located within the chassis of the HP 1000 computer with each converter multiplexing 40 analog channels; thus, this system had the capability to record 160 analog data channels. The Hewlett Packard system sampled data at two different rates: the slow data acquisition rate was 10 samples per second, and the fast data acquistion rate was 1400 samples per second. Because the system was new, the data were backed up using fast-streaming tape.

The backup data acquisition for the $\mathrm{DCH}-3$ and $\mathrm{DCH}-4$ tests utilized two Honeywell Model 101 recorders on each test. One was a fourteen track unit and the other was a twenty-eight track unit. The signals were recorded at a center frequency of 
$54 \mathrm{kHz}$ using a recorder speed of 15 inches per second. The raw signal from the tapes was processed, converted into engineering units, and plotted.

Permanent instrumentation lines were run from the surtsey vessel directly into the instrumentation building. Each of the various transducers were connected to these lines via patch panels installed on the vessel. The signals were split and were fed into various signal conditioning and recording devices.

\subsubsection{Gas Analyses}

A schematic of the gas-sampling system used in the $\mathrm{DCH}-3 / 4$ experiments is shown in Figure 2-6. All sample lines, manual valves, and other fittings were made of stainless steel. The sample tube inside the Surtsey vessel was $1 \mathrm{~m}$ long and had an outside diameter of $9.5 \mathrm{~mm}(0.375$. in); the open end of this tube was located directly under the melt generator. The tubing outside the vessel had an outer diameter of $6.4 \mathrm{~mm}(0.250 \mathrm{in})$ and was connected as shown in Figure 2-6.

The gas-sampling system had two types of in-line filters to remove aerosol particles from the gas samples: a pre-filter of loosely packed stainless steel wool, followed by two Gelman high efficiency particulate (HEPA) filters with a pore size of $0.3 \mu \mathrm{m}$. Downstream of the filters were a gas mass spectrometer (in DCH-3 only), a gas-grab sample tree, a Dwyer rotameter, a vacuum pump, and a sierra flowmeter. The components of the gas sampling system are described in the paragraphs below.

The grab sample scheme was designed to collect gas samples for posttest analyses. The grab sample tree, which was located under the surtsey vessel, was composed of 23 stainless steel bottles, each with an internal volume of $75 \mathrm{~cm}^{3}$. A Welch two-stage vacuum pump was used to evacuate these bottles. The bottles were plumbed into a gas manifold that was connected to the primary flow line with stainless steel tubing having a dead volume of less than $50 \mathrm{~cm}^{3}$. A Validyne pressure transducer with a range of 0-1000 torr was used to monitor the pressure in 
the gas manifold. The valves that opened and closed the gas grab samples were actuated remotely. The pressure readings from the validyne pressure transducer gave the timing of the gas grab samples, as shown in Figure 2-7 for $\mathrm{DCH}-4$. Three or four gas bottles were opened prior to the HPME as background samples. The rest of the gas samples were taken after the HPME. Each gas bottle was opened for approximately 20 seconds. The posttest gas analyses were performed using a Tracor MT-150g gas chromatograph and a Finnigan Mat 271/45 mass spectrometer.

In the $\mathrm{DCH}-3$ experiment, an on-line gas mass spectrometer was used for real time analysis of gas compositions in the surtsey vessel. The mass spectrometer used was an Infocon IQ200 Quadrupole Residual Gas Analyzer configured to scan specifically selected masses in a table mode. The gases scanned were $\mathrm{H}_{2}, \mathrm{H}_{2} \mathrm{O}, \mathrm{N}_{2}, \mathrm{O}_{2}, \mathrm{Ar}$, and $\mathrm{CO}_{2}$. The results of these analyses were rather uninformative and are not included in this report. On-line gas mass spectroscopy was not used in the $\mathrm{DCH}-4$ experiment.

A Gast oiless diaphragm pump was used to draw gas from the Surtsey vessel through the gas-sampling system. Two flowmeters were used to measure the flow rate through the gas-sampling system: a Dwyer rotameter with a range of $0-10 \mathrm{l} / \mathrm{min}$ and a Sierra thermal-type flowmeter (used to provide a flow/no flow indication) with a range of $0-15 \mathrm{l} / \mathrm{min}$. The signals from the Validyne pressure transducer (0-10 volts per 0-1000 torr) and from the sierra flowmeter (0-5 volts per $0-15 \mathrm{l} / \mathrm{min})$ were recorded with the Hewlett Packard 1000 computer.

In the $\mathrm{DCH}-3 / 4$ experiments, the sample line flow was established one hour prior to the HPME by starting the Gast vacuum pump and adjusting the flow rate to $6 \mathrm{l} / \mathrm{min}$ on the Dwyer rotameter. The position of each valve was verified and the flow was routed through one HEPA filter.

\subsubsection{Aerosol Instrumentation}

The aerosol sampling system was modified before the $\mathrm{DCH}-3$ experiment to avoid two problems observed in previous surtsey 
DCH experiments [Tarbell et al. 1987; Tarbell et al. 1988a]: (1) uncertainties introduced by inhomogeneous aerosol concentrations in the surtsey vessel and (2) damage to the aerosol instrumentation inside the vessel by molten debris. A U-shaped $20-\mathrm{cm}$ inside diameter black iron pipe was installed vertically between two adjacent penetrations on the side of the surtsey vessel. This pipe, which is shown in Figure 2-8, acted as flow path for sampling aerosol. Aerosol was drawn into the upper leg of the aerosol loop by means of a fan in the lower horizontal leg. Gate valves in the upper and lower sections isolated the loop to protect the aerosol instrumentation during the HPME transient. A photograph of the aerosol sampling loop with the aerosol sampling instrumentation in-place is shown in Figure 2-9.

When the Surtsey vessel pressure had decreased to an acceptable level, the gate valves were opened and aerosol was sampled from the upper leg. The fan circulated aerosol through the loop at a flow rate between 1 and $2 \mathrm{~m}^{3} / \mathrm{s}$. Thus, a one-minute sample allowed sampling from a 60 to $120 \mathrm{~m}^{3}$ volume instead of the few liters surrounding a sampler inlet, as in the previous $D C H$ tests. Sampling from the loop also allowed a single inlet to serve several samplers and permited the introduction of a known flow of dilution gas downstream of the inlet; the dilution gas prevented overloading the aerosol samplers. The aerosol instruments used in the $\mathrm{DCH}-3 / 4$ experiments are 1 isted in Table 2.3 below. A complete description of the aerosol instrumentation can be found in Tarbell et al. [1987], Tarbell et al. [1988a, 1988d], and Yamano and Brockmann [1989].

Aerosol samples were drawn from the upper leg of the aerosol loop into the sample manifold through a gooseneck sample nozzle. Figure $2-10$ is a schematic drawing of the gooseneck sample nozzle. The nozzle had an inside diameter of $0.64 \mathrm{~cm}$ and was positioned coaxially in the center of the upper horizontal leg of the aerosol loop. The nozzle expanded to a $1.6-\mathrm{cm}$ inside diameter stainless steel tube.

Figure 2-11 is a schematic diagram of the aerosol sampling system. A dilution system was located upstream of the inlet section of the impactor and filter banks. The diluter was designed to pass the sampled aerosol and make up the additional 
flow to the samplers with dilution gas (air). The diluter is shown schematically in Figure 2-12. A critical orifice was used to maintain the dilution flow rate at a known value. The dilution gas was controlled with a pressure regulator and monitored with a strain gage-type pressure transducer (Model $\mathrm{XT}-190$, Kulite Semiconductor Products Inc., Ridgefield, NJ) .

Table 2.3

\section{Aerosol Instrumentation Used in DCH-3 and DCH-4}

$\begin{aligned} 1 & \text { Sierra Cascade Cyclone, Type 286-1 } \\ 14 & \begin{array}{l}\text { Andersen Mark III Cascade Impactors } \\ \text { W/Preseparators }\end{array} \\ 22 & \text { Gelman High Pressure Type Filter Holders } \\ 1 & \text { Dynatron Opacity Monitor, Model } 301 \\ 1 & \text { Diluter (Sandia Design) } \\ 7 & \text { Millipore Critical Orifices } \\ 1 & \text { Modicon Programmable Controller Micro } 84\end{aligned}$

An Andersen Mark III cascade impactor was used to measure the mass concentration as a function of aerodynamic particle size. Figure 2-13 is a photograph of a disassembled Andersen Mark III impactor. The impactor was made up of a preseparator, 8 stages, and a backup filter. A glass fiber filter was used as a collection substrate on each stage. The filter substrates were placed in a desiccator for approximately two days before weighing to prevent the possibility of erroneous weights due to absorbed water. After weighing, the filter weights were recorded and the impactors were carefully assembled and leak tested.

Figure 2-14 is a photograph of an assembled bank of Andersen Mark III cascade impactors. The impactor bank was connected to the aerosol sampling system with Leybold-Heraeus quick connect vacuum fittings. Two impactors were operated simultaneously: one was operated at 10 actual $\mathrm{l} / \mathrm{min}$, and the other was operated at 15 actual $\ell / m i n$. A bypass filter arrangement was installed 
to maintain constant flow through the aerosol sampling system when an impactor sample was not being taken.

Each of the Gelman filter holders contained a single 47-mm diameter filter (Nuclepore polycarbonate filter with a pore diameter of $1 \mu \mathrm{m})$; these filters were used to measure aerosol mass concentration. Figure 2-15 is a photograph of a disassembled Gelman filter holder. Figure 2-16 is a photograph of an assembled filter bank. The filters were desiccated and assembled in a manner similar to the impactor substrates. The filter bank was assembled with Leybold-Heraeus quick connect fittings and attached to the assembled impactor bank. An Andersen preseparator was installed between the impactor and filter banks to remove particles larger than $10 \mu \mathrm{m}$ from the aerosol going to the filters. The filters sampled at a nominal flow rate of $10 \mathrm{l} / \mathrm{min}$.

A Sierra Cascade Cyclone was used to measure aerosol mass distribution as a function of aerodynamic particle diameter. Figure 2-17 is a photograph of a disassembled cyclone separator. The cyclone contained six stages and a glass fiber backup filter, and was capable of collecting large quantities of aerosol (typically several hundred milligrams per stage). The cyclone was used to collect enough size-segregated material to perform chemical analyses. The cyclone was installed on the third level of the surtsey vessel through an instrumentation port with a $1.3-\mathrm{cm}$ stainless steel tube that extended $51 \mathrm{~cm}$ into the vessel. The cyclone sampled aerosol-laden gas from the surtsey vessel following the HPME transient at a flow rate of $25 \mathrm{l} / \mathrm{min}$.

A Dynatron Opacity Monitor was installed in the aerosol loop to obtain a real time indication of aerosol concentration in the Surtsey vessel. Quartz windows were installed in the aerosol loop $2.5 \mathrm{~cm}$ downstream of the aerosol sampling nozzle. The opacity monitor consisted of a light source and photodetector which measured the extinction of light across the aerosol loop. Figure 2-18 is a diagram of the photodetector and light source. A sheath air injection system was used to keep the quartz windows from becoming covered with aerosol. The sheath air flow rate was maintained at approximately $25 \mathrm{l} / \mathrm{min}$ with a critical orifice. An in-situ calibration of the monitor was 
accomplished by comparing the monitor output to the aerosol mass concentration measured with the filter samples.

Sample flows were controlled by critical orifices manufactured by Millipore. These orifices were calibrated in the sandia calibrations laboratory. They were housed in a flow box in which temperature and pressure were monitored. Kulite pressure transducers with built-in amplifiers were used to monitor the pressures of the gas upstream and downstream of the critical orifices. Pressures upstream and downstream of the flow controlling orifices indicated whether critical flow was achieved. The pressure transducers were also calibrated in the Sandia calibrations laboratory.

A microprocessor-based programmable controller was used to switch the ASCO solenoid valves that were used to control the on-off sequence of the samplers. Figure 2-19 is a photograph of the controller and programmer.

Both filter and impactor samples were taken in sets. A sample set consisted of three filter samples of one minute each taken in sequence. During the middle filter sample of each set, two one-minute impactor samples were taken concurrently. The impactors were operated at nominal flow rates of 10 and 15 actual $\ell / \mathrm{min}$, and each filter sample was operated at a nominal flow rate of 10 actual $\ell / m i n$. During the first and third filter sample in the sample set (when no impactor samples were taken) bypass flows at the impactor sample flow rate were used to maintain similar flow conditions in the sample system. Four of these sample sets were taken following the HPME experiment.

Long-term sampling was accomplished by replacing the impactor bank and filter bank with fresh banks. The new bank of cascade impactors had four Andersen Mark III impactors that were opened at random times in the hours following the HPME. The filter bank had ten Gelman filter holders; a 15 minute filter sample was started by a signal from the programmable controller every 30 minutes until all ten filter samples were taken. 
An Aerodynamic Particle Sizer (TSI, Inc., Minneapolis, MN) was used in conjunction with an Andersen Mark III impactor to measure the dynamic shape factor of particles in the $\mathrm{DCH}-3$ test. The dynamic shape factor allows transformation between particle mass and particle aerodynamic behavior. The principle of this technique is that both a particle number distribution (from the APS) and a particle mass distribution (from the impactor) are obtained by sampling from a diluted aerosol drawn into a small chamber located below the surtsey vessel. With both of these distributions as functions of the particles' aerodynamic diameters, the dynamic shape factor can be calculated. A detailed explanation is given in Brockmann and Rader [1989; 1990].

After the test, the Gelman filter holders were disassembled and the filter substrates were placed into dishes that were returned to the desiccator for two days. The filters were then weighed and their weights recorded. The differences in weights were used to calculate mass concentrations. The impactors were disassembled and the collection substrates and backup filters plared in dishes which were then placed in the desiccator. The cascade cyclone was disassembled in a manner similar to the impactors, and the material collected on each stage was brushed into pre-weighed dishes and then weighed. The differences in weights were again used to determine mass concentrations.

\subsection{Initial Conditions}

The initial conditions for $\mathrm{DCH}-1$ through $\mathrm{DCH}-4$ are listed in Table 2.4. Both $\mathrm{DCH}-3$ and $\mathrm{DCH}-4$ used an initial melt mass of $80 \mathrm{~kg}$, consisting of $76.48 \mathrm{~kg}$ of iron oxide/aluminum thermite and $3.52 \mathrm{~kg}$ of fission product dopants. This mixture was compacted to approximately $57 \%$ of the theoretical density of thermite. Prior to $\mathrm{DCH}-4$, surtsey experiments were conducted with air at atmospheric pressure in the vessel; however, in DCH-4, the surtsey vessel was purged with argon in order to perform the test in an atmosphere that was almost oxygen free. The argon prevented chemical reactions between metallic debris and oxygen in the surtsey atmosphere. 
In $\mathrm{DCH}-3$ and $\mathrm{DCH}-4$, bottled nitrogen gas was used to pressurize the welt generator prior to ignition of the thermite melt simulant. The melt generator was pressurized to approximately $4.2 \mathrm{MPa}$ (610 psig) initially and attained a driving pressure of $6.2 \mathrm{MPa}(900 \mathrm{psig})$ when ejection occurred. A Mgo-filled crucible was used to contain the metallothermitic reaction between the iron oxide and alumin'n powders. The reaction was initiated with an ignitor placed at the top of the powder bed. The reaction front propagated downward, forming a molten mixture of iron and alumina. Upon contacting and failing a fusible brass plug at the bottom of the crucible, the molten thermite in the crucible was expelled by high-pressure nitrogen into the cavity, and was then forcibly ejected by the blowdown nitrogen into the surtsey vessel.

Table 2.4

Initial Conditions for the DCH Experiments

\begin{tabular}{lcccc}
\hline & $\underline{D C H}-1$ & $\underline{D C H}-2$ & $\underline{D C H}-3$ & $\underline{D C H}-4$ \\
$\begin{array}{c}\text { Melt mass } \\
\text { (kg) }\end{array}$ & 20 & 80 & 30 & 80 \\
$\begin{array}{l}\text { Driving } \\
\text { pressure } \\
\text { (MPa) }\end{array}$ & 2.6 & 6.7 & 6.1 & 6.2 \\
$\begin{array}{l}\text { Driving } \\
\text { gas volume } \\
\text { (m) }\end{array}$ & 0.11 & 0.11 & 0.27 & 0.27 \\
$\begin{array}{l}\text { Initial } \\
\text { plug dia. } \\
\text { (cm) }\end{array}$ & 4.8 & 4.8 & 4.8 & 4.8 \\
$\begin{array}{l}\text { Vertical } \\
\text { exit chute }\end{array}$ & Yes & No & Yes & Yes \\
$\begin{array}{l}\text { Surtsey } \\
\text { vessel gas }\end{array}$ & Air & Air & Air & Argon \\
\hline
\end{tabular}


The thermite melt simulant in the $\mathrm{DCH}-3$ and $\mathrm{DCH}-4$ experiments was doped with nonradioactive isotopes of radionuclides that would be present in a nuclear reactor core. The level of these dopants was approximately 0.5 wt. of of the thermite melt simulant. It is assumed in the tests that $\mathrm{Fe}, \mathrm{Ni}, \mathrm{Mn}$, and Mo were present as metals, and $\mathrm{Al}, \mathrm{Ba}, \mathrm{La}, \mathrm{Ce}$, and $\mathrm{Ti}$ were present as oxides [Tarbell et al. 1988b]. $\mathrm{Nb}$ is likely to be present as an oxide as well. Table 2.5 gives the elemental mass of the constituents in the melts used in the DCH tests.

Table 2.5

Melt Constituents by Element (kg)

\begin{tabular}{ccccc}
\hline Element & DCH-1 & DCH-2 & DCH-3 & DCH-4 \\
Fe & 11.04 & 42.68 & 41.96 & 41.96 \\
$\mathrm{Ni}$ & 0.100 & 0.400 & 0.400 & 0.400 \\
$\mathrm{Mo}$ & 0.101 & 0.401 & 0.400 & 0.400 \\
$\mathrm{Mn}$ & - & - & 0.430 & 0.430 \\
$\mathrm{Al}$ & 4.74 & 18.32 & 18.02 & 18.02 \\
$\mathrm{Ba}$ & 0.145 & 0.141 & 0.443 & 0.443 \\
$\mathrm{La}$ & 0.101 & 0.418 & 0.398 & 0.398 \\
$\mathrm{Nb}$ & 0.100 & 0.409 & 0.398 & 0.398 \\
$\mathrm{Ce}$ & - & 0.405 & 0.454 & 0.454 \\
$\mathrm{Ti}$ & - & - & 0.155 & 0.155 \\
\end{tabular}

The initial conditions for the $\mathrm{DCH}-3$ experiment are listed in Table 2.6 and the initial mass of each component in the melt simulant is given in Table 2.7. Table 2.8 lists the initial conditions for the $\mathrm{DCH}-4$ experiment and Table 2.9 gives the initial mass of each component in the melt simulant.

\subsection{Experimental Procedures}

The DCH-3/4 experiments were conducted using procedures similar to those of the earlier $\mathrm{DCH}^{-1}$ [Tarbell et al. 1987] and $\mathrm{DCH}-2$ tests [Tarbell et al. 1988a]. The experimental procedures began with preparation of the thermite. The iron oxide was baked in an oven at $600^{\circ} \mathrm{C}$ for 24 hours to drive off moisture. 
The desired amounts of iron oxide, aluminum, and fission product simulants were weighed out and mixed in an electric mixer for 5 minutes. Then approximately one-third of the $\mathrm{mix}$ was compacted in the Mgo crucible at 75 tons for two minutes. This procedure was repeated until all of the thermite was compacted. Approximately one $\mathrm{kg}$ of thermite was saved and placed in a flat film can with the ignitor, which was a braided pyrofuse comprised of a metallic alloy of ruthenium, palladium, and aluminum. The ignitor was then placed on top of the compacted thermite and shorted for safety. The charged crucible was transported to the test apparatus and installed in the melt generator.

Table 2.6

DCH-3 Initial conditions

Melt simulant mass:

$79.522 \mathrm{~kg}$

Thermite composition(1). (compacted)

Iron Oxide $\left(\mathrm{Fe}_{3} \mathrm{O}_{4}\right) \quad 76.3$ wt.\%

Aluminum (A1)

23.7 wt. $\%$

Surtsey atmosphere:

$\begin{aligned} \text { gas - } & \text { Air } \\ \text { pressure - } & 0.08 \mathrm{MPa} \\ \text { temperature - } & 22^{\circ} \mathrm{C} \\ \text { volume - } & 103 \mathrm{~m}^{3}\end{aligned}$

Driving gas:

Dry bottled nitrogen

Gas volume:

$0.242 \mathrm{~m}^{3}$

Final driving pressure: $\quad 6.1 \mathrm{MPa}$

Fusible plug diameter: $\quad 4.8 \mathrm{~cm}$

Note: (1) See Table 2.7 
Table 2.7

Initial Melt simulant Mass in DCH-3

\begin{tabular}{|c|c|c|}
\hline Material & & Mass $(\mathrm{kg})$ \\
\hline \multicolumn{3}{|l|}{ Thermite: } \\
\hline $\mathrm{Fe}_{3} \mathrm{O}_{4}$ & & 57.984 \\
\hline \multirow[t]{2}{*}{ A1 } & & 18.015 \\
\hline & Subtotal & 75.999 \\
\hline \multicolumn{3}{|c|}{ Fission product dopants: } \\
\hline $\mathrm{La}_{2} \mathrm{O}_{3}$ & & 0.470 \\
\hline $\mathrm{BaTiO}_{3}$ & & 0.753 \\
\hline Mo & & 0.400 \\
\hline $\mathrm{Ni}$ & & 0.400 \\
\hline $\mathrm{Nb}_{2} \mathrm{O}_{5}$ & & 0.570 \\
\hline CeO & & 0.500 \\
\hline \multirow[t]{3}{*}{$\mathrm{Mn}$} & & 0.430 \\
\hline & Subtotal & 3.523 \\
\hline & Total & 79.522 \\
\hline
\end{tabular}


Table 2.8

DCH-4 Initial Conditions

Melt simulant mass: $\quad 80.003 \mathrm{~kg}$

Thermite composition(1): Iron oxide $\left(\mathrm{Fe}_{3} \mathrm{O}_{4}\right) \quad 76.3$ wt.\%

(compacted)

Aluminum (A1)

23.7 wt. $\%$

Surtsey atmosphere:

gas -

pressure -

temperature -

volume -

Driving gas:

Gas volume:

Final driving pressure

Fusible plug diameter
Argon

$0.08 \mathrm{MPa}$

$20^{\circ} \mathrm{C}$

$103 \mathrm{~m}^{3}$

Dry bottled nitrogen

$0.242 \mathrm{~m}^{3}$

$6.3 \mathrm{MPa}$

$4.8 \mathrm{~cm}$

Note: (1) See Table 2.9 
Table 2.9

Initial Melt simulant Mass in DCH-4

\begin{tabular}{|c|c|c|}
\hline Material & & Mass $(\mathrm{kg})$ \\
\hline \multicolumn{3}{|l|}{ Thermite: } \\
\hline $\mathrm{Fe}_{3} \mathrm{O}_{4}$ & & 58.350 \\
\hline \multirow[t]{2}{*}{ Al } & & 18.130 \\
\hline & subtotal & 76.480 \\
\hline \multicolumn{3}{|c|}{ Fission product dopants: } \\
\hline $\mathrm{La}_{2} \mathrm{O}_{3}$ & & 0.470 \\
\hline $\mathrm{BaTIO}_{3}$ & & 0.753 \\
\hline Mo & & 0.400 \\
\hline $\mathrm{Ni}$ & & 0.400 \\
\hline $\mathrm{Nb}_{2} \mathrm{O}_{5}$ & & 0.570 \\
\hline $\mathrm{CeO}$ & & 0.500 \\
\hline \multirow[t]{3}{*}{ Mn } & & 0.430 \\
\hline & Subtotal & 3.523 \\
\hline & Total & 80.003 \\
\hline
\end{tabular}


After the test apparatus was assembled and all personnel were in the control center, the melt generator was pressurized with nitrogen to a predetermined pressure. For the DCH-3 experiment, the pressure was $3.9 \mathrm{MPa}$ (566 psig), and for the $\mathrm{DCH}-4$, it was $4.2 \mathrm{MPa}(610 \mathrm{psig})$. The ignitor in the crucible was then triggered and the thermite reaction started. The thermite melt front propagated downward from the top of the thermite and failed the fusible brass plug located at the bottom of the crucible. The pressure in the accumulator increased during the reaction to a final pressure that was about 60\% higher than the initial pressure. Therefore, the driving gas pressure at the initiation of the HPME was on the order of $6.4 \mathrm{MPa}(930 \mathrm{psig})$. Upon failure of the melt plug, the high pressure gas forced the melt into the cavity. The blowdown gas then entrained molten thermite from the cavity into the vessel, which caused the vessel pressure to rise.

Zero time for HPME was set by the data acquisition system as the time at which the melt failed the brass plug and entered the cavity. This event was signaled by a photodiode located at the melt plug exit. When the hot melt burst through the brass plug, the intense light emitted by the melt caused the photodiode to emit a signal that was used to mark the initiation of the HPME. 


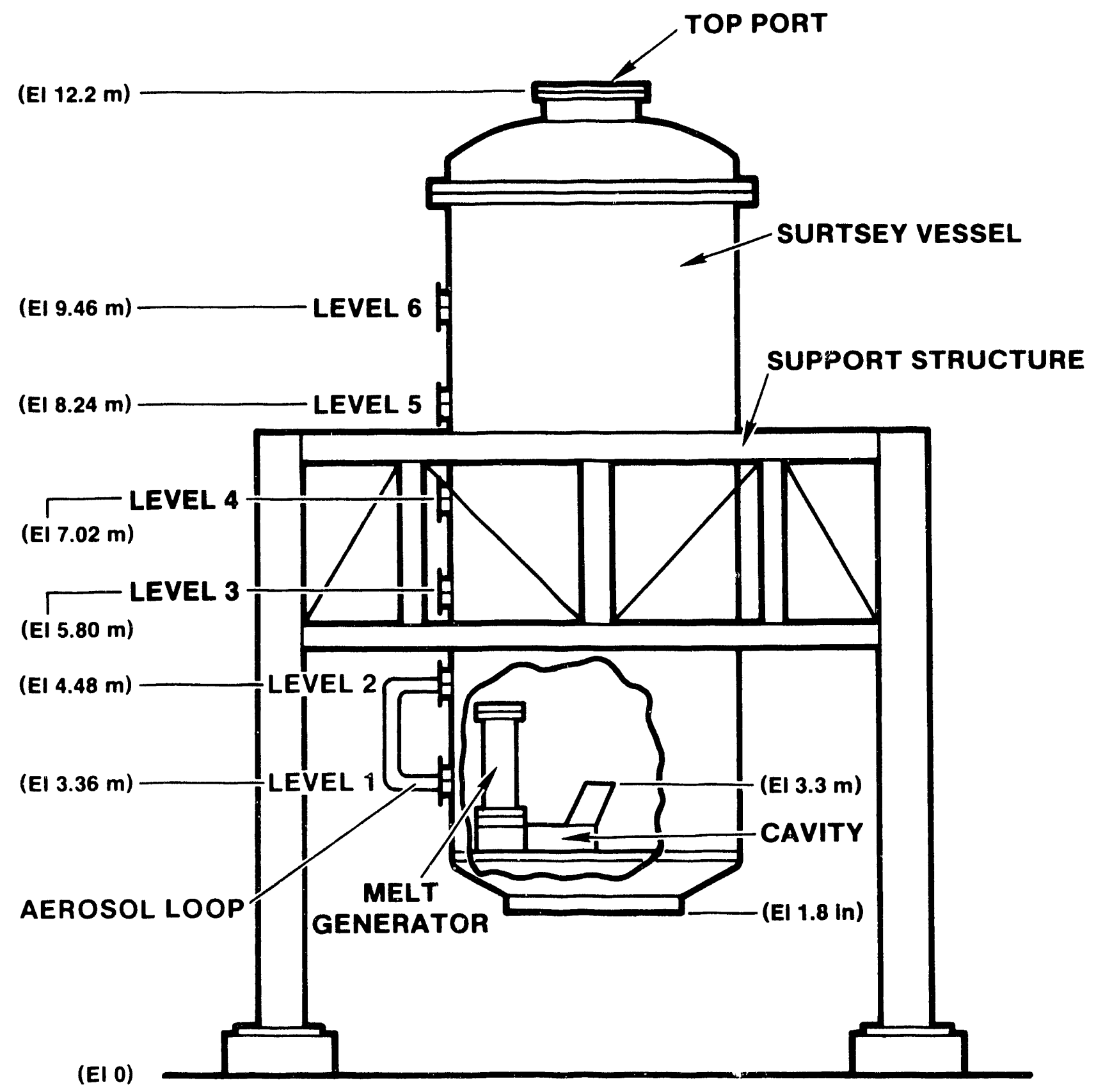

Figure 2-1. Schematic diagram of the melt generator and cavity in the surtsey vessel. 


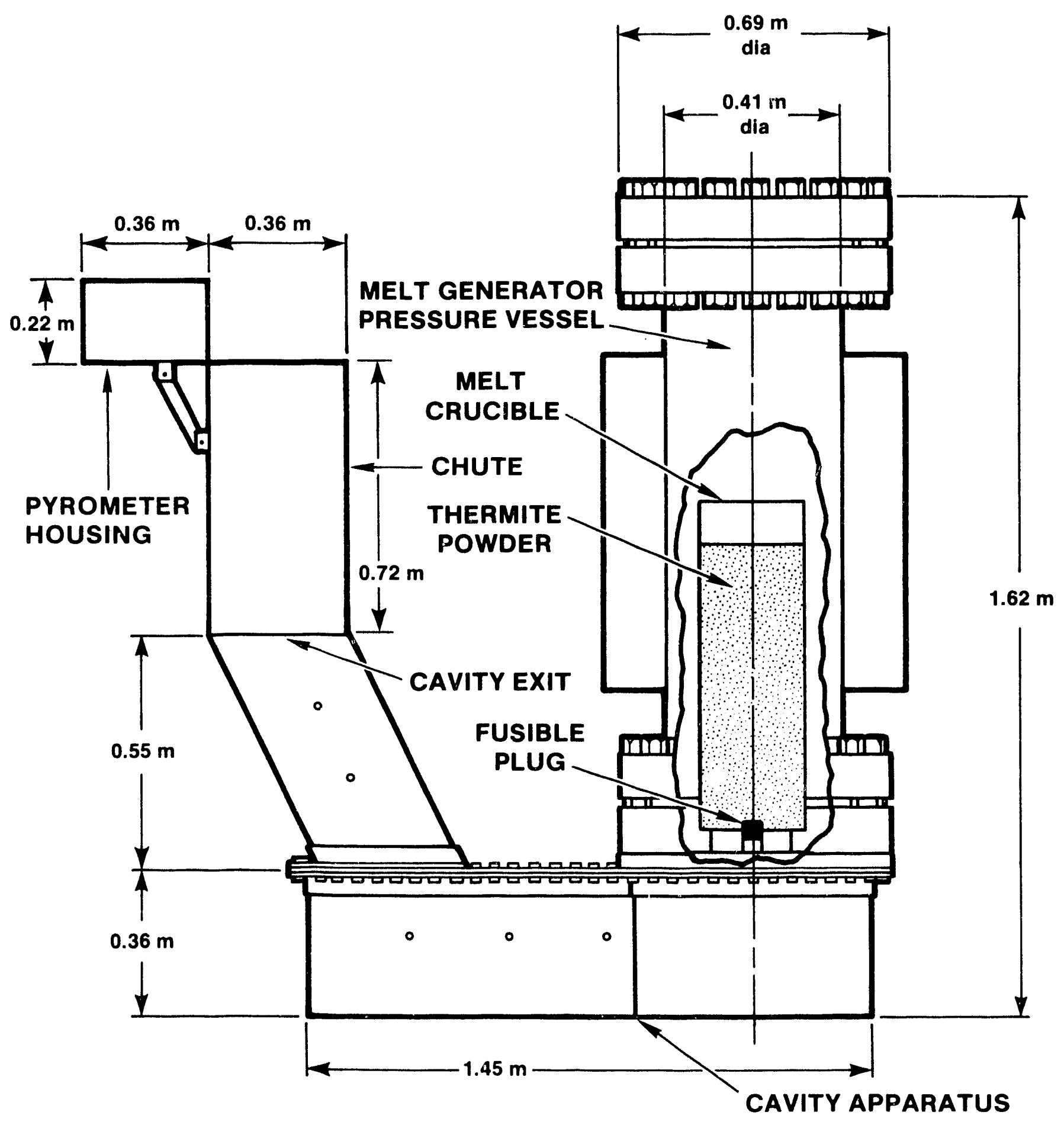

Figure 2-2. Schematic diagram of the melt generator assembly. 


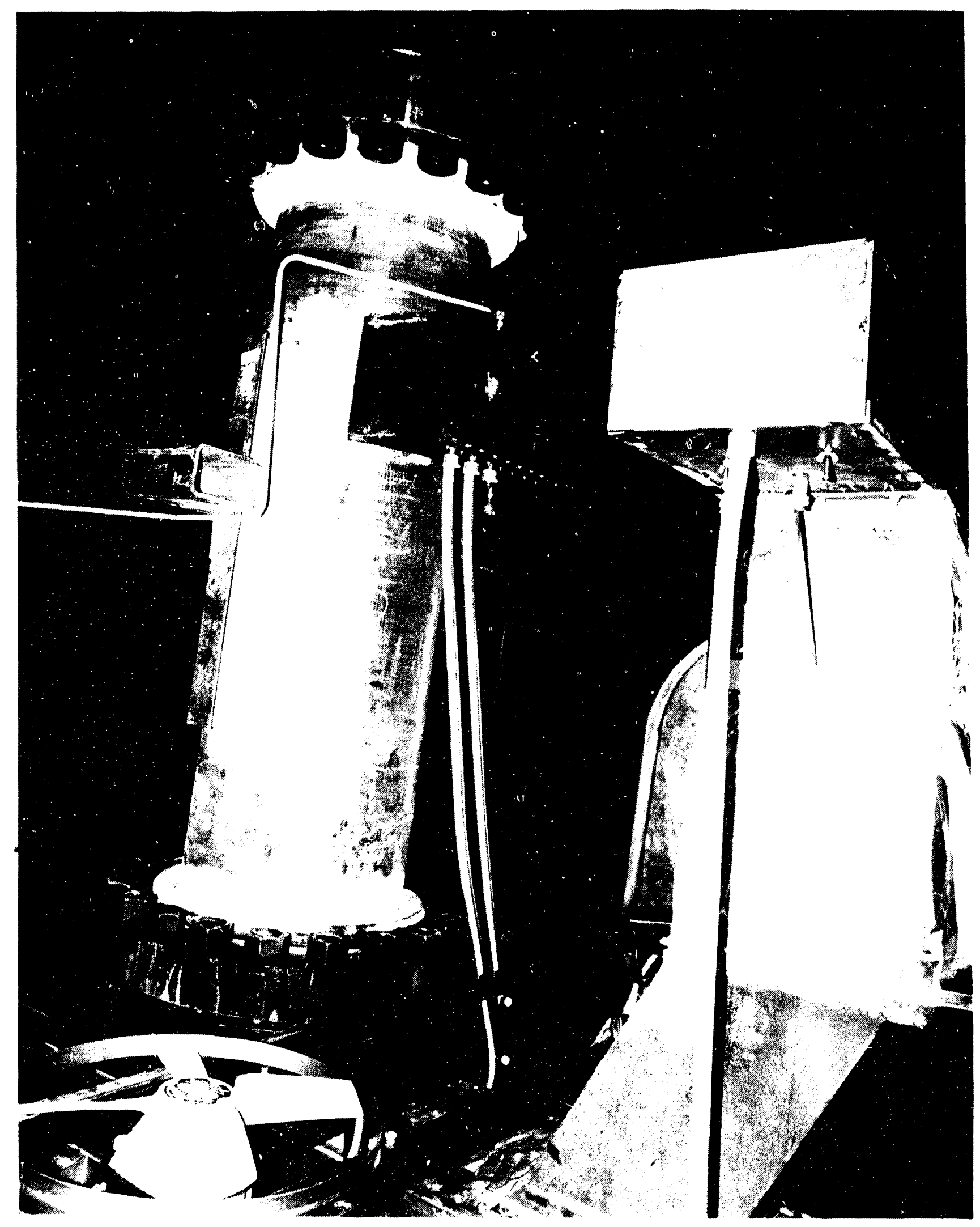

Figure 2-3. Photogragh of the melt generator in $\mathrm{DCH}-3$. 

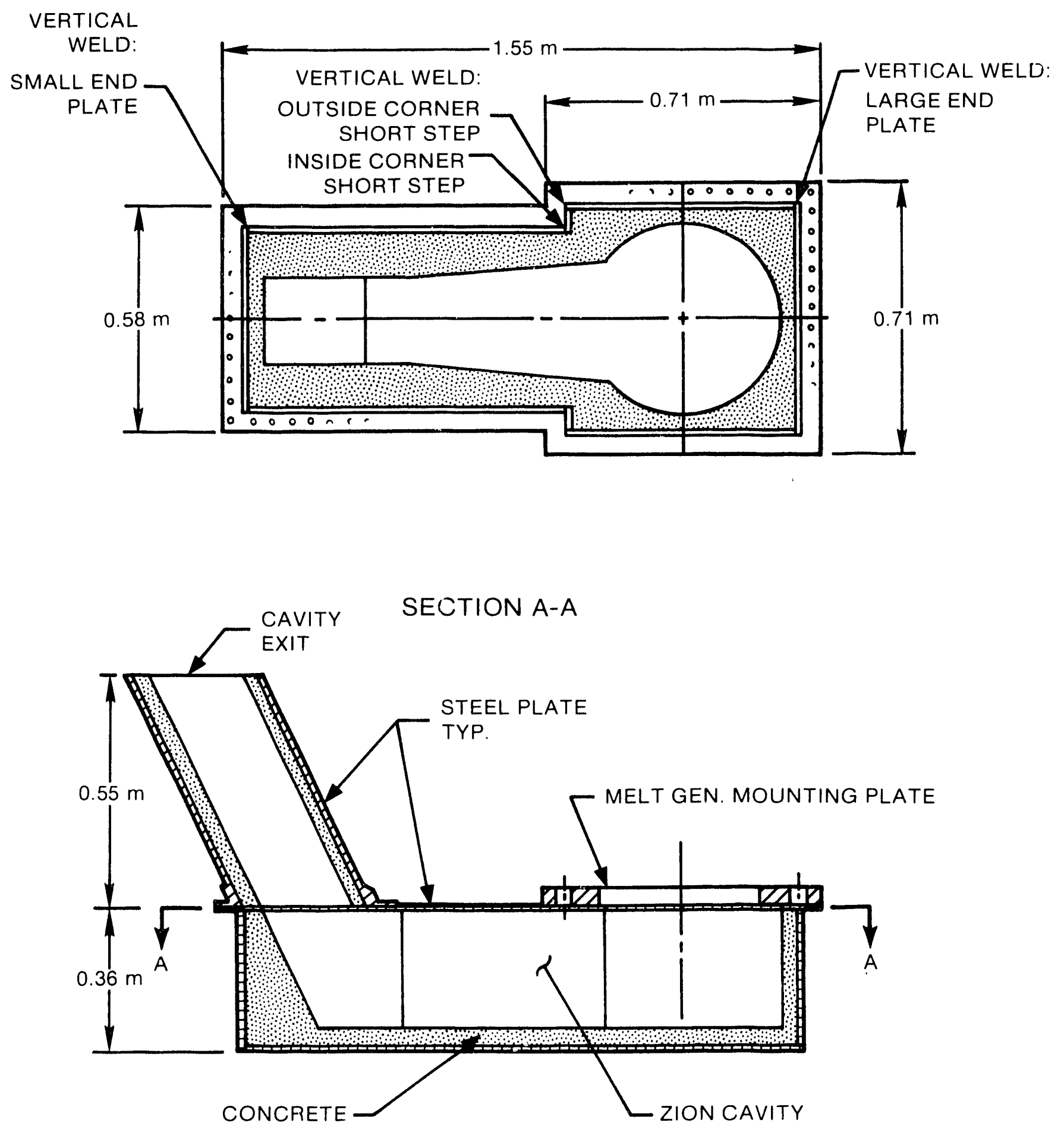

Figure 2-4. Schematic drawing of the scaled zion cavity. 


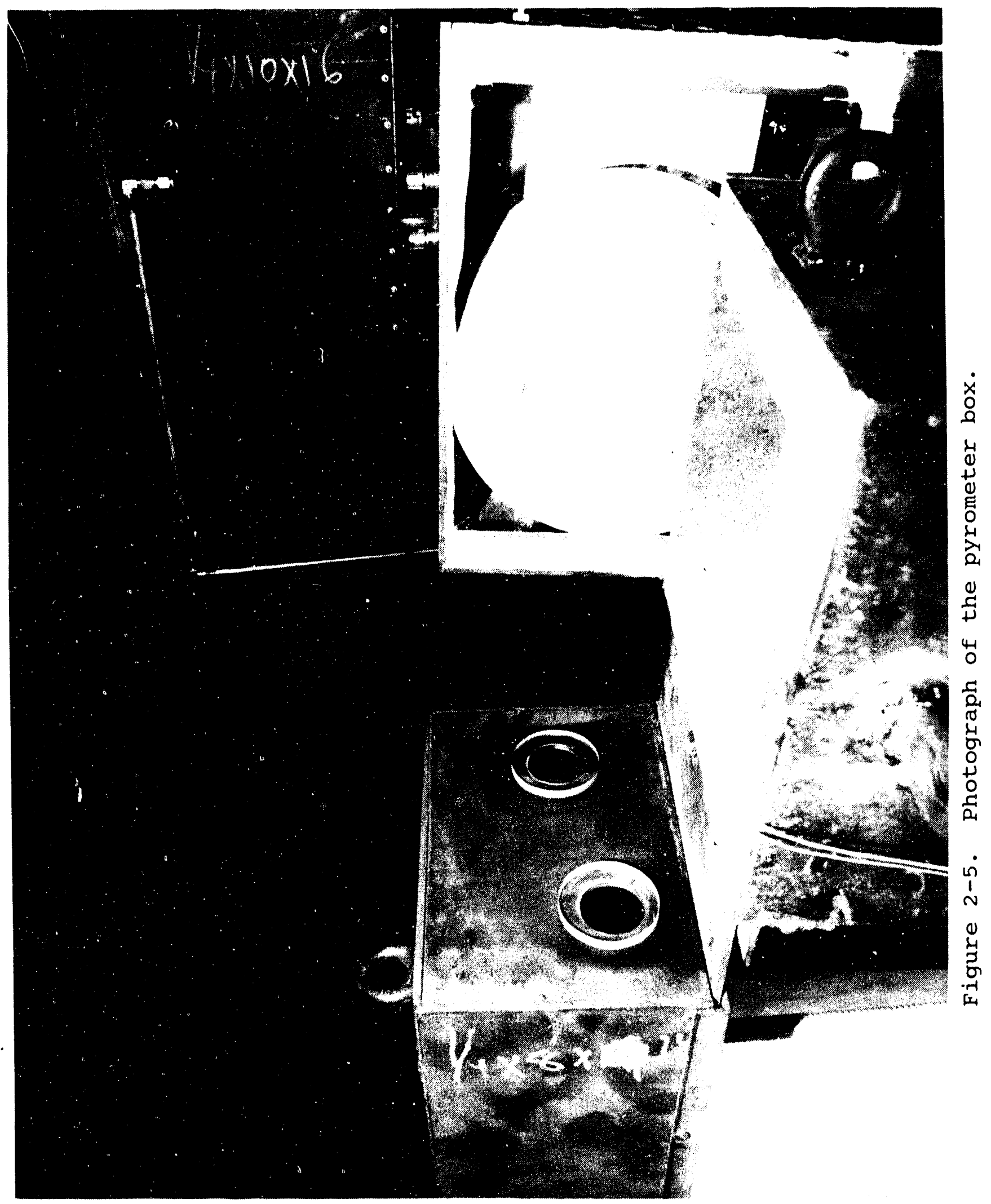




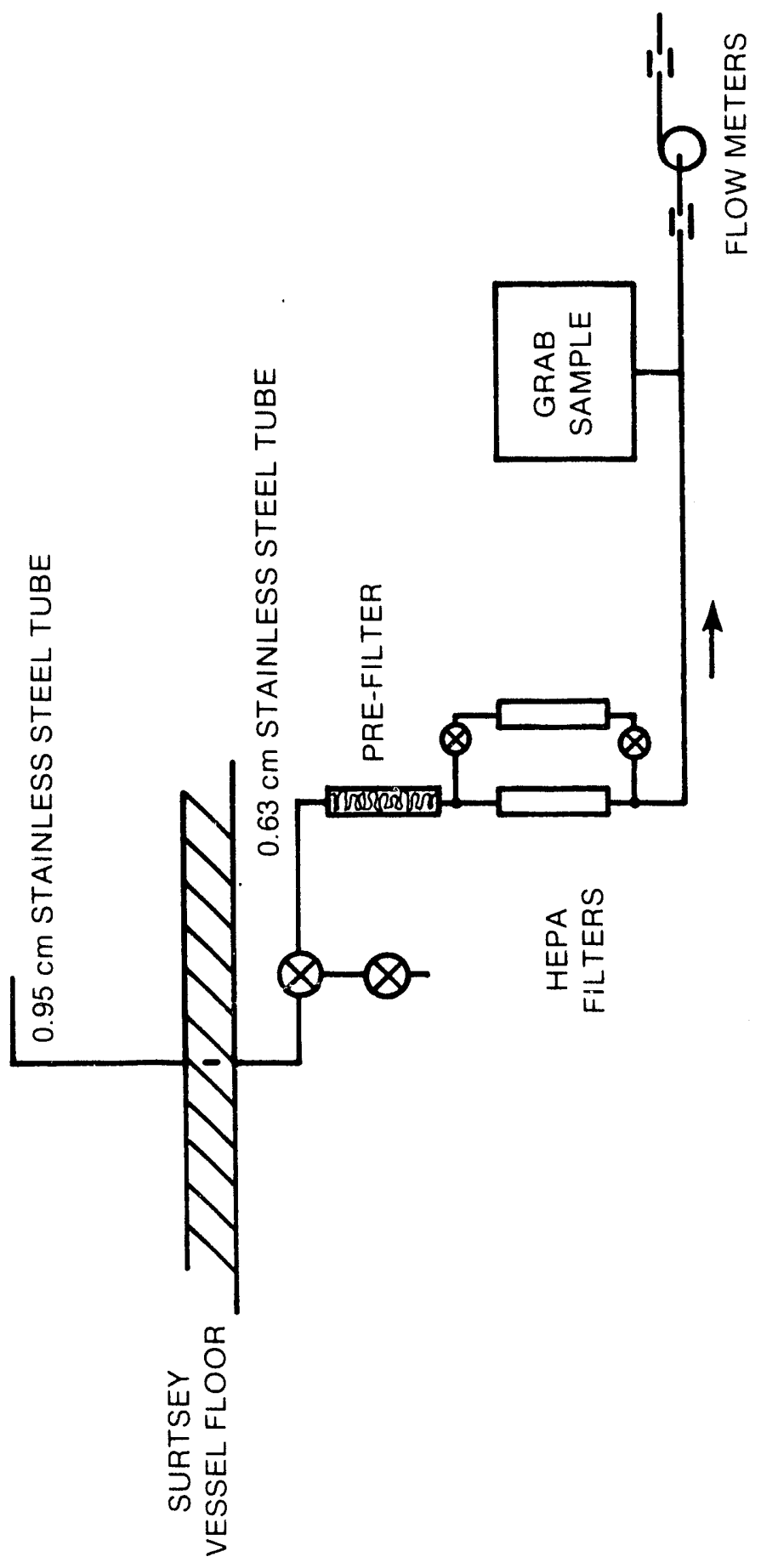

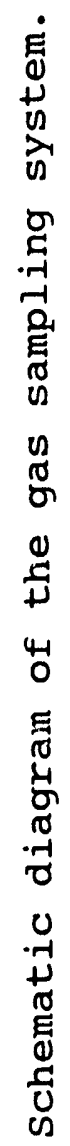

$\stackrel{\dot{0}}{1}$

峁 


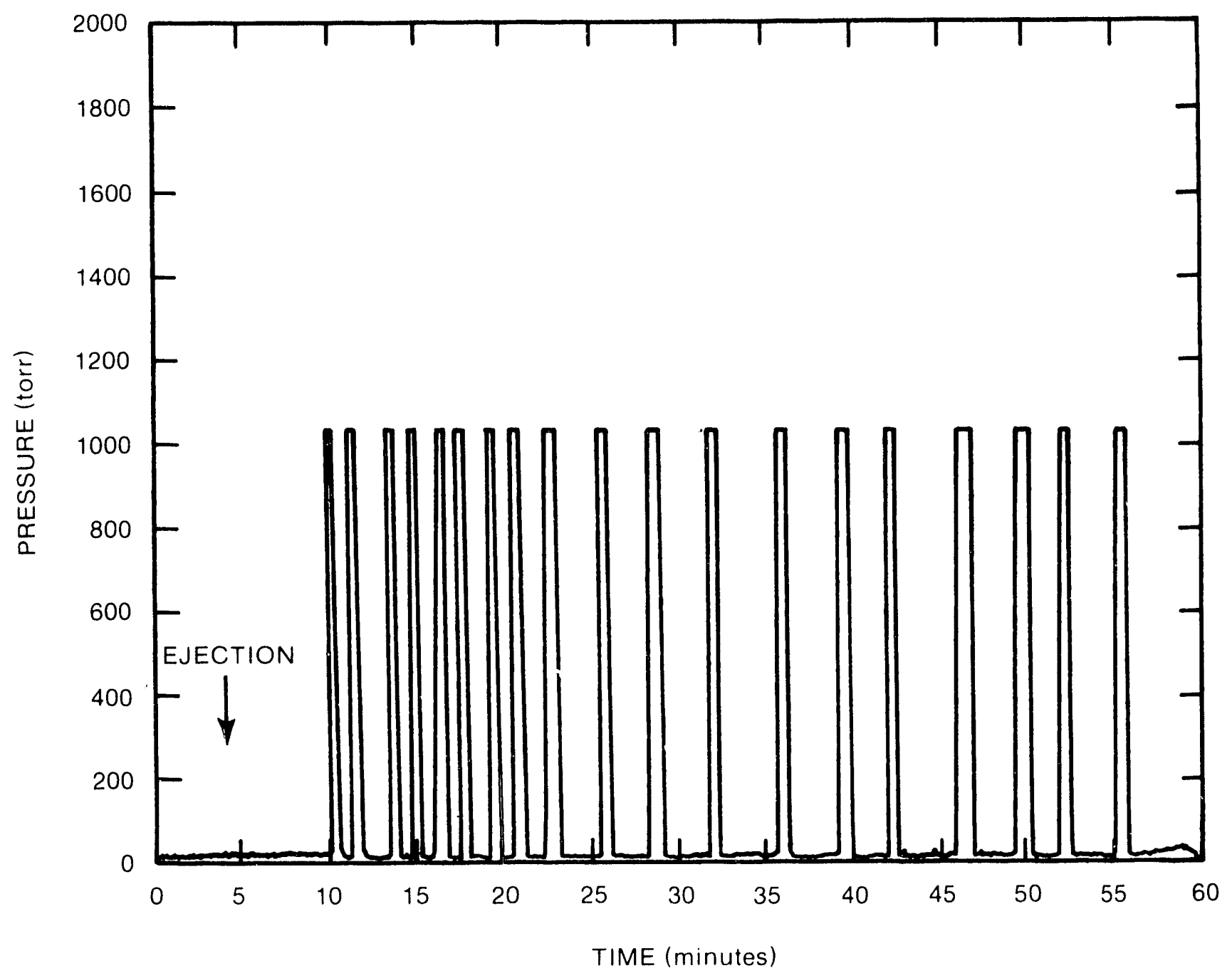

Figure 2-7. Gas grab sample manifold pressure versus experiment time in $\mathrm{DCH}-4$. 


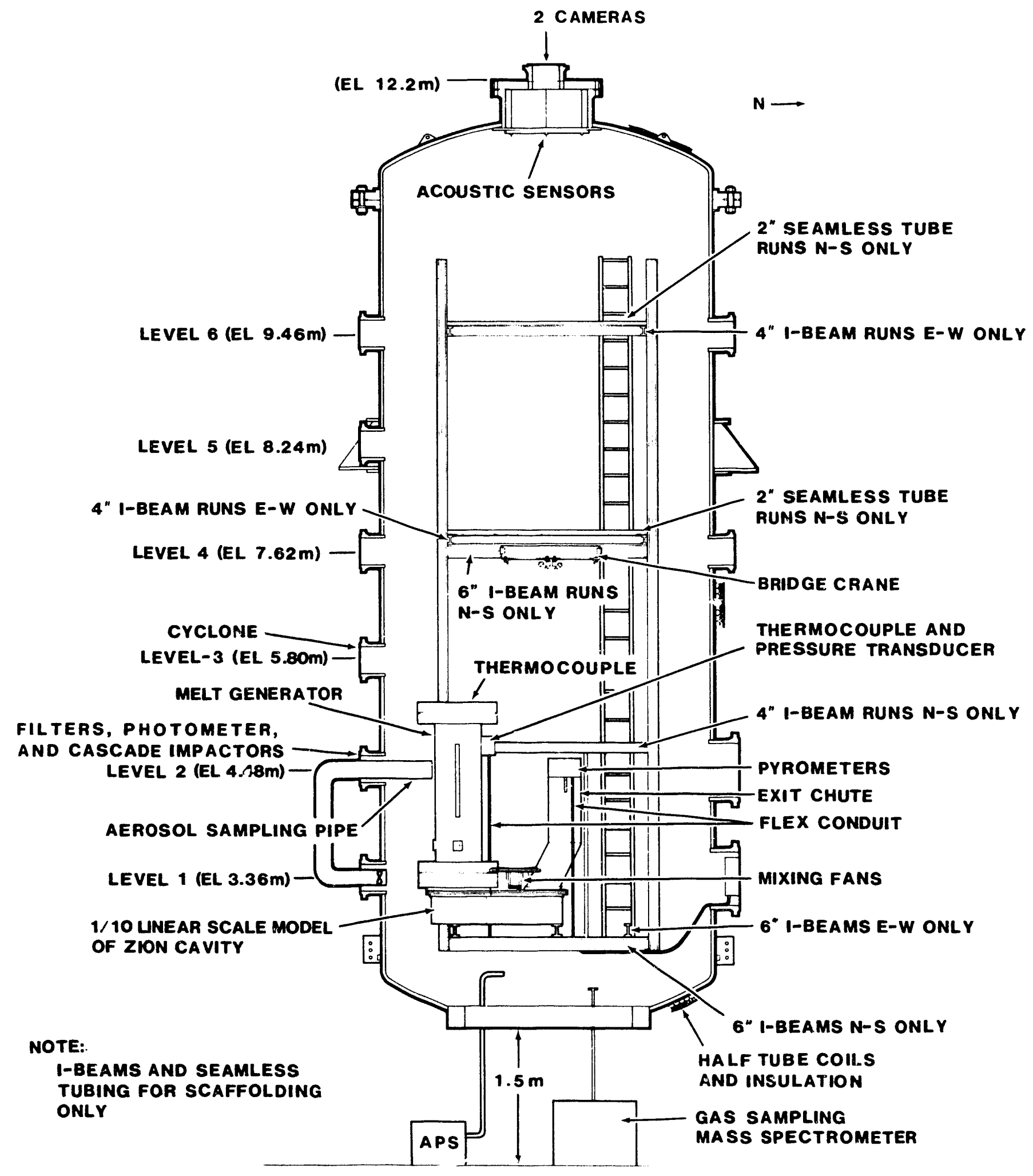

Figure 2-8. Cross-sectional view of the surtsey vessel showing the internal structures, melt generator, scaled zion cavity, and aerosol instrumentation. 


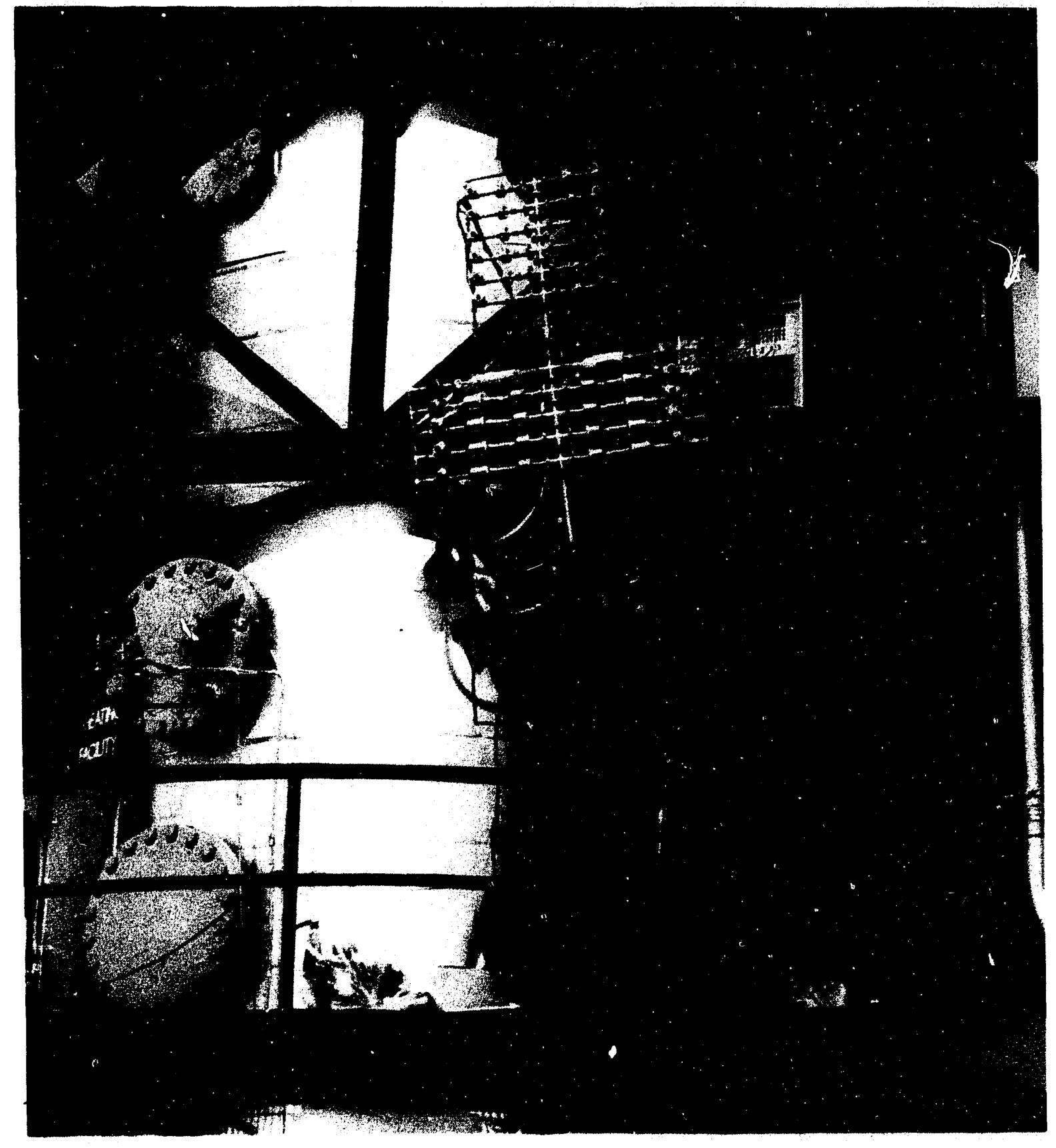

Figure 2-9. Fhotograph of the aerosol sampling loop with the assembled aerosol sampling equipment. 


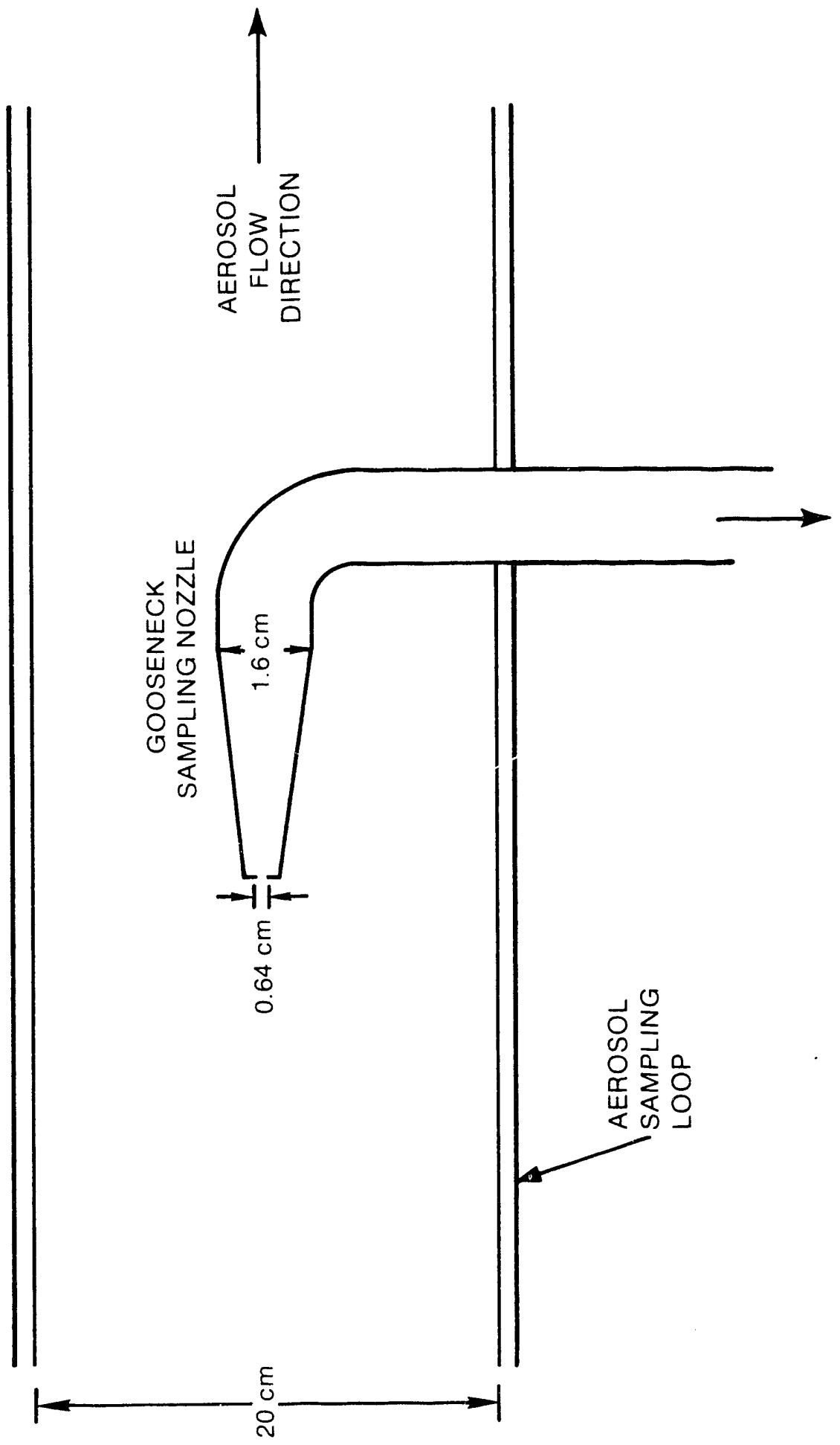

$\stackrel{0}{\square}$

통

品

넌

N

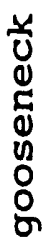

岂

崩

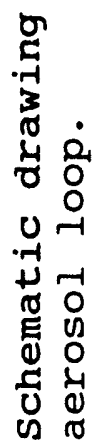

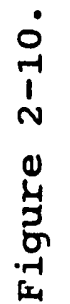




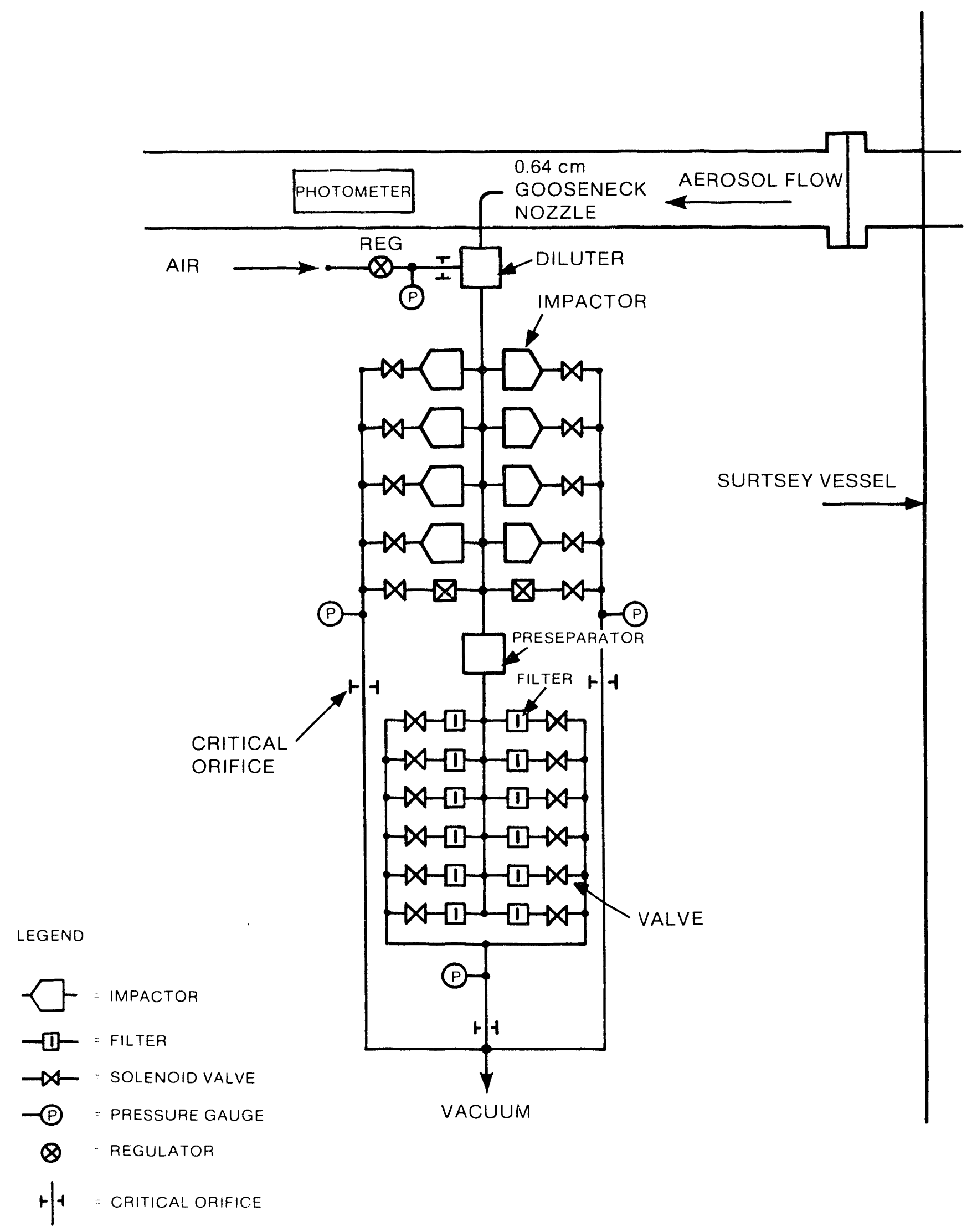

Figure 2-11. Schematic diagram of the DCH aerosol sampling instrumentation. 


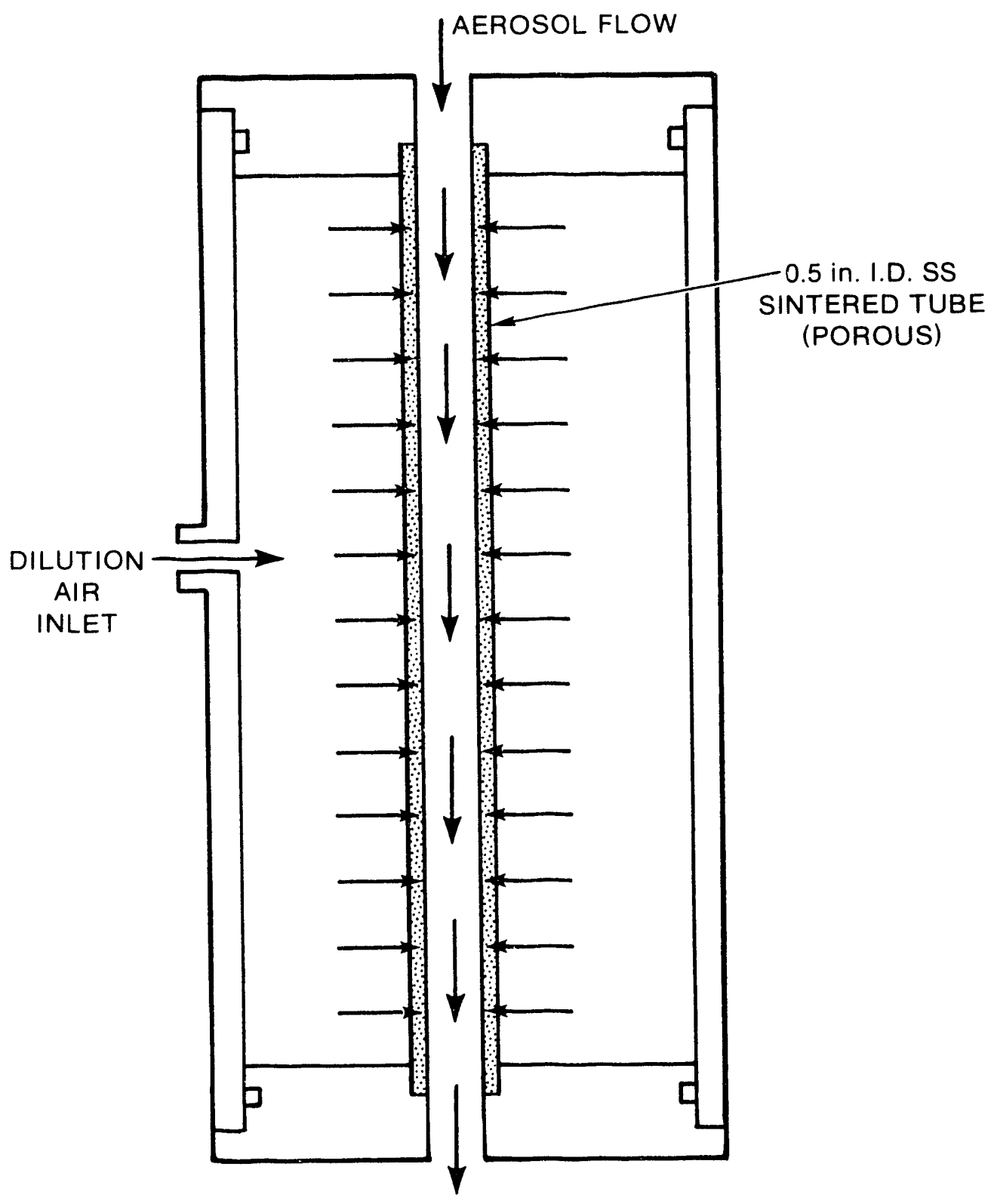

Figure 2-12. Schematic diagram of the aerosol flow dilutor. 


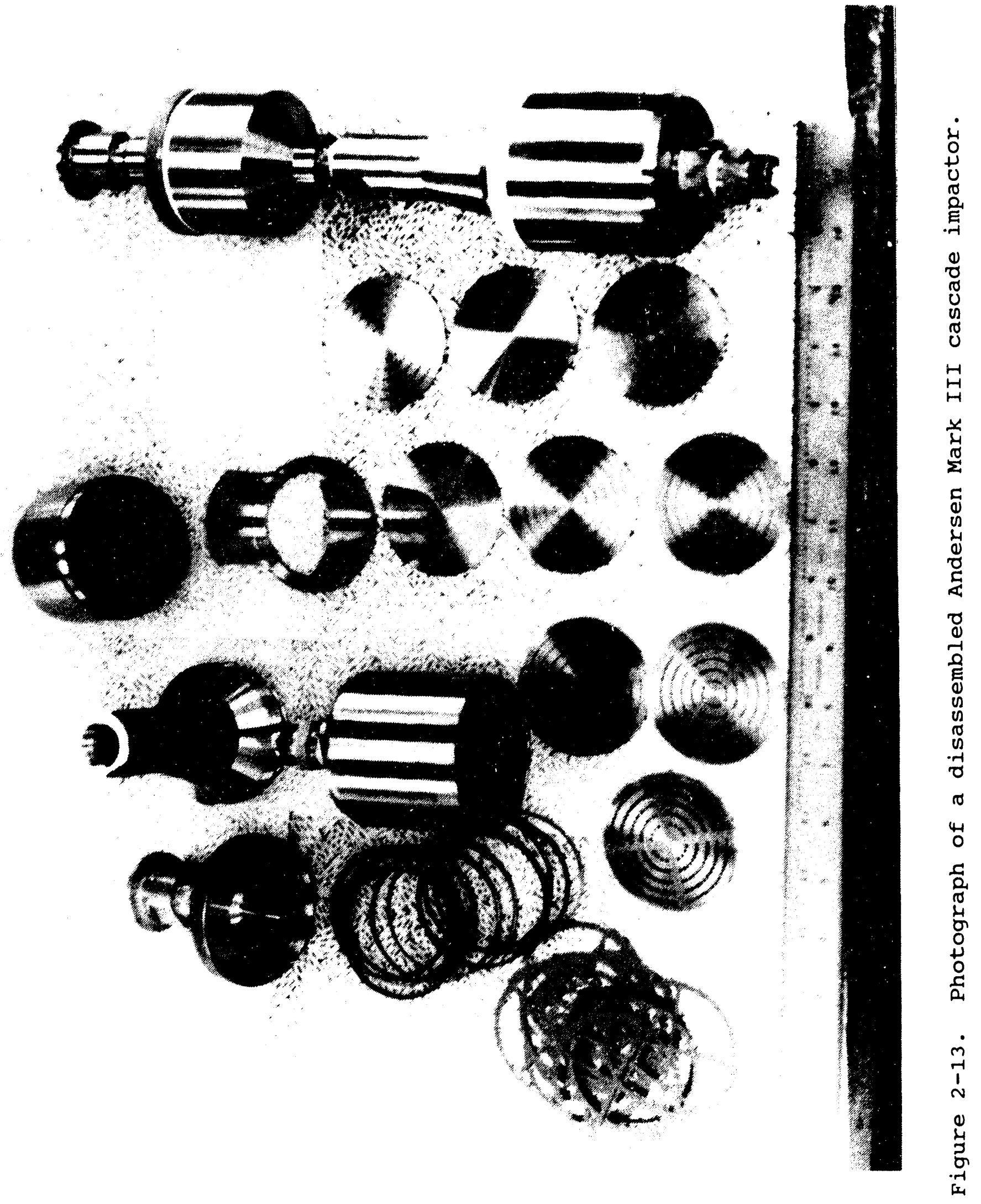




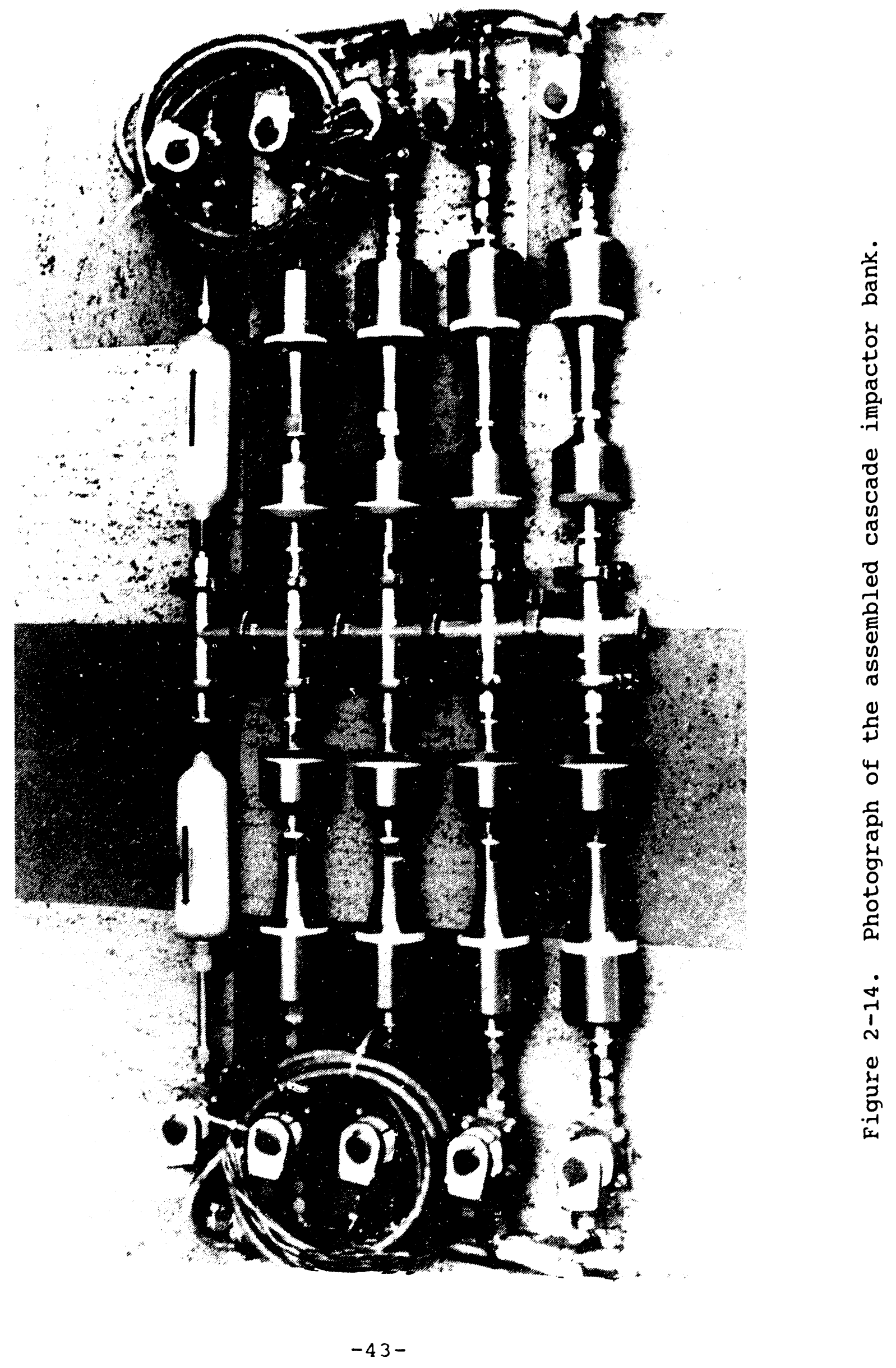



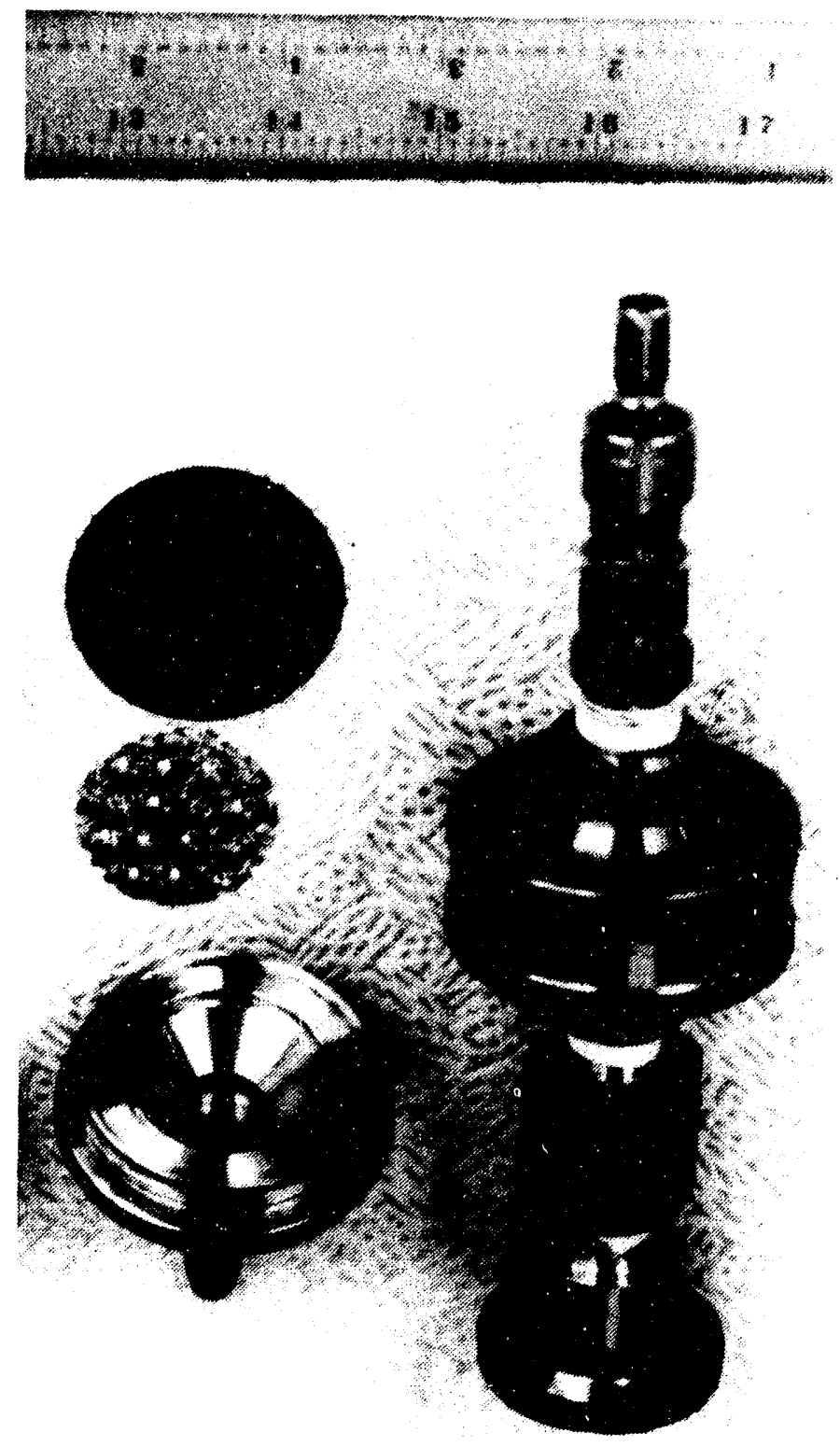

Figure 2-15. Photograph of a disassembled Gelman filter holder. 


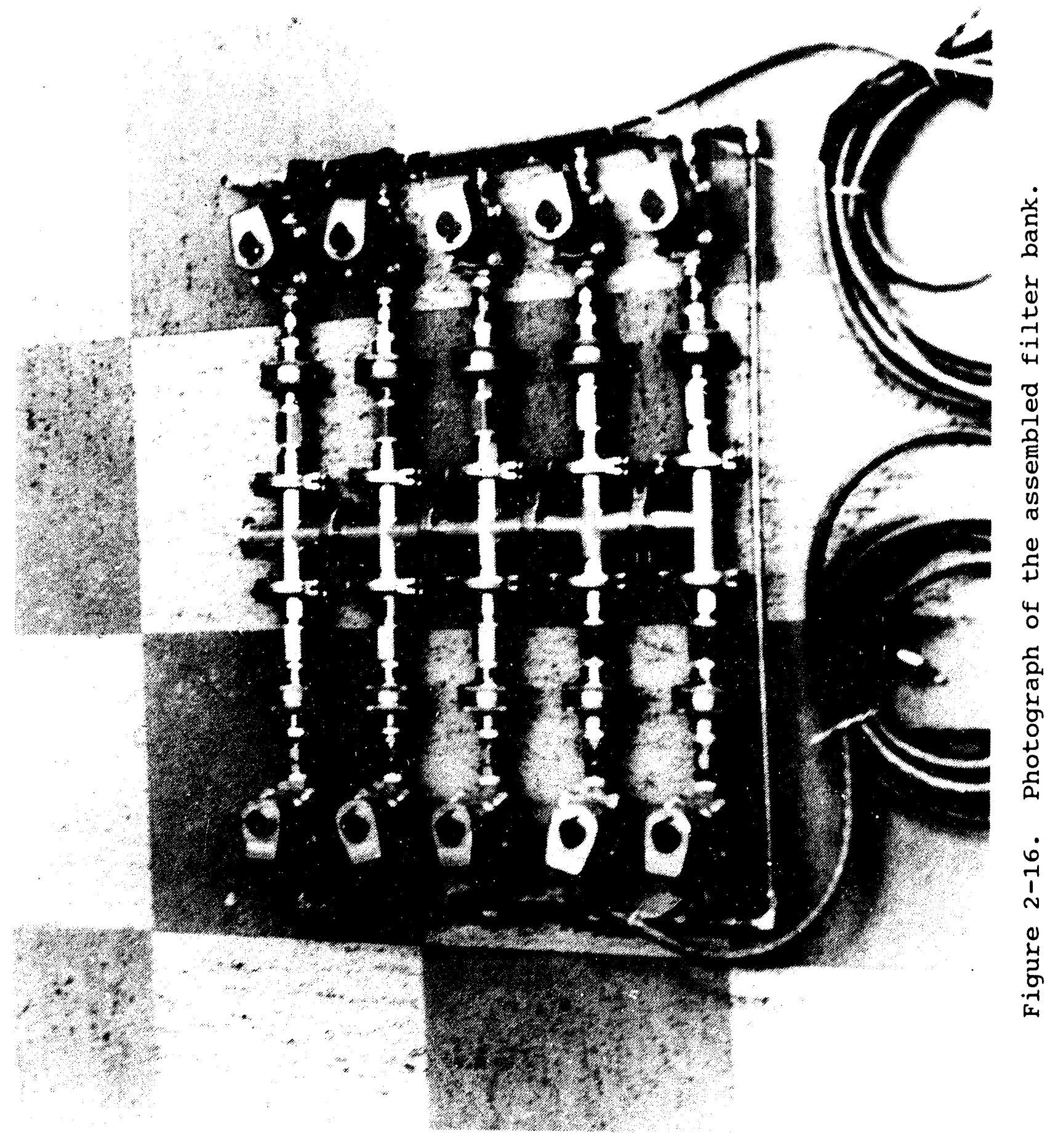




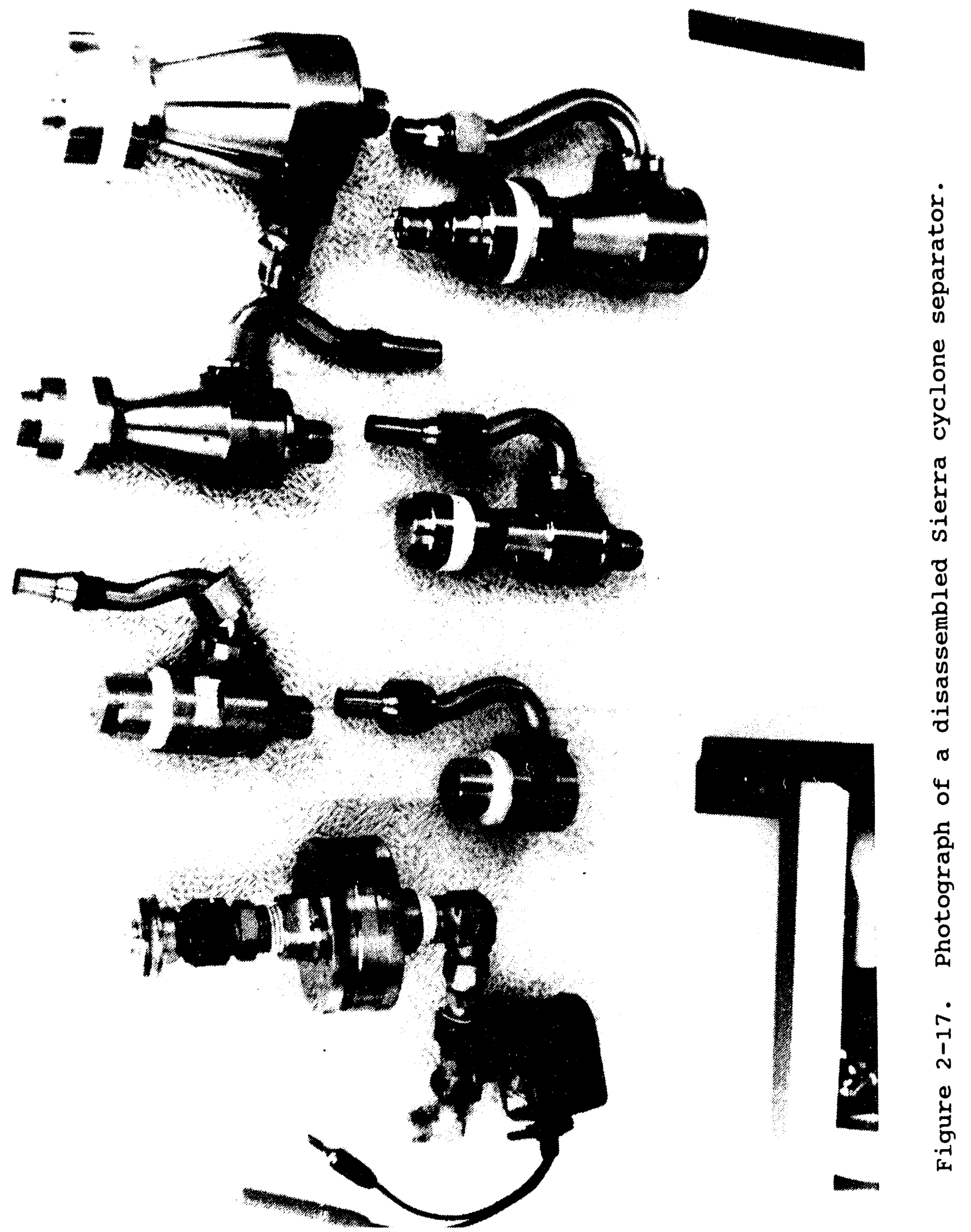




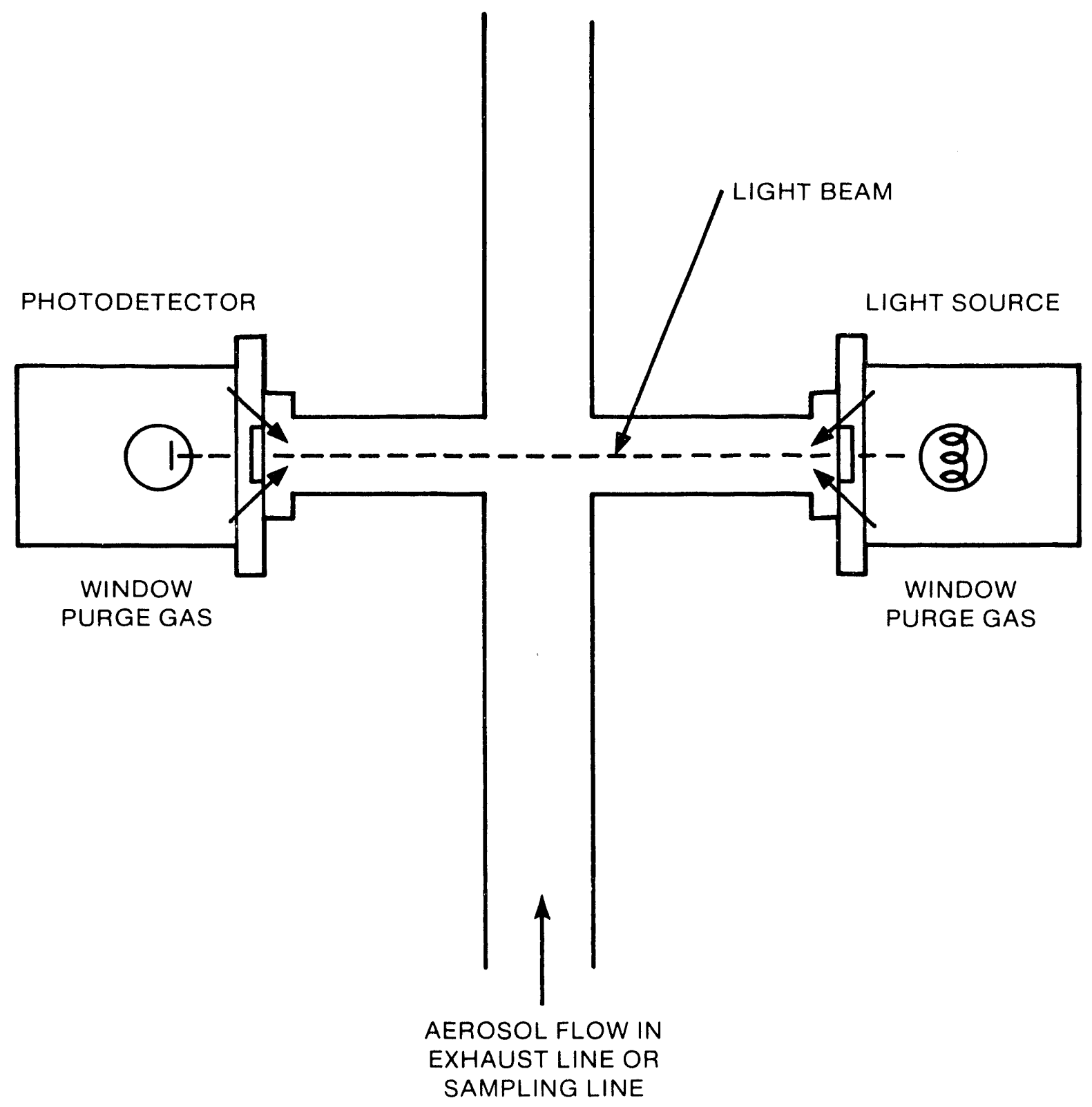

Figure 2-18. Schematic diagram of the Dynatron opacity monitor. 


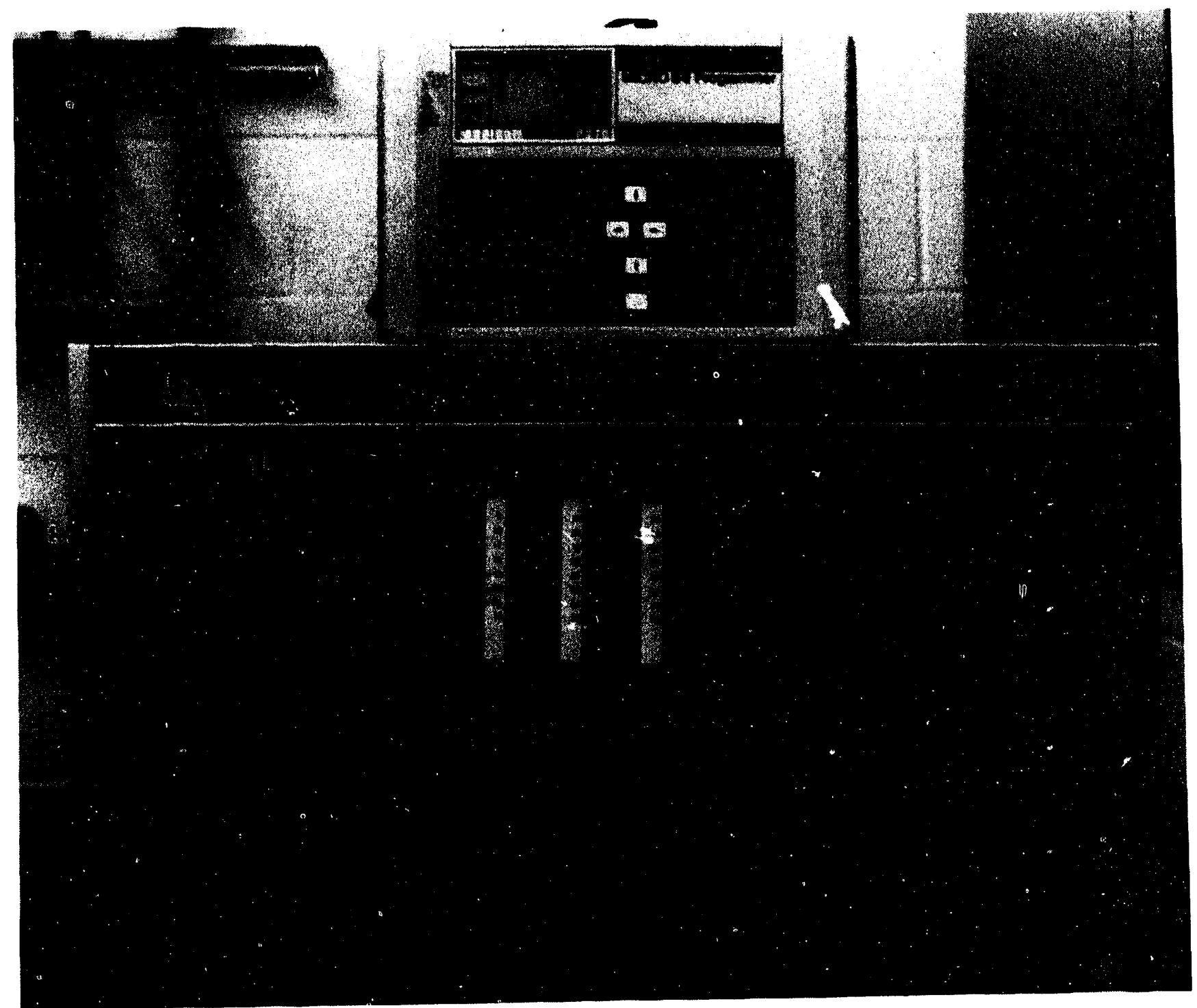

Figure 2-19. Photograph of the programmer and controller used to control the sampling scheme for the aerosol instrumentation. 


\subsection{EXPERIMENTAL RESULTS}

The measurements made in the $\mathrm{DCH}-3$ and $\mathrm{DCH}-4$ experiments are reported in this chapter. The figures in section 3.1 are plots of the raw data from the $\mathrm{DCH}-3$ experiment instrumentation listed in Table 2.1. The figures in section 3.2 are similar plots for the DCH-4 experiment. Section 3.3 reports the results of gas analyses for both experiments, and section 3.4 gives the results of the debris recovery and characterization. Section 3.5 reports the results of the aerosol measurements for the $\mathrm{DCH}-3$ and $\mathrm{DCH}-4$ experiments.

\subsection{Pressure and Temperature Measurements in DCH-3}

Time zero of the experiment was marked in the data acquisition system when a photodiode under the fusible brass plug in the base of the crucible first sensed the melt ejection. Figure 3-1 is a plot of the signal from the photodiode below the melt plug. All experiment times in this report are with respect to this zero time, which marks the beginning of molten thermite ejection into the cavity. Figure 3-2 shows that the thermite was ignited at an experiment time of $-24.12 \mathrm{~s}$; this means that it took $24.12 \mathrm{~s}$ for the melt front to propagate downward through the thermite and melt the brass plug.

Figures $3-3$ and 3-4 show the gauge pressure in the melt generator versus an experiment time from $-30 \mathrm{~s}$ to $+60 \mathrm{~s}$ for two pressure transducers (labelled PMG-29 and PMG-30 in Table 2.1). These curves are in good agreement. The melt generator was prepressurized with nitrogen to about $3.7 \mathrm{MPa}$. Shortly after the thermite was ignited at an experiment time of $-24 \mathrm{~s}$, the melt generator pressurized linearly to about $6.3 \mathrm{MPa}$. At an experiment time of $0 \mathrm{~s}$, melt ejection started and the pressure in the melt generator quickly dropped to equal the vessel pressure. Figures $3-5$ and $3-6$ show the gauge pressure in the melt generator for an experiment time from $-1 \mathrm{~s}$ to $+2 \mathrm{~s}$ for the same two pressure transducers. These curves show that blowdown of the driving gas in the melt generator takes approximately $1.5 \mathrm{~s}$. 
Figure 3-7 shows the gas temperature in the melt generator versus experiment time recorded from the thermocouple labelled HMGSID. The signal from this type-K thermocouple was very noisy. The gas temperature started increasing shortly after the thermite was ignited. The gas temperature reached about $110^{\circ} \mathrm{C}$ when melt ejection started.

Following failure of the fusible plug in the bottom of the crucible, melt was discharged into the cavity by the driving gas in the melt generator. The flow of the high-temperature melt through the exit aperture in the steel plate caused ablation [Pilch and Tarbell 1985; Tarbell et al. 1988g]. The final size of the aperture determined the mass flow rate of gas during the blowdown of the melt generator. For these experiments, the time interval for melt discharge into the cavity was 100-300 ms. Near the end of the liquid discharge phase, there was a short period $(\approx 50 \mathrm{~ms})$ where both debris and gas were discharged; this is referred to as gas blowthrough and pneumatic atomization. The gas blowdown of the pressure vessel lasted one to two seconds. Film and $x$-ray records indicated that the period of debris discharge from the cavity was on the order of $500 \mathrm{~ms}$.

Figures 3-8 through 3-15 give the gauge pressure in the surtsey vessel as a function of experiment time. The signals from these pressure transducers were noisy but show good agreement, with one exception: a transducer at level 1 (labelled PLI-20) measured pressures approximately $60 \mathrm{kPa}$ lower than the other transducers, but showed the same general shape and timing of the pressure response curve. One transducer listed in Table 2.1 labelled PL5-28 malfunctioned and recorded no data; the data from this transducer are not presented here.

Figures 3-9 through 3-15 show a pressure response in the Surtsey vessel that had two humps. The first hump occurred between 1 and $2 \mathrm{~s}$ and had a peak gauge pressure between 170 and $180 \mathrm{kPa}$. The second hump was higher than the first; it occurred between 3 and 4 s and had a peak gauge pressure between 200 and $210 \mathrm{kPa}$. These curves showed that vessel pressurization occurred within a few hundred milliseconds after breach of the crucible (experiment time $=0 \mathrm{~s}$ ) and increased rapidly over a period of about $100 \mathrm{~ms}$. The two-hump appearance 
of the pressure response curves was analyzed with the Kiva-DCH code and is discussed in section 4.2 of this report.

Figures 3-16 through 3-21 show gas temperatures measured in the Surtsey vessel at level 1 with aspirated thermocouples. All of these temperature response curves are in good agreement. They indicate that the peak gas temperature in the Surtsey vessel at level 1 was about $550^{\circ} \mathrm{C}$ at an experiment time of $4.5 \mathrm{~s}$.

Figures 3-22 through 3-27 give gas temperatures measured in the Surtsey vessel at level 3 with aspirated thermocouples. These temperature response curves are in good agreement, which indicates that the aspirated thermocouple measurements are reproducible. These firures show that the peak gas temperature in the surtsey vessel at level 3 was approximately $920^{\circ} \mathrm{C}$ at an experiment time of $1 \mathrm{~s}$. They also show a broad peak in the gas temperature with a maximum value of about $500^{\circ} \mathrm{C}$ at an experiment time of about $4.5 \mathrm{~s}$.

Figures 3-28 through 3-33 show gas temperatures measured in the Surtsey vessel at level 5 with aspirated thermocouples. The agreement among the six temperature response curves measured at level 5 is not as good as the agreement of those at the lower levels. The reason for differences among these curves is probably the violent spreading of debris and hot particles after the plume impacted the upper head of the vessel. A hot particle intercepted by an aspirated thermocouple lead might result in a spurious high-temperature peak. The temperature peak with a maximum value of about $1900^{\circ} \mathrm{C}$ at an experiment time of $2.4 \mathrm{~s}$ in Figure 3-28 may have been due to the collection of a hot particle on that thermocouple wire (labelled HL5-13); however, this measurement is probably not accurate since $1900^{\circ} \mathrm{C}$ is higher than a type $K$ thermocouple can measure. In general, the level 5 thermocouples indicated a peak gas temperature of about $1060^{\circ} \mathrm{C}$ at an experiment time of $0.8 \mathrm{~s}$.

\subsection{Pressure and Temperature Measurements in DCH-4}

Figure 3-34 is a plot of the signal from the photodiode below the brass melt plug. When the photodiode in the cavity first 
sensed melt ejection, its signal set the experiment time in the data acquisition system to $0 \mathrm{~s}$. Figure $3-35$ is a plot of the ignitor signal. It shows that the thermite was ignited at an experiment time of $-23.3 \mathrm{~s}$. Thus, the time from ignition to melt ejection into the cavity was $23.3 \mathrm{~s}$.

Figure $3-36$ is a plot of the gauge pressure in the melt generator as a function of experiment time. This pressure history shows that the melt generator was initially pressurized with nitrogen to about $1 \mathrm{MPa}$ and held at that pressure for approximately $80 \mathrm{~s}$. The melt generator was then pressurized to 4.2 MPa, and at an experiment time of $-23.3 \mathrm{~s}$ the thermite was ignited remotely with a wire pyrofuse. shortly after the thermite was ignited, the melt generator pressurized to 6.4 MPa. At an experiment time of $0 \mathrm{~s}$, melt ejection into the cavity started and the pressure quickly dropped to equal the vessel pressure.

Figures 3-37 through 3-44 show the gauge pressure in the Surtsey vessel plotted as a function of experiment time. The signals from these pressure transducers had an excellent signal-to-noise ratio compared to the signals measured in $\mathrm{DCH}-3$. The improved signal-to-noise ratio in DCH-4 was accomplished by including an amplifier/signal conditioner in the data acquisition system. Figures 3-37 through 3-44 show a pressure response in the surtsey vessel that had two humps. The first hump had a peak gauge pressure of between 160 and $210 \mathrm{kPa}$ at an experiment time of $1.1 \mathrm{~s}$. The second hump had a peak pressure that was approximately equal in magnitude to the first hump for the data from each of the transducers. The second hump occurred at an experiment time of about $2.7 \mathrm{~s}$. These curves showed that pressurization of the surtsey vessel in DCH-4 occurred within a few hundred milliseconds after breach of the crucible and increased rapidly over a period of about $100 \mathrm{~ms}$. The two hump appearance of the pressure response curves was analyzed with the Kiva-DCH code and is discussed in section 4.2 of this report.

Figures $3-45$ and $3-50$ show gas temperatures measured in the Surtsey vessel at level 1 with aspirated thermocouples. The measurements with different thermocouples at the same level are in excellent agreement. The "noisy" appearance of the 
temperature response curves is probably the result of aerosol particles impacting the thermocouple wires, not electronic noise. These curves show an initial peak with a maximum temperature of about $190^{\circ} \mathrm{C}$ at an experiment time between 0 and $2 \mathrm{~s}$, and a second broad peak with a temperature of about $300^{\circ} \mathrm{C}$ between 4 and $10 \mathrm{~s}$.

Figures 3-51 through 3-56 give gas temperatures measured in the Surtsey vessel at level 3 with aspirated thermocouples. The three thermocouples used to measure the data in Figures 3-51, 3-52, and 3-52 were located in the same anodized aluminum tube and measured temperature response curves that were in excellent agreement. These curves indicate a peak gas temperature of $520^{\circ} \mathrm{C}$ at an experiment time of $1.4 \mathrm{~s}$. Another anodized aluminum tube, located at the same elevation as the one discussed above, housed the three thermocouples used to measure the data in Figures 3-54, 3-55, and 3-56. The temperature response curves measured by the thermocouples in the same tube were in excellent agreement, but were different from those measured by the other three thermocouples at the same level. The temperature response curves shown in Figures 3-54, 3-55, and 3-56 indicate a peak gas temperature of approximately $590^{\circ} \mathrm{C}$ at an experiment time of about $0.75 \mathrm{~s}$. The fact that the two sets of thermocouples showed a different temperature response was probably the result of hot molten debris in the end of the aluminum tube.

Figures 3-57 through 3-61 give gas temperatures measured in the Surtsey vessel at level 5 with aspirated thermocouples. The three thermocouples used to measure temperatures in Figures $3-57,3-58$, and 3-59 were located in one aluminum tube, while the two thermocouples used to measure the data in Figures 3-60 and 3-61 were located in a second aluminum tube (one of the thermocouples in this tube did not record data). The temperature response curves shown in Figures 3-57, 3-58, and 3-59 are in good agreement. These curves show a peak with a gas temperature of $920^{\circ} \mathrm{C}$ at an experiment time of about $0.7 \mathrm{~s}$, and a second peak with a gas temperature of $920^{\circ} \mathrm{C}$ at an experiment time of $0.9 \mathrm{~s}$. The temperature response curves shown in Figures $3-60$ and $3-61$ are in excellent agreement with those of Figures 3-57 to 3-59. These curves shown that the gas temperature started to rise at an experiment time of $0.5 \mathrm{~s}$ and reached a peak temperature of $920^{\circ} \mathrm{C}$ at an experiment time of 
about $0.8 \mathrm{~s}$. These two curves (Figures 3-60 and 3-61) look very similar to the temperature response curves in Figures 3-57, 3-58, and 3-59 except for the dip at an experiment time of $0.8 \mathrm{~s}$ in the latter. This dip may be the result of a brief problem in the data acquisition system. The actual temperature response at level 5 is probably best reflected by the curves shown in Figures $3-60$ and 3-61. Figure 3-62 is a photograph of three aspirated thermocouples: the one in the center had not been used and the two on the sides were used at level 5 in the DCH-3 experiment. This photograph shows that the end of the aluminum tube was melted by molten debris. This may have affected the temperature measurements from the aspirated thermocouples.

An automatic optical pyrometer and a two-color pyrometer (wavelengths $=0.7$ and $1.05 \mu \mathrm{m}$ ) were placed at the cavity exit to measure the temperature of the debris as it emerged into the Surtsey vessel in the $\mathrm{DCH}-3$ and $\mathrm{DCH}-4$ experiments. Figure 3-63 shows the debris temperature history at the chute exit in the DCH-3 experiment measured with the optical pyrometer. The optical pyrometer is only calibrated for temperatures in the range between 1700 and $2800^{\circ} \mathrm{C}$, and consequently any output (in $\mathrm{mV}$ ) that corresponds to a temperature less than $1700^{\circ} \mathrm{C}$ shows up as a zero temperature in the optical pyrometer plot, even though the temperature may not really be zero. Figure 3-63 indicates measured temperatures in $\mathrm{DCH}-3$ up to $2250^{\circ} \mathrm{C}$ over an experiment time of 0.12 to $0.76 \mathrm{~s}$. Figure $3-64$ shows the debris temperature at the chute exit in the $\mathrm{DCH}-3$ experiment measured with the two-color pyrometer. The calibrated temperature range for the two-color pyrometer is 1500 to $3500^{\circ} \mathrm{C}$; thus, any output (in $\mathrm{mV}$ ) from the two-color pyrometer that corresponds to a temperature less than $1500^{\circ} \mathrm{C}$ shows up as a zero temperature in the plot. Figure 3-64 indicates debris temperatures above $1500^{\circ} \mathrm{C}$ between 0.04 and $0.95 \mathrm{~s}$ and a peak temperature of about $2300^{\circ} \mathrm{C}$. The agreement between the optical pyrometer and two-color pyrometer measurements is excellent, especially considering differences in their operating characteristics such as response time.

Figure 3-65 shows the debris temperature at the chute exit in the DCH-4 experiment measured with the optical pyrometer. This I igure inaicates debris temperatures above $1700=\hat{C}$ between 0.06 and $0.78 \mathrm{~s}$ and a peak temperature of about $2350^{\circ} \mathrm{C}$. Figure $3-66$ 
shows the debris temperature history at the chute exit measured in the $\mathrm{DCH}-4$ experiment with the two-color pyrometer. Figure 3-66 indicates measured temperatures in $\mathrm{DCH}-4$ up to $2240^{\circ} \mathrm{C}$ over an experiment time between 0.06 and $0.81 \mathrm{~s}$. The pyrometer measurements in the $\mathrm{DCH}-3$ and $\mathrm{DCH}-4$ experiments were in good agreement with each other and with previous tests. Approximately ten previous experiments using the same melt generator configuration and thermite composition have shown debris temperatures in the range $2000-2200^{\circ} \mathrm{C}$ [Tarbell et al. 1986]. This range appears to be typical of this type of experiment. It is also the temperature expected for core debris derived from $U-Z r-O$ mixtures rich in zirconium. The measured temperatures are all much less than the adiabatic reaction temperature used in some experiments [Spencer 198?] to characterize direct containment heating tests.

\subsection{Gas Analyses}

Previous tests have shown that the pre-filter was quite efficient in removing most of the aerosols, and consequently, only one HEPA filter was used in each of these experiments. The self-indicating rotameter was visually monitored during the sampling period and no indication of blocked flow was observed in either experiment.

Twenty-three gas grab samples were taken for the $D C H-3$ experiment and were subsequently analyzed by gas chromatography/mass spectrometry. The results of the analyses are listed in Table 3.1, which gives volume percent (vol.o a function of experiment time for $\mathrm{N}_{2}, \mathrm{O}_{2}, \mathrm{Ar}$, and $\mathrm{CO}_{2}$. Four samples were taken prior to HPME and nineteen samples were taken beginning 5 minutes after the melt ejection. There was a general power failure at 14.5 minutes after the HPME, but this should not have had an impact on the results of the gas analyses. The oxygen concentration in the background samples was 21.4 vol.\% (which is identical to the standard atmospheric o.'rgen concentration); however, the oxygen concentration in the gas samples following the HPME was 14.4 vol.\%. This oxygen depletion was a result of reactions between the metallic debris and oxygen in the surtsey vessel. 
Table 3.1

Gas Grab sample Results from DCH-3

\begin{tabular}{|c|c|c|c|c|c|}
\hline \multirow[b]{2}{*}{ Time (min) } & \multirow[b]{2}{*}{ Sample No. } & \multicolumn{3}{|c|}{ Volume $\%$} & \multirow[b]{2}{*}{$\mathrm{CO}_{2}$} \\
\hline & & $\mathrm{N}_{2}$ & $\mathrm{O}_{2}$ & Ar & \\
\hline$-15 \cdot 5$ & $10-1$ & 77.88 & 21.14 & 0.95 & 0.02 \\
\hline-15.0 & $10-2$ & 77.55 & 21.41 & 0.97 & 0.07 \\
\hline-14.5 & $10-3$ & 77.55 & 21.48 & 0.94 & 0.03 \\
\hline-14.0 & $10-4$ & 77.56 & 21.48 & 0.94 & 0.03 \\
\hline 0.0 & & & & & Melt Ejection \\
\hline 5.0 & $9-2$ & 81.75 & 16.53 & 0.91 & 0.79 \\
\hline 4.5 & $9-3$ & 79.76 & 18.76 & 0.92 & 0.54 \\
\hline 6.0 & $9-4$ & 83.84 & 14.02 & 0.89 & 1.20 \\
\hline 6.3 & $8-2$ & 83.93 & 13.93 & 0.89 & 1.21 \\
\hline 6.6 & $8-3$ & 83.57 & 14.34 & 0.90 & 1.14 \\
\hline 7.0 & $8-4$ & 84.05 & 13.90 & 0.89 & 1.12 \\
\hline 9.0 & $7-2$ & 83.96 & 13.93 & 0.89 & 1.18 \\
\hline 11.0 & $7-3$ & 83.98 & 13.88 & 0.89 & 1.21 \\
\hline 14.5 & & & & & Power Failure \\
\hline 25.0 & $6-3$ & 83.96 & 13.90 & 0.89 & 1.22 \\
\hline 28.0 & $6-4$ & 81.45 & 16.83 & 0.90 & 0.81 \\
\hline 29.0 & $5-2$ & 82.09 & 16.07 & 0.90 & 0.92 \\
\hline 31.0 & $5-3$ & 83.84 & 14.05 & 0.88 & 1.19 \\
\hline 35.0 & $5-4$ & 84.22 & 13.64 & 0.88 & 1.22 \\
\hline 39.0 & $4-2$ & 84.28 & 13.58 & 0.88 & 1.22 \\
\hline 49.0 & $4-4$ & 84.34 & 13.54 & 0.87 & 1.21 \\
\hline 56.0 & $3-2$ & 84.44 & 13.43 & 0.87 & 1.21 \\
\hline 62.0 & $3-3$ & 84.45 & 13.44 & 0.87 & 1.20 \\
\hline 69.0 & $3-4$ & 84.47 & 13.44 & 0.86 & 1.19 \\
\hline 76.0 & $2-4$ & 84.33 & 13.64 & 0.86 & 1.13 \\
\hline
\end{tabular}


Twenty-three gas grab samples were also taken for the DCH-4 experiment and subsequently analyzed. The results are listed in Table 3.2, which gives volume percent as a function of experiment time for $\mathrm{N}_{2}, \mathrm{O}_{2}$, and $\mathrm{Ar}$. Three samples were taken prior to HPME, and twenty samples were taken beginning 6 minutes after the melt ejection. Some of the gas samples obviously had leaked and consequently these results are not included in Table 3.2. The oxygen concentration in the background samples was 2.2 vol. $\%$, whereas the oxygen concentration after the HPME was 0.85 vol. $\%$. The surtsey vessel had been purged with argon to inert the atmosphere in an attempt to eliminate the reaction between metallic debris and oxygen. The oxygen concentration was obviously further decreased by the metallic debris ejected into the vessel in the DCH-4 experiment.

Table 3.2

Gas Grab Sample Results from DCH-4

\begin{tabular}{rrrrr}
\hline & & \multicolumn{3}{c}{ Volume 8} \\
\cline { 3 - 5 } Time(min.) & Sample No. & $\mathrm{N}_{2}$ & $\mathrm{O}_{2}$ & Ar \\
& & & & \\
-11.0 & $10-2$ & 12.4 & 2.6 & 84.9 \\
-10.0 & $10-3$ & 11.2 & 2.3 & 86.5 \\
-10.0 & $10-4$ & 8.9 & 1.6 & 89.5 \\
4.0 & & & & Melt Ejection \\
10.0 & $9-2$ & 12.8 & 1.1 & 85.7 \\
13.0 & $9-4$ & 17.0 & 0.8 & 81.3 \\
14.0 & $8-2$ & 16.9 & 0.8 & 81.2 \\
16.0 & $8-3$ & 16.9 & 0.7 & 81.3 \\
17.0 & $8-4$ & 16.9 & 0.7 & 81.3 \\
21.0 & $7-3$ & 17.1 & 0.7 & 81.0 \\
23.0 & $7-4$ & 17.2 & 0.7 & 80.9 \\
28.0 & $6-4$ & 18.0 & 0.7 & 80.2 \\
39.0 & $5-4$ & 18.0 & 0.9 & 80.0 \\
42.0 & $4-2$ & 18.2 & 0.9 & 79.8 \\
49.0 & $4-4$ & 18.5 & 1.0 & 79.3 \\
52.0 & $3-2$ & 18.6 & 1.0 & 79.2 \\
55.0 & $3-3$ & 18.6 & 1.0 & 79.2
\end{tabular}




\subsection{Debris Recovery and Mass Balance}

Debris was recovered following the $\mathrm{DCH}-3$ and $\mathrm{DCH}-4$ experiments to determine the mass of dispersed material retained at specific locations in the vessel. The general debris recovery procedures and observations were very similar for $\mathrm{DCH}-3$ and $\mathrm{DCH}-4$, so the description below applies to both experiments. Initial inspection of the surtsey vessel revealed a fine rustcolored dust in $\mathrm{DCH}-3$, and a fine gray dust in $\mathrm{DCH}-4$ that coated all of the horizontal surfaces in the vessel. Underneath the dust, large pieces of solid debris were observed on the lower head of the surtsey vessel. Solid debris was also found on some of the horizontal surfaces of the vessel.

Debris recovery began with vacuuming the aerosol dust from the lower head. Following this, the larger pieces of debris were recovered. Debris recovery then proceeded from the bottom to top of the surtsey vessel, cleaning each component of the vessel and test apparatus in sequence.

Table 3.3 gives the relative amounts of debris recovered (percentage of the total mass recovered) from specific locations (cavity, upper head, walls, and lower head). It should be noted that the recovered mass represents the debris in its final state, after oxidation of the metallic phase had taken place. Thus, the recovered mass exceeded the initial mass of the thermite powder placed in the melt generator.

The first row of Table 3.3 lists the percentage of the mass that remained in the cavity for the $\mathrm{DCH}-1$ through $\mathrm{DCH}-4$ experiments. Debris recovered from the cavity and keyway consisted of a crust that was approximately 1 to $4 \mathrm{~mm}$ thick in $\mathrm{DCH}-3$ and 1 to $8 \mathrm{~mm}$ thick in $\mathrm{DCH}-4$. It was dull black in appearance and very brittle. This film of material coated the entire keyway and exit chute. The thicker material was found where the wall of the cavity met the floor at the closed end; the thinner material was found on the open end of the cavity and was present on both the vertical and horizontal surfaces of the cavity. The underside of this crust was contaminated with concrete from the cavity. The material in the circular portion 
of the keyway was nonrecoverable but appeared to be 2 to $4 \mathrm{~mm}$ thick. Estimates of the material remaining in this section of the cavity were based on this estimated thickness. In addition, portions of the exit chute could not be accessed and the debris remaining there was estimated to have a thickness of $2 \mathrm{~mm}$. Because of the extreme heat of the melt, the upper layers of the concrete decomposed and stuck to the frozen crust. Therefore, the crust removed was accompanied by some decomposed concrete from the cavity.

Table 3.3

Mass, Location, and Oxidation of Recovered Debris

Cavity ( $\%$ )

Upper head $(\%)$

Walls ( $\%$ )

Lower head $(\%)$

Percent

trapped (1)

Total

mass $(\mathrm{kg})$

Iron

oxidized

\section{Percent of Total Mass}

$\underline{\mathrm{DCH}-1} \underline{\mathrm{DCH}-2} \underline{\mathrm{DCH}-3} \quad \underline{\mathrm{DCH}-4}$

$\begin{array}{rrrr}48 & 10 & 3 & 6 \\ 8 & 28 & 60 & 49 \\ -10 & 45 & 14 & 8 \\ 34 & 17 & 23 & 37\end{array}$

18

73

74

57

21.3

99.5

97.4

87.5

Note: (1) Total on upper head and walls

The upper head retained the majority of the debris recovered from the vessel. After striking the head, the molten material apparently flowed radially outward from the center and froze, leaving a (1- to 2-mm thick) layer of tightly bonded material. Removal of debris from the upper head was difficult. Some of 
this material was nonrecoverable, but it was estimated that this quantity was less than one kilogram. Molten material apparently ran in rivulets to the outside perimeter of the upper head and froze in large sheets of somewhat malleable material. This debris was generally loosely bound to the vessel and was easily removed.

The third row of Table 3.3 lists the percentage of the mass that was recovered from the walls of surtsey for the $\mathrm{DCH}-1$ through DCH-4 experiments. The vertical walls of the surtsey vessel were covered primarily by aerosol. However, there was some spherical sintered material on the horizontal surfaces of the instrument penetration ports and on other horizontal surfaces of the internal structures in the vessel. Figure 3-67 is a posttest photograph showing aerosol dust covering the melt generator, the cavity chute, and a mixing fan after the DCH-3 experiment. This figure is similar to the pretest photograph shown in Figure 2-3.

The fourth row of Table 3.3 gives the percentage of the total mass dispered into the vessel that was recovered from the lower head. Debris on the lower head of the surtsey vessel was generally found to be of four types: (1) a fine layer of aerosol dust, (2) smaller loosely bound material that the vacuum could pick up, (3) frozen porous sheets, and (4) heavier dense material that lay around the perimeter of the lower head flange of the vessel. Figure $3-68$ is a photograph of the lower head of the surtsey vessel prior to the $\mathrm{DCH}-3$ experiment, and Figure 3-69 is a similar photograph after the DCH-3 test. A layer of aerosol covers the lower head and other horizontal surfaces shown in Figure 3-69. The small, loosely bound material was comprised of frozen spherical particles, typical of molten drops that have been quenched as they fall through the atmosphere. The frozen sheets of material were brittle and very porous. The thickness of these sheets averaged approximately 2 to $3 \mathrm{~mm}$. The material that lay around the perimeter of the lower flange of the vessel contained enough heat after impact so that it formed fairly dense chunks of solidified debris that were 3 to $4 \mathrm{~cm}$ thick. The outer surface of this material contained spherical droplets frozen into place. 
No solidified debris was recovered from inside the melt generator or crucible. The melt generator was clean because the chimney on the crucible prevented melt from splashing out during the violent thermite reaction. The crucible maintained its overall integrity, but portions of the thin, steel inner liner were eroded away and the Mgo insulation was visible in places. Globs of once molten material clung to the sides of the interior walls of the crucible, and there was also a layer of debris on the 2-inch thick bottom plate. All of the material on the crucible was tightly bonded and there was no way to determine visually whether it came from the crucible or the melt.

The material recovered from the vessel and the cavity was weighed to give an overall mass balance. Table 3.3 shows the location and amount of material recovered in all four $\mathrm{DCH}$ experiments. The total mass of the collected debris is greater than the initial charge of $80 \mathrm{~kg}$. There are three reasons that may account for this:

1. The loss of mass of the melt crucible accounts for approximately $7 \mathrm{~kg}$.

2. The addition of foreign material picked up during the debris recovery process, e.g., the concrete that adhered to the melt.

3. The reaction of molten iron with the oxygen in the surtsey atmosphere.

The last row of Table 3.3 shows an estimate of the extent of iron oxidation in the four DCH experiments. The values are based upon the oxygen consumed in the vessel, using gas composition measurements taken $100 \mathrm{~s}$ after the HPME transient. The lower and upper limits of the range were calculated by assuming that the metal formed $\mathrm{FeO}$ or $\mathrm{Fe}_{2} \mathrm{O}_{3}$, respectively.

Table 3.4 gives an estimated debris mass balance for the $\mathrm{DCH}-3$ and $\mathrm{DCH}-4$ experiments. In $\mathrm{DCH}-3$, pre- and posttest oxygen measurements indicated that approximately $10.3 \mathrm{~kg}$ of oxygen reacted with molten iron to form iron oxides. In $\mathrm{DCH}-4$, in which the surtsey vessel contained argon with $\approx 1.4$ vol. 
oxygen, about $0.5 \mathrm{~kg}$ of oxygen reacted with molten iron. In DCH-3, the mass lost from the crucible was estimated to be approximately $7 \mathrm{~kg}$. In $\mathrm{DCH}-4$, the crucible weighed $125 \mathrm{~kg}$ prior to the test and $117.7 \mathrm{~kg}$ after the test; thus, the crucible lost $7.3 \mathrm{~kg}$ of mass by melting and ablation of the inner steel liner. The additional oxygen and mass lost from the crucible were added to the initial.charge to get the estimated mass available for dispersal. The estimated mass balance is only accurate to about $\pm 1 \mathrm{~kg}$.

Table 3.4

Estimated Mass Balance

\begin{tabular}{|c|c|c|}
\hline & $\mathrm{DCH}-3$ & $\mathrm{DCH}-4$ \\
\hline Initial charge & $80.0 \mathrm{~kg}$ & $80.0 \mathrm{~kg}$ \\
\hline $\begin{array}{l}\text { Mass lost from } \\
\text { crucible }\end{array}$ & $-7.0 \mathrm{~kg}$ & $7.3 \mathrm{~kg}$ \\
\hline $\mathrm{O}_{2}$ reactiun with $\mathrm{Fe}$ & $10.3 \mathrm{~kg}$ & $\simeq 0.5 \mathrm{~kg}$ \\
\hline Estimated total & $97.3 \mathrm{~kg}$ & $87.8 \mathrm{~kg}$ \\
\hline Measured debris & $97.4 \mathrm{~kg}$ & $87.4 \mathrm{~kg}$ \\
\hline
\end{tabular}

\subsection{Aerosol Measurements}

Thorough characterization of the aerosol produced by a HPME is necessary for the development of aerosol formation and release models to be used in reactor accident calculations. The quantities determined from the $\mathrm{DCH}-3$ and $\mathrm{DCH}-4$ experiments that are applicable to such modeling efforts are (1) the fraction of the total debris ejected into the vessel that forms aerusol; (2) the mass fraction of each element (including fission product dopants) in the total aerosol mass; (3) the aerosol mass concentration as a function of time; (4) the aerodynamic size distribution; (5) and the 
aerosol particle morphology, which is specified quantitatively by the dynamic shape factor.

Aerosol mass concentration measurements in the $\mathrm{DCH}-3$ and $\mathrm{DCH}-4$ experiments were made by drawing a known volume of aerosol-laden gas through a filter. The total aerosol release was determined by a taggant method employing the $z$ inc in the brass melt plug and elemental analysis of the filter samples. An opacity monitor was used to measure the aerosol mass concentration continuously. It was calibrated posttest based on the discrete concentrations measured with filter samples. Cascade impactors were used to measure massweighted aerosol size distributions and mass concentrations. Number-weighted aerosol size distributions were determined with an Aerodynamic Particle sizer (APS). These distributions were used to calculate the dynamic shape factor of the aerosol [Brockmann and Rader 1990]. A cascade cyclone was used to collect large masses of size-classified aerosol for size-dependent elemental analyses.

\subsubsection{Aerosol Mass Release}

The aerosol mass concentrations in the earlier DCH-1 and DCH-2 experiments (measured with filters and cascade impactors) showed considerable scatter. The spread in the data was attributed to the nonuniform distribution of aerosol within the surtsey vessel. The measured concentrations appeared to be excessively high because the samplers were in a location having a higher than average aerosol concentration. In addition, some of the sampling devices were overloaded by excessive amounts of aerosol, which altered their collection characteristics and reduced the accuracy of the measurements. The aerosol loop in DCH-3 and DCH-4 resulted in much more representative aerosol samples, and consequently, more accurate aerosol measurements.

Tables 3.5 and 3.6 show the filter information for the $\mathrm{DCH}-3$ and $\mathrm{DCH}-4$ tests, respectively. The tables indicate sample time, sample flow rate, dilution ratio, aerosol mass collected, and aerosol mass concentration. similar data have 
been reported for $\mathrm{DCH}^{-1}$ [Tarbell et al. 1987] and $\mathrm{DCH}-2$ [Tarbell et al. 1988].

The improved quality of the aerosol sampling system in the DCH -3 and $\mathrm{DCH}-4$ tests (compared to the $\mathrm{DCH}-1$ and $\mathrm{DCH}-2$ tests) allowed the aerosol mass concentration in the surtsey vessel to be determined from the filter samples. Filter samples were taken at several times after melt ejection to measure the aerosol mass concentration as a function of time. The photometer (an opacity monitor) was set up across the sampling loop to monitor the opacity continuously as a function of time. The opacity readings corresponding to mass concentration measurements (determined from filter samples) were used to determine an empirical relationship between opacity as indicated by the meter and aerosol mass concentration. This correlation was applied to the opacity data to give a continuous indication of the aerosol mass concentration. These data are plotted in Figures 3-70 and 3-71, along with the filter data for $\mathrm{DCH}-3$ and $\mathrm{DCH}-4$, respectively. These figures show the aerosol mass concentration in the surtsey vessel in actual $\mathrm{g} / \mathrm{m}^{3}$ as a function of time for the $\mathrm{DCH}-3$ and $\mathrm{DCH}-4$ tests. Because the aerosol loop was isolaced during the HPME transient and the isolation valves were not opened until the pressure in the vessel had decreased, the aerosol concentration in the vessel had declined substantially before the first samples were taken. To estimate the initial concentration, the aerosol concentration curve was extrapolated exponentially back to zero time. The resultant concentration was multiplied by the $103 \mathrm{~m}^{3}$ volume of the surtsey vessel to determine the initial aerosol mass. From the filter data plotted in Iigure 3-70 the initial aerosol concentration in $\mathrm{DCH}-3$ was estimated to be $8.6 \mathrm{~g} / \mathrm{m}^{3} \pm 30 \%$, giving an aerosolized mass of $0.89 \mathrm{~kg} \pm$ $30 \%$ ( $1.2 \%$ of the mass of the initial charge dispersed into the Surtsey vessel). The initial aerosol concentration in $\mathrm{DCH}-4$ was estimated to be $3.8 \mathrm{~g} / \mathrm{m}^{3} \pm 30 \%$, giving an aerosolized mass of $0.39 \mathrm{~kg} \pm 30 \%(0.53 \%$ of the mass of the initial charge relocated into the surtsey vessel). 


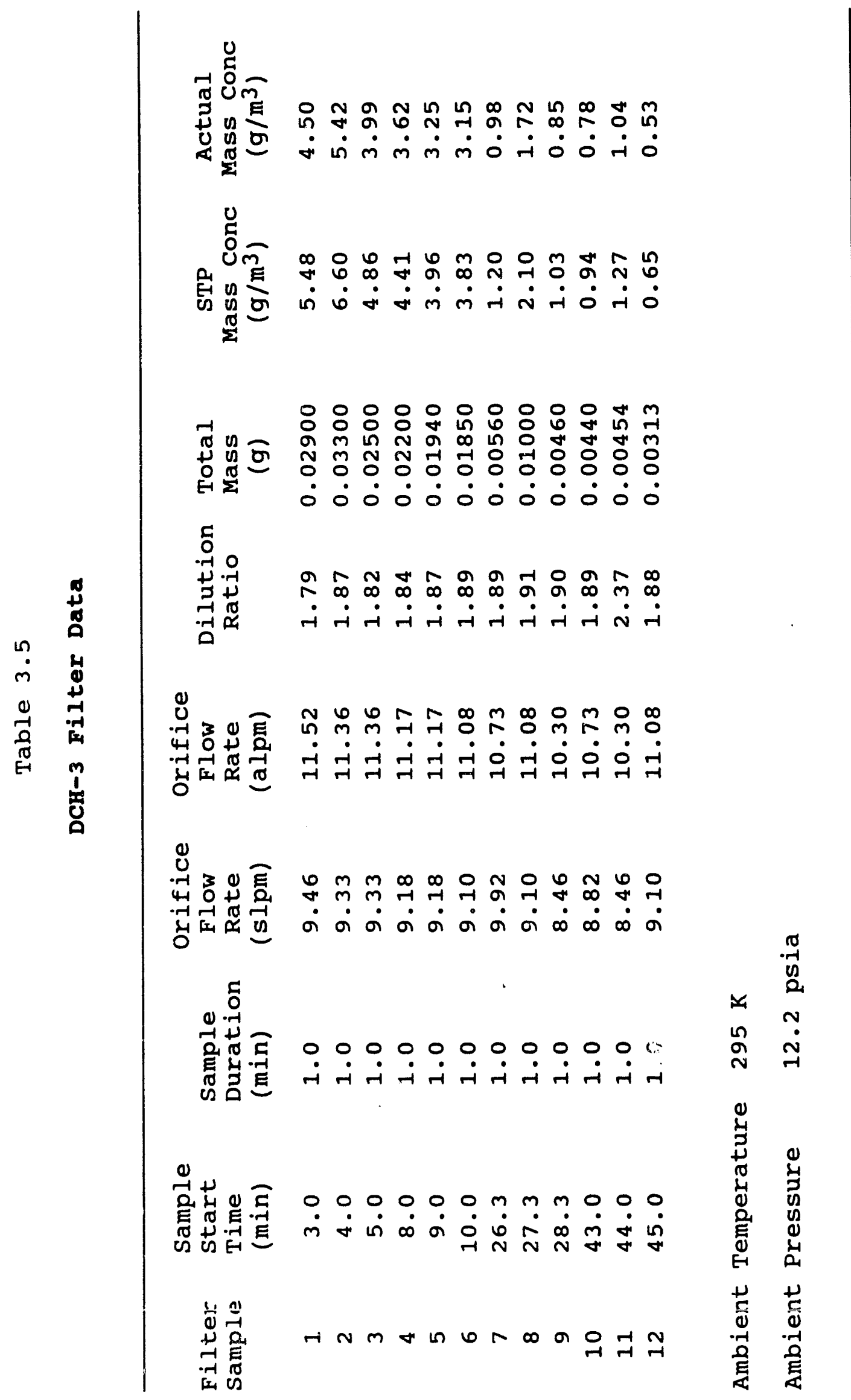




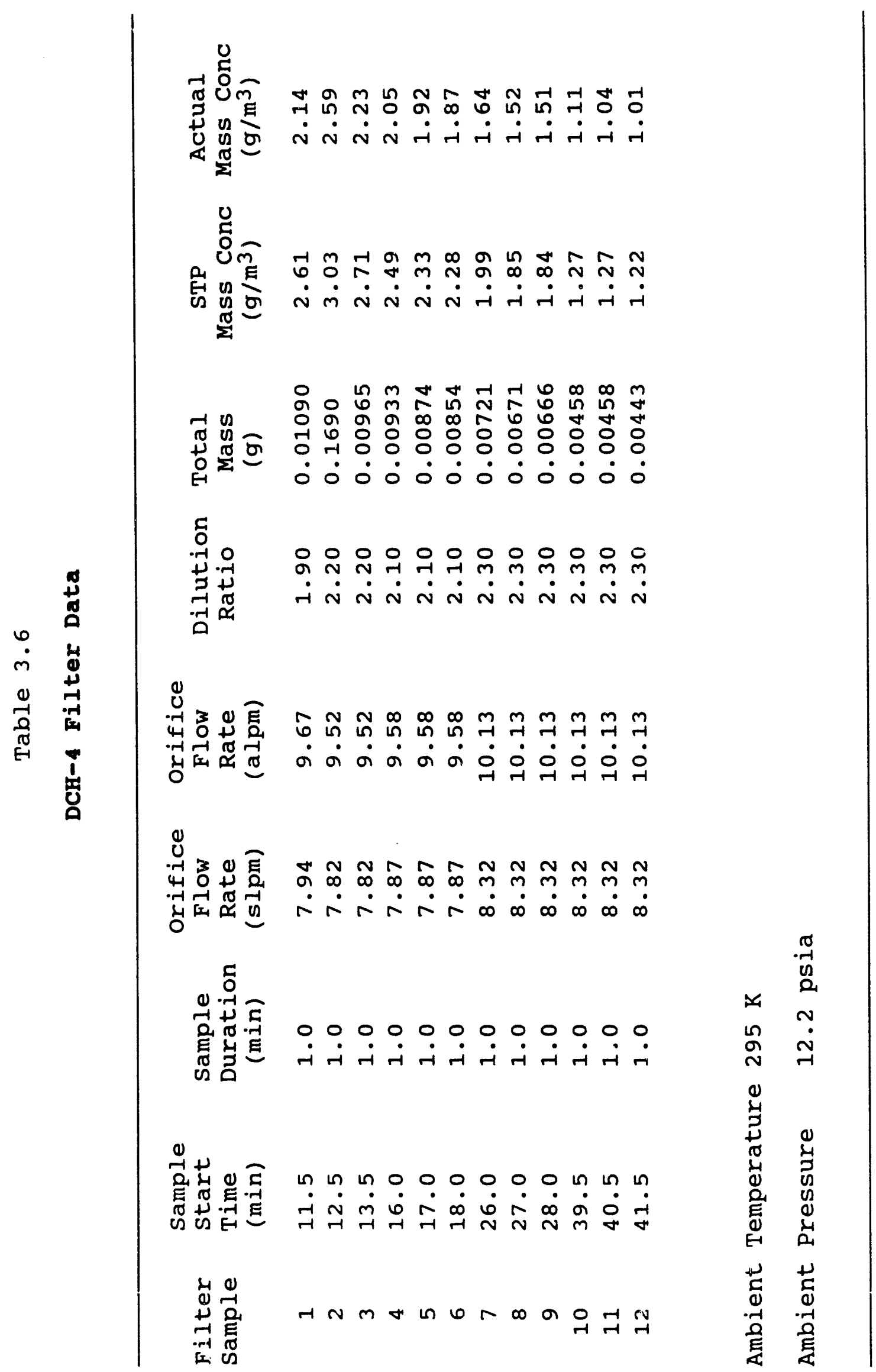


The total aerosol mass released by the HPME in these experiments was also determined by the zinc taggant method described below. This method is the preferred technique since it requires no extrapolation. It was the only method employed for the $\mathrm{DCH}-1$ and $\mathrm{DCH}-2$ experiments and is in close agreement with the filter sample extrapolation results for $\mathrm{DCH}-3$ and $\mathrm{DCH}-4$. Approximately $103 \mathrm{~g}$ of $\mathrm{zinc}$ was contained in the fusible brass plug. Because the melt temperature exceeded the boiling point of zinc $(1186 \mathrm{~K})$, it was assumed that the $z$ inc in the plug was nearly completely vaporized and formed an aerosol. Elemental analyses by inductively coupled plasma (ICP) emission spectroscopy of the melt debris and melt frozen on structural surfaces in the $\mathrm{DCH}-1$ and $\mathrm{DCH}-2$ tests indicated that about $10 \%$ of the zinc in each of the tests remained in the melt; thus, about $90 \%$ of the zinc was associated with the aerosol. These analyses support the assumption of complete vaporization of the zinc during the experiment.

Elemental analyses of the aerosol samples with ICP gave the mass fraction of the zinc in the aerosol. The mass of the $z$ inc in the aerosol from the brass plug $(\approx 90 \%$ of the amount contained in the plug) divided by the mass fraction in the aerosol gave an estimate of the total aerosol mass released into the surtsey vessel by the HPME.

In the DCH-1 test, the fusible brass plug contained $103 \mathrm{~g}$ of $z$ inc. The mass fraction of $z$ inc in the largest size range of sieved debris was 0.00051 . If it is assumed that this is representative of the zinc remaining in the melt, then about $11 \mathrm{~g}$ of $z$ inc was not aerosolized and $92 \mathrm{~g}$ of $\mathrm{zinc}$ was aerosolized. The average of filters $H, I$, and $F$ indicated that $11.2 \%$ of the aerosol was zinc. The zinc taggant method for the $\mathrm{DCH}-1$ test indicated that $0.82 \mathrm{~kg} \pm 20 \%$ (or $7.3 \%$ of the initial charge dispersed into the surtsey vessel) was aerosolized by the HPME.

Damage to the filter media used in the samplers in the DCH-2 test caused uncertainty in the aerosol concentration measurements. Consequently, the initial aerosol concentration and the totai aerosoi mass were determined using the zinc taggant method described above. Based upon ICP analyses of debris samples recovered posttest, it was estimated that $0.026 \%$ 
of the $36 \mathrm{~kg}$ of melt frozen to the wall, $0.013 \%$ of the $22 \mathrm{~kg}$ melt frozen to the upper head, and $0.008 \%$ of the $5 \mathrm{~kg}$ melt trapped in the cavity and keyway were composed of $z$ inc. These results indicate that $12 \mathrm{~g}$ of the $103 \mathrm{~g}$ of $\mathrm{zinc}$ in the $\mathrm{DCH}-2$ experiment were not aerosolized, and thus, approximately $91 \mathrm{~g}$ of $z$ inc was associated with the aerosol. The average of filter sample $G$ and the cyclone samples indicated that $3.8 \%$ of the aerosol was zinc. The $z$ inc taggant method for the $\mathrm{DCH}-2$ test indicated that the total mass that formed aerosol was $2.4 \mathrm{~kg} \pm$ $30 \%$ (or $3.3 \%$ of the initial charge relocated into the surtsey vessel).

In the DCH-3 experiment, ICP analyses of filters 4 and 6 for zinc indicated that an average of $9.6 \%$ of the aerosol was $z$ inc. The same amount of zinc was assumed to be aerosolized as in $\mathrm{DCH}-1$ and $\mathrm{DCH}-2, \mathrm{i} . \mathrm{e} . \approx 90 \mathrm{~g}$, which gave a total of $0.94 \mathrm{~kg}$ of aerosol. The uncertainty in this value is $\pm 10 \%$. The initial aerosol concentration in $\mathrm{DCH}-3$ was estimated from the $\mathrm{zinc}$ taggant method to be $9.1 \mathrm{~g} / \mathrm{m}^{3} \pm 10 \%$ (compared to $8.6 \mathrm{~g} / \mathrm{m}^{3} \pm 30 \%$ from the concentration extrapolation). This considerable improvement over the uncertainties in the aerosol mass estimated in the $\mathrm{DCH}-1$ and $\mathrm{DCH}-2$ tests comes from the use of the aerosol loop, which resulted in more representative aerosol samples.

In the DCH-4 experiment, ICP analyses for zinc from filter sample 2 indicated that about $23 \%$ of the aerosol was $z$ inc. As before, $\approx 90 \mathrm{~g}$ of the $\mathrm{zinc}$ was assumed to be aerosolized, which gave a total aerosol mass of $0.39 \mathrm{~kg} \pm 10 \%$. The initial aerosol concentration in $\mathrm{DCH}-4$ was estimated from the $z$ inc taggant method to be $3.8 \mathrm{~g} / \mathrm{m}^{3} \pm 10 \%$ (compared to the $3.8 \mathrm{~g} / \mathrm{m}^{3} \pm$ $30 \%$ from the concentration extrapolation).

The results from the zinc taggant method are in excellent agreement with the initial concentration values arrived at by extrapolation of the filter data back to zero. The results are well within the stated uncertainty limits. 


\subsubsection{Aerosol Mass Distribution and Particle Morphology}

Two mechanisms are believed to produce aerosols in a HPME scenario: (1) vaporization of melt followed by condensation of the vapor into nearly spherical primary particles that agglomerate into branched, chainlike aerosol particles and (2) mechanical generation of aerosol by fragmentation of debris into aerosol-sized droplets [Brockmann and Tarbell 1984]. These particles are known to occupy different aerosol size modes in aerodynamic size distributions (aerosol particles formed by vaporization/condensation are aerodynamically smaller than mechanically fragmented particles) [Brockmann and Tarbel] 1984]. The data from the $\mathrm{DCH}-3$ and $\mathrm{DCH}-4$ experiments are consistent with these observations.

Figures 3-72 and 3-73 show the aerosol size distributions measured by the impactors in the $\mathrm{DCH}-1$ and $\mathrm{DCH}-2$ experiments, respectively. The distribution is presented as aerosol mass concentration per logarithmic size interval plotted as a function of aerodynamic equivalent diameter. This commonly accepted representation of the aerosol size distribution [Berry 1967; Whitby et al. 1972] has the advantage that the aerosol mass is directly represented by the area under the curve. The distributions show a distinct aerosol mode between 1 to $2 \mu \mathrm{m}$ aerodynamic diameter. A second mode beyond $10 \mu \mathrm{m}$ was observed in the $\mathrm{DCH}-1$ and $\mathrm{DCH}-2$ tests. This may be attributable to the short sampling line to the impactors in these tests (a few $\mathrm{cm}$ ) and to high vessel pressures that may have assisted in moving large aerosol particles into the impactors.

Figures 3-74 and 3-75 show the aerosol size distributions measured by the impactors in the $\mathrm{DCH}-3$ and $\mathrm{DCH}-4$ experiments, respectively. The second mode appears to have been depressed to a size below $10 \mu \mathrm{m}$. Fragmentation of the debris plume and mixing in the vessel in the $\mathrm{DCH}-3$ and $\mathrm{DCH}-4$ tests may not have been as vigorous as in the first two tests. In the DCH-1 test, the ejected melt encountered the aerosol instrumentation pipe at level 5 in the surtsey vessel, causing the debris to scatter and disperse before impacting the upper head. The debris in the DCH-2 experiment was ejected into the vessel wall, also causing it to scatter and disperse as it moved along the wall to the upper head and back to the floor. 
The aerosol transport efficiency to the samplers was lower ir. DCH-3 and $\mathrm{DCH}-4$ than in $\mathrm{DCH}-1$ and $\mathrm{DCH}-2$ because the flow path to the aerosol instrumentation was longer in $\mathrm{DCH}-3$ and $\mathrm{DCH}-4$. The aerosol loop was designed to transport only $50 \%$ of the 20- $\mu \mathrm{m}$ aerosols to the samplers [Yamano and Brockmann 1989]; however, greater than $99 \%$ of the material still airborne $\approx 60$ seconds after the HPME in these experiments had aerodynamic diameters less than $20 \mu \mathrm{m}$. This design resulted in a decrease in the number of large particles entering the aerosol instrumentation compared to $\mathrm{DCH}-1$ and $\mathrm{DCH}-2$, in which the instruments were located inside the surtsey vessel. In addition, the aerosol sampling instrumentation in DCH-3 and $\mathrm{DCH}-4$ was isolated from the vessel in the initial few minutes following the melt ejection and during this time the concentration of large particles would have decreased appreciably due to gravitational settling.

An electron micrograph taken of the $\mathrm{DCH}-3$ aerosol collected in one of the impactors is presented in Figure 3-76. The photograph shows aerosol collected on the last sizing stage of a cascade impactor. The particles were agglomerates of roughly $0.1 \mu \mathrm{m}$ primary spheres. These chain aggregate particles had a morphology typical of vapor condensation aerosols. similar branched, chainlike aggregates were observed on earlier stages of the cascade impactor, along with larger spherical particles with physical diameters greater than $1 \mu \mathrm{m}$, which were probably formed by melt fragmentation. In the $\mathrm{DCH}$ experiments it was assumed that the aerosol mode at an aerodynamic diameter of 1-2 $\mu \mathrm{m}$ was formed predominantly by vapor condensation and that the mode near $10 \mu \mathrm{m}$ was formed primarily by melt fragmentation.

\subsubsection{Aerosol Release Fractions}

The total aerosol release fraction of each element was determined from the measured aerosol composition, the total mass aerosolized, the mass of the initial charge relocated into the surtsey vessel, and the mass fraction of the element in the initial charge. The total aerosol release fraction (ARFi) of the ith element from the relocated mass is defined as: 


$$
A R F_{i}=\frac{f_{i A} M_{A}}{f_{i R} M_{R}}
$$

where

$$
\begin{aligned}
& f_{i A}=\text { mass fraction of the } i \text { th element in the aerosol, } \\
& M_{A}=\text { total released aerosol mass, } \\
& f_{i R}=\text { mass fraction of the } i \text { th element in the initial } \\
& M_{R}=\text { charge, and } \\
& \text { total mass of the initial charge relocated into } \\
& \text { the surtsey vessel. }
\end{aligned}
$$

Tables $3.7,3.8,3.9$, and 3.10 give $f_{i A}, f_{i R}, M_{A}$, and $M_{R}$ for DCH tests $1,2,3$, and 4, respectively. From these values the aerosol release fraction for each element (ARFi) was calculated using the equation above. The calculated $A F_{i}$ values are listed in the last column of Tables $3.7,3.8,3.9$, and 3.10 for $\mathrm{DCH}$ tests $1,2,3$, and 4 , respectively.

Elemental analysis was performed by inductively coupled plasma (ICP) emission spectroscopy on selected filter samples from each of the four tests. Tables $3.11,3.12,3.13$, and 3.14 present these analyses for the $\mathrm{DCH}-1$ through $\mathrm{DCH}-4$ experiments, respectively. The elements assumed to be present as metals in all of the $\mathrm{DCH}$ experiments include iron, nickel, molybdenum, and also manganese in $\mathrm{DCH}-3$ and $\mathrm{DCH}-4$. The elements assumed to be present as oxides in all of the tests include aluminum, barium, lanthanum, niobium, and also titanium and cerium in the DCH-3 and $\mathrm{DCH}-4$ tests. ICP results for the constituents of the fusible brass plug, which include copper, lead, and zinc (used as a taggant in these experiments), are presented in these tables. Silicon and calcium from ablation of concrete in the cavity are also included in these tables. Iron is the dominant aerosol constituent, followed by $z$ inc.

ICP analyses were also performed on the cascade cyclone samples to obtain the size-segregated elemental composition of the aerosols. The manufacturer's correlations for size ranges of the stages were used without independent calibration and are treated qualitatively here. Tables $3.15,3.16,3.17$, and 3.18 give the resuits of the ICP analyses of tre size-classified 
Table 3.7

Calculated Aerosol Release Fractions for Each Element in DCH-1

\begin{tabular}{cccc}
\hline Element & $\begin{array}{c}\text { Initial } \\
\text { charge } \\
f_{\text {iR }} \\
(w t .8)\end{array}$ & $\begin{array}{c}\text { Aerosol } \\
f_{i A} \\
(w t . \%)\end{array}$ & $\begin{array}{c}\text { Aerosol } \\
\text { Release Fraction } \\
\text { (ARF) }\end{array}$ \\
$\mathrm{Fe}$ & 53.4 & & \\
$\mathrm{Ni}$ & 0.48 & 37.2 & 0.051 \\
$\mathrm{Mn}$ & 0 & 0.50 & 0.077 \\
$\mathrm{Mo}$ & 0.49 & 0 & 0.150 \\
$\mathrm{Al}$ & 22.9 & 1.0 & 0.0151 \\
$\mathrm{Ba}$ & 0.70 & 4.7 & 0.0126 \\
$\mathrm{La}$ & 0.49 & 0.12 & 0.0045 \\
$\mathrm{Nb}$ & 0.48 & 0.03 & 0.0153 \\
$\mathrm{Ce}$ & 0 & 0.10 & - \\
$\mathrm{Ti}$ & 0 & 0 & -
\end{tabular}

Total mass of the initial charge ejected into the surtsey vessel $=M_{R}=11.3 \mathrm{~kg}$

Total aerosol mass in the surtsey vessel $=M_{A}=0.83 \mathrm{~kg}$

Total aerosol release fraction $=A R F=M_{A} / M_{R}=0.073$

Notes:

(1) Values given are the wt. $\%$ of the specified element in the initial charge.

(2) Values listed are the average of the wt. $\%$ of the specified element in the aerosol collected on filters $H, I$, and $F$. 
Table 3.8

Calculated Aerosol Release Fraction for Each Element in DCH-2

\begin{tabular}{cccc}
\hline Element & $\begin{array}{c}\text { Initial } \\
\text { charge (1) } \\
f_{i R} \\
(\text { wt. } 8)\end{array}$ & $\begin{array}{c}\text { Aerosol } \\
f_{i A} \\
(w t .8)\end{array}$ & $\begin{array}{c}\text { Aerosol } \\
\text { Release Fraction } \\
\text { (ARF) }\end{array}$ \\
$\mathrm{Fe}$ & 53.4 & & \\
$\mathrm{Ni}$ & 0.50 & 49.4 & 0.030 \\
$\mathrm{Mn}$ & 0 & 0.65 & 0.043 \\
$\mathrm{Mo}$ & 0.50 & 0 & 0.070 \\
$\mathrm{Al}$ & 22.9 & 1.07 & 0.0039 \\
$\mathrm{Ba}$ & 0.177 & 2.7 & - \\
$\mathrm{La}$ & 0.52 & $\mathrm{NA}$ & - \\
$\mathrm{Nb}$ & 0.51 & $\mathrm{NA}$ & 0.0046 \\
$\mathrm{Ce}$ & 0 & 0.071 & - \\
$\mathrm{Ti}$ & 0 & 0 & -
\end{tabular}

Total mass of the initial charge ejected into the surtsey vessel $=M_{R}=73 \mathrm{~kg}$

Total aerosol mass in the Surtsey vessel $=M_{A}=2.4 \mathrm{~kg}$

Total aerosol release fraction $=A R F=M_{A} / M_{R}=0.033$

Notes:

(1) Values given are the wt. $\%$ of the specified element in the initial charge.

(2) Values listed are the wt. $\%$ of the specified element in the aerosol collected on filter $\mathrm{G}$. 
Table 3.9

Calculated Aerosol Release Fraction for Each Element in DCH-3

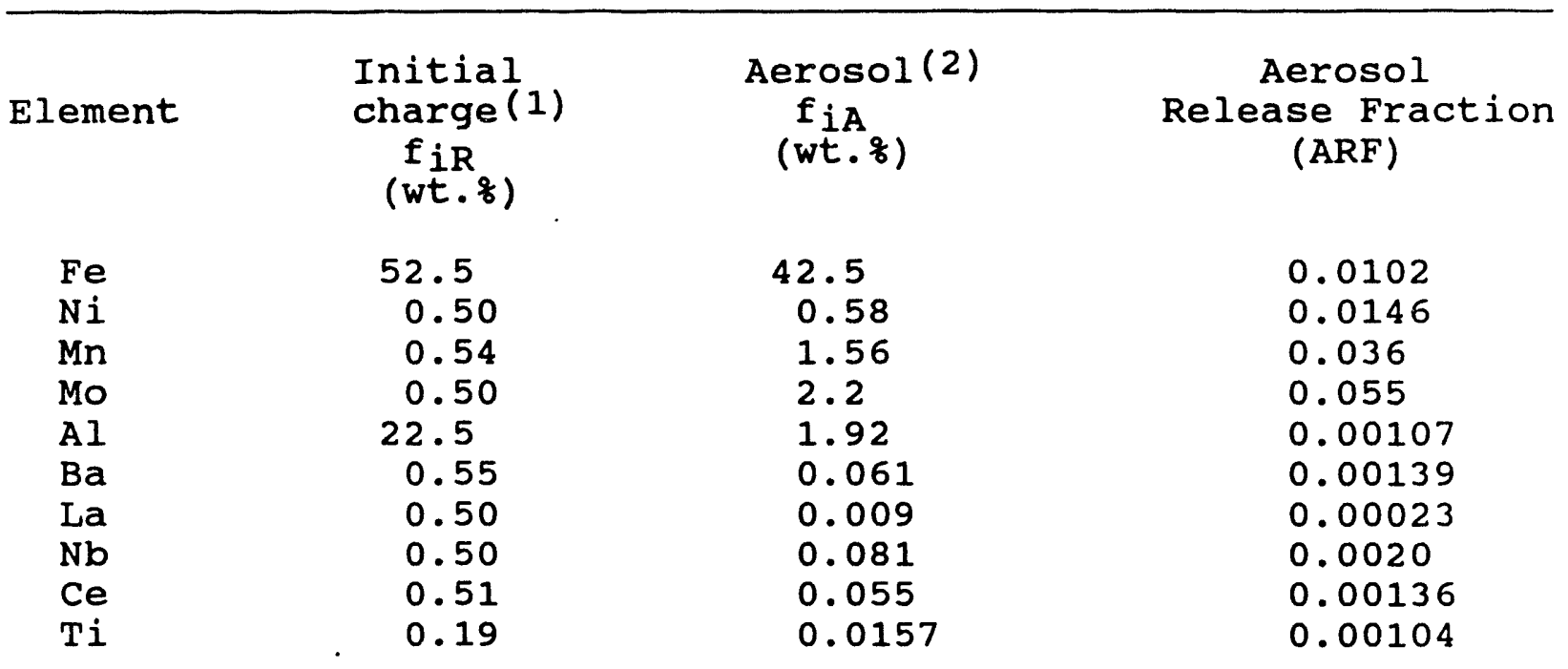

Total mass of the initial charge ejected into the surtsey vessel $=M_{R}=74 \mathrm{~kg}$

Total aerosol mass in the surtsey vessel $=\mathrm{M}_{\mathrm{A}}=0.93 \mathrm{~kg}$

Total aerosol release fraction $=A R F=M_{A} / M_{R}=0.0126$

Notes:

(1) Values given are the wt. $\%$ of the specified element in the initial charge.

(2) Values listed are the average of the wt.\% of the specified element in the aerosol collected on filters 1,2 , and 3 . 
Table 3.10

\section{Calculated Aerosol Release Fraction for Each Element in DCH-4}

\begin{tabular}{cccc}
\hline Element & $\begin{array}{c}\text { Initial } \\
\text { charge (1) } \\
\text { fiR }_{\text {(wt.\%) }}\end{array}$ & $\begin{array}{c}\text { Aerosol (2) } \\
f_{\text {iA }} \\
(\text { wt. })\end{array}$ & $\begin{array}{c}\text { Aerosol } \\
\text { Release Fraction } \\
\text { (ARF) }\end{array}$ \\
$\mathrm{Fe}$ & 52.5 & & \\
$\mathrm{Ni}$ & 0.50 & 26.4 & 0.0027 \\
$\mathrm{Mn}$ & 0.54 & 0.21 & 0.0022 \\
$\mathrm{Mo}$ & 0.50 & 6.1 & 0.060 \\
$\mathrm{Al}$ & 22.5 & 0.29 & 0.0031 \\
$\mathrm{Ba}$ & 0.55 & 3.5 & 0.00082 \\
$\mathrm{La}$ & 0.50 & 0.057 & 0.00055 \\
$\mathrm{Nb}$ & 0.50 & 0.015 & 0.000158 \\
$\mathrm{Ce}$ & 0.51 & $<0.020$ & $<0.00021$ \\
$\mathrm{Ti}$ & 0.19 & 0.011 & 0.000114 \\
& & $<0.005$ & $<0.000139$
\end{tabular}

Total mass of the initial charge ejected into the surtsey vessell $=: M_{R}=74 \mathrm{~kg}$

Total aerosol mass in the surtsey vessel $=M_{A}=0.39 \mathrm{~kg}$

Total aerosol release fraction $=A R F=M_{A} / M_{R}=0.0053$

Notes:

(1) Values given are the wt. $f$ of the specified element in the initial charge.

(2) Values listed are the average of the wt. $\%$ of the specified element in the aerosol collected on filter 2 . 
Table 3.11

Elemental Analysis of DCH-1 Filter samples

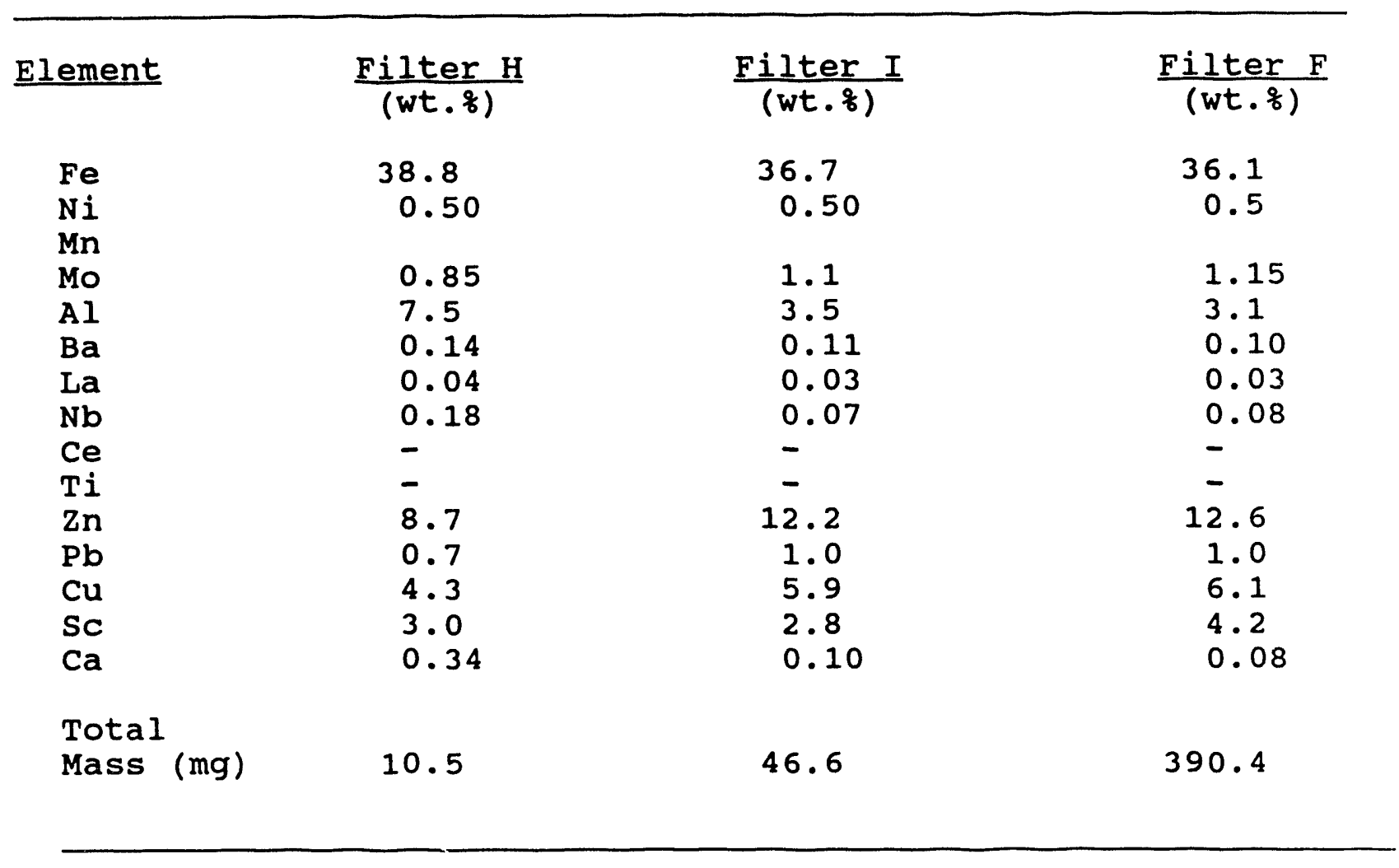


Table 3.12

Elemental Analysis of DCH-2 Filter samples

\begin{tabular}{lcc}
\hline Element & Filter D & Filter G \\
& $\frac{(w t .8)}{(w t .8)}$ & 49.4 \\
Fe & 26.5 & 0.65 \\
$\mathrm{Ni}$ & 0.34 & - \\
$\mathrm{Mn}$ & - & 1.07 \\
$\mathrm{Mo}$ & 0.58 & 2.7 \\
$\mathrm{Al}$ & 1.27 & - \\
$\mathrm{Ba}$ & - & - \\
La & - & 0.071 \\
$\mathrm{Nb}$ & 0.032 & - \\
$\mathrm{Ce}$ & - & - \\
$\mathrm{Ti}$ & - & 3.1 \\
$\mathrm{Zn}$ & 2.1 & 0.39 \\
$\mathrm{~Pb}$ & 0.23 & 2.32 \\
$\mathrm{Ca}$ & 1.38 & 1.07 \\
$\mathrm{Se}$ & 0.28 & 0.107 \\
$\mathrm{Ca}$ & 0.101 & \\
Total & & 16.8 \\
Mass(mg) & 18.8 & \\
& & \\
\hline
\end{tabular}




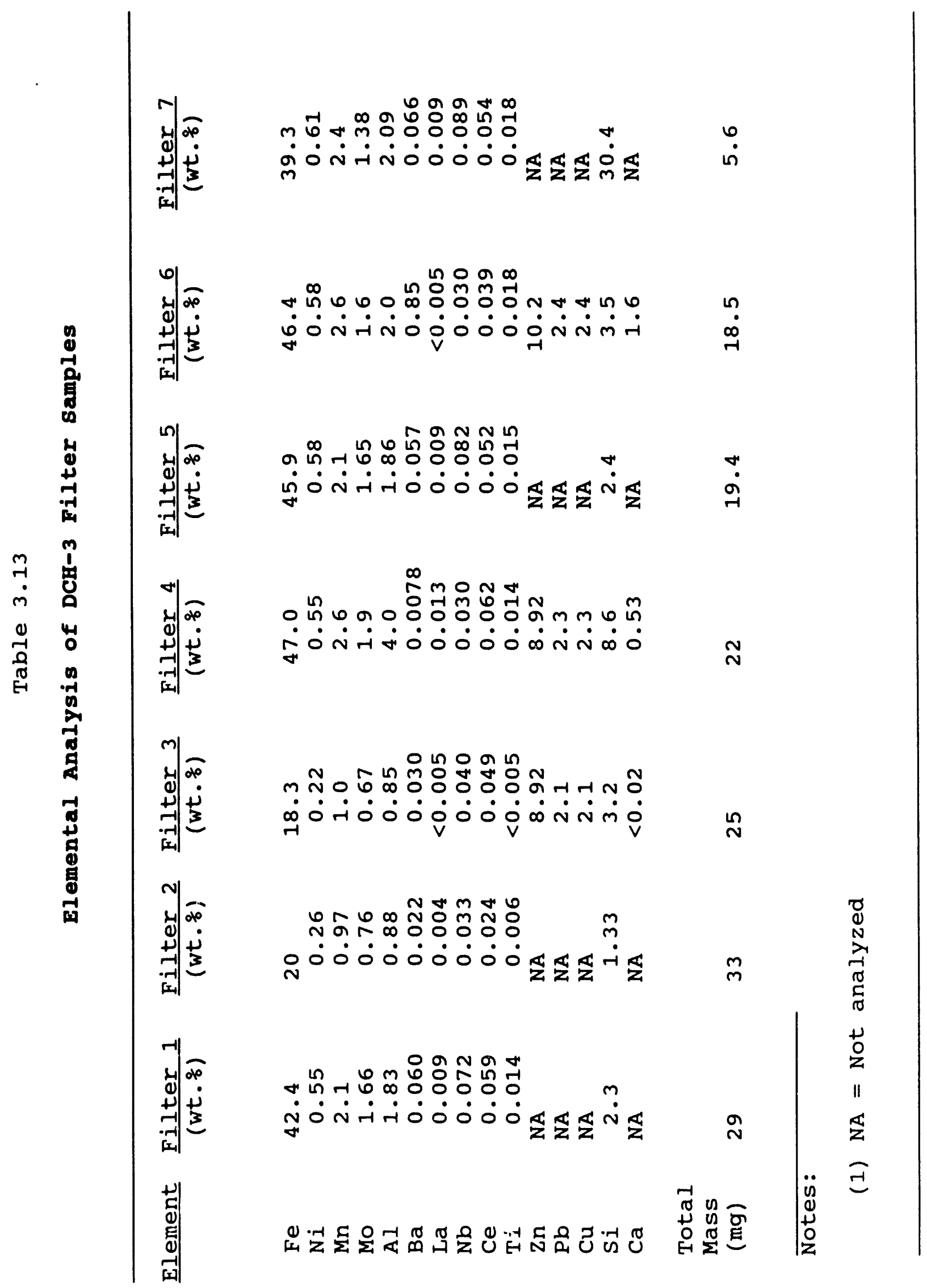


Table 3.14

Elemental Analysis of DCH-4 Filter samples

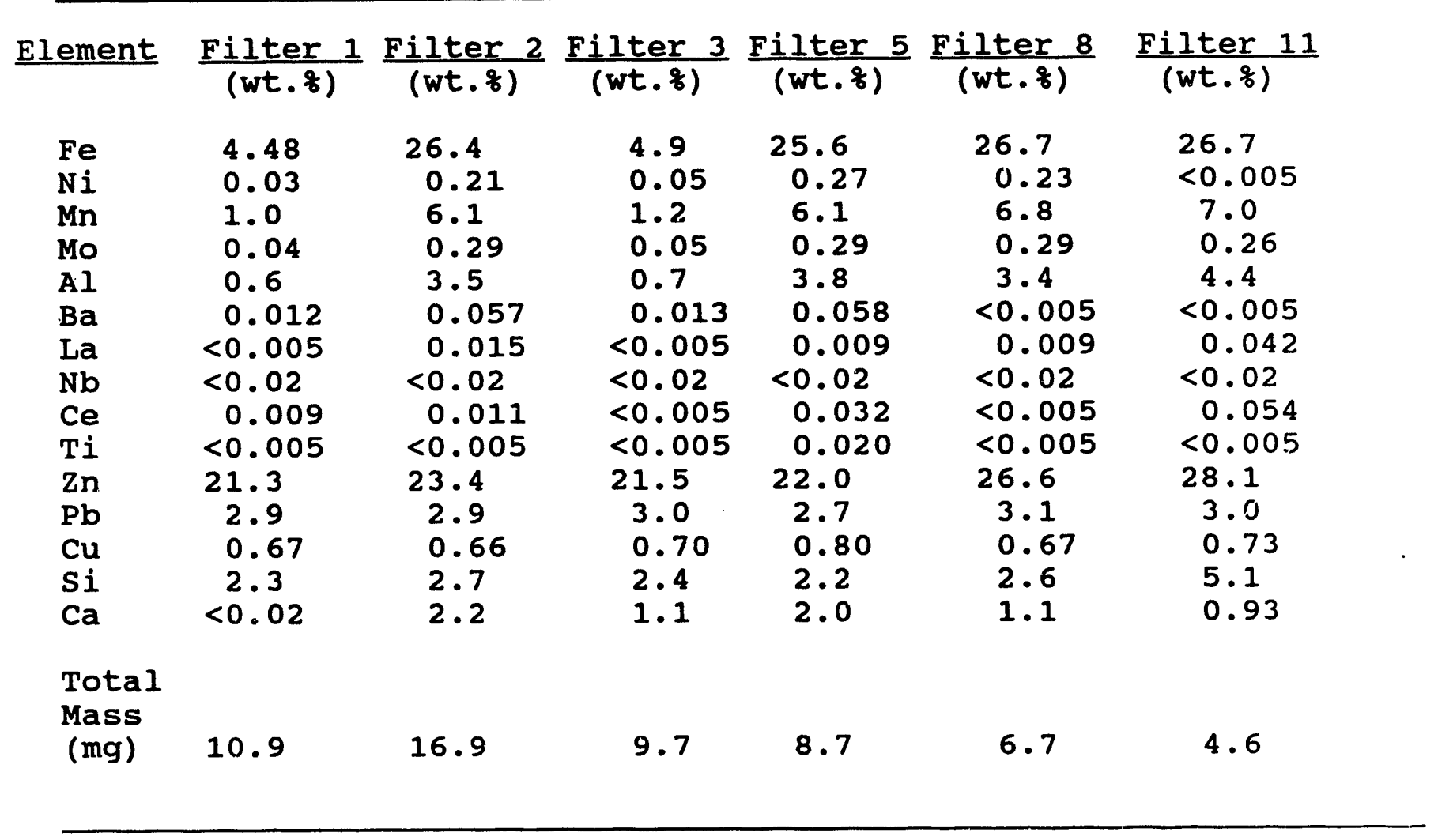




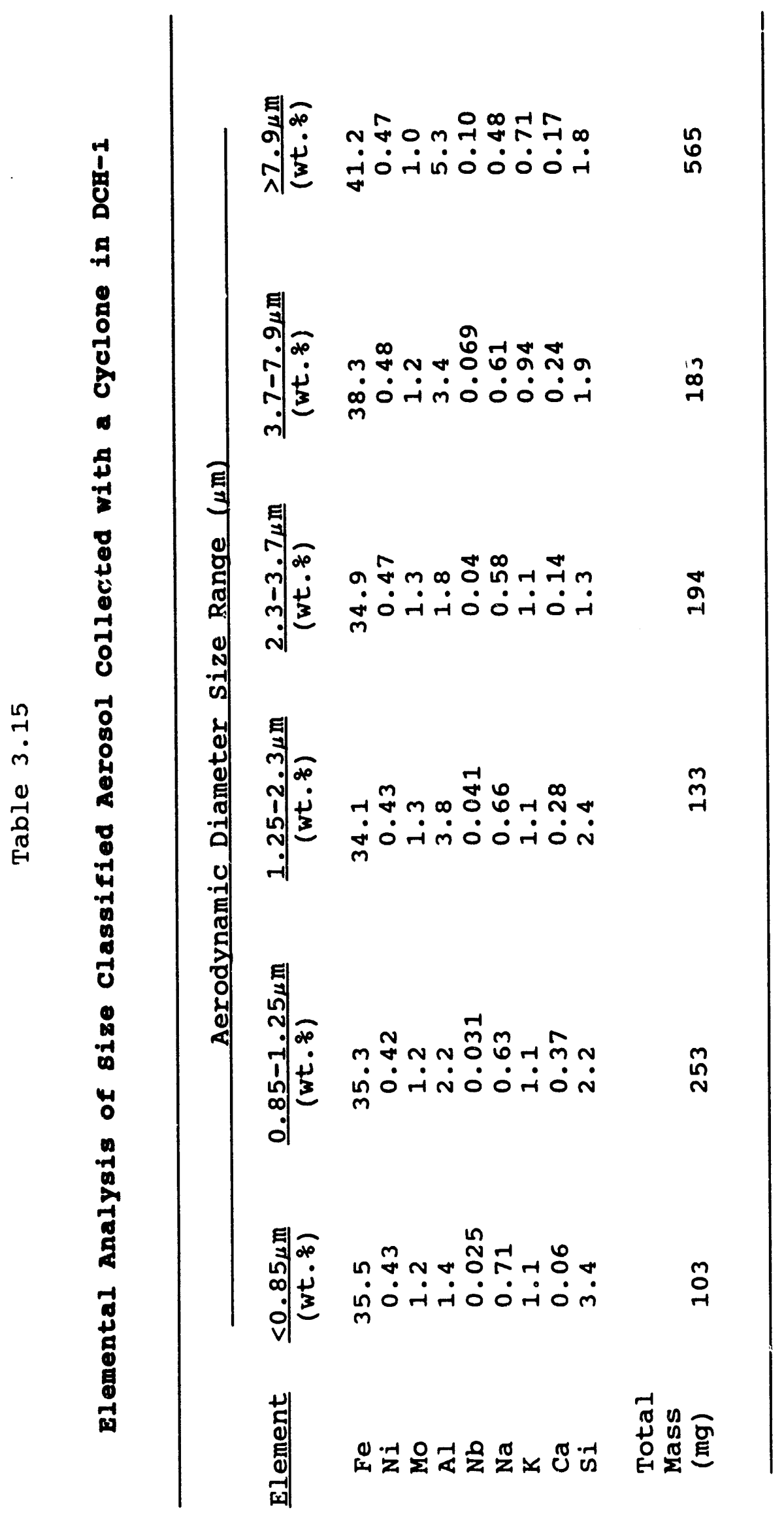




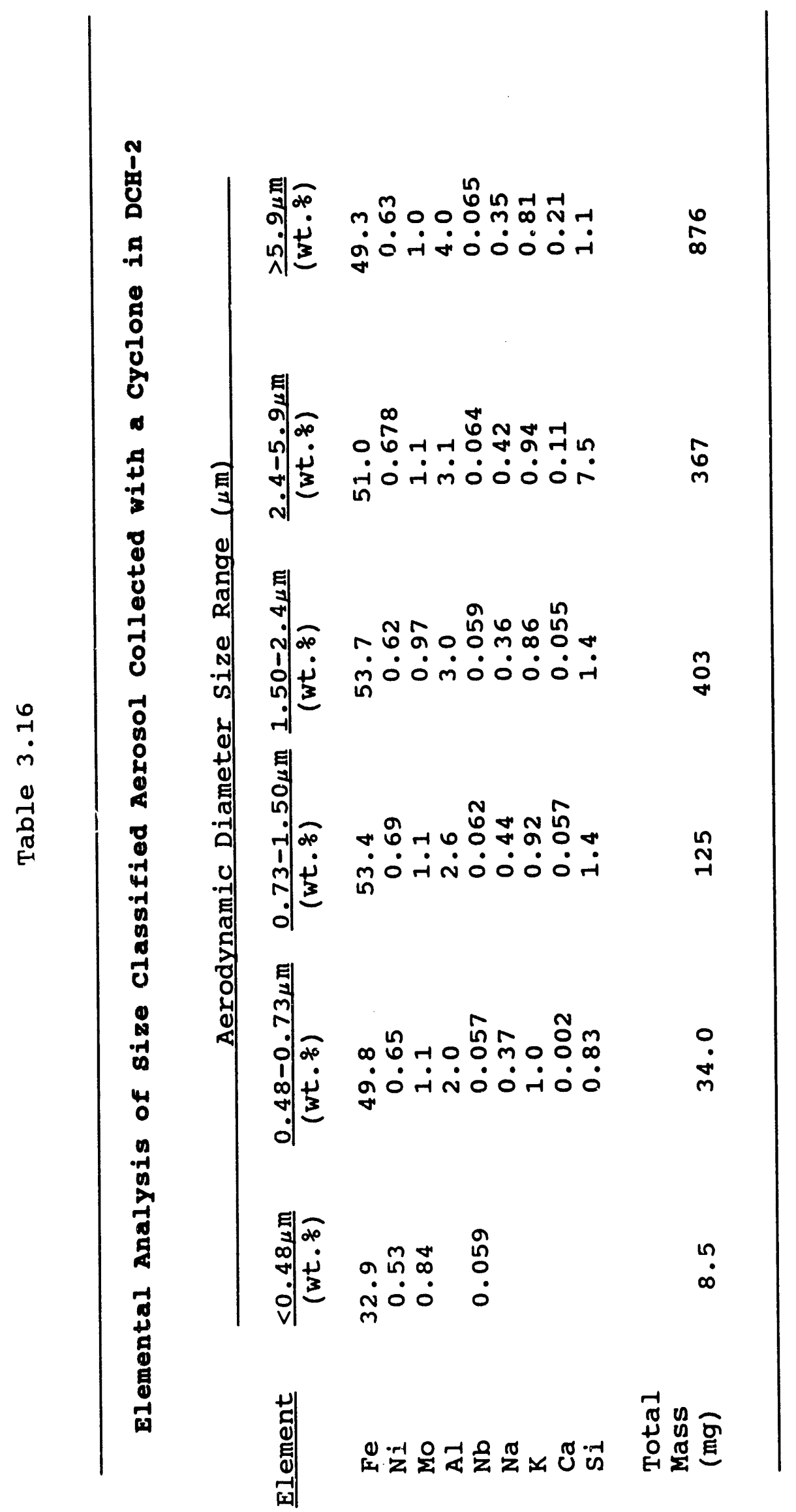




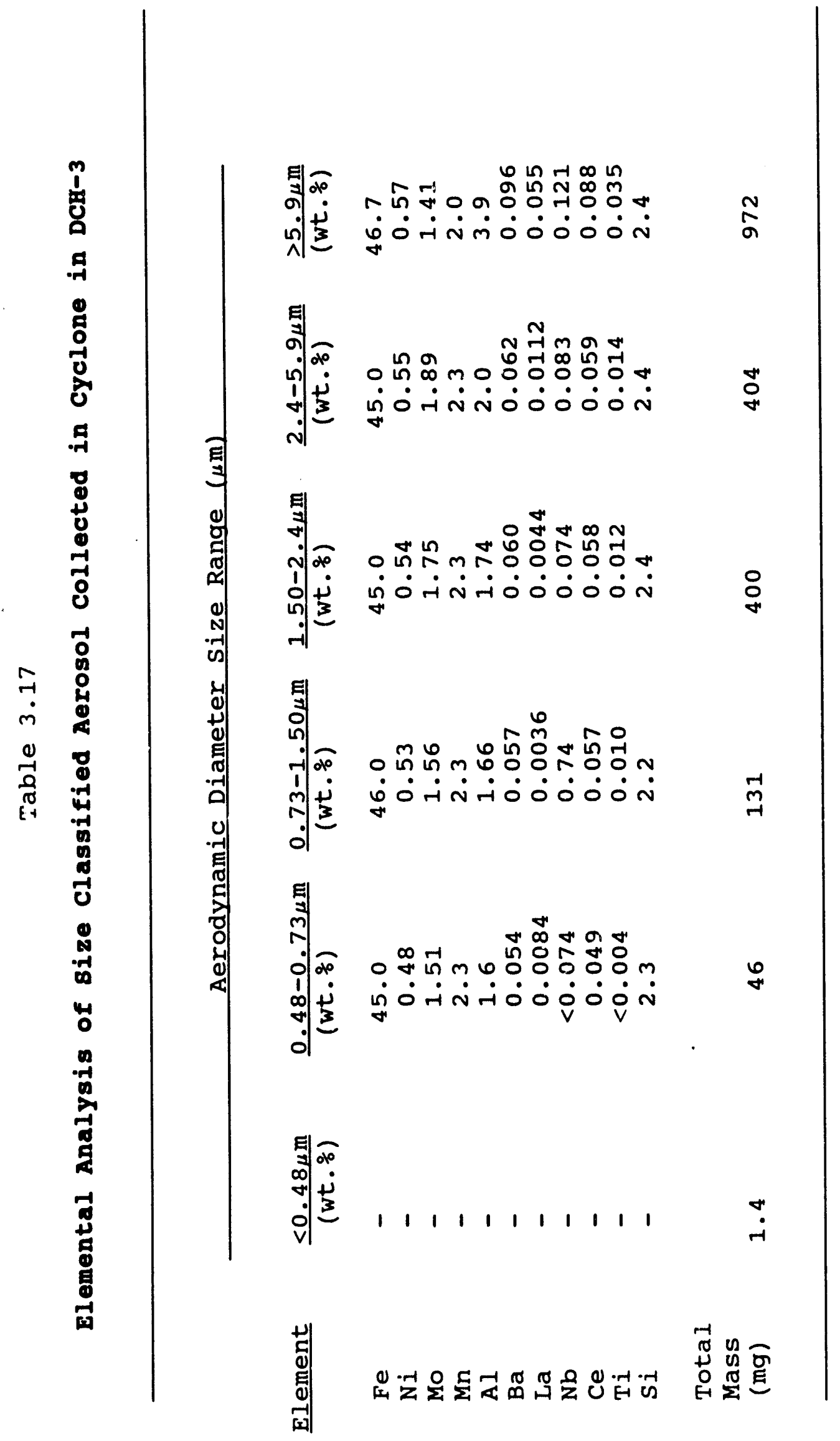




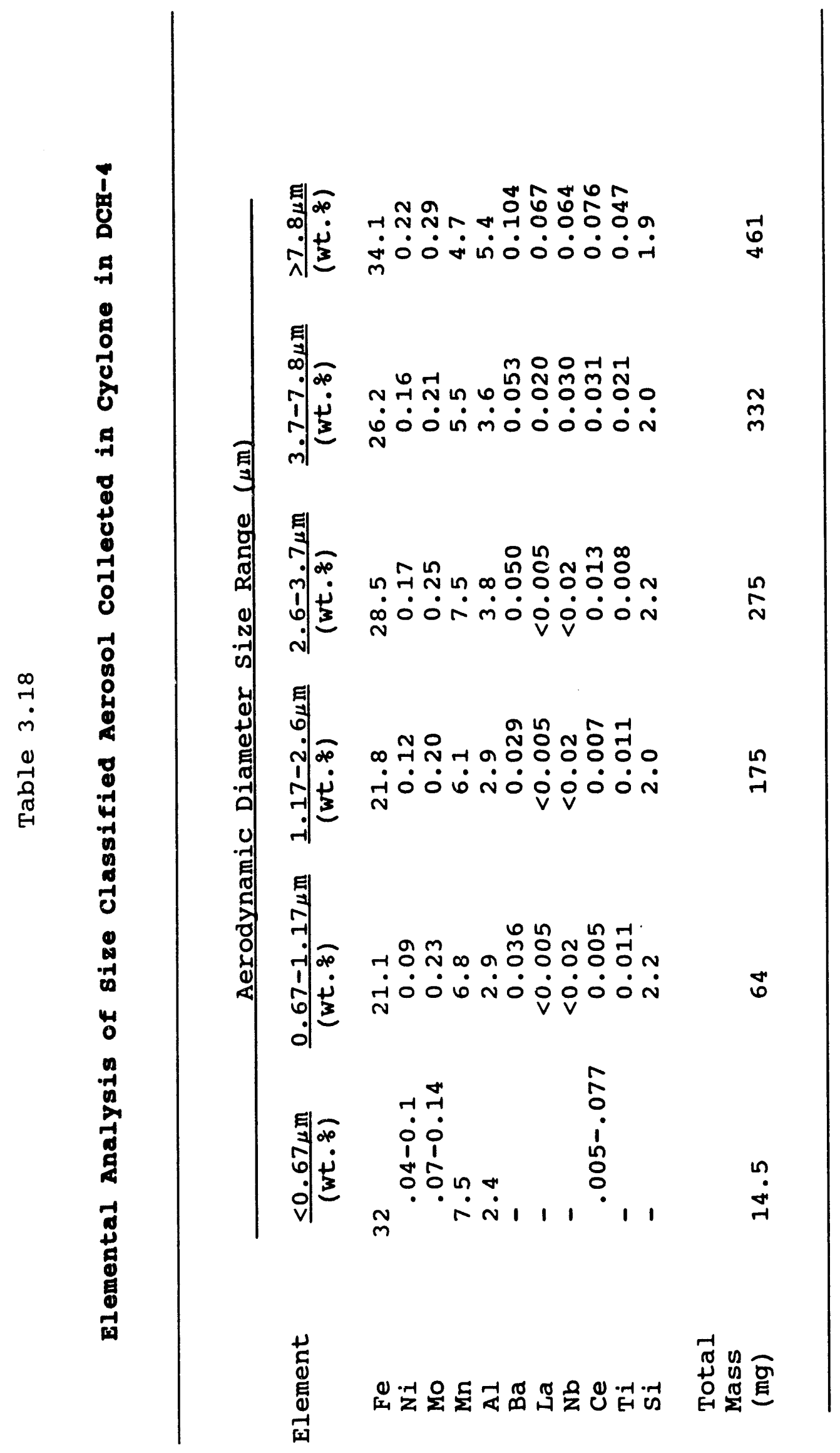


aerosol samples for $\mathrm{DCH}-1$ through $\mathrm{DCH}-4$, respectively. These tables give the elemental composition (in wt. $z$ ) in the total aerosol mass collected by each stage of the cyclone.

The metals (Fe, Ni, Mn, and Mo) appear to be more or less uniformily distributed; i.e. the metallic elements have roughly the same mass fraction of aerosol for all aerodynamic size ranges. The elements assumed to be present in the melt as oxides ( $\mathrm{Al}, \mathrm{Ba}, \mathrm{La}, \mathrm{Nb}, \mathrm{Ce}$, and $\mathrm{Ti}$ ) appear to have a generally increasing mass fraction with increasing particle size. This is consistent with the observation that the metals (with their higher vapor pressures) have higher releases and are more likely to be released by vaporization. Because of their low vapor pressures, the oxides are more likely to be released by melt fragmentation and consequently are concentrated in larger particles.

Elemental release percentages for $\mathrm{DCH}-1,-2,-3$, and -4 are summarized in Table 3.19, which also gives the total aerosol mass, the mass of the initial charge that was relocated into the surtsey vessel, and the fraction of the relocated mass that is aerosolized. Melt fragmentation is an important aerosol generation mechanism. The melt is fragmented by dynamic forces (Weber instabilities) as it is ejected at high velocities from the cavity and by collisions with structures and between melt droplets [Frid 1988]. In addition, gas effervescing from the melt can result in fragmentation [Powers et al. 1983]. Generally, melt fragmentation particles are larger than about $10 \mathrm{~m}$ aerodynamic diameter and most are excluded from the filter samples by the pre-separator. Smaller particles formed by melt fragmentation may pass through the pre-separator and be collected on filters, and subsequently included in the elemental analyses.

The total aerosol release fraction (ARF) reported in Table 3.19 is composed of the sum of the vaporization release fraction (VRF) and the fragmentation release fraction (FRF). VRF and FRF are defined as follows: 
Table 3.19

Elemental Release Fractions from

Relocated Mass in the DCH Experiments

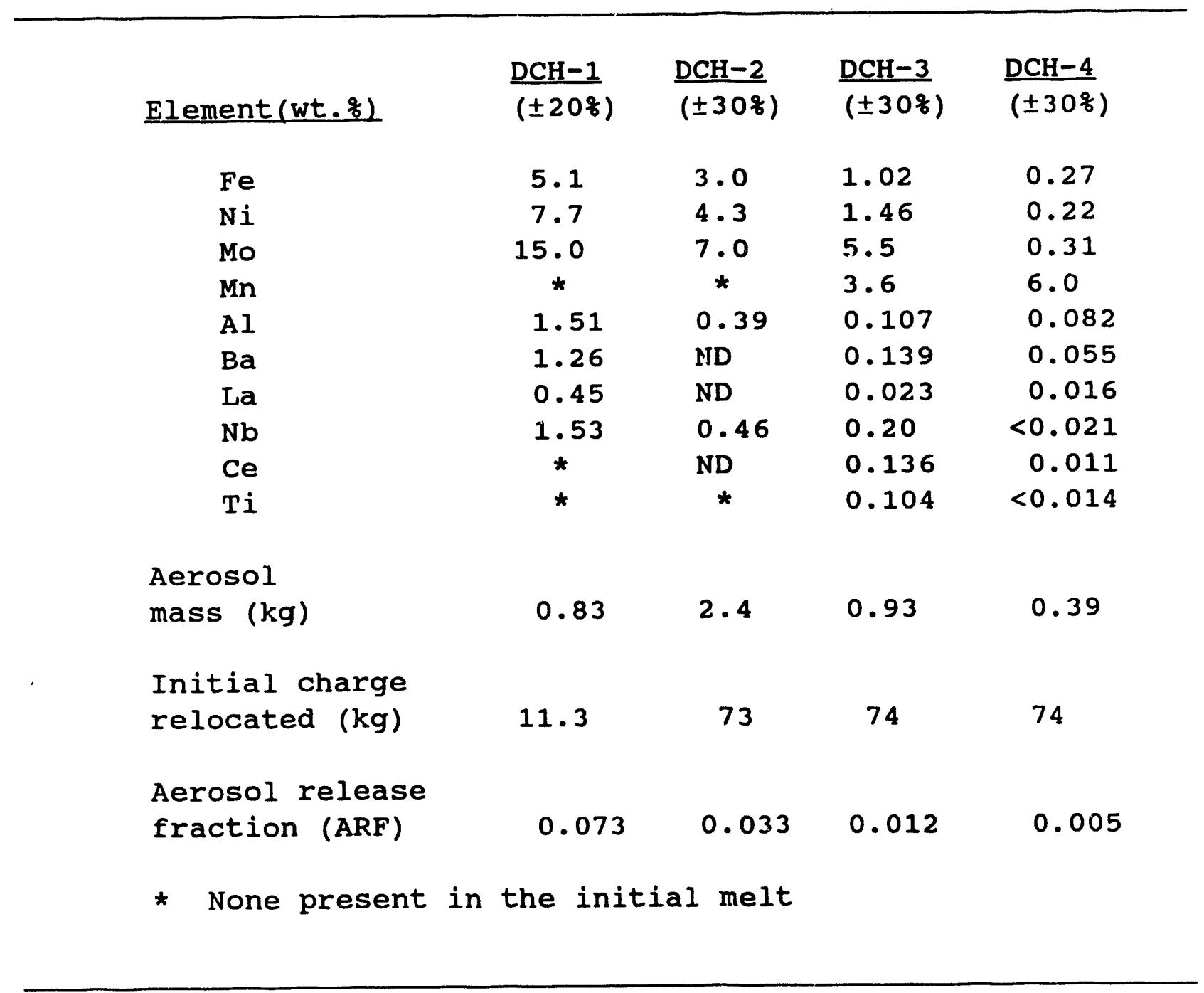




$$
\begin{aligned}
& \mathrm{FRF}_{i}=\frac{\mathrm{f}_{i R} \mathrm{f}_{f} \mathrm{M}_{A}}{f_{i R^{M}}}=f_{f} f_{A} \\
& V R F_{i}=A R F_{i}-F R F_{i}
\end{aligned}
$$

where

$$
\begin{aligned}
f_{i R}= & \text { mass fraction of } i \text { th component in the mass of the } \\
& \text { initial charge relocated into the surtsey vessel, } \\
f_{f}= & \text { fraction of aerosol mass from melt fragmentation, } \\
& \text { and } \\
f_{A}= & \text { fraction of the mass of the initial charge relocate } \\
& \text { into the surtsey vessel that is aerosolized. }
\end{aligned}
$$

FRF is assumed to be the same for all elements and is only a function of the fraction of aerosol mass that comes from melt fragmentation $\left(f_{f}\right)$ and the fraction of the relocated mass that is aerosolized $\left(f_{A}\right)$. This assumption requixes that the metallic and oxidic components of the melt produce melt fragmentation particles with the same efficiency. This assumption has questionable validity but is made because of the limited information currently available.

The dynamic shape factor is a quantitative description of particle morphology and provides a means to translate between the aerodynamic diameter (necessary for aerosol behavior and transport calculations) and mass-equivalent diameter (necessary for composition tracking and mass conservation) [Brockmann and Rader 1989]. The dynamic shape factor is defined as the ratio of the stokesian drag on the particle to that of a sphere of the same volume and moving at the same velocity [Fuchs 1964; clift et al. 1978]. The dynamic shape factor determined in the DCH-3 experiment for the 2- $\mathrm{m}$ aerosol mode is $2 \pm 25 \%$, which is an indication that the particles have a large void fraction, i.e., they are agglomerates [Brockmann and Rader 1990]. The dynamic shape factor for the aerosol in the larger mode at $\simeq 10 \mu \mathrm{m}$ could not be determined using the technique of Brockmann and Rader [1990]; however, the dynamic shape factor of the larger particles would be very close to 1 if they are solid since particles produced by fragmentation (i.e., by entrainment and splashing) are usually nearly spherical. 


\section{6 observations from Film Records}

The DCH-3 and DCH-4 experiments were observed visually with five video cameras and a real time $x$-ray imaging system. The observations from $\mathrm{DCH}-3$ and $\mathrm{DCH}-4$ were similar. The following sections describe these observations.

\subsubsection{Video Observations}

Five Lo Cam framing cameras were used in $\mathrm{DCH}-3$ and $\mathrm{DCH}-4$ to obtain visual records of the HPME/DCH transient: two cameras at level 2 (one with a framing rate of 200 frames per second and one with a framing rate of 400 frames per second); one camera at level 4 with a framing rate of 200 frames per second; and two cameras mounted on the top of the surtsey vessel focused downward at the chute exit (one with a framing rate of 200 frames per second and one with a framing rate of 400 frames per second).

Both cameras at level 2 showed a view of the debris plume as it was ejected from the cavity exit chute. A coherent, bright yellow/orange debris plume was ejected from the chute exit over a period of about $0.5 \mathrm{~s}$. After debris ejection ceased, the melt generator and cavity were obscured by a dense aerosol cloud. The surtsey vessel appeared completely opaque until $2.5 \mathrm{~s}$, when individual luminous particles filled the lower portion of the vessel. These particles persisted in the vessel atmosphere from 2.5 to 3.75 s after the beginning of the HPME transient. The luminous particles generally had a net downward motion, however they appeared to be moved about by convection caused by the mixing fans and the violent HPME transient. They were apparently formed by dripping from the upper head. Dripping of molten debris from the upper head was originally believed to have caused the second pressure peak; however, Kiva analyses did not support this hypothesis and it is currently believed that $\mathrm{CO} / \mathrm{H}_{2}$ burning caused the second pressure peak (Section 4.2 ).

The camera at level 4 showed a bright, luminous debris plume as it moved upward. If the time at which the debris plume first 
became visible at level 4 is taken as a reference time of $0 \mathrm{~s}$, then a fairly coherent debris plume was observed for $\approx 0.6 \mathrm{~s}$. At $\approx 0.75 \mathrm{~s}$, luminous particles that had apparently splashed from the upper head were observed moving downward in the Surtsey vessel. The chamber was then obscured between $\approx 1$ s and $\approx 2.25 \mathrm{~s}$. Between $2.25 \mathrm{~s}$ and $3.75 \mathrm{~s}$, many luminous particles that appeared to be moving downward in the video from level 4 . These particles were apparently caused by dripping from the upper head of the vessel. The highest concentration of luminous particles was observed at a reference time of $\approx 3 \mathrm{~s}$ (i.e., $\propto 3$ s after the plume was first observed in the video from level 4 ).

Both cameras positioned on top of the Surtsey vessel showed a bright, luminous debris plume moving upward at the lucite window. After the molten debris struck the window, the film was overexposed and showed up as a bright white spot. Later the vessel atmosphere was obscured by a dense aerosol cloud.

\subsubsection{Real Time X-ray Imaging 8ystem}

The DCH-4 experiment utilized a real time $\mathrm{X}$-ray imaging system to obtain information on debris particle size leaving the cavity exit. A Spin Physics camera with a framing rate of 1000 frames per second was located inside the Surtsey vessel at $\approx 2$ feet from the chute exit. An image intensifier was located inside the surtsey vessel on the opposite side of the chute.

There were faint signs of debris ejection from the chute at a reference time of $51.20 \mathrm{~s}$. A substantial amount of debris ejection began at $51.22 \mathrm{~s} ;$ the debris appeared as films or sheets of molten material (not individual particles) being forced from the cavity by high velocity blowdown gas. Thick sheets of molten debris were ejected continuously between $51.22 \mathrm{~s}$ and $51.62 \mathrm{~s}$, with the heariest concentration at $51.32 \mathrm{~s}$. Between $51.62 \mathrm{~s}$ and $51.80 \mathrm{~s}$ thin films of debris were ejected intermittently. Individual particles were not observed at the chute in the $\mathrm{x}$-ray film. The sheets of molten debris apparently did not fragment into smaller individual particles until the debris was at least $20 \mathrm{~cm}$ away from the chute. 


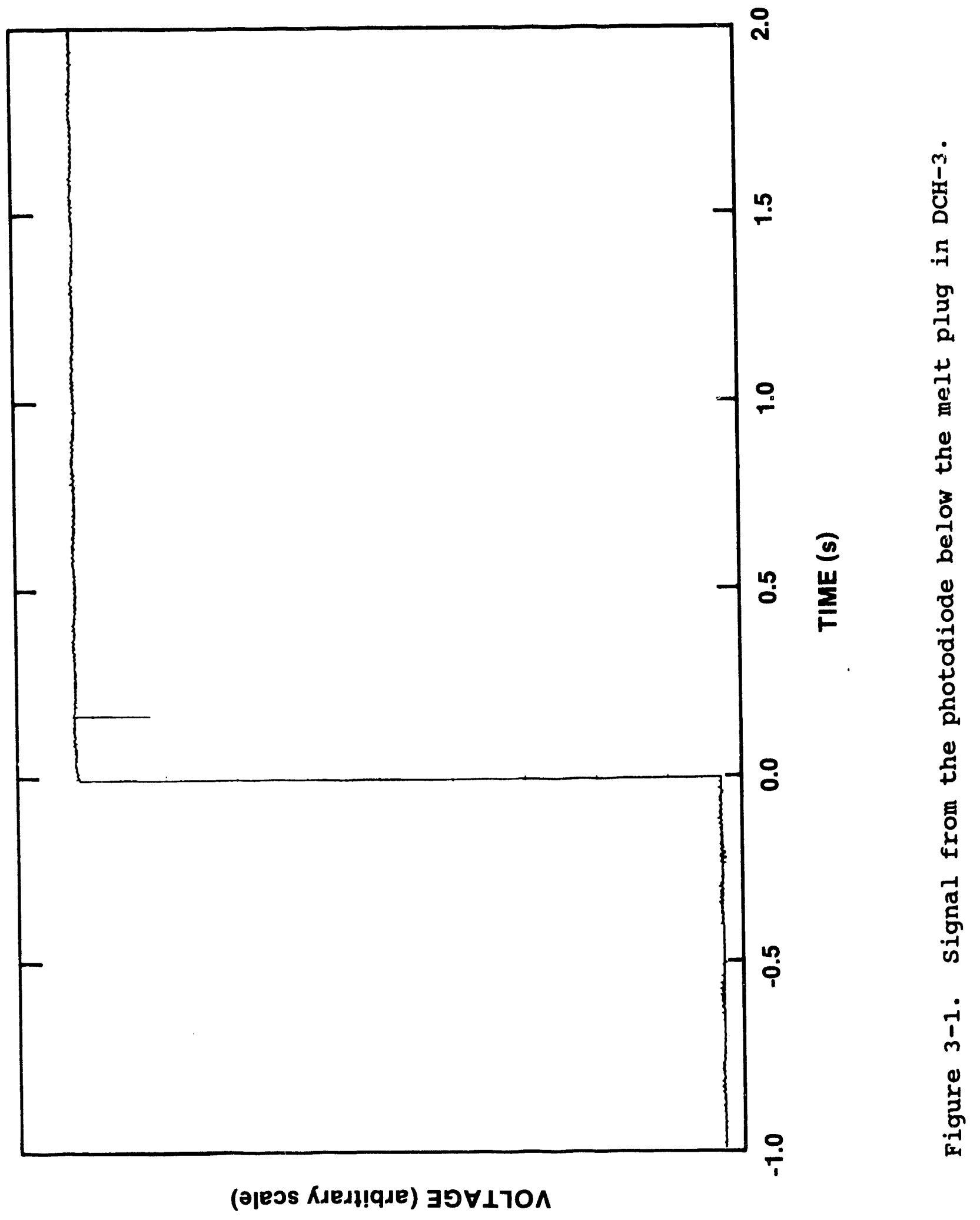




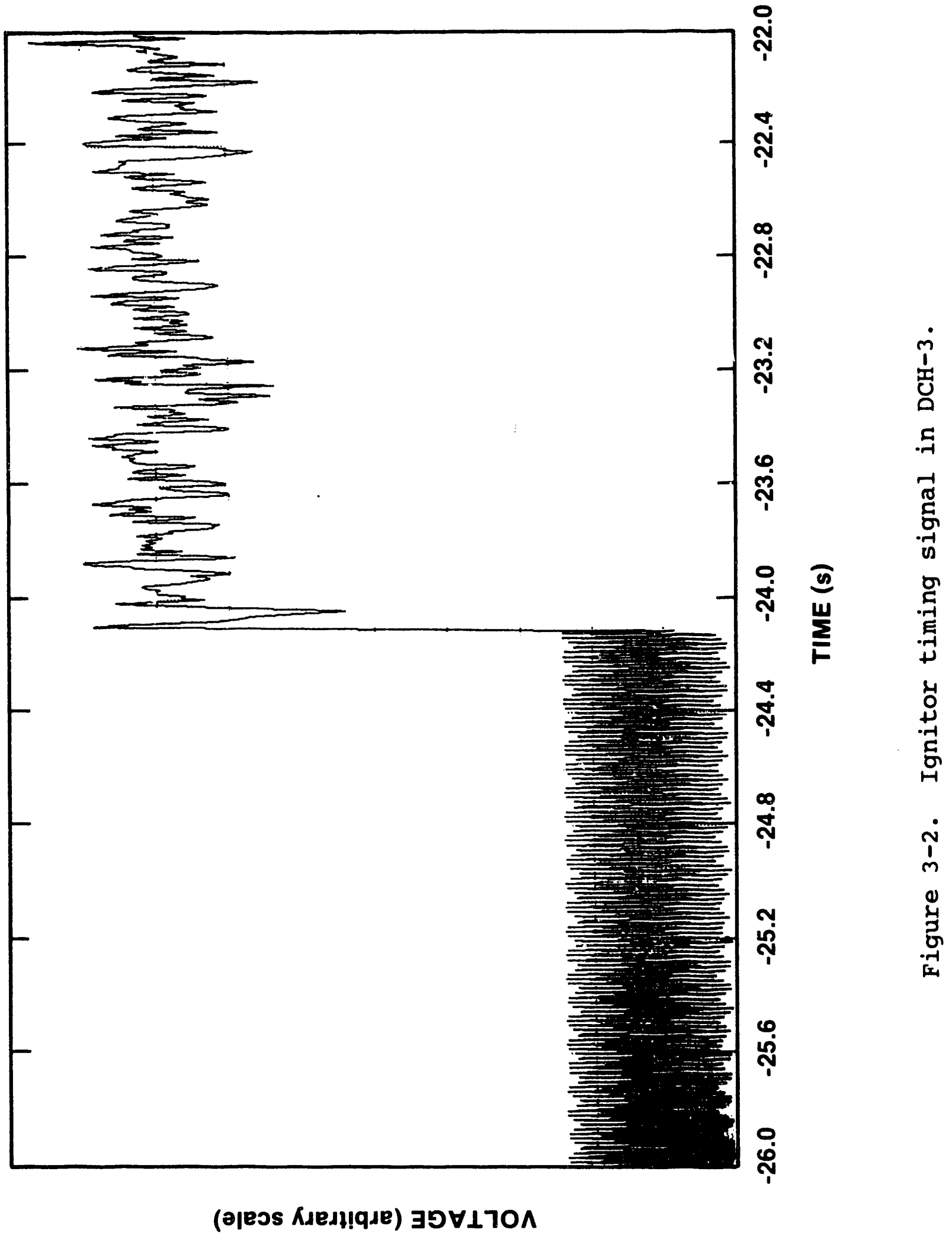


(6!sd) Jynss $34 d$

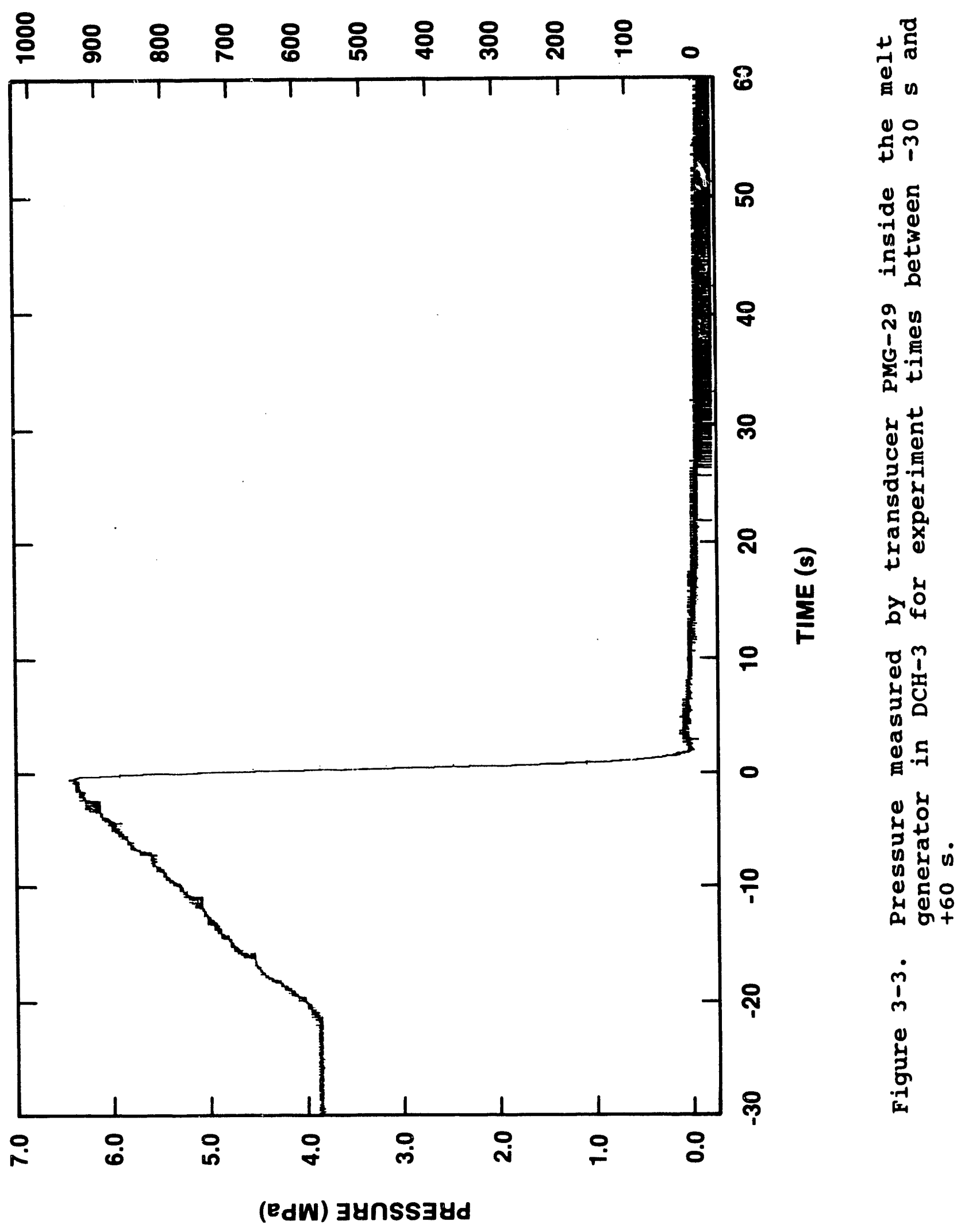




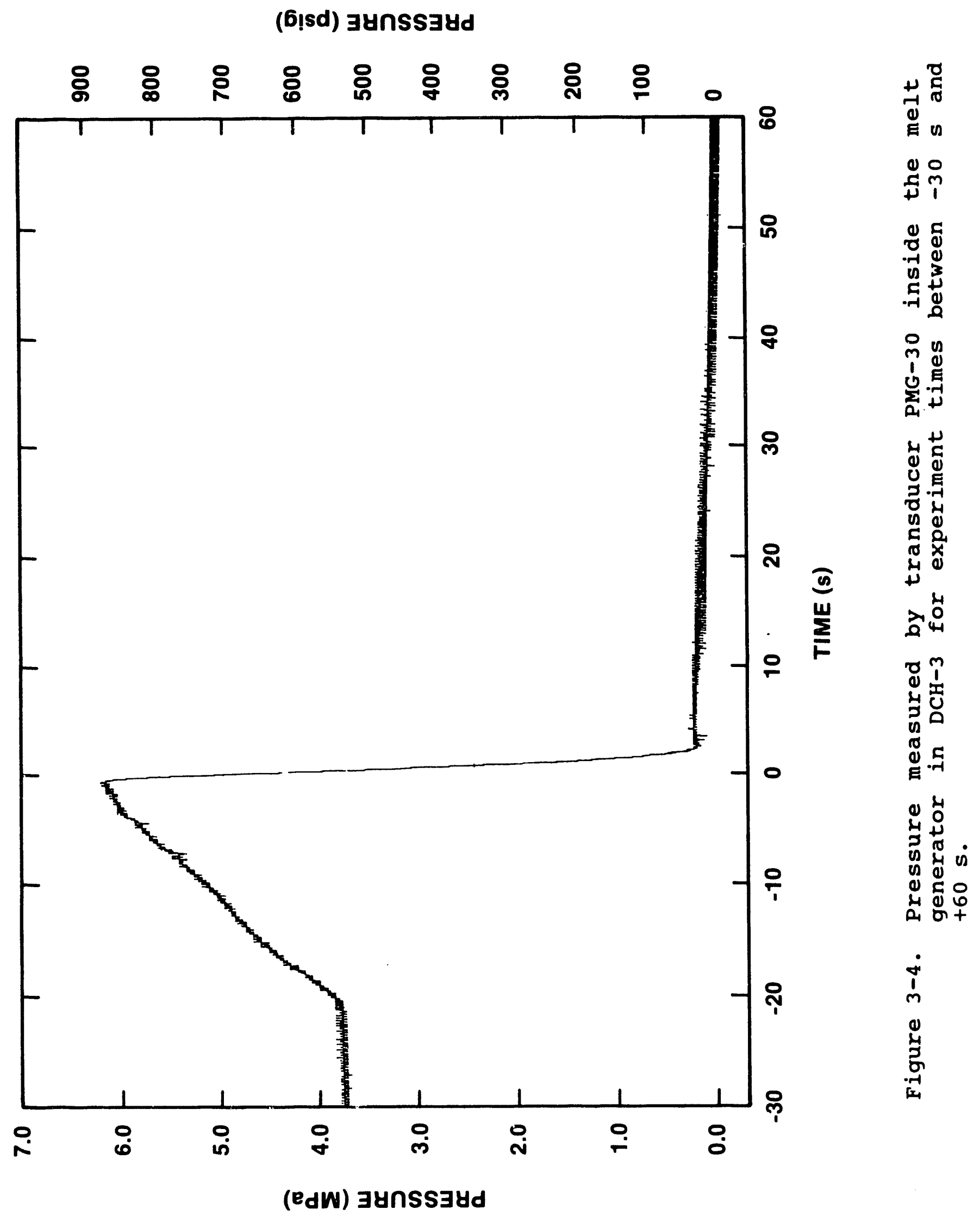


(6!̣d) 3 ynss $34 d$

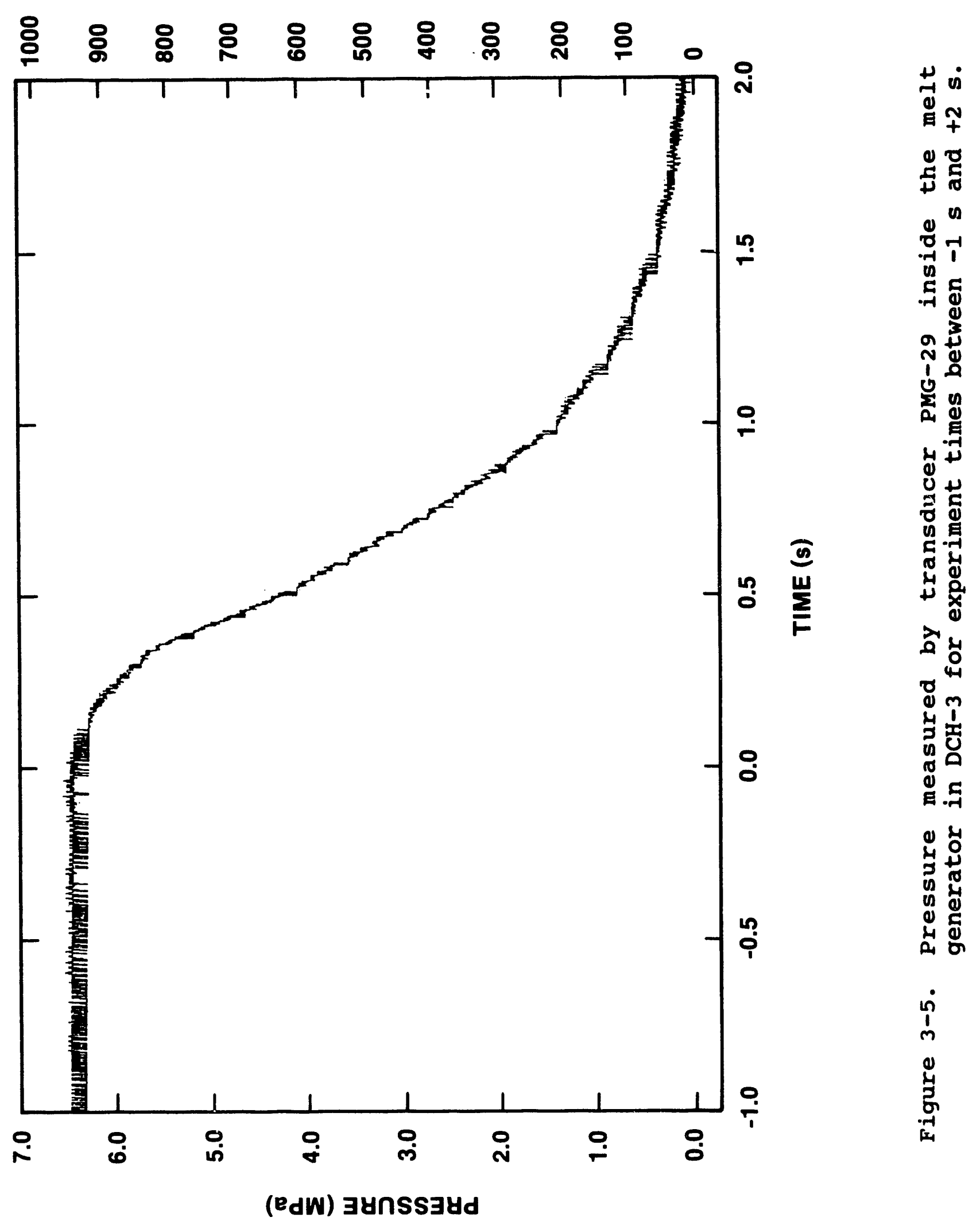


(6!̣d) $\exists$ unss $34 d$

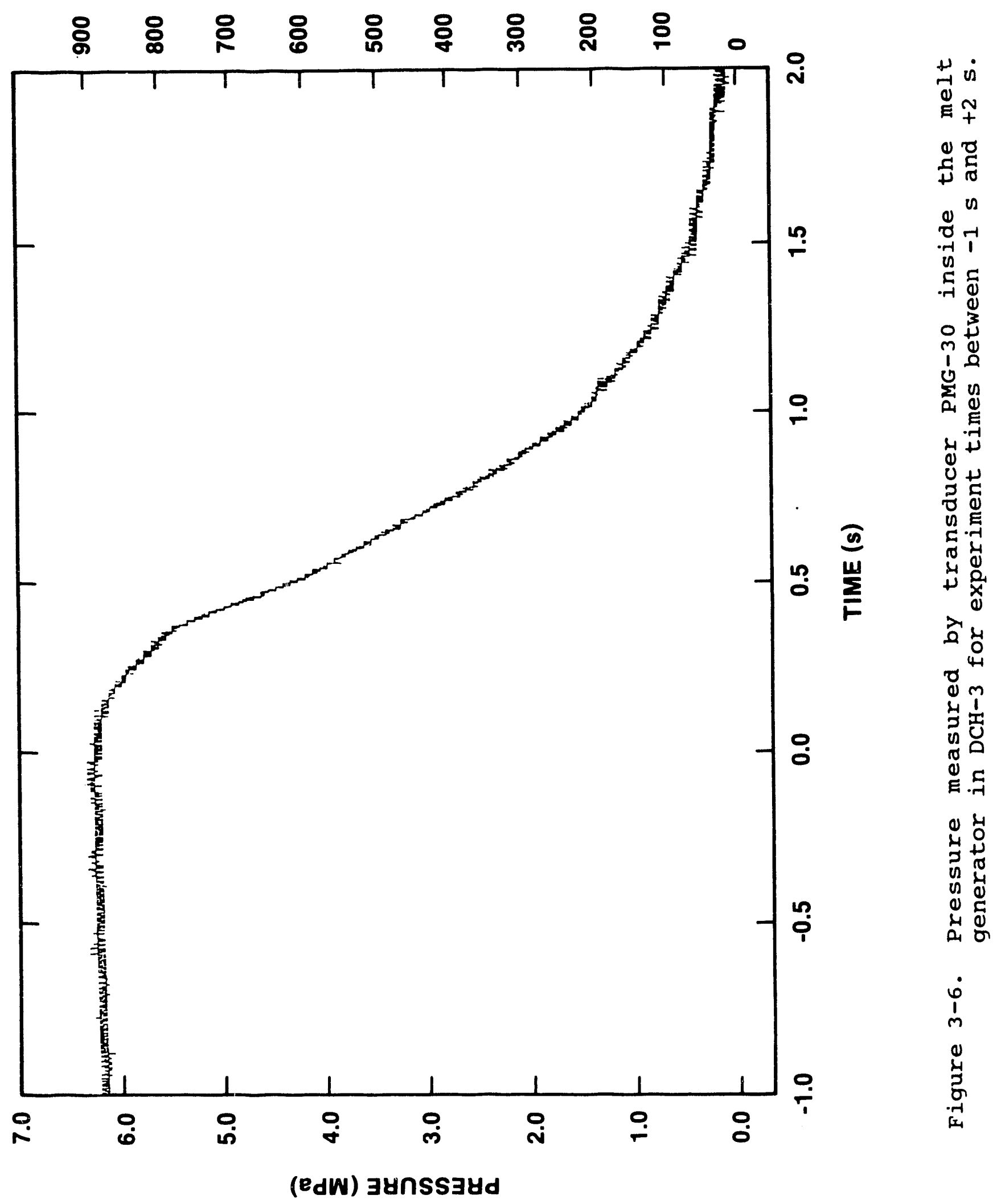




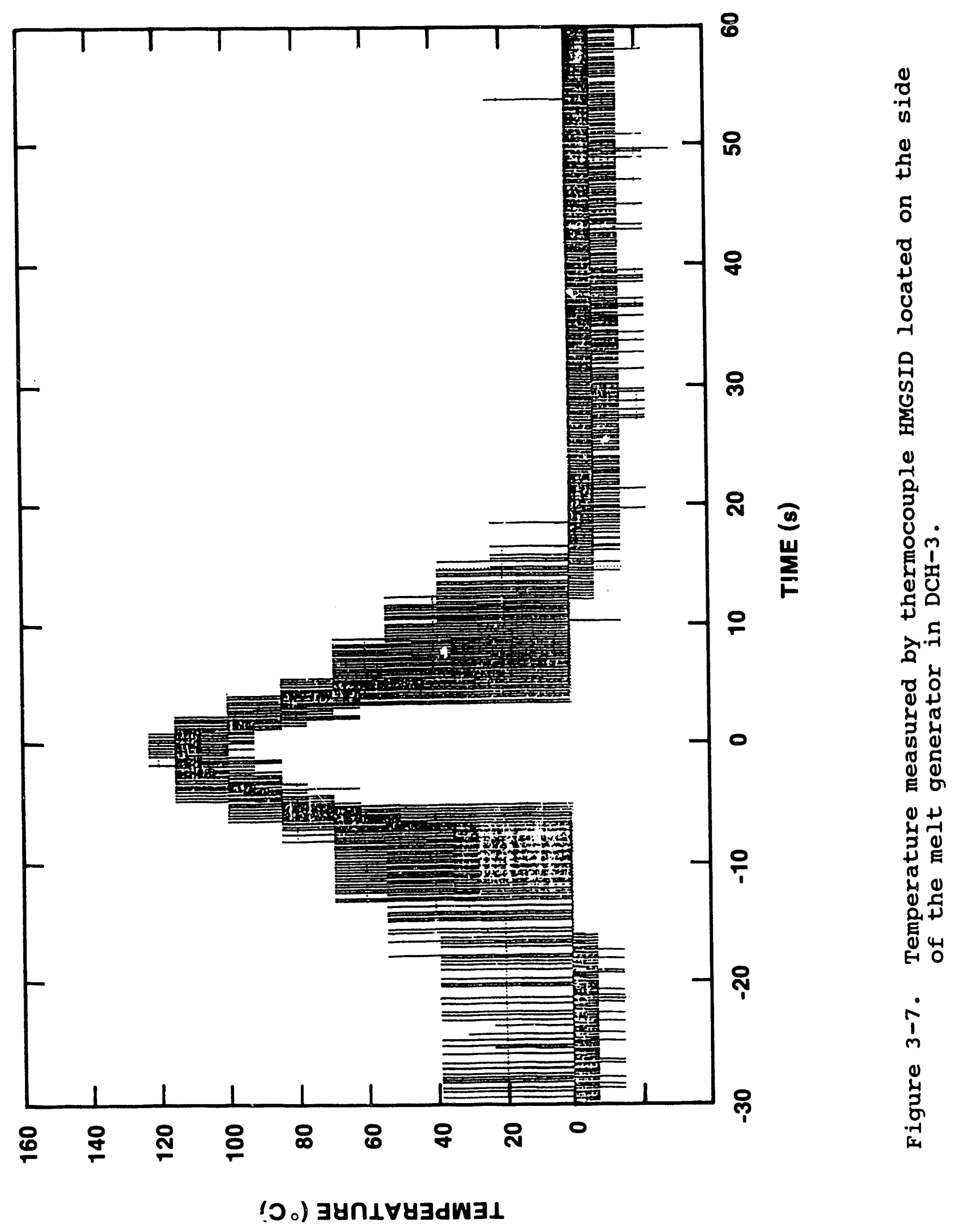


(6!sd) ヨynss $34 d$

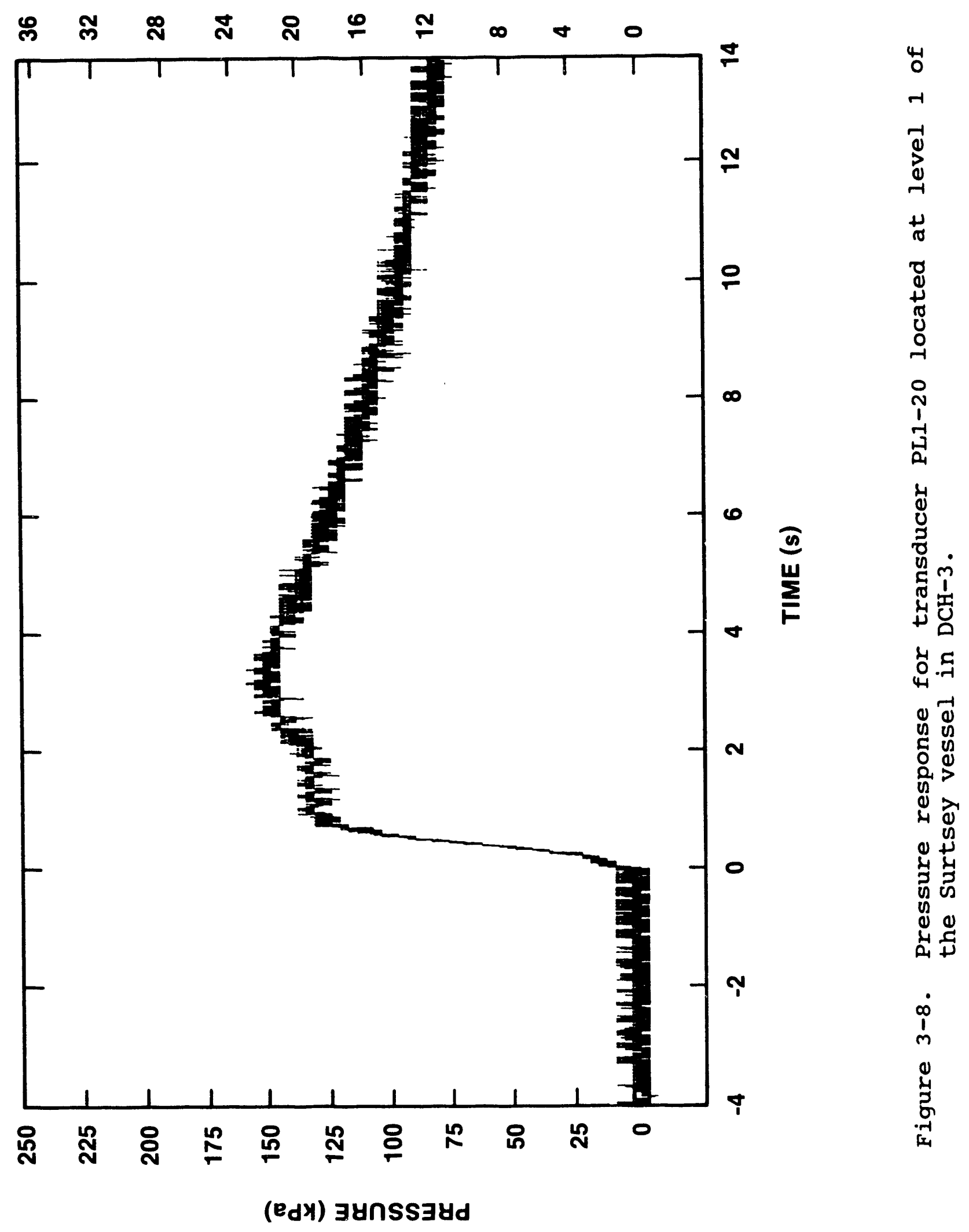


(b!sd) $\exists$ ynss $\exists y d$

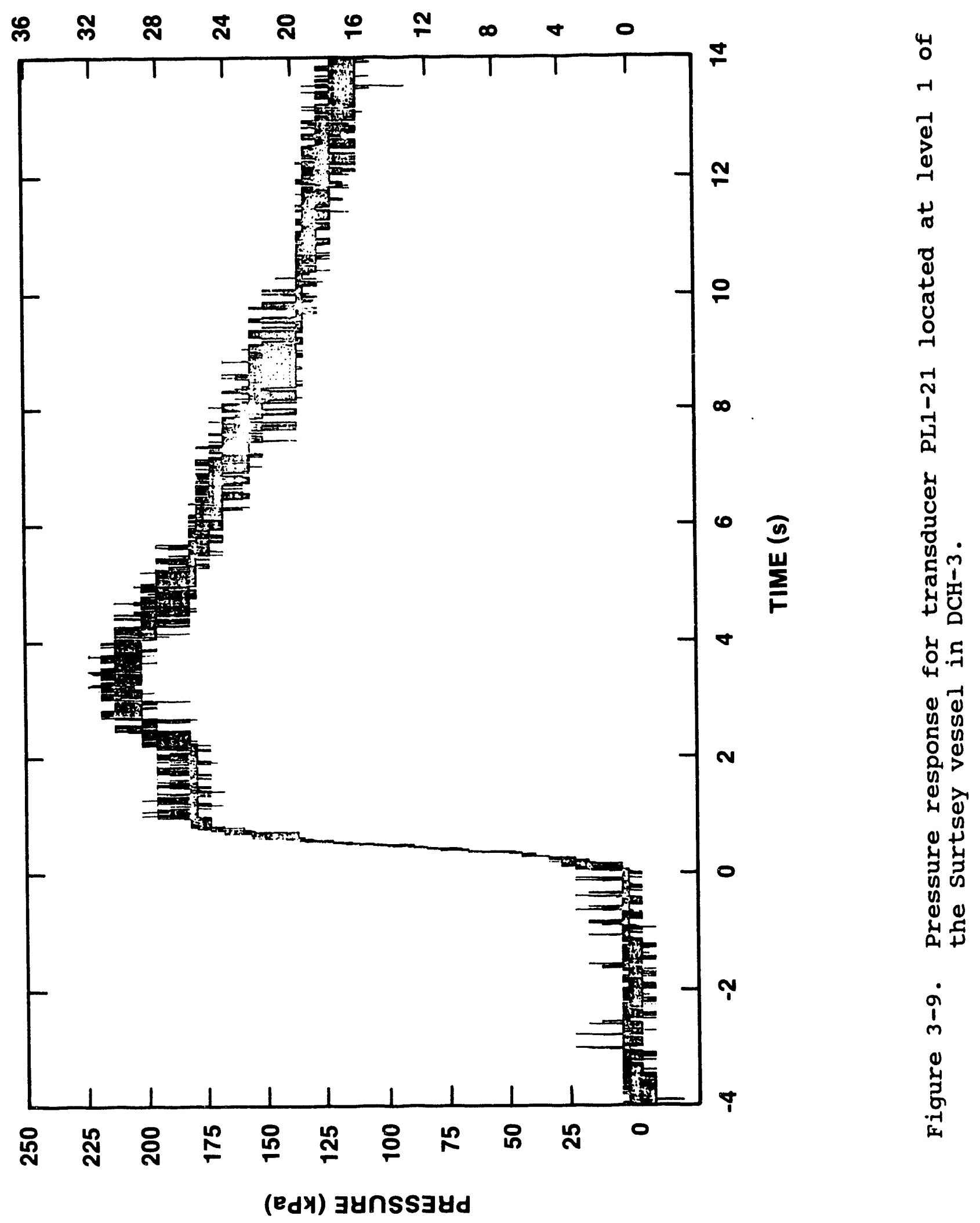


(6!sd) $\exists y n s s \exists y d$

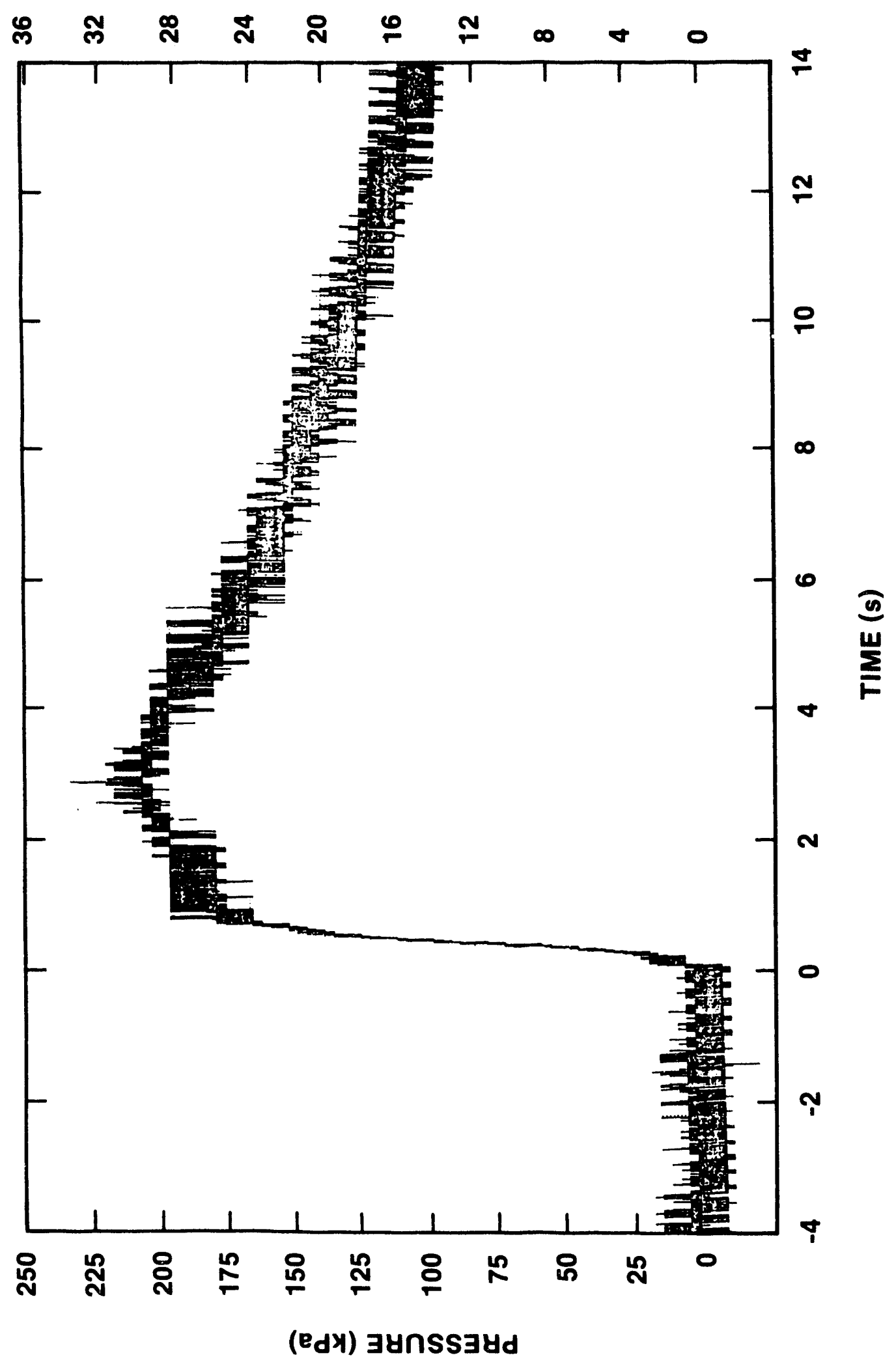

Hั

$-1$

$\int_{0}^{-1}$

$+\infty$

8

$\underset{⿱}{0}$

ర్ల

N

告

䎂

언.

0

on on

엉

a

o

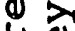

4 on

0

วู่ วิ

is

近

का

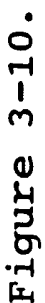

(edy) $\exists y n s s \exists y d$ 
(6!sd) $\exists$ ynss $\exists y d$

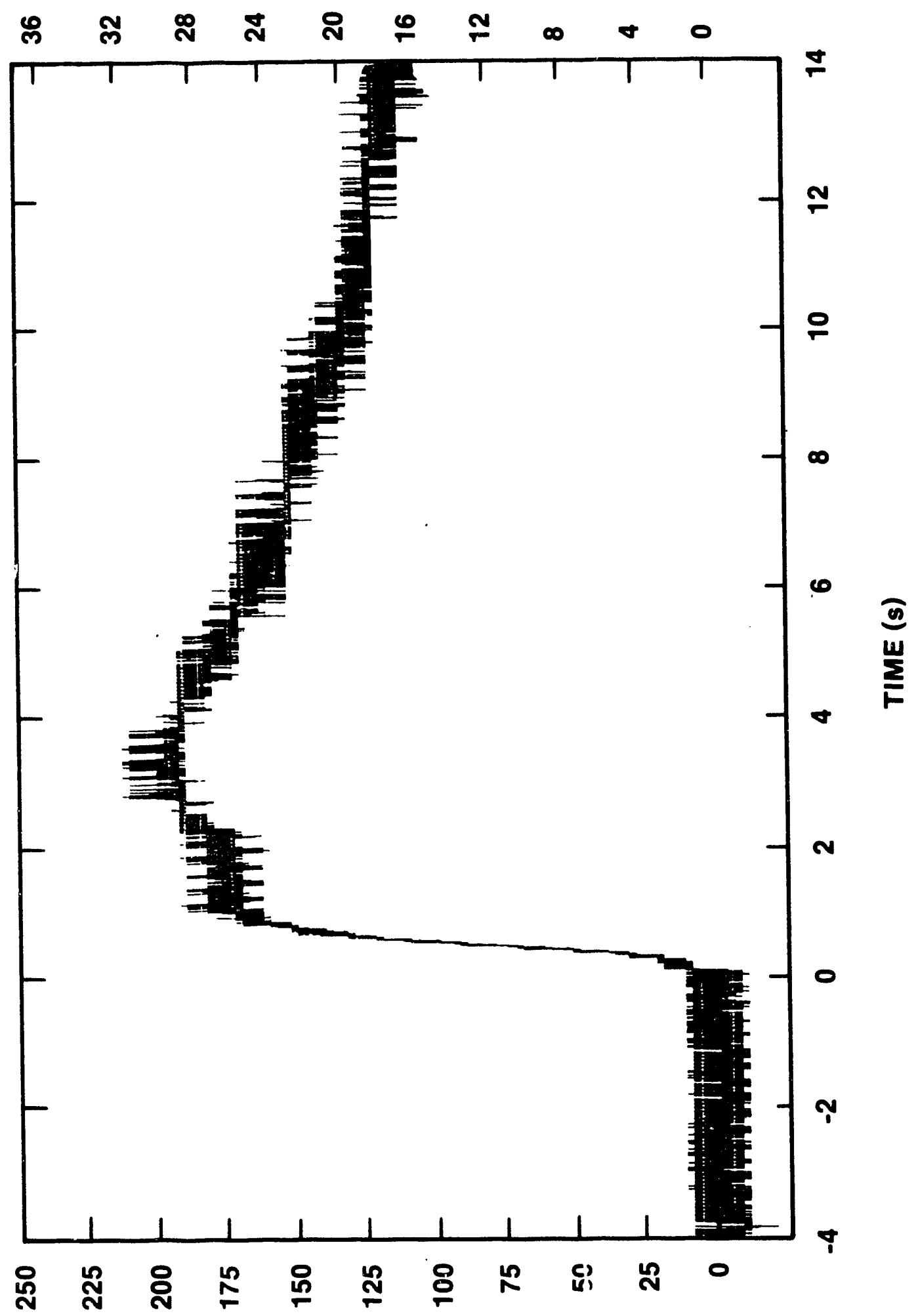

㟧

m

$\sum_{0}^{1}$

$+\infty$

ర్

in

范

苍.

व 0

on

है

a

g

4 过

$0+$

क्ष

(1)

告

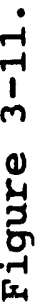

(edy) $\exists$ ynSS $3 y d$ 
(6!sd) $\exists$ ynsS $\exists y d$

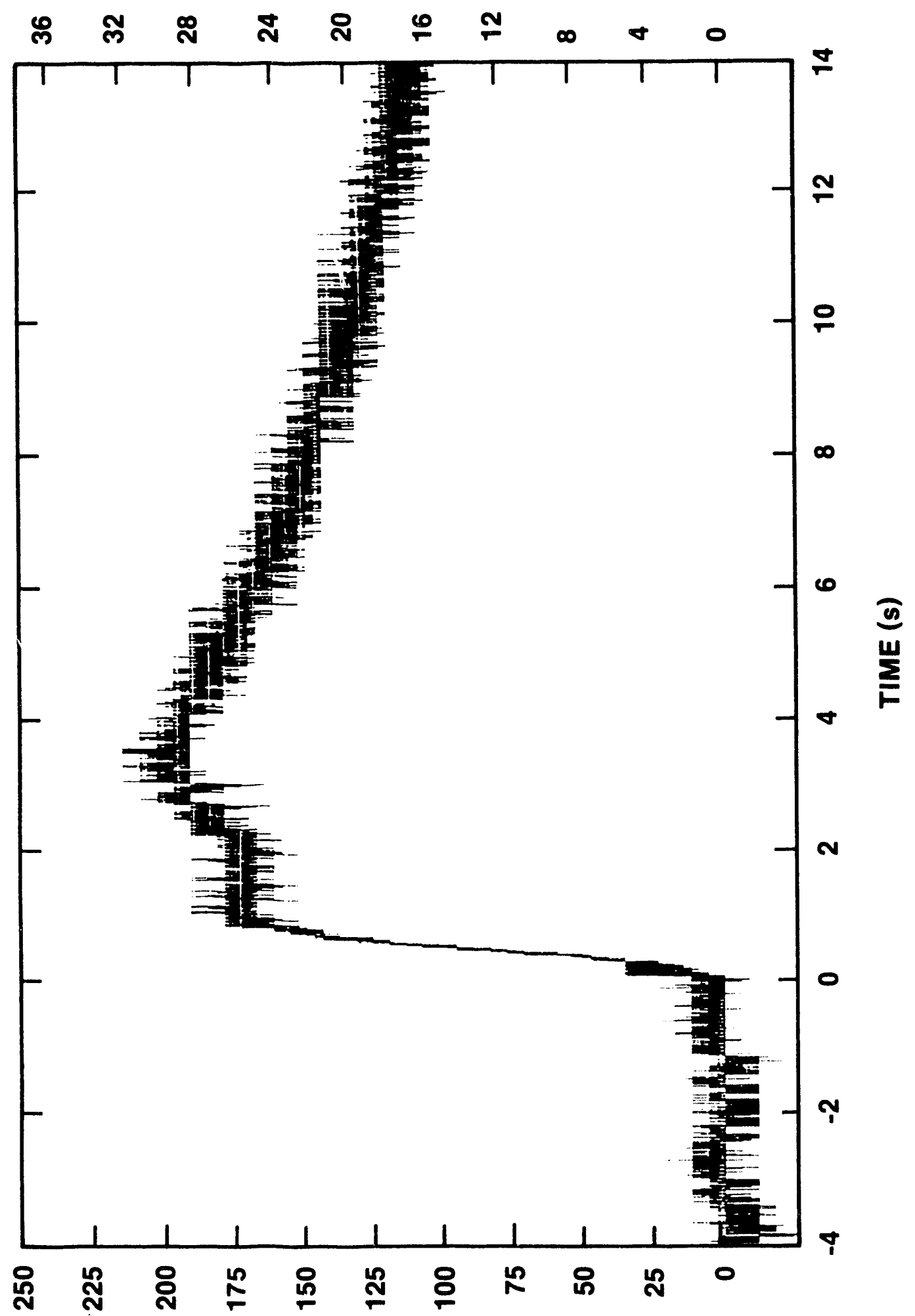

㟧

m

齐

$+$

ช્

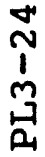

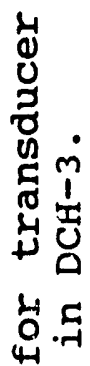

o)

证

¿ू ฏ

d

거 ญ

o) तै

造 岇

क

कै 0

मे

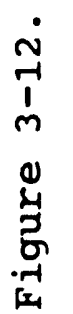

(edy) $\exists$ ynss $3 y d$ 
(6!sd) $\exists$ thSS $34 d$

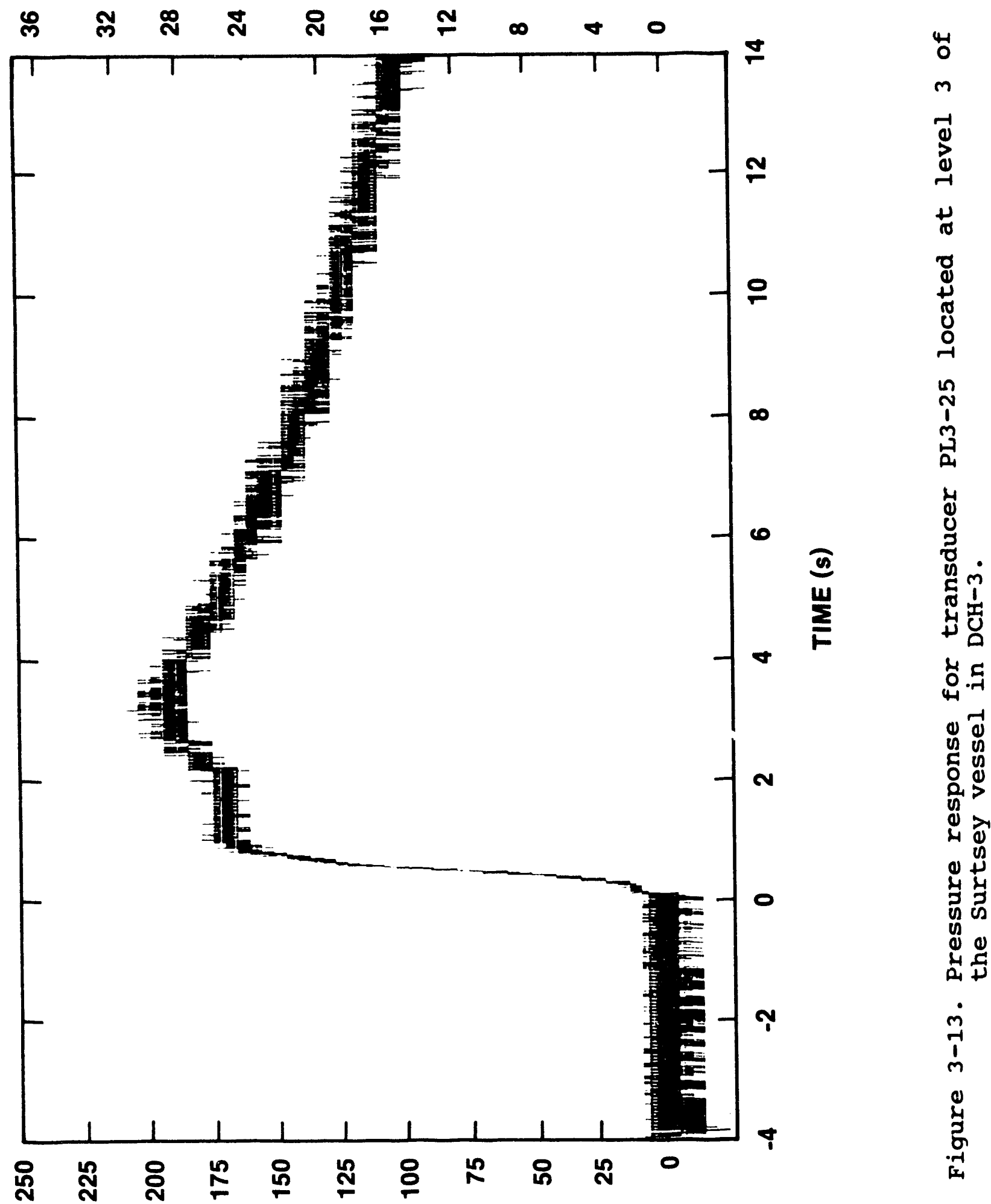

(Edy) $\exists$ ynSS $3 y d$ 
(b!̣s) $\exists$ ynss $\exists$ ४d

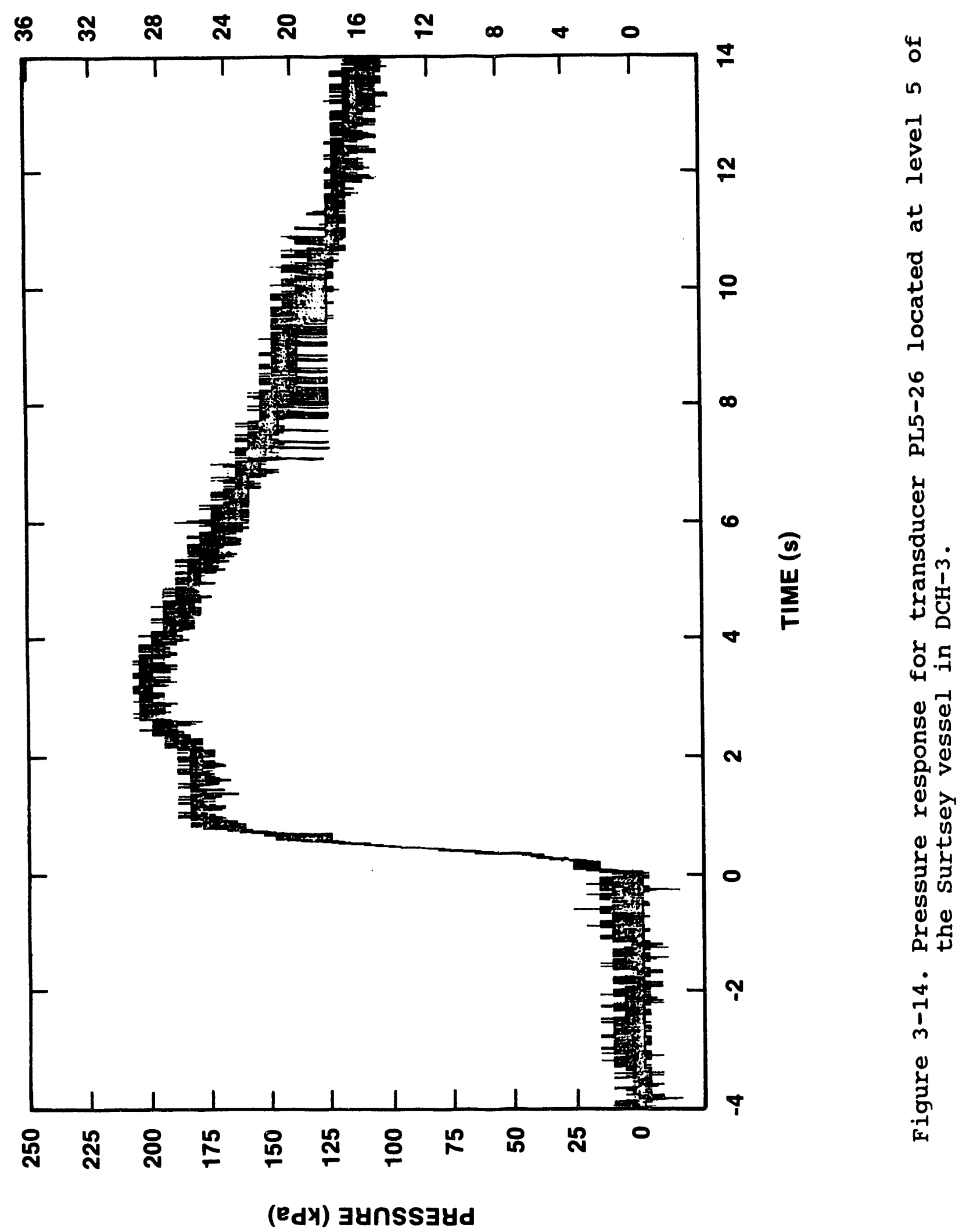


(6!sd) $\exists$ ynss $3 y d$

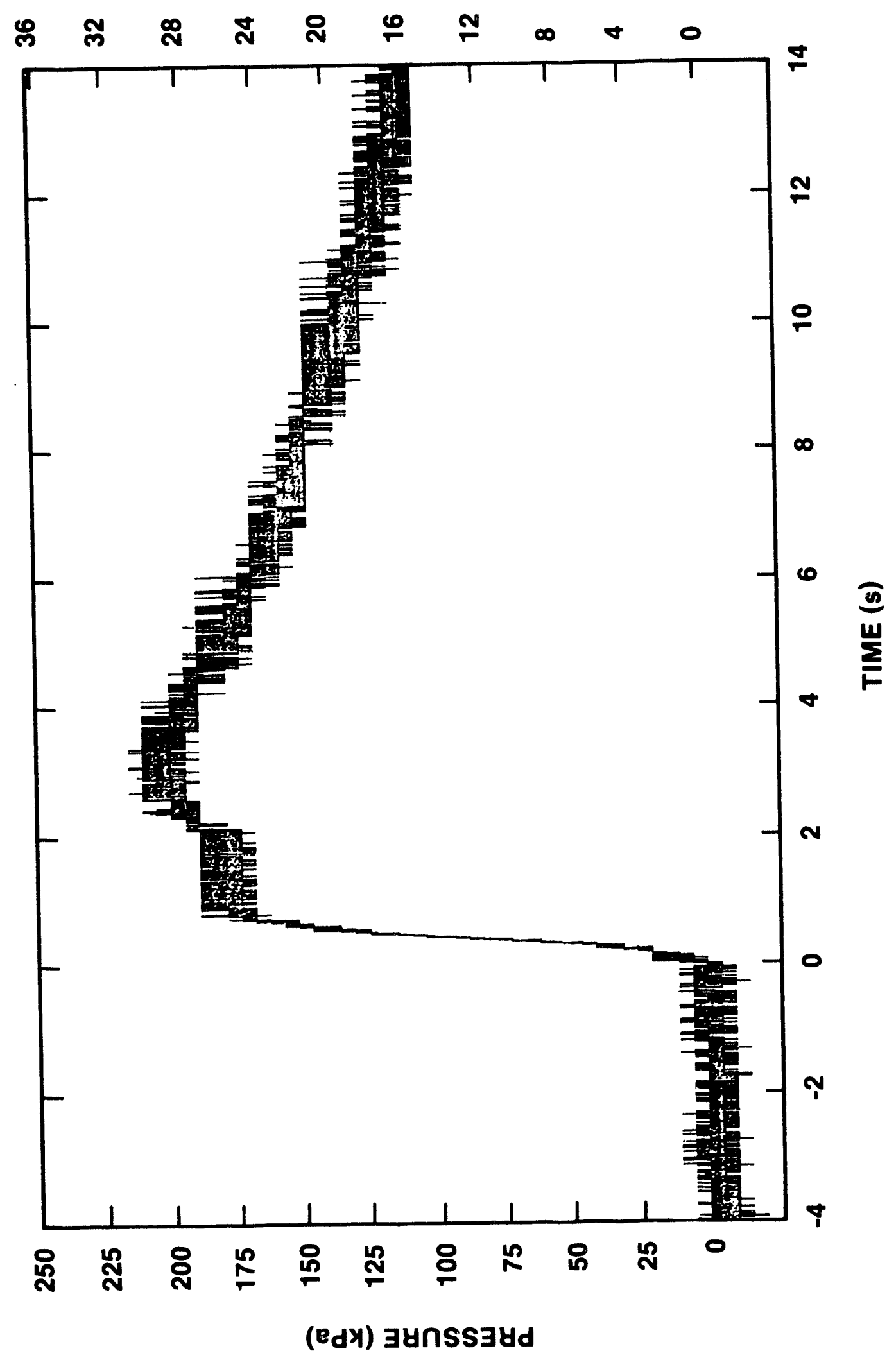

崩

n

式

$\Perp_{\infty}$

ช

ชู

$\stackrel{N}{N}$

望

䎂

언.

7

ข

है क

a

is

강

(1)

낵

(

ขै 0

क्ष.

ñ

(edy) $\exists y n s s \exists y d$ 


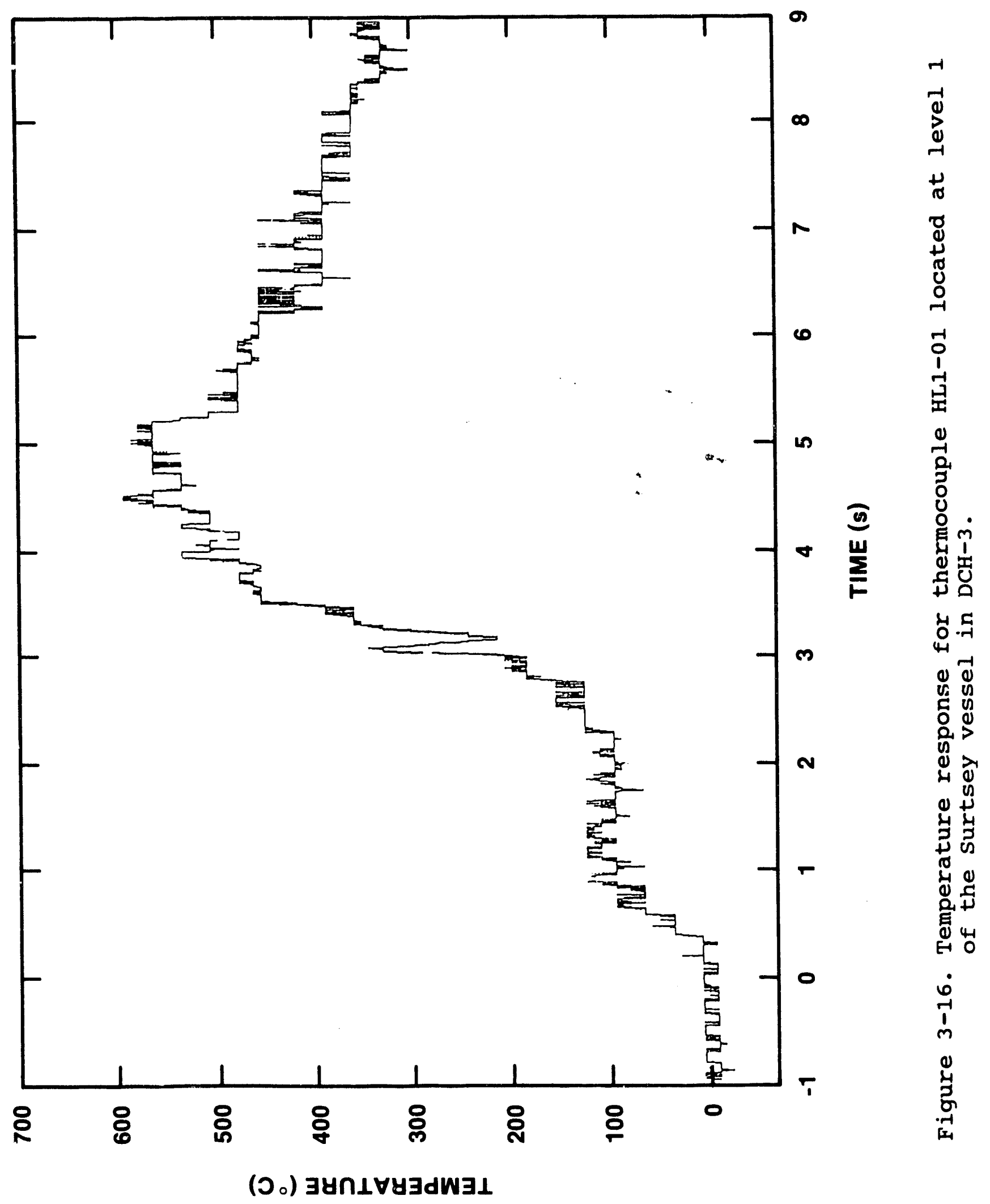




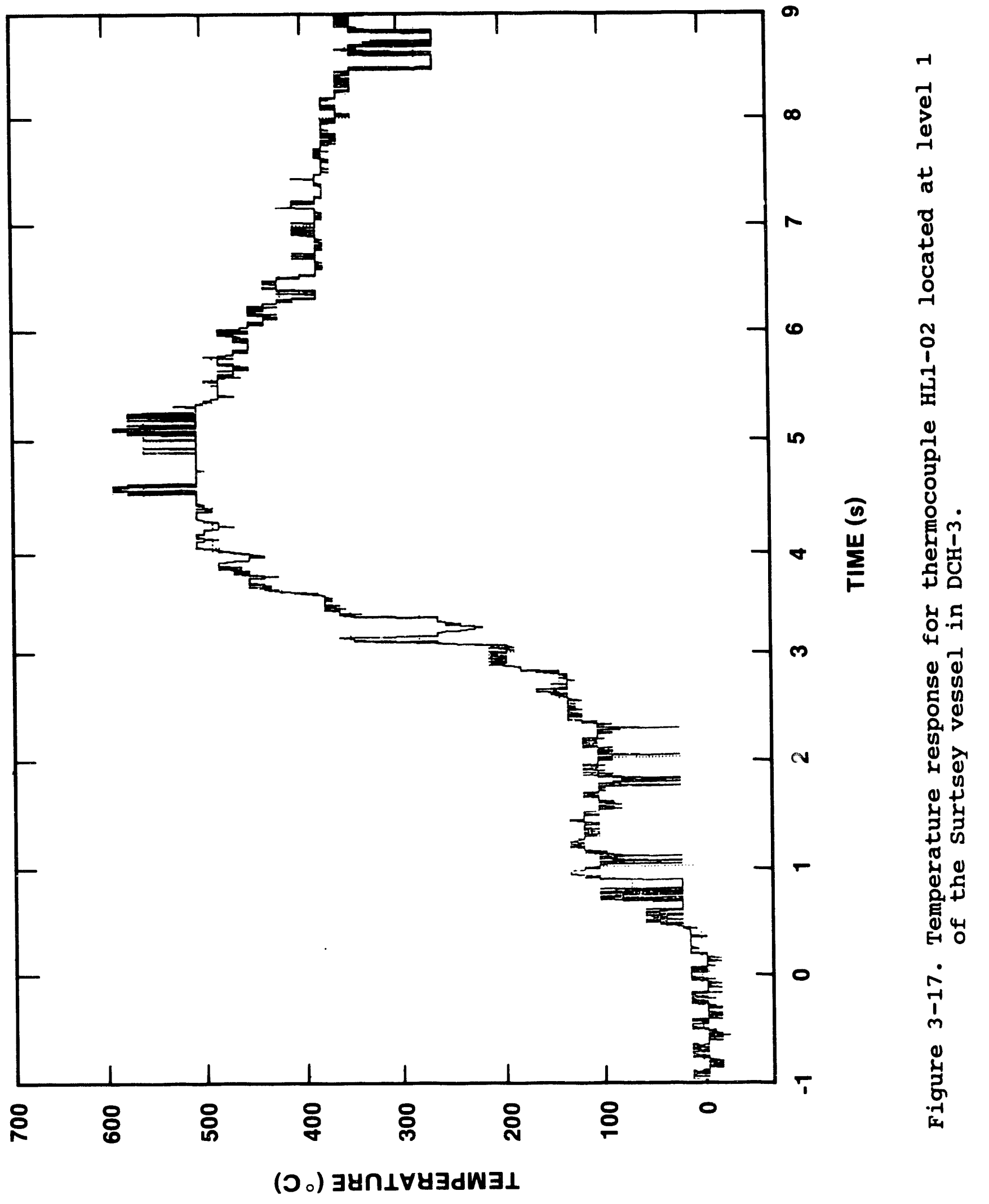




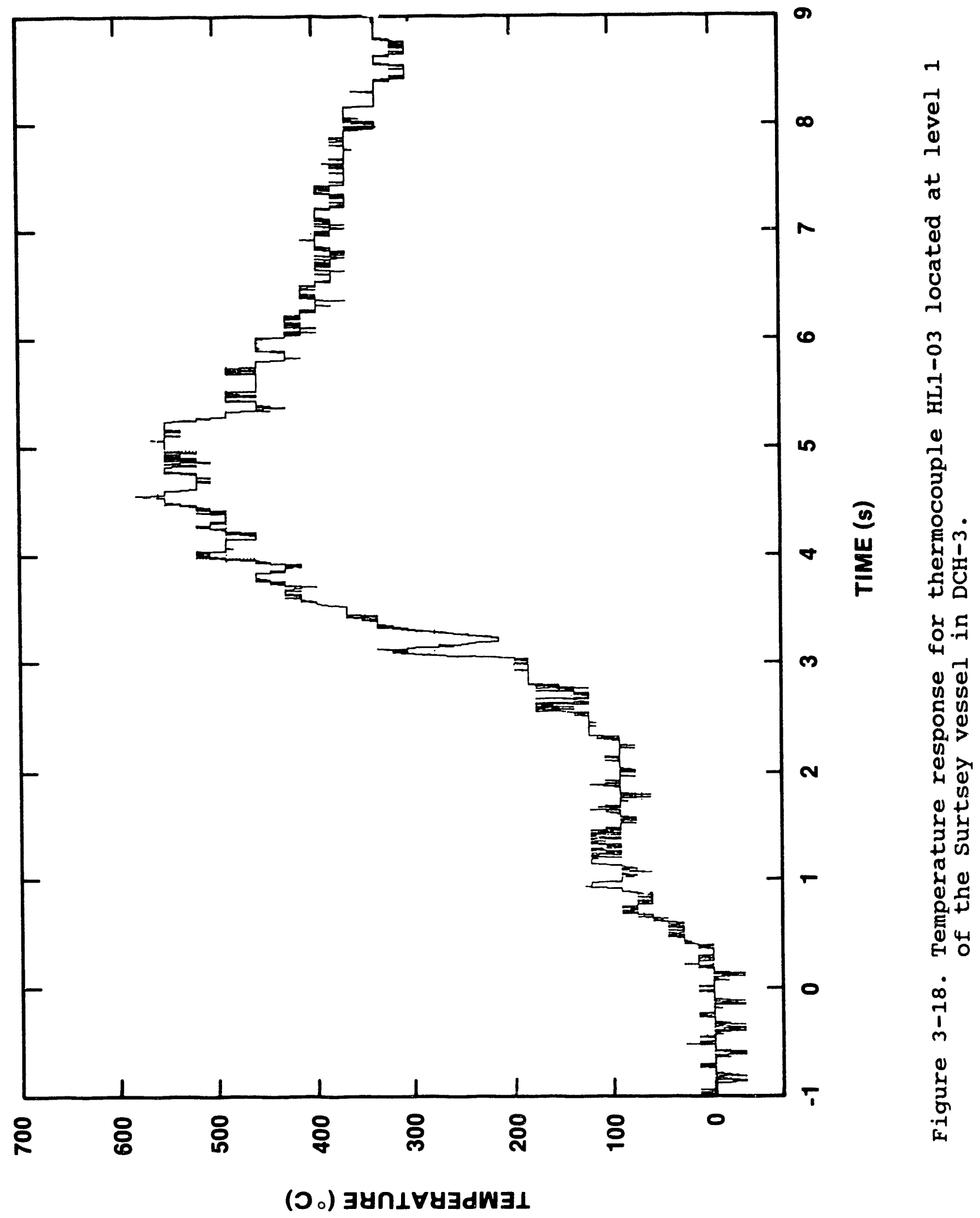




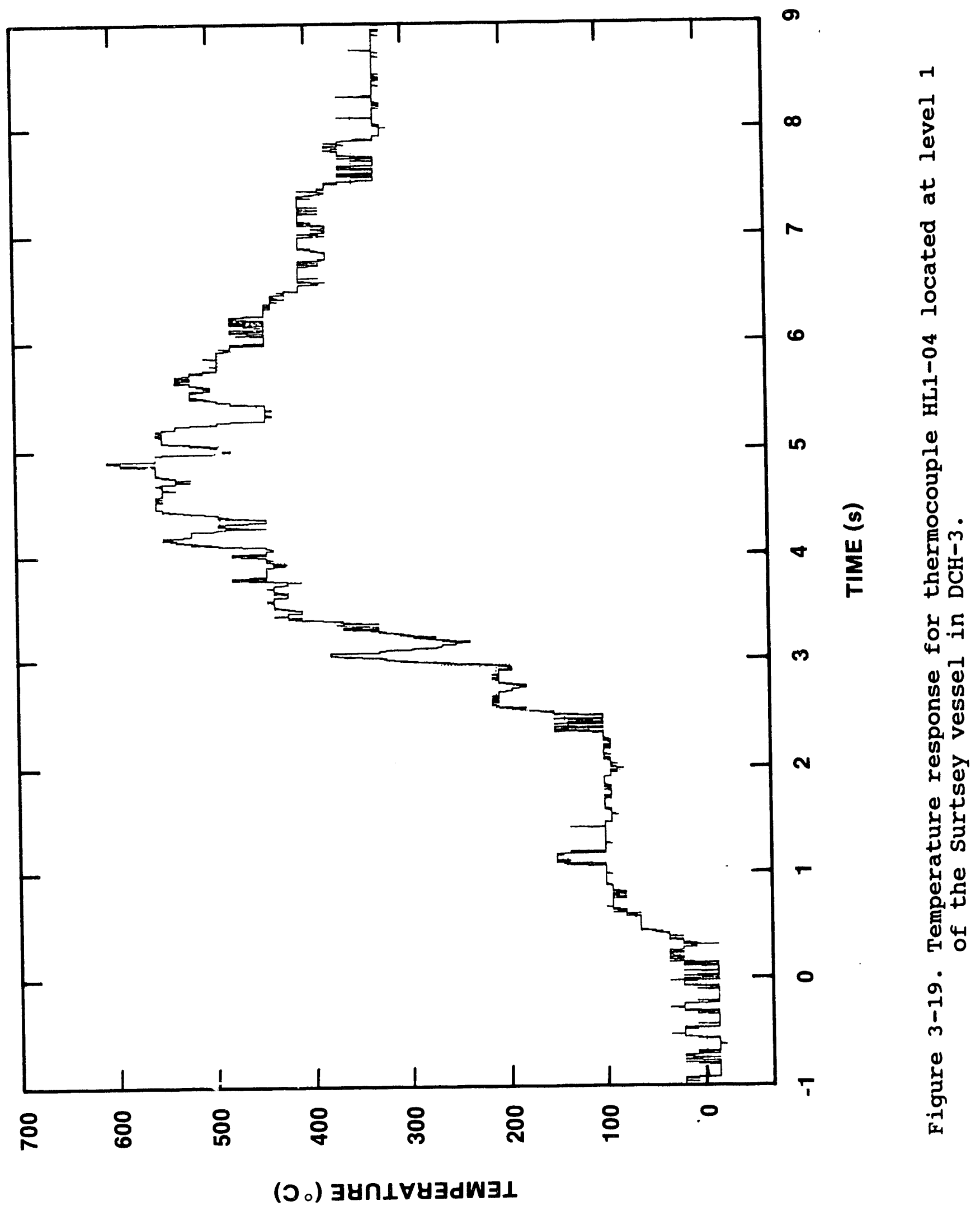




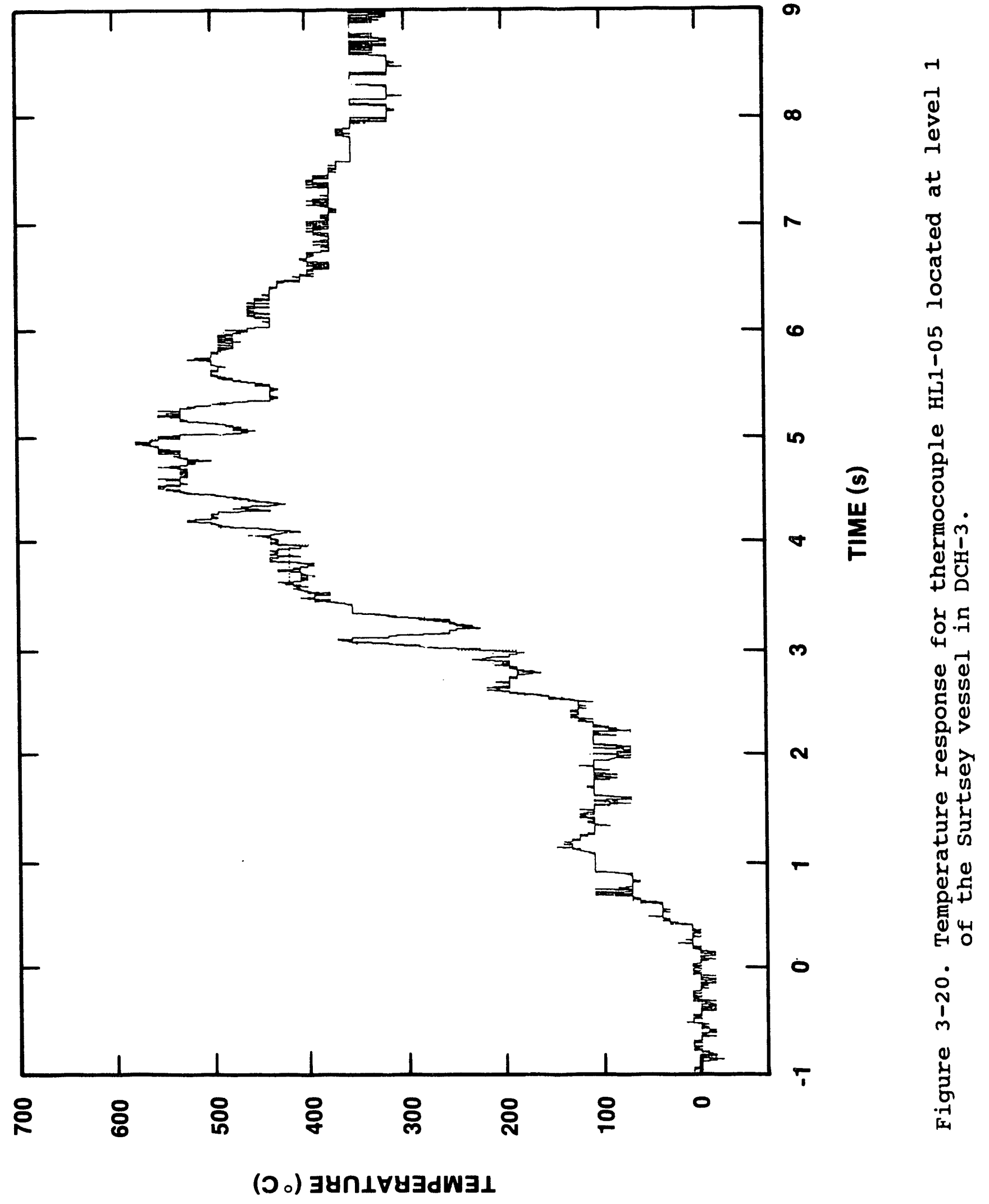




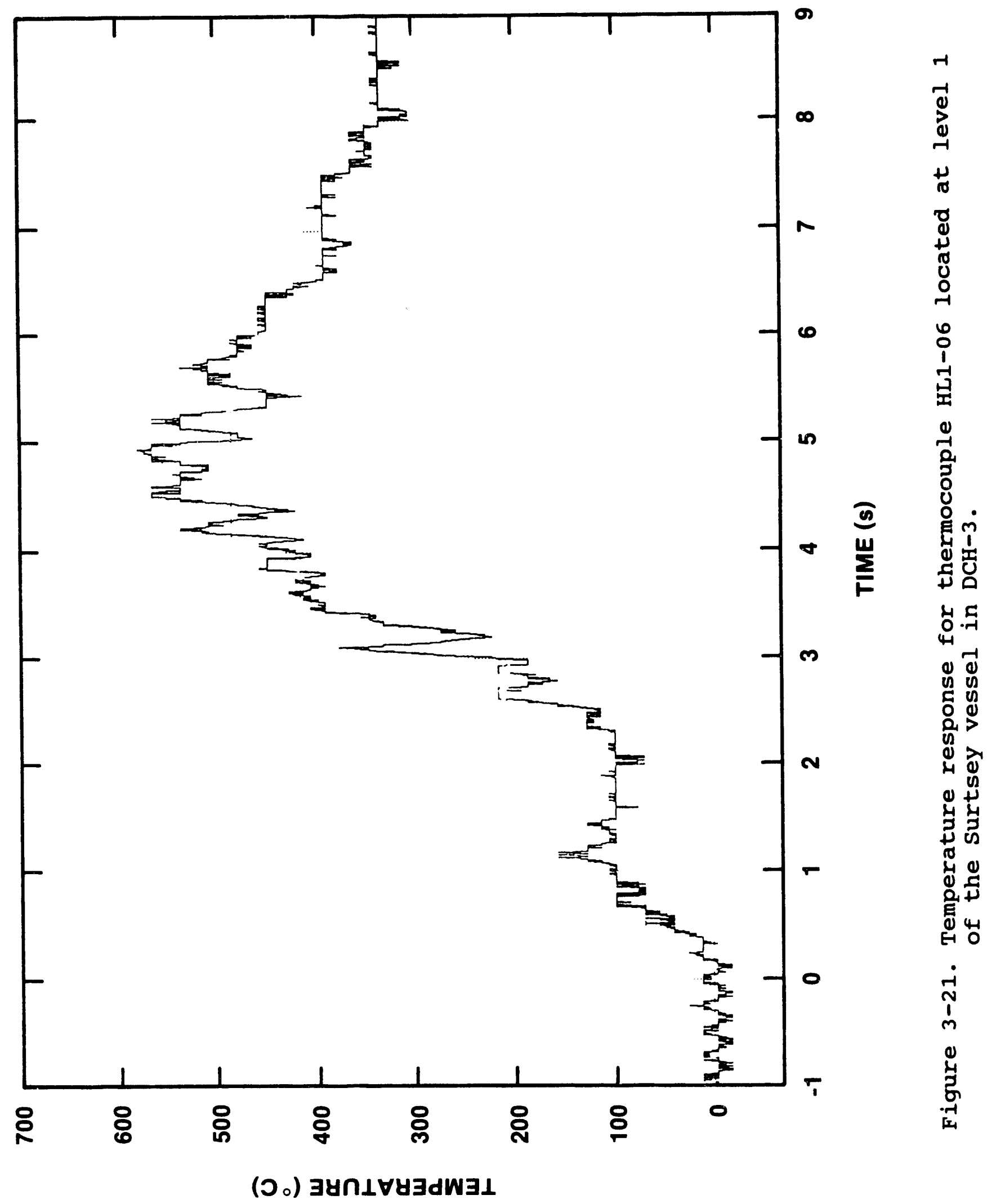




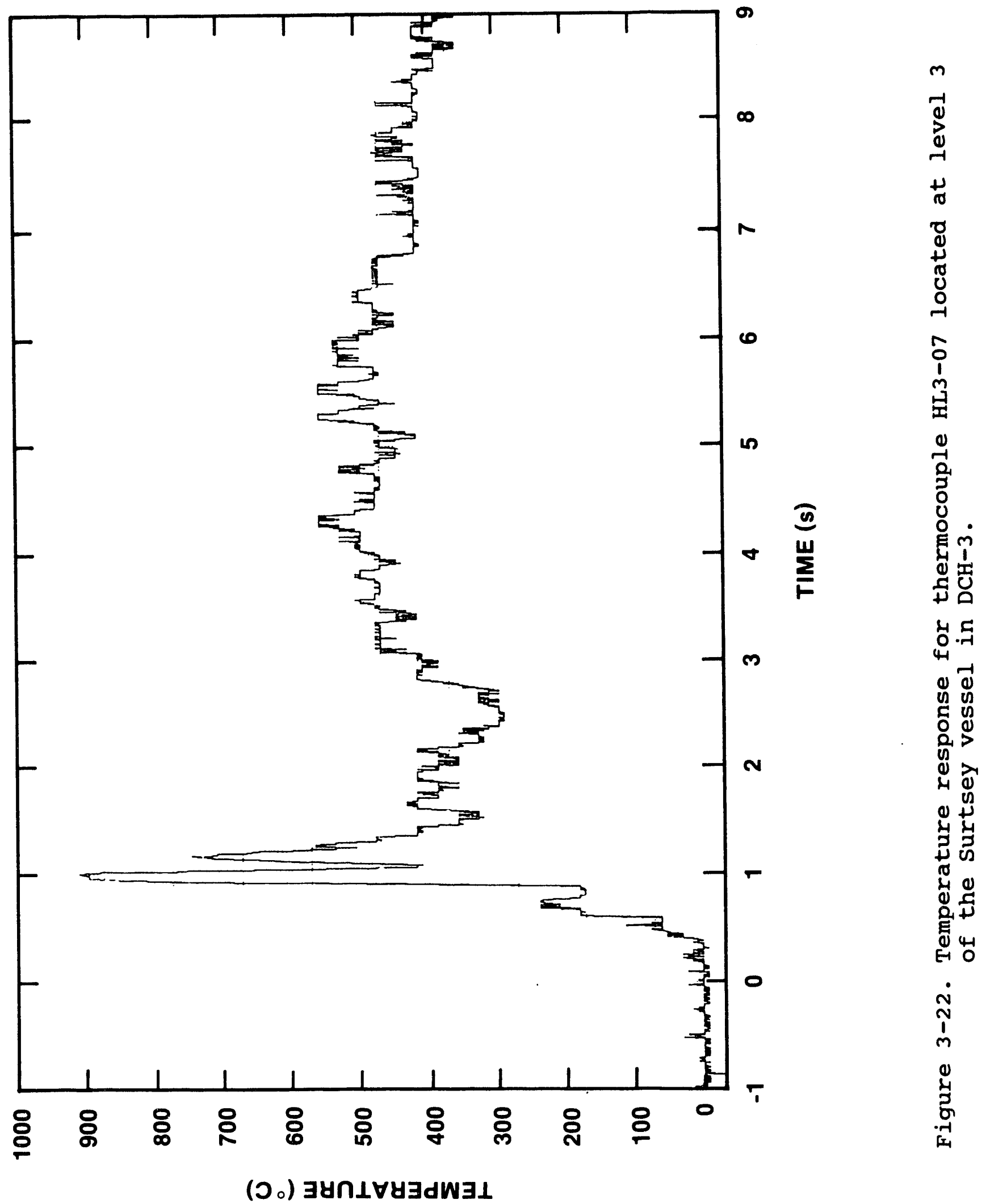




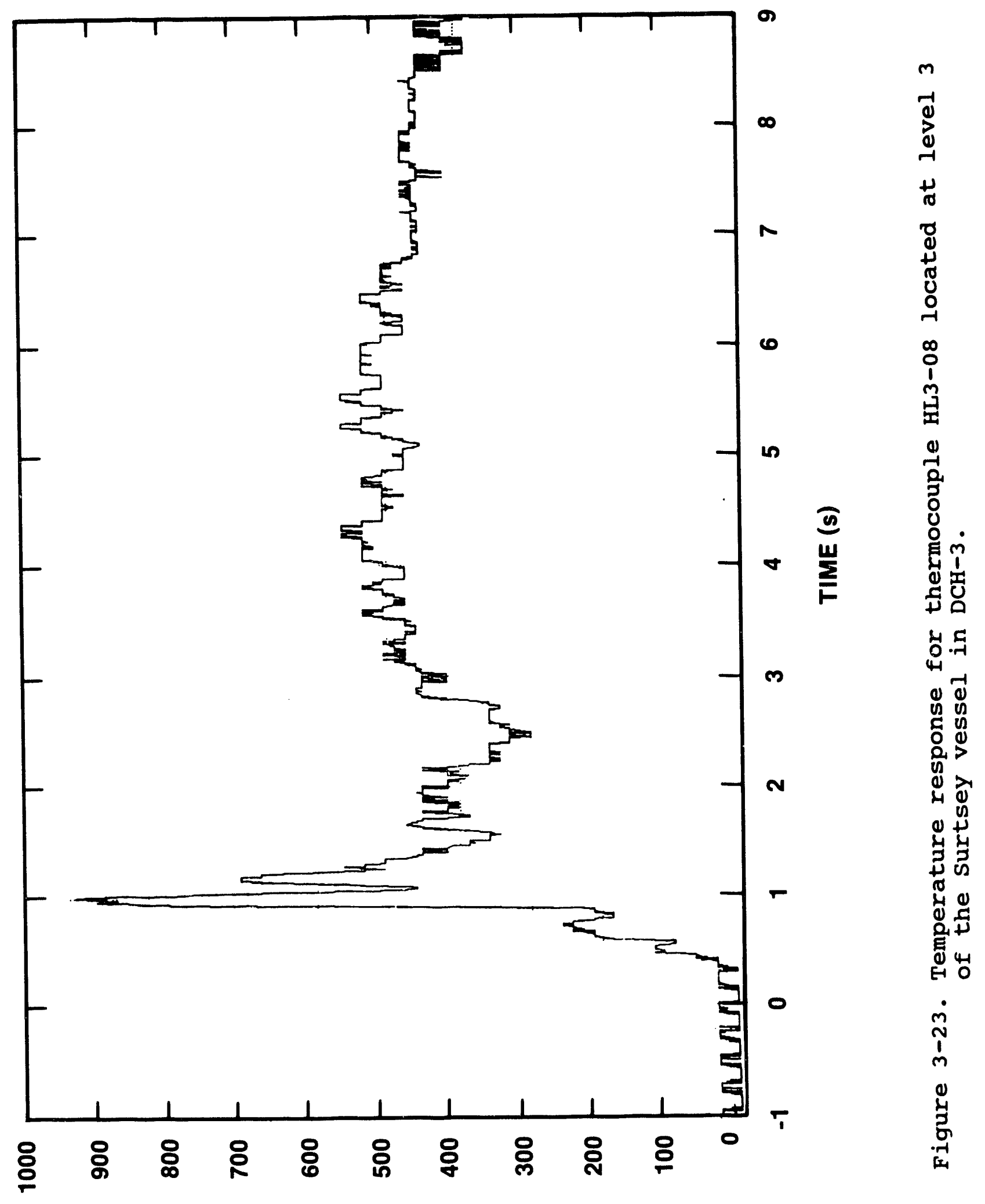

(0.) $\exists \forall n \perp \forall \forall \exists d W \exists \perp$ 


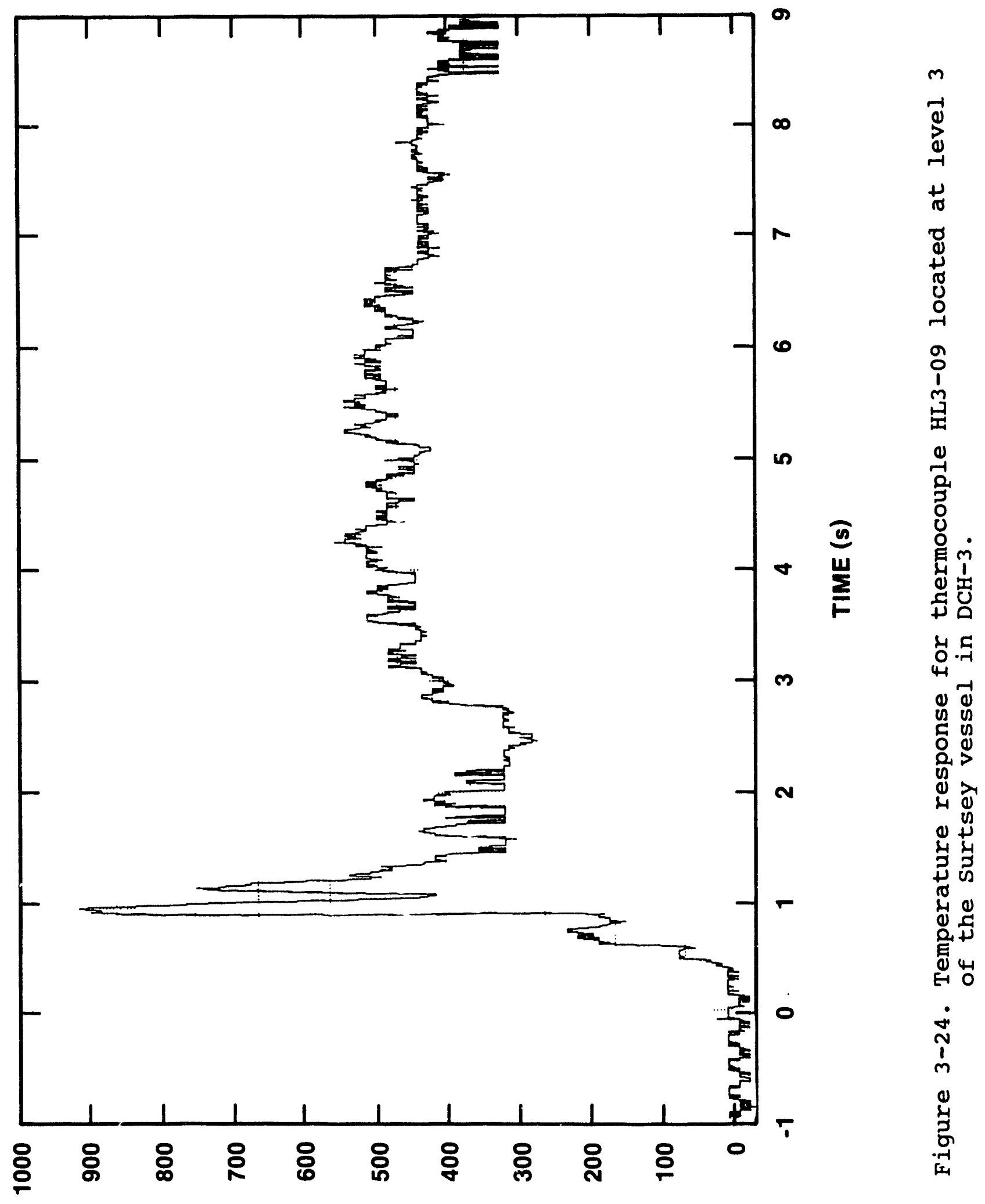

(ว。) $\exists y \cap \perp \forall y \exists d W \exists \perp$ 


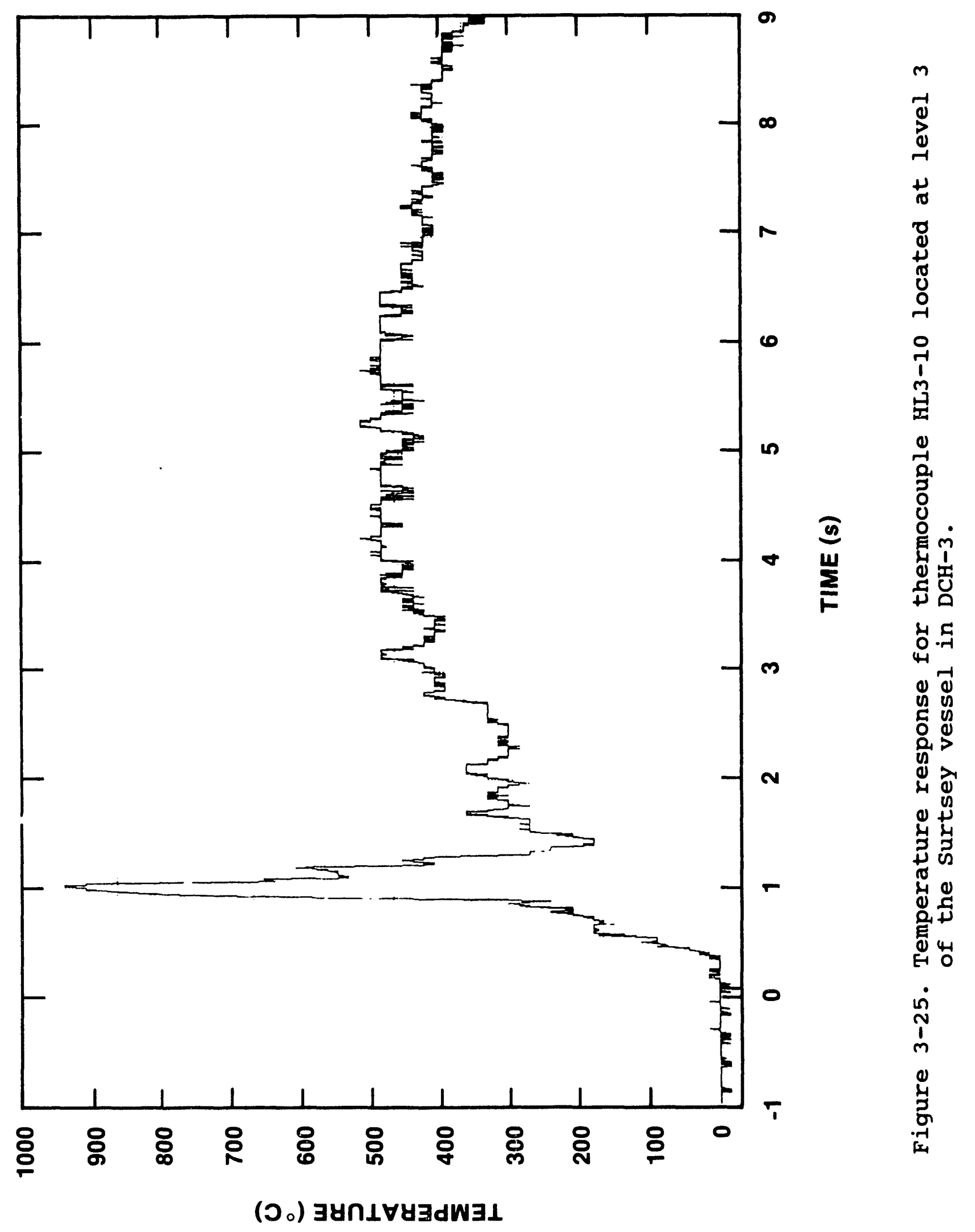




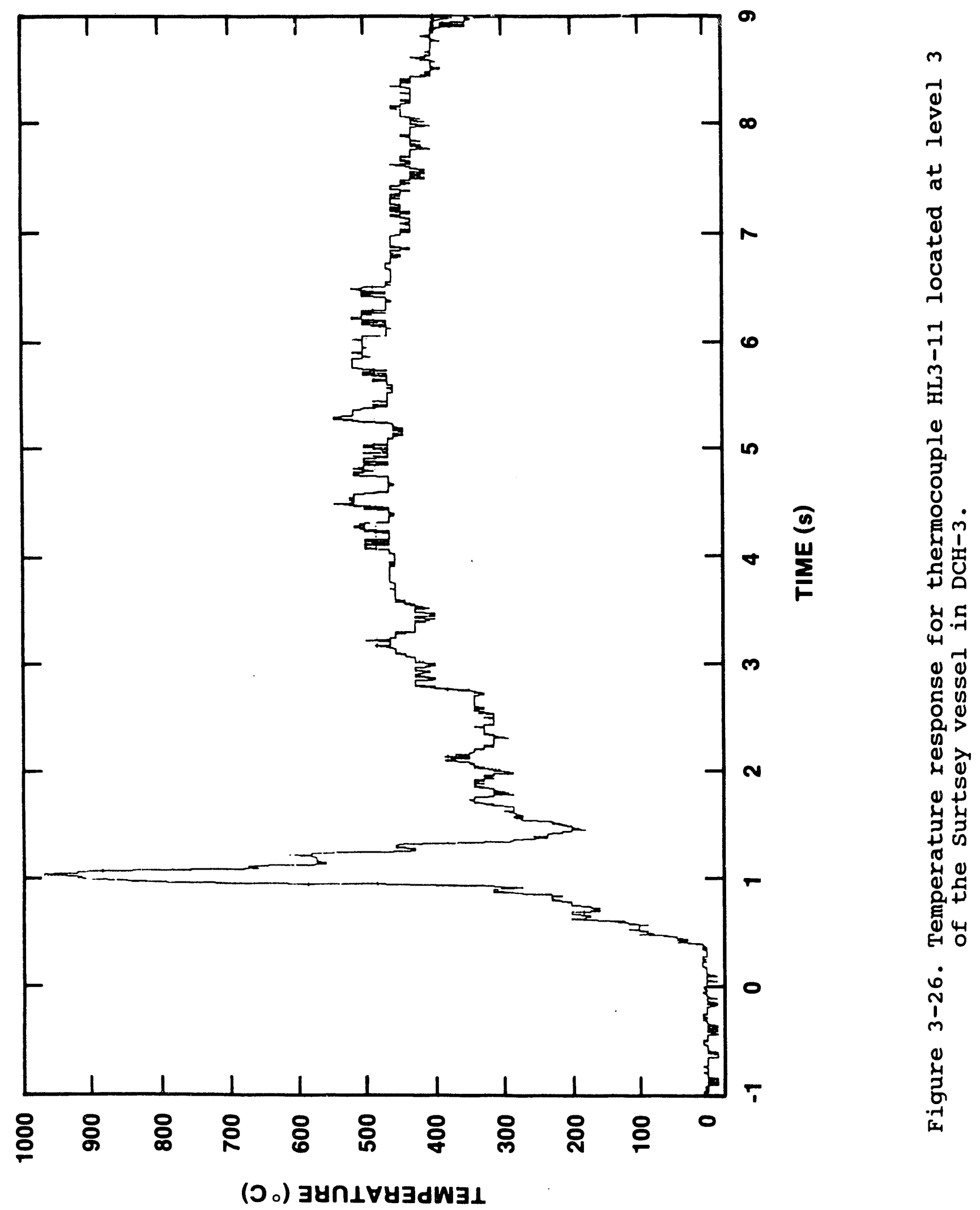




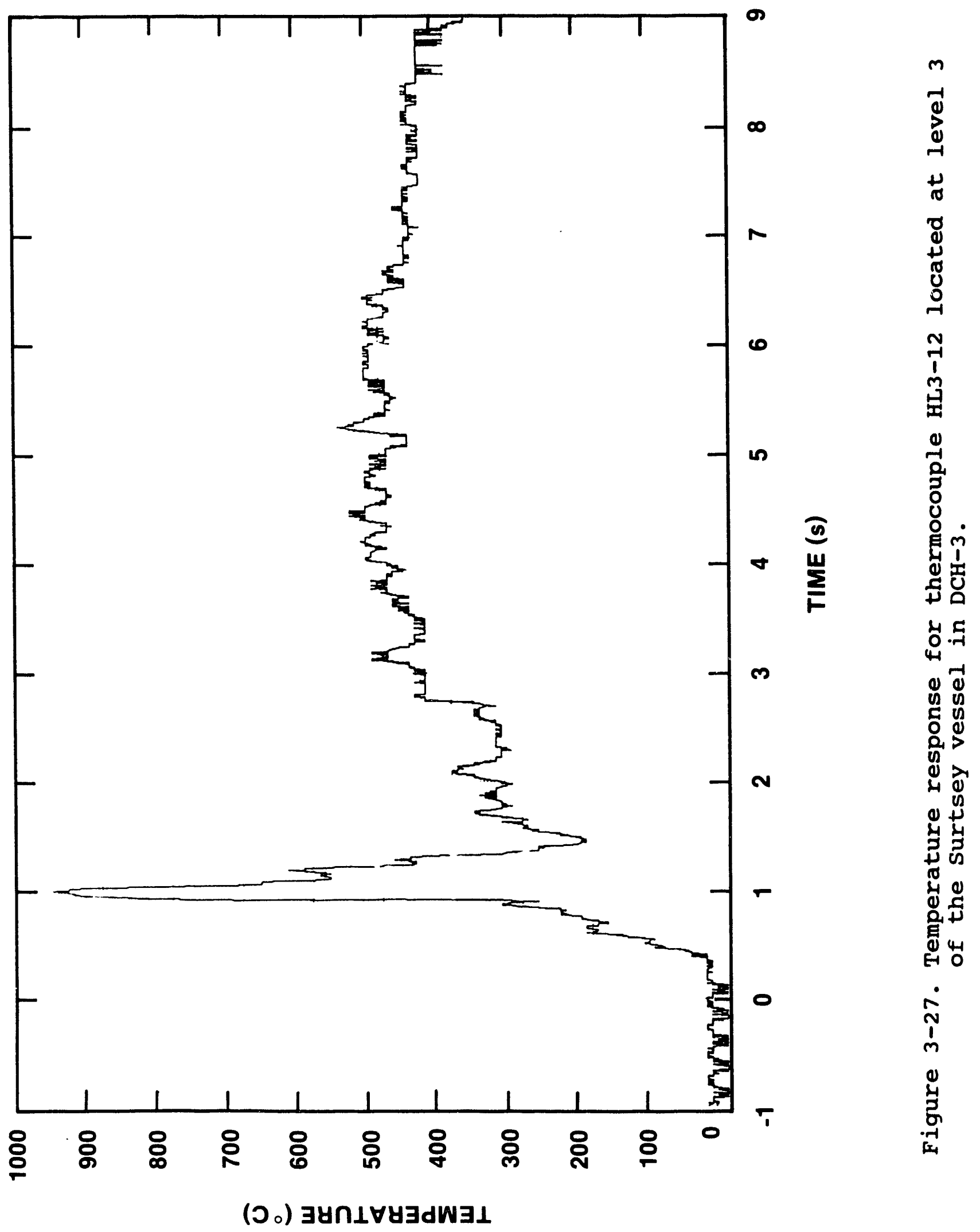




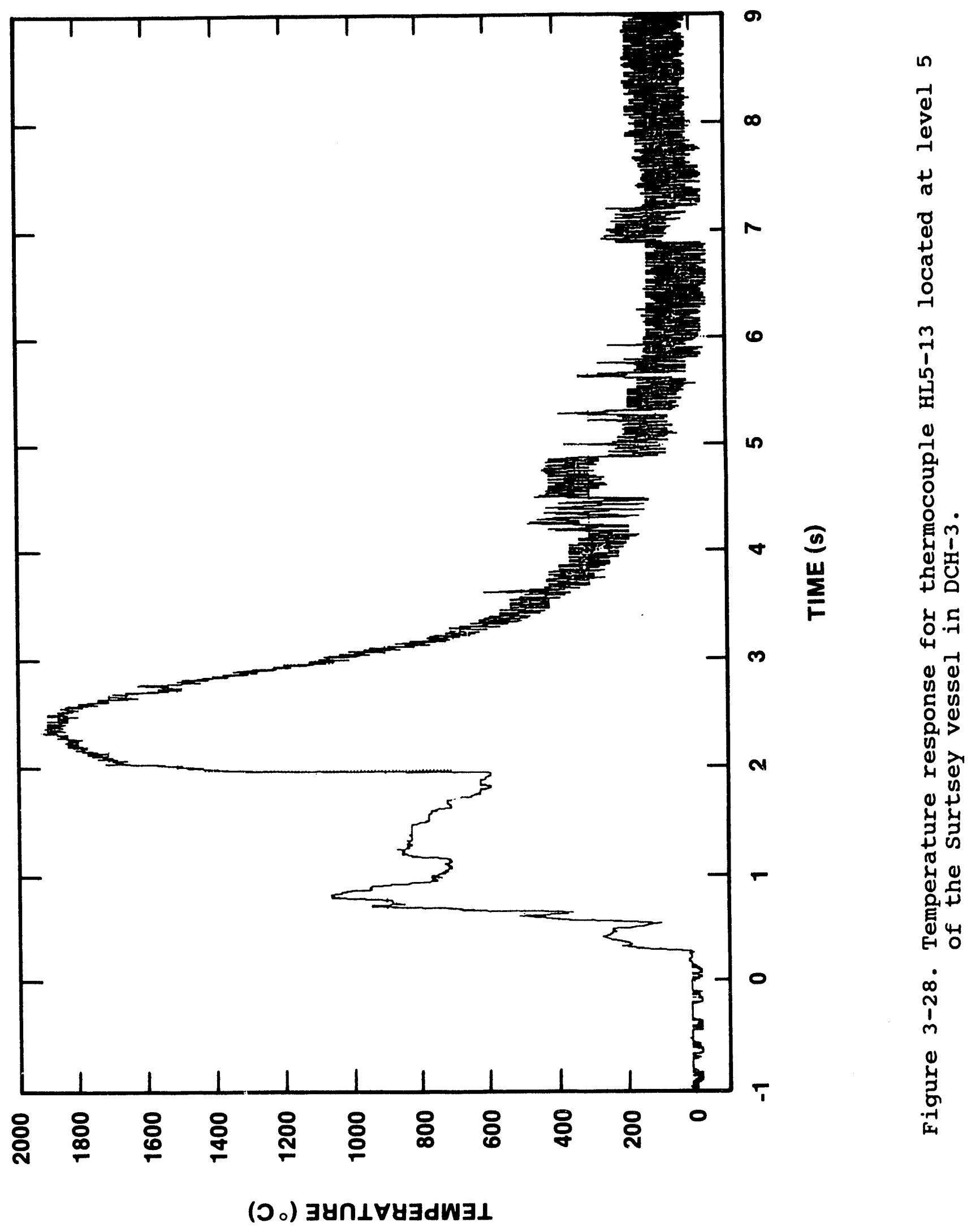




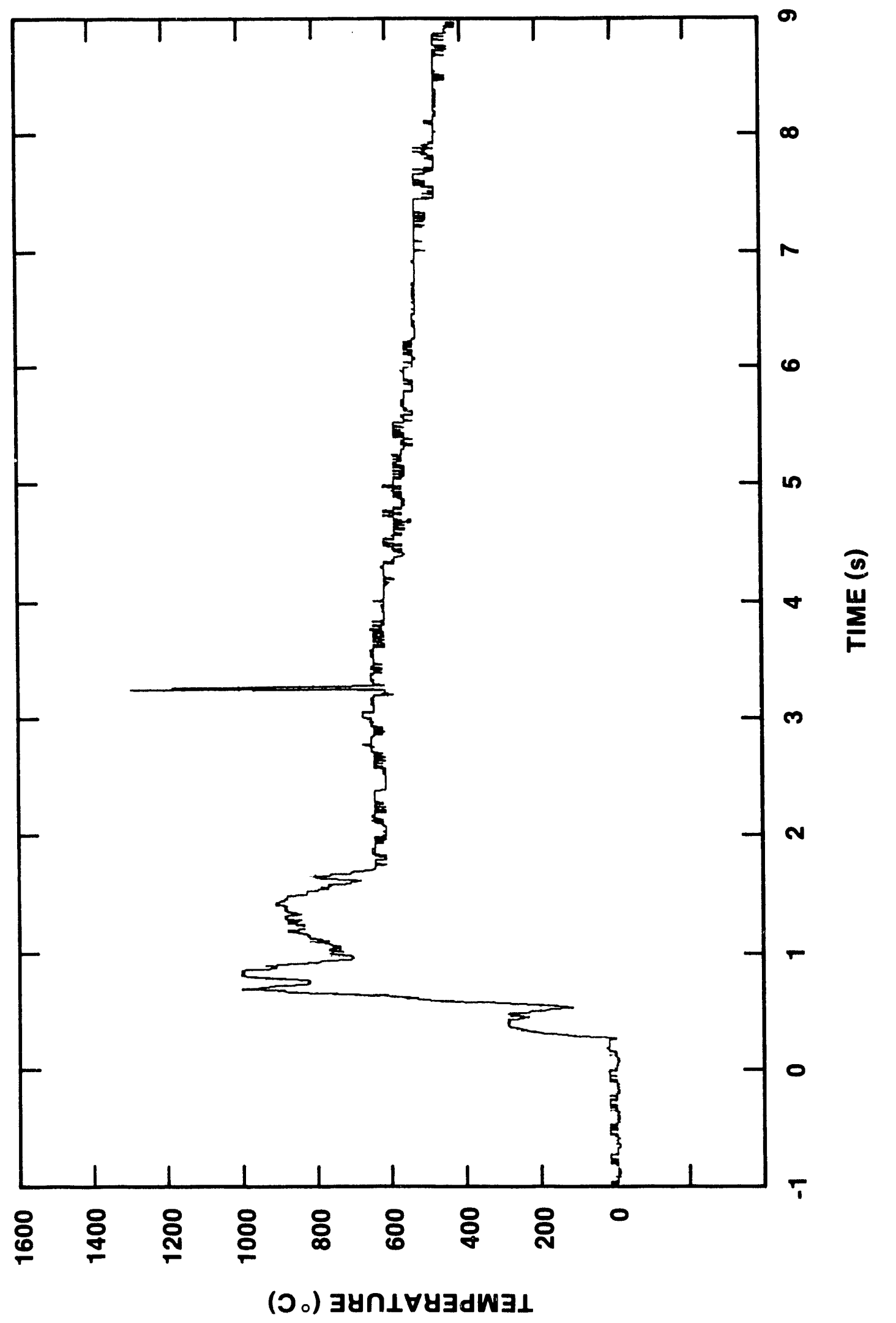

م

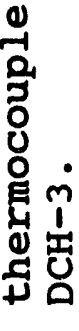

당.

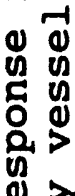

㟧 各

a)

氙

$+$

40

这

है

ต

ì

点 


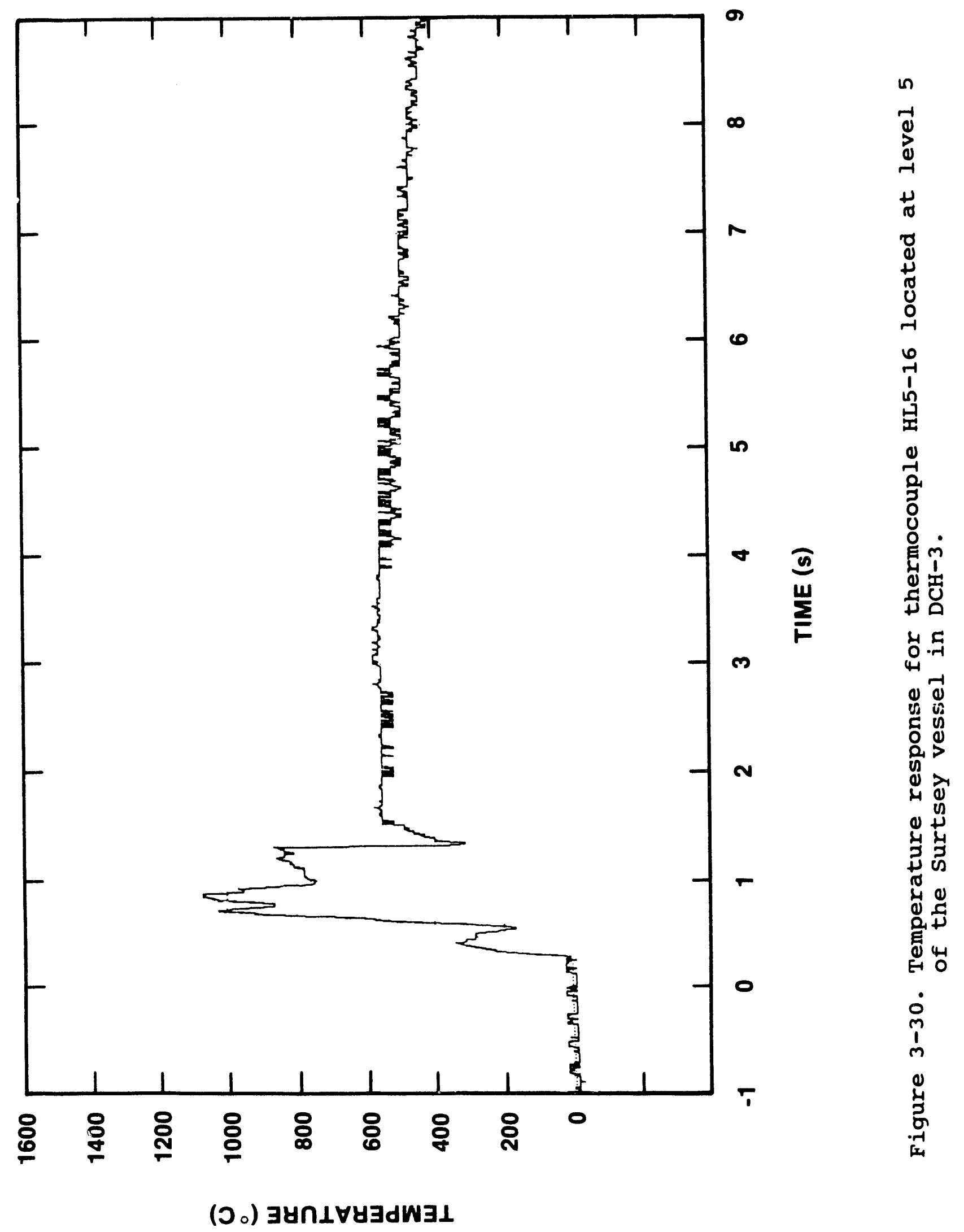




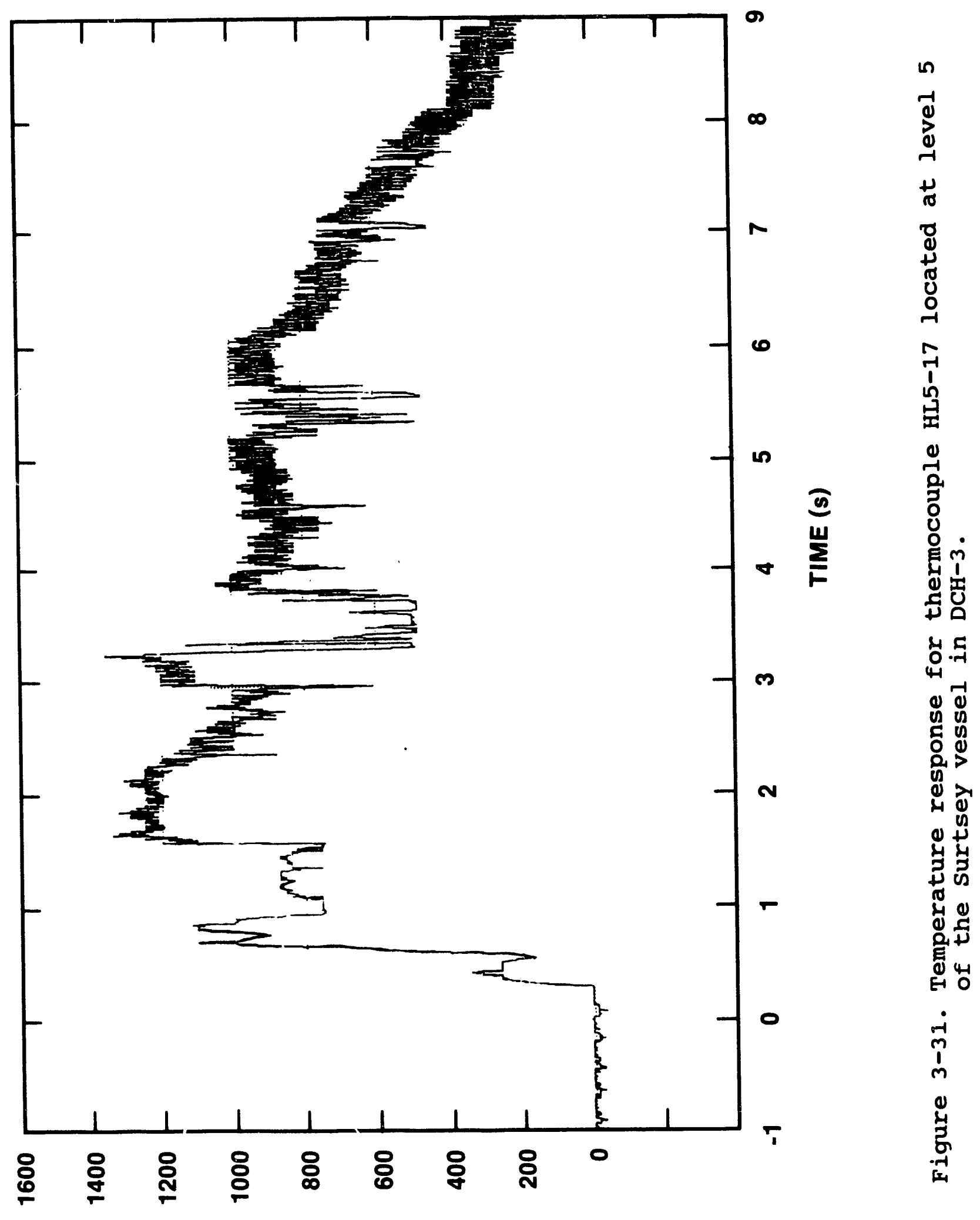

(0.) $\exists y n \perp \forall y \exists d W \exists \perp$ 


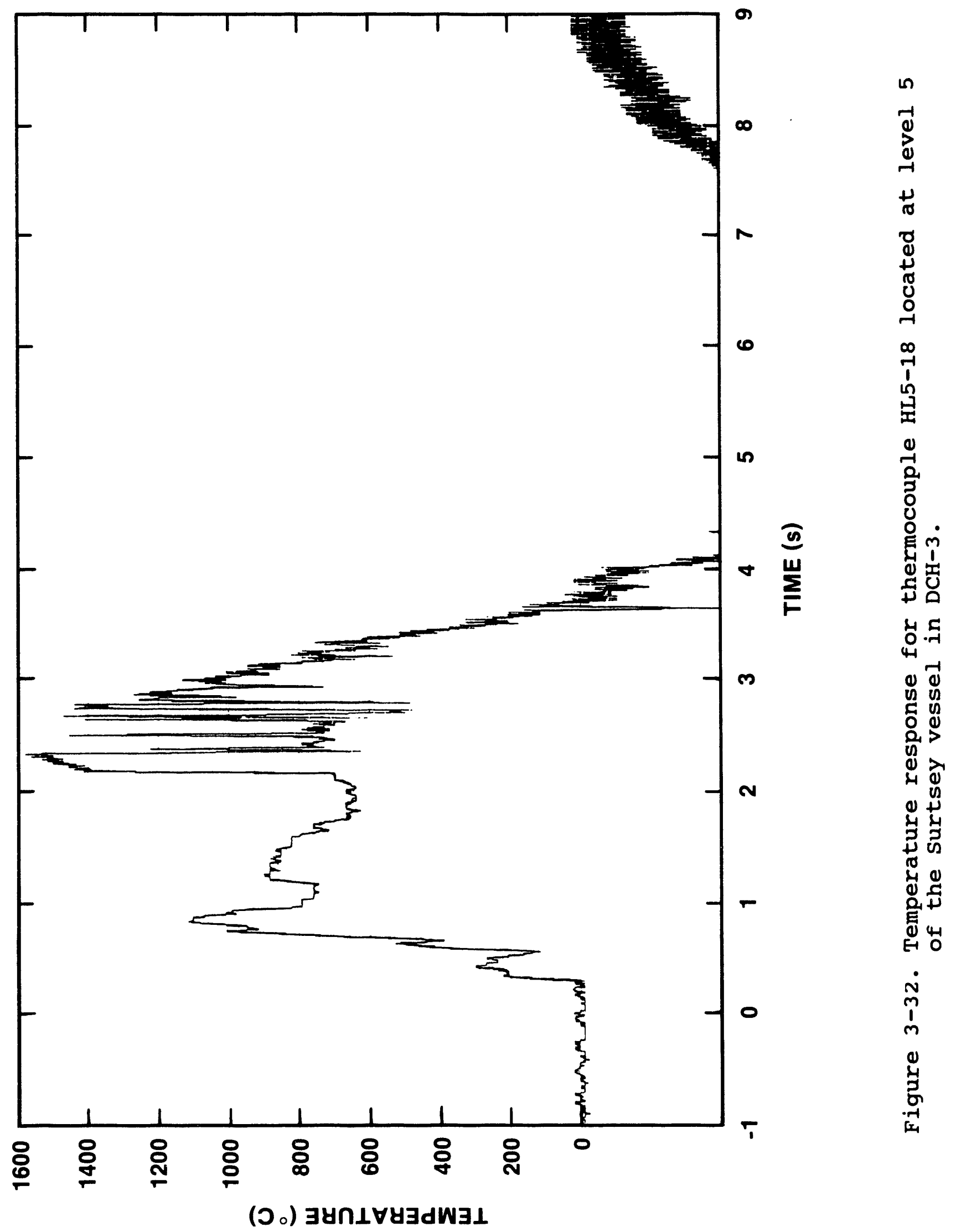




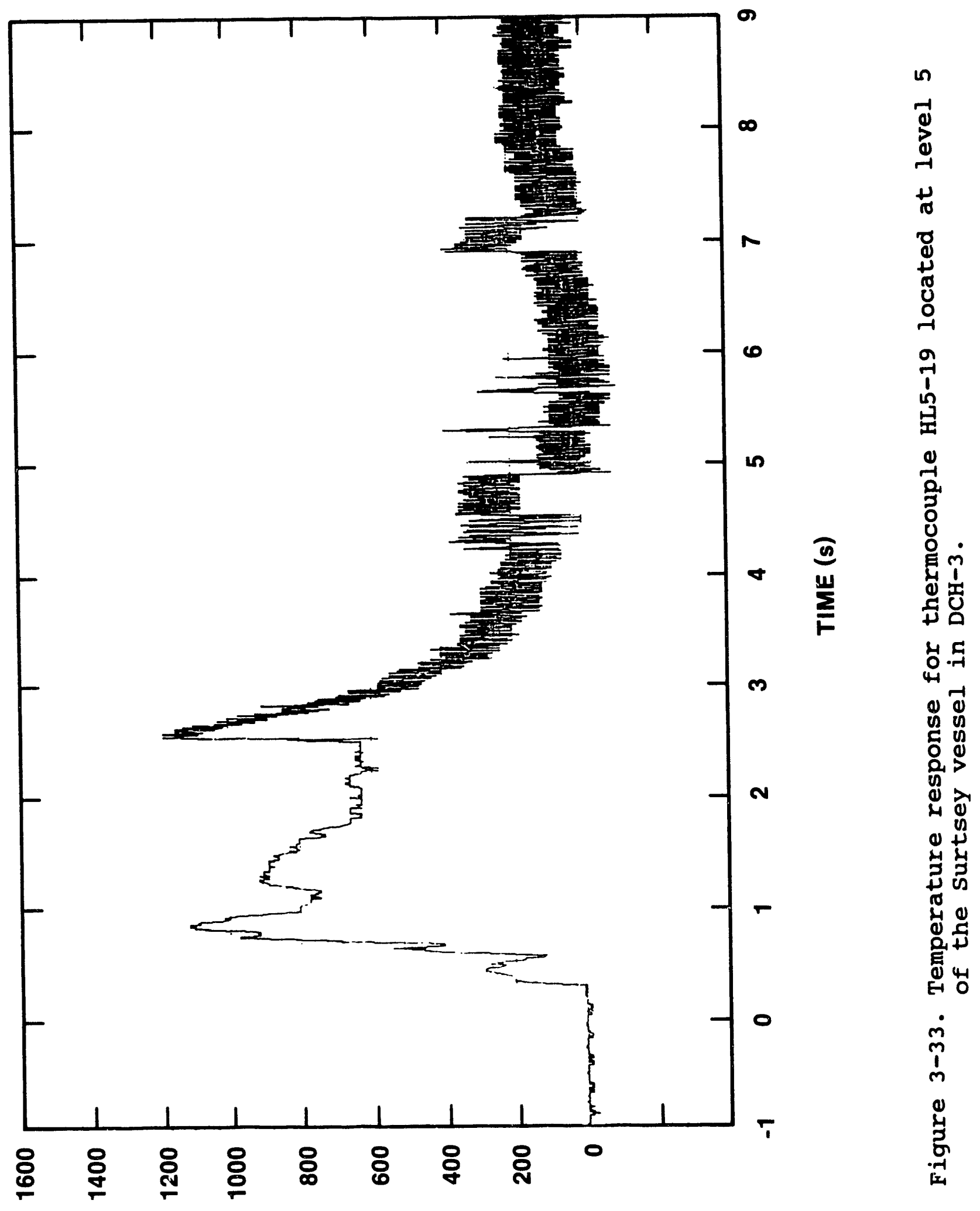

(0) $\exists \forall n \perp \forall \forall \exists d W \exists \perp$ 


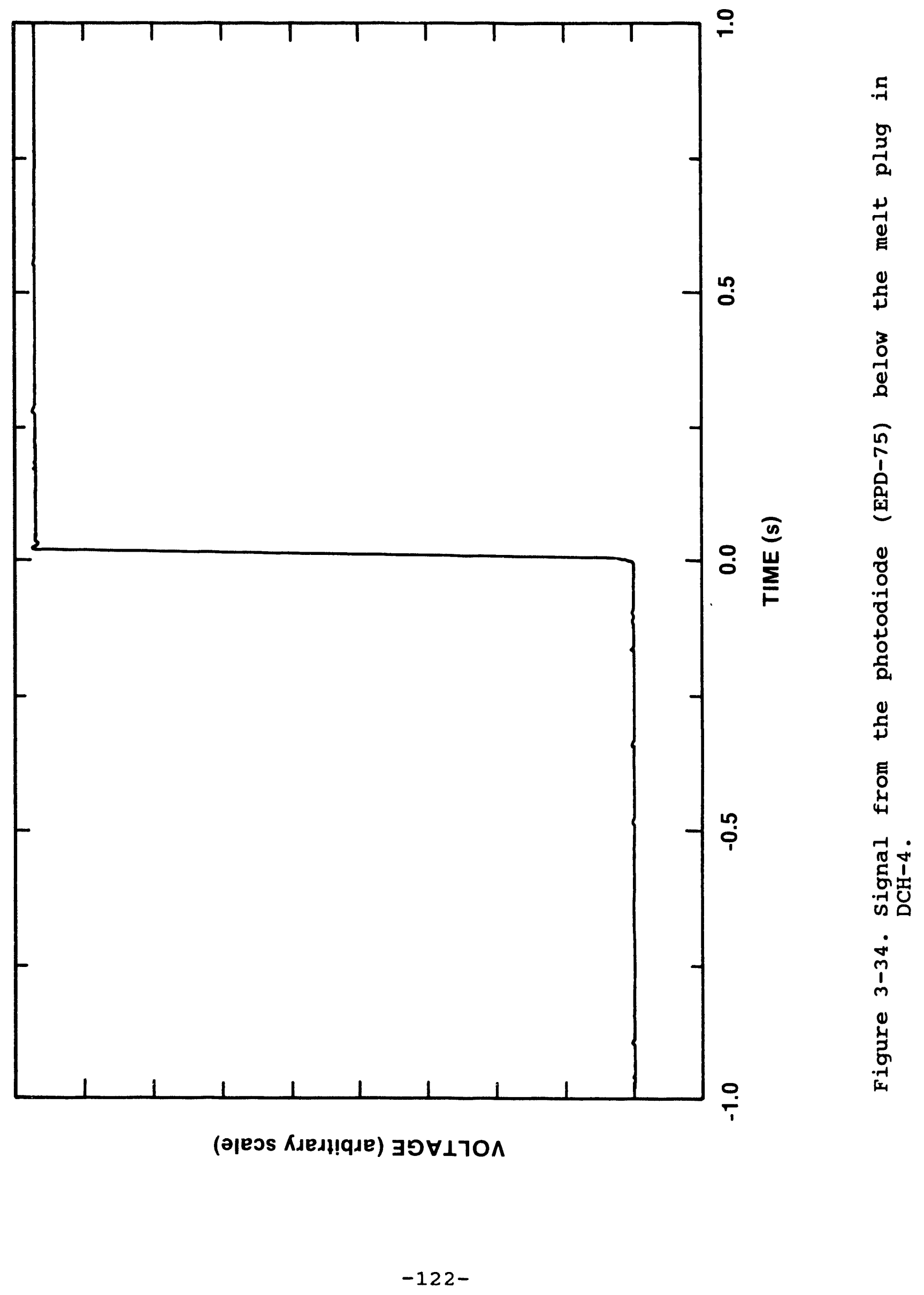




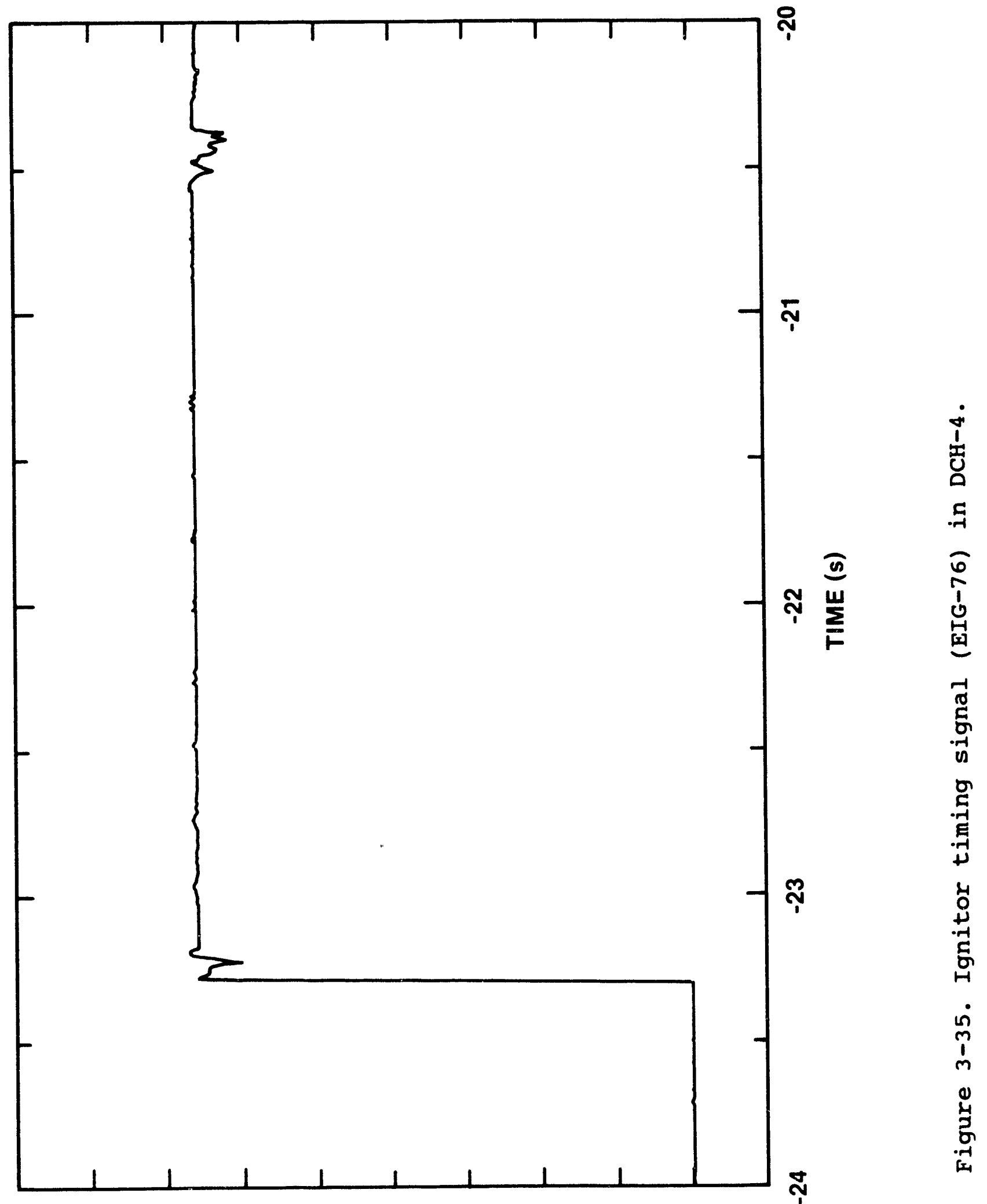

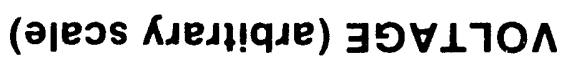


(6!sd) 3 ynss $34 d$

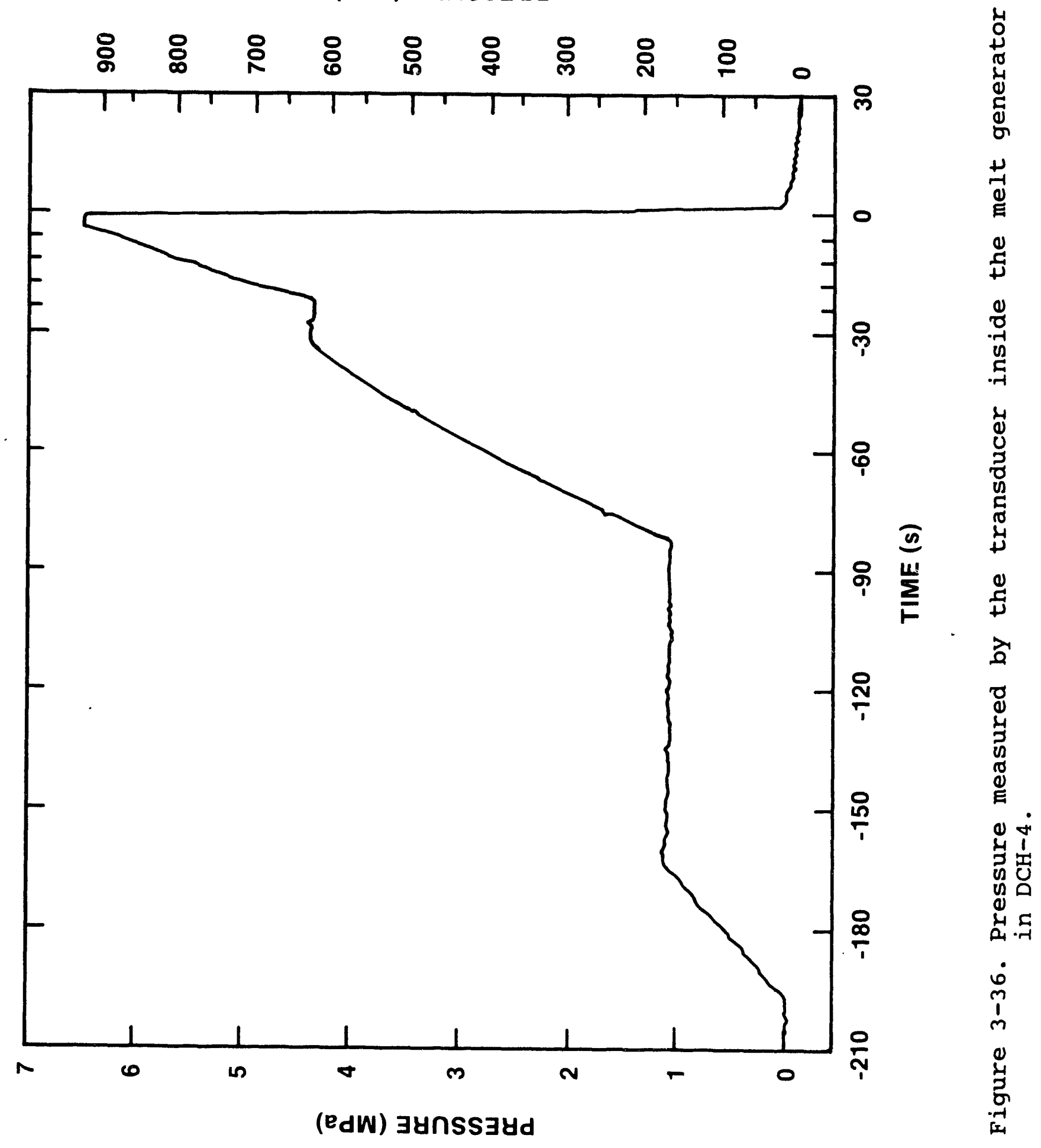




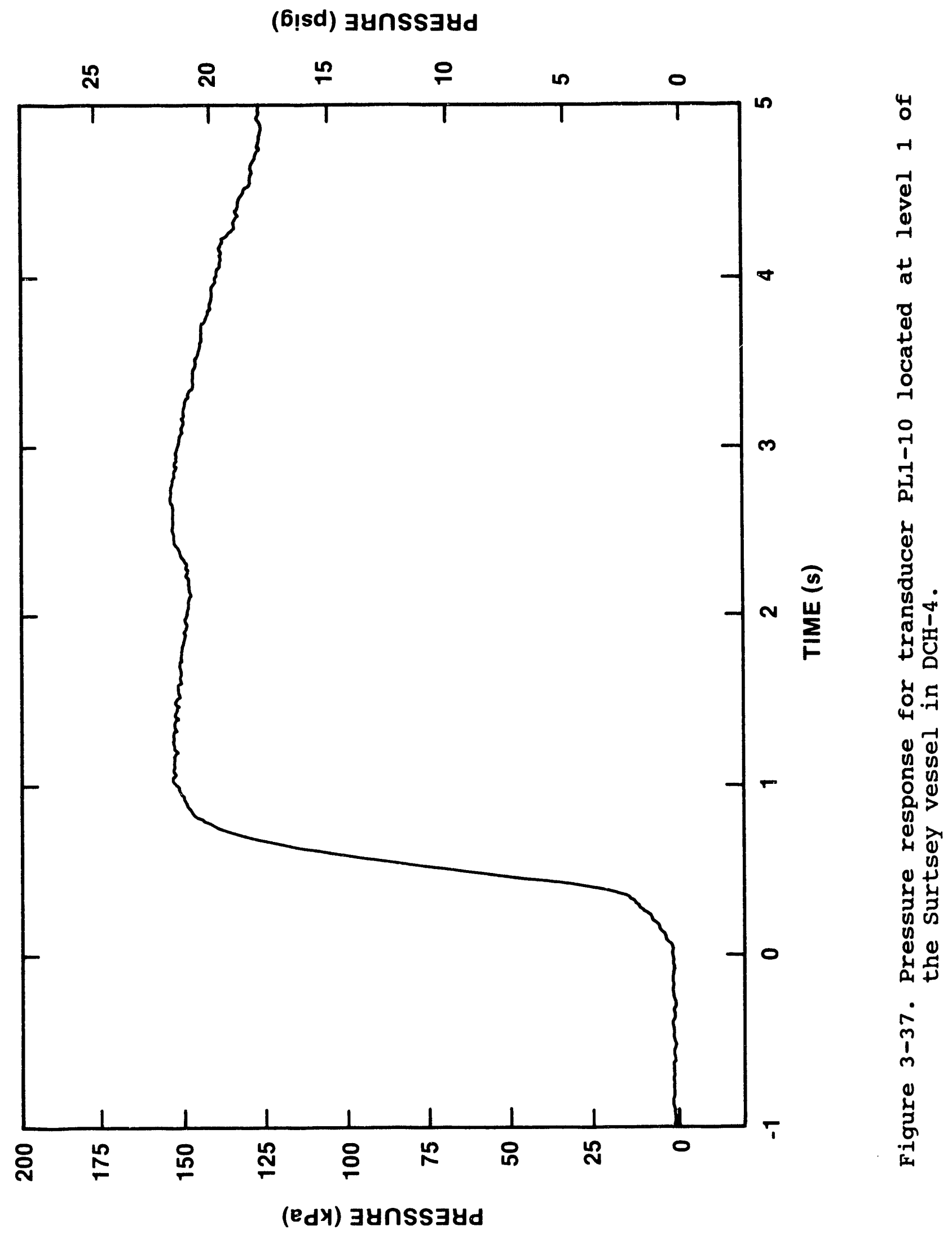


(b!̣sd) $\exists$ ynSS $\exists y d$

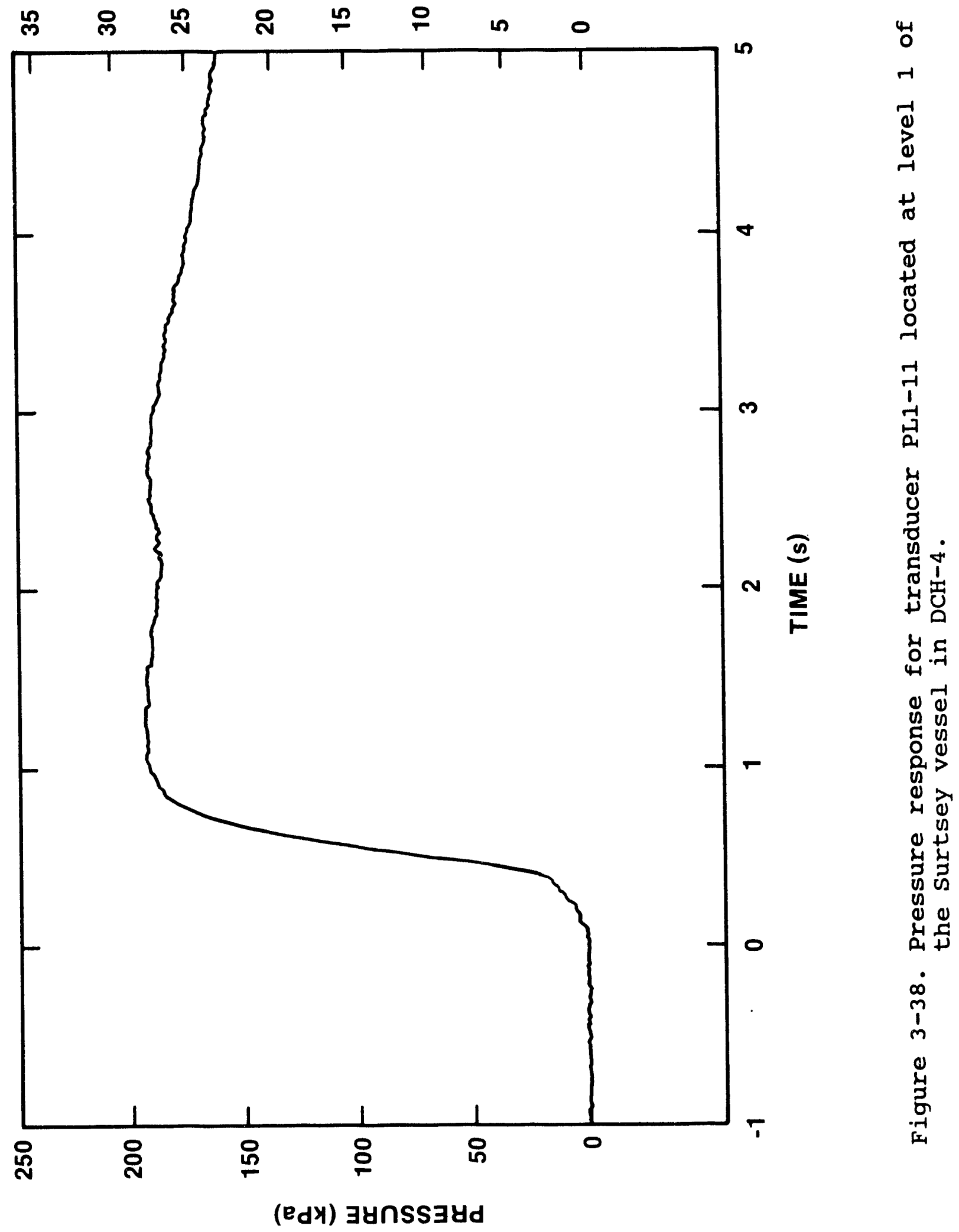


(b!sd) $\exists$ ynss $\exists y d$

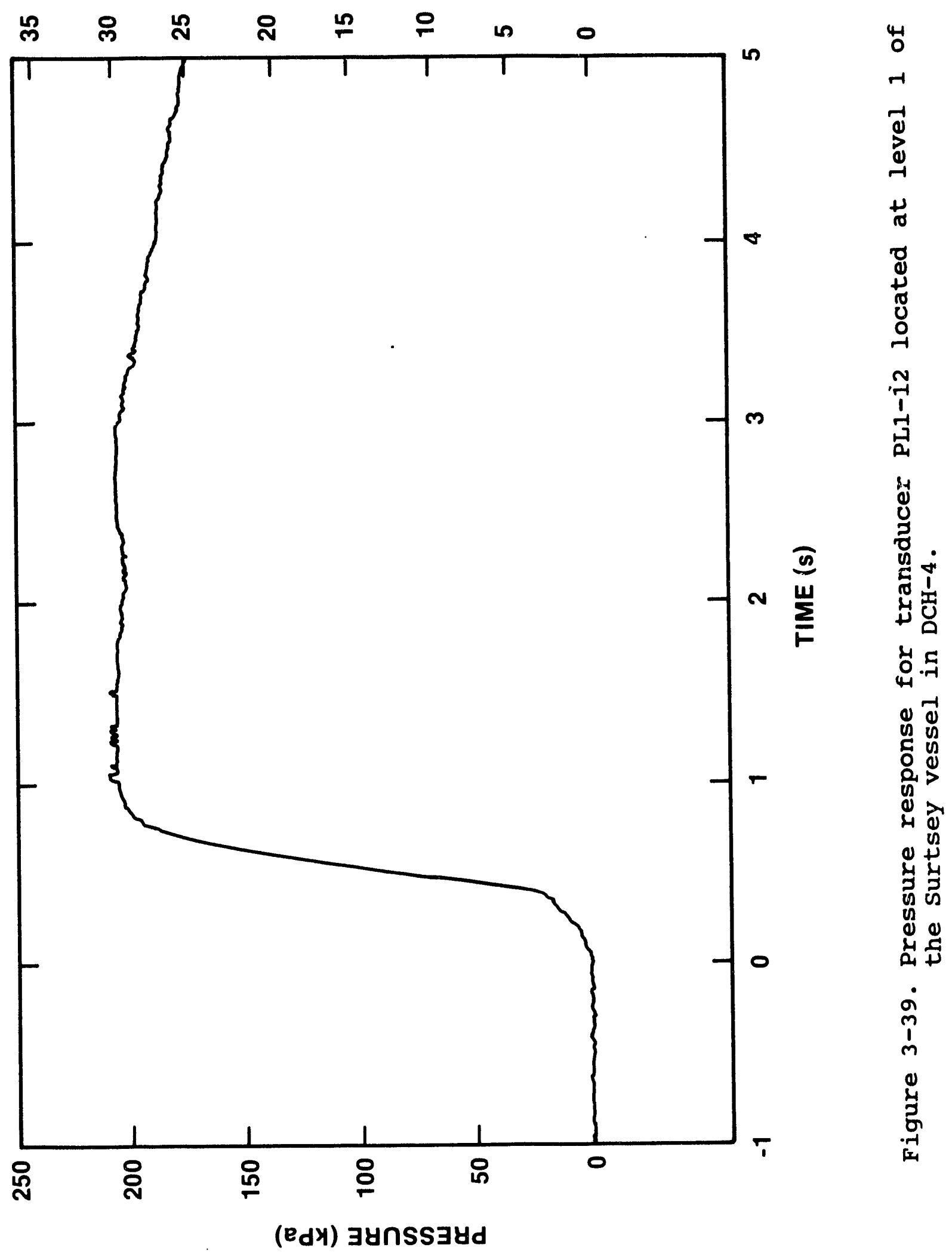


(6!sd) $\exists y n s s \exists y d$

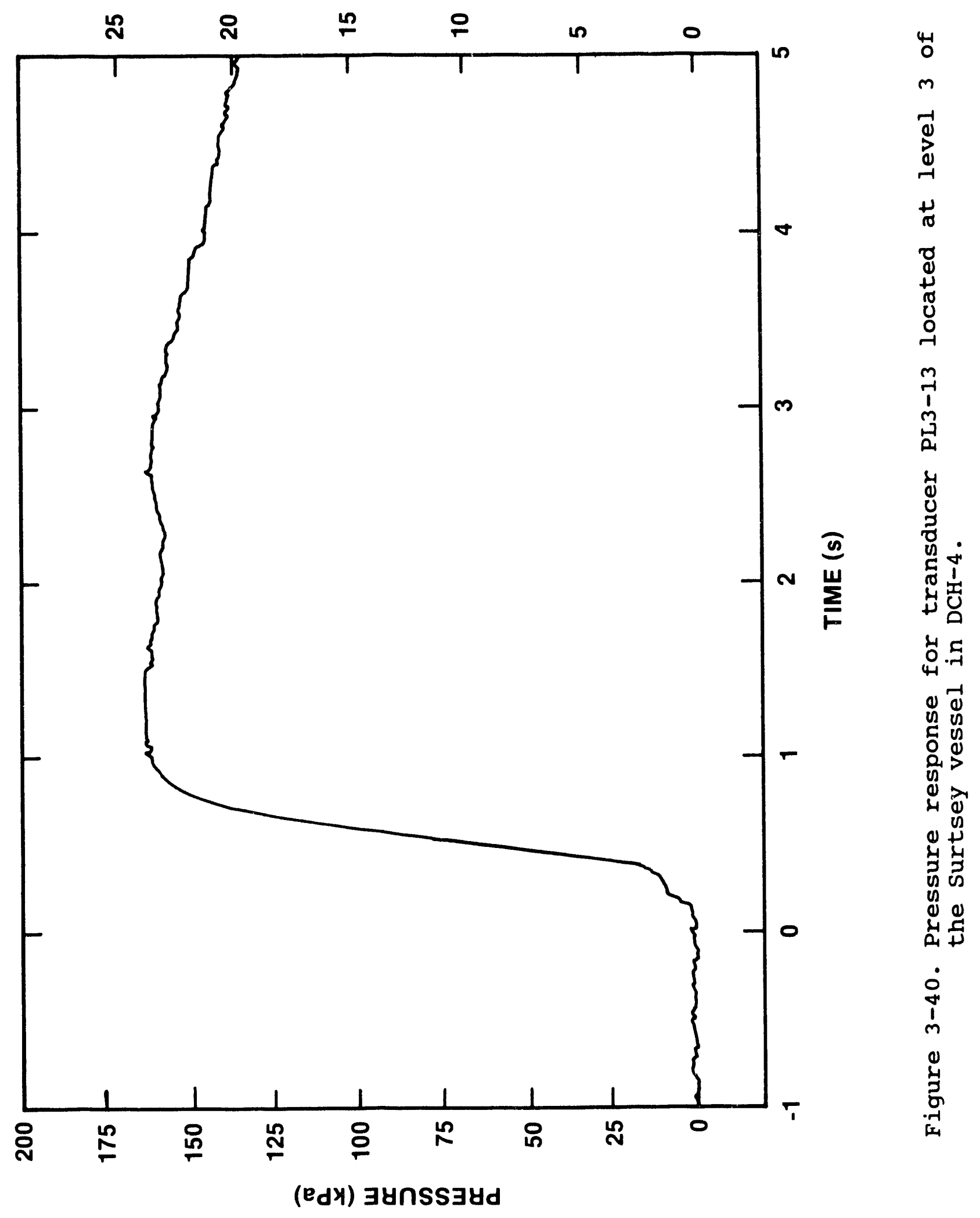


(6!sd) $\exists y n s s \exists y d$
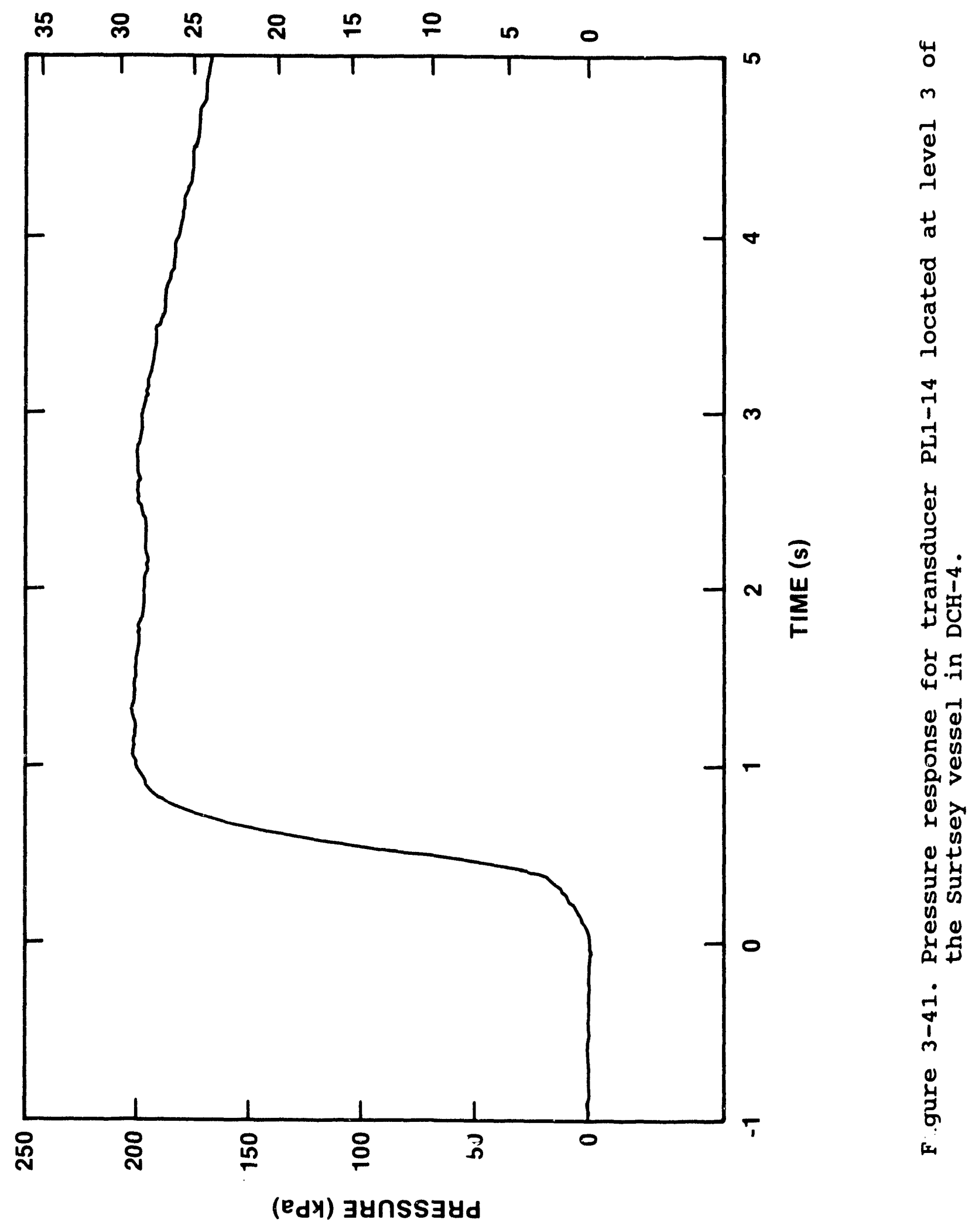
(6!sd) $\exists y n s s \exists y d$

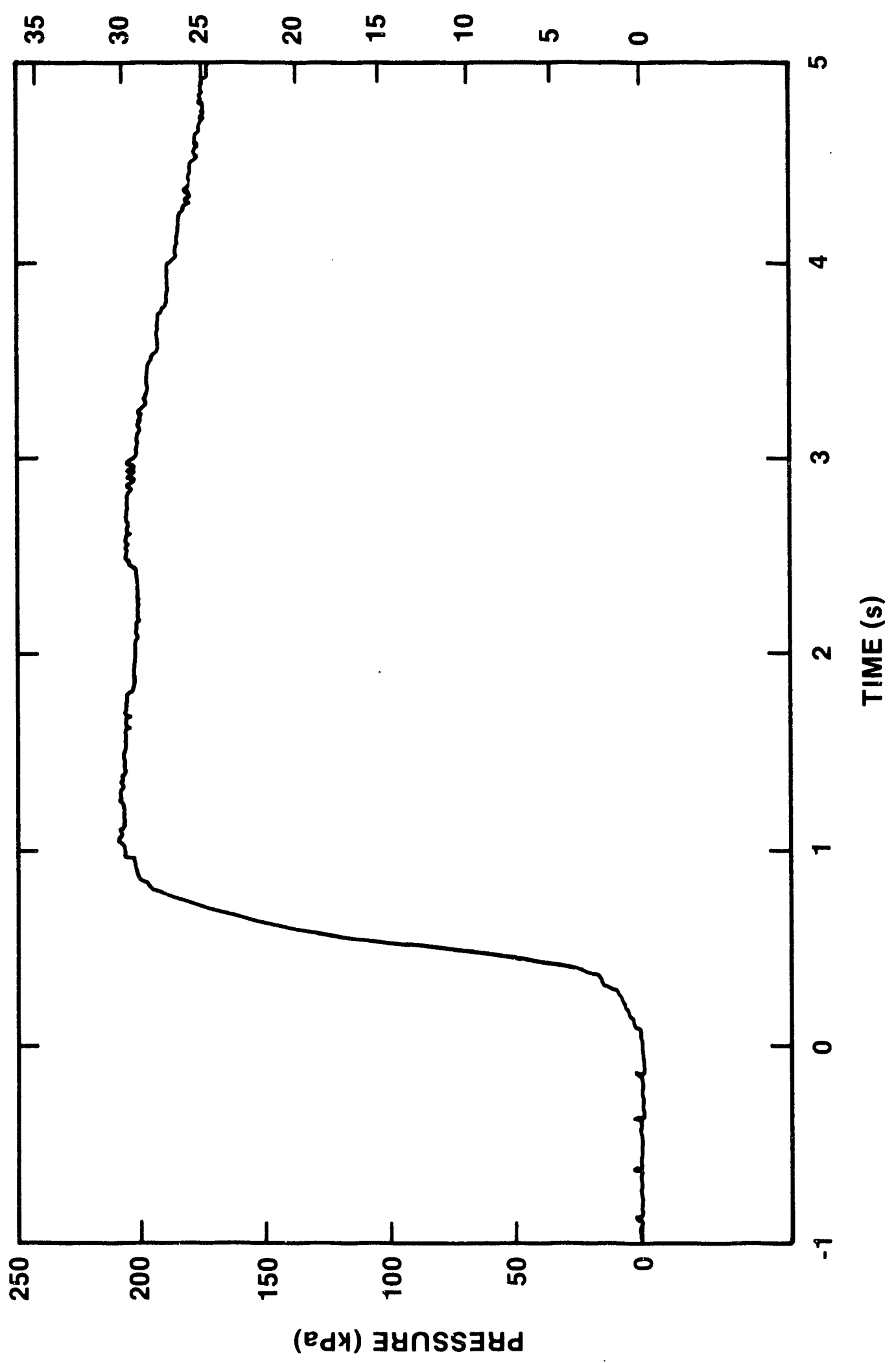

㟧

$m$

$\sum_{0}^{-1}$

$\stackrel{+\infty}{\infty}$

8

$+$

0

م્1

4

ชั

o

告

$\mapsto 0$

유.

0

ยู ข

a

d)

\& 0

o

늘

ข

ป

넘 自

i

in

崩 
(6!sd) $\exists y n s s \exists y d$

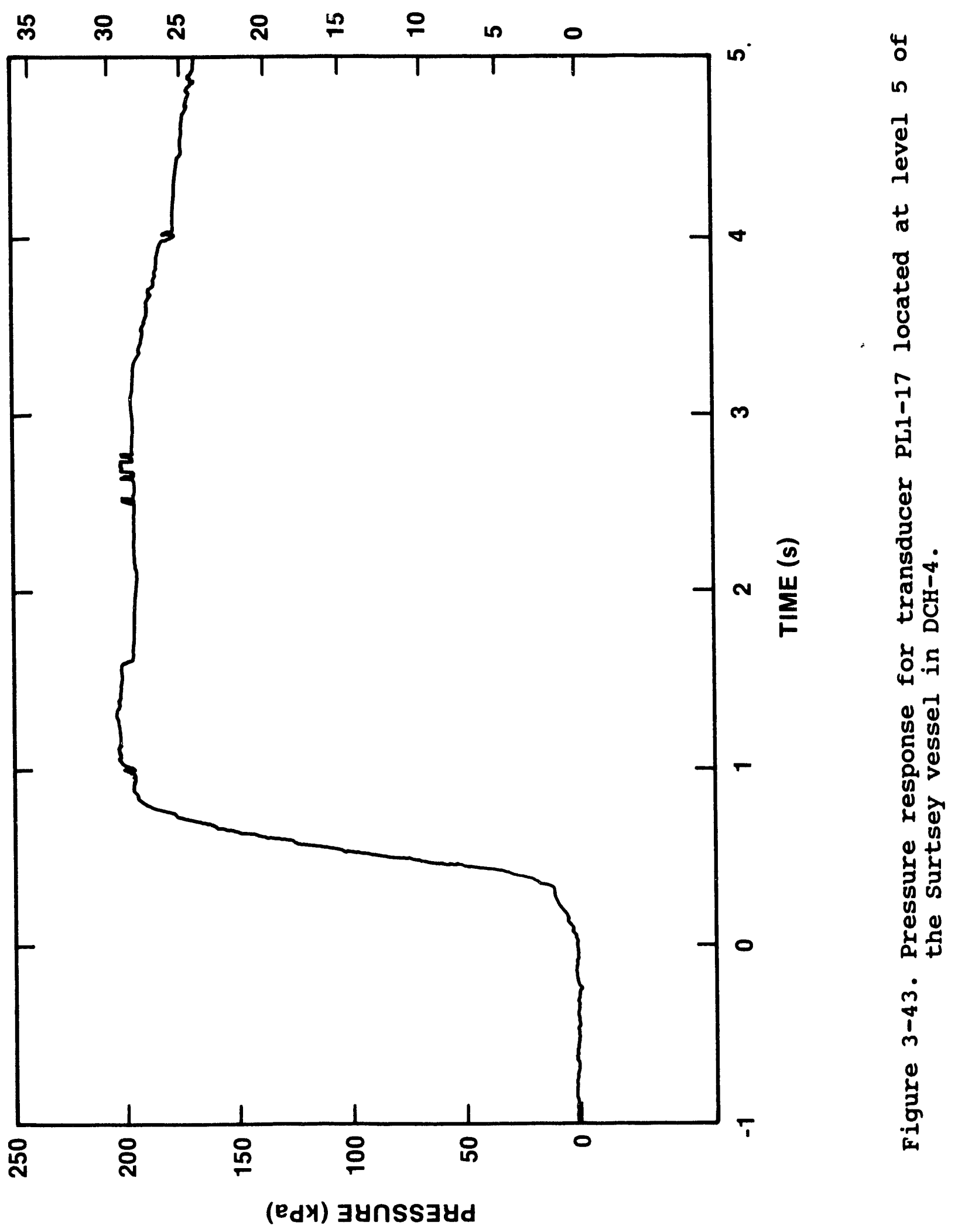


(b!sd) $\exists$ ynSS $\exists y d$

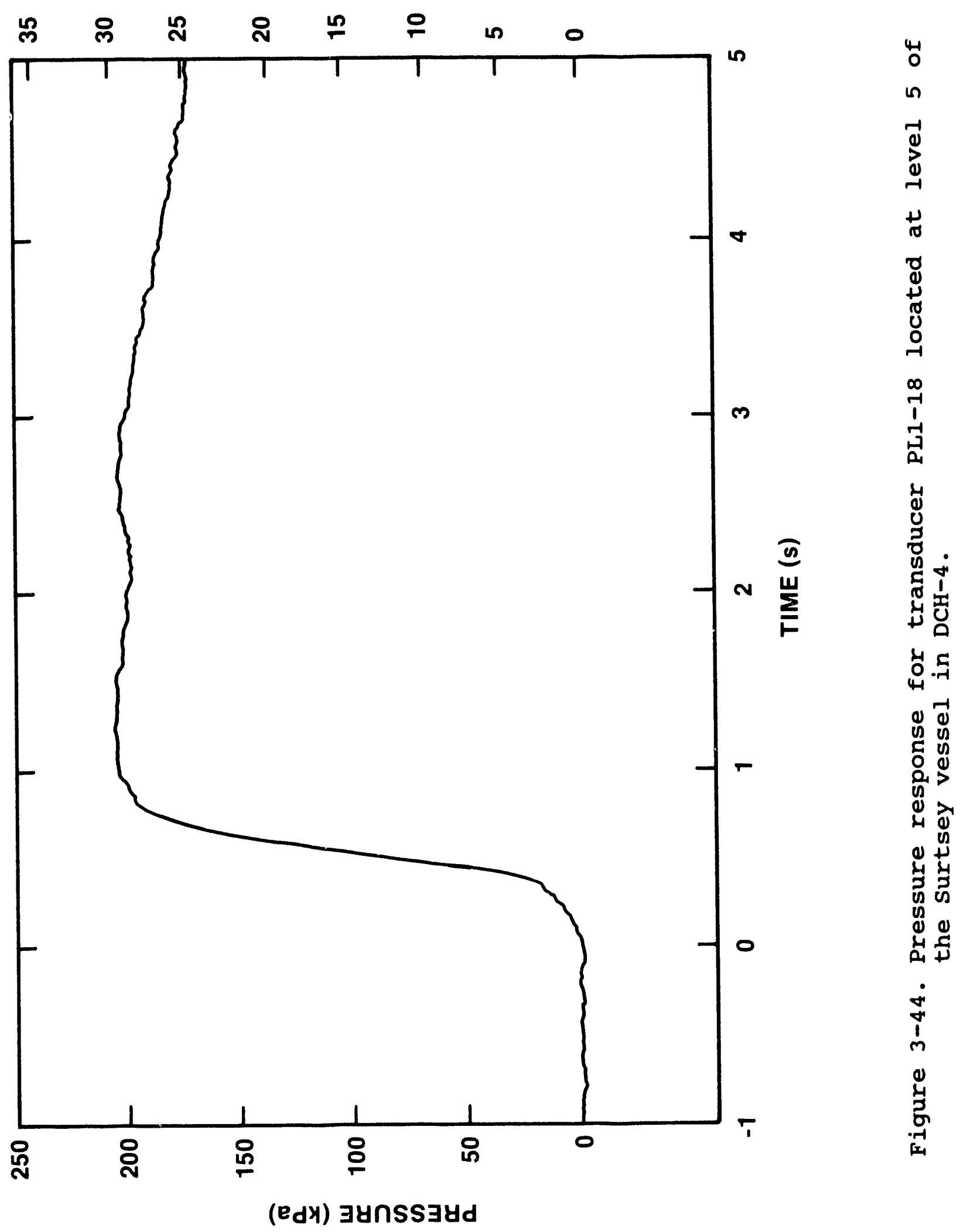




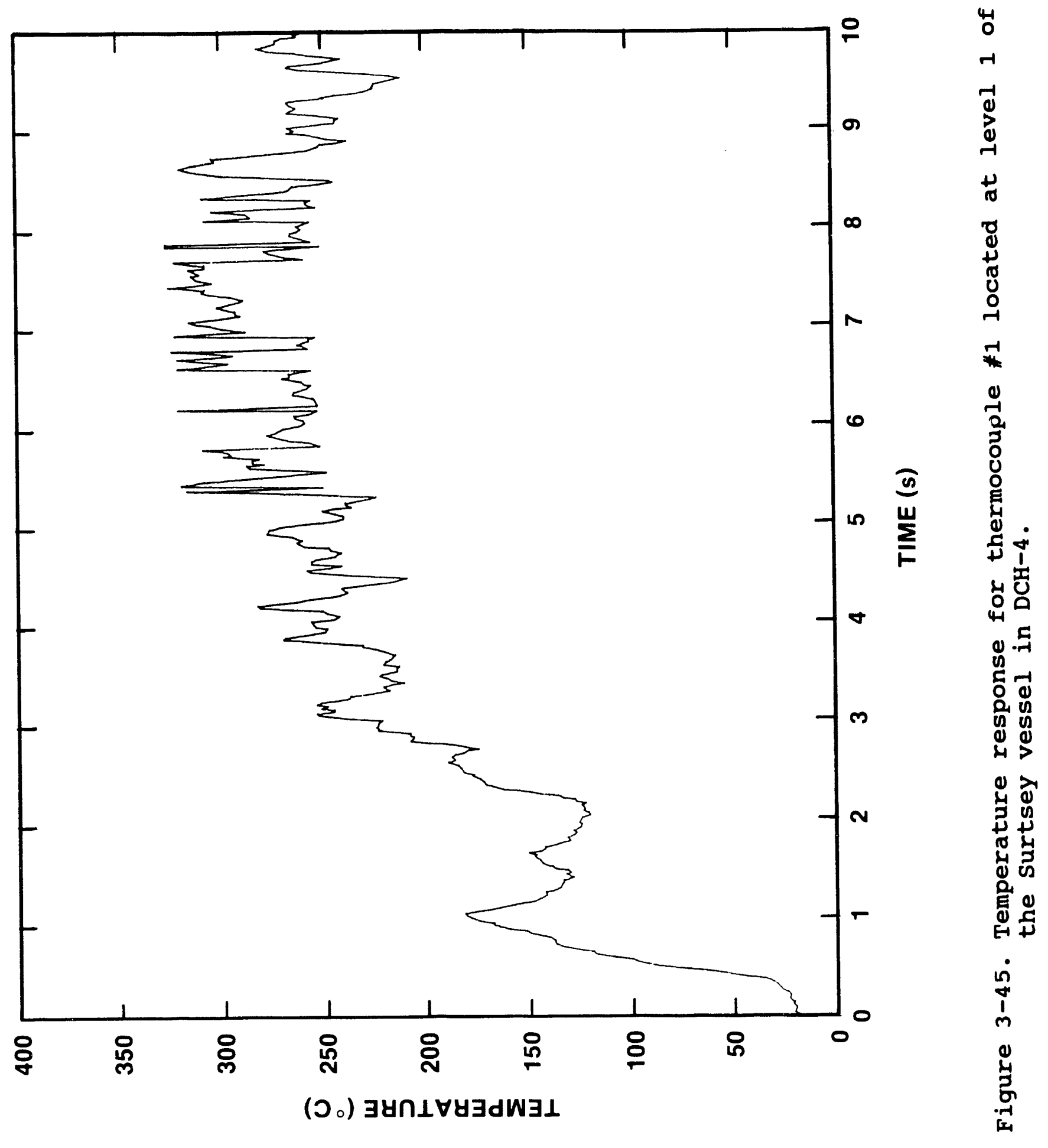




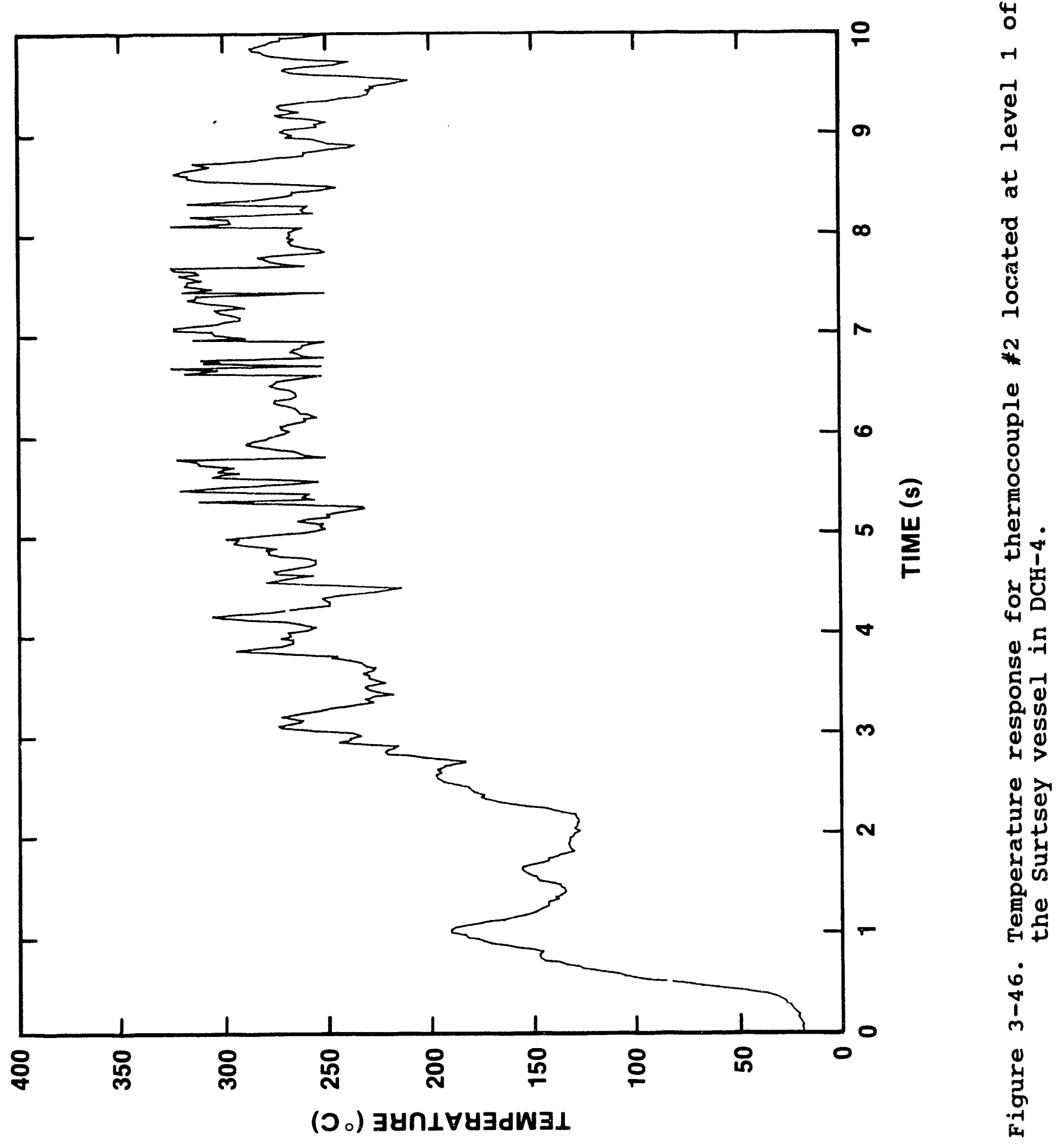




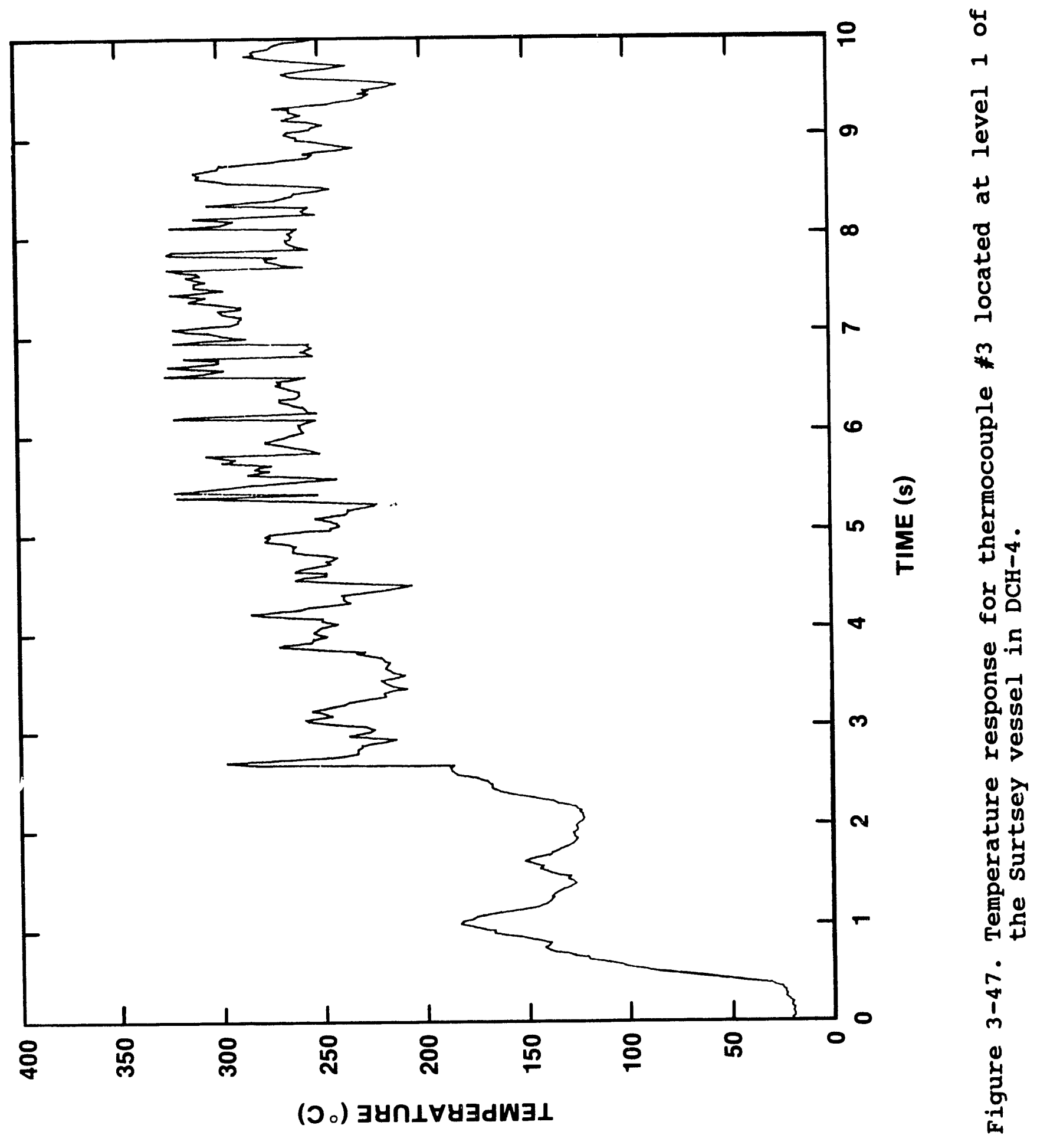




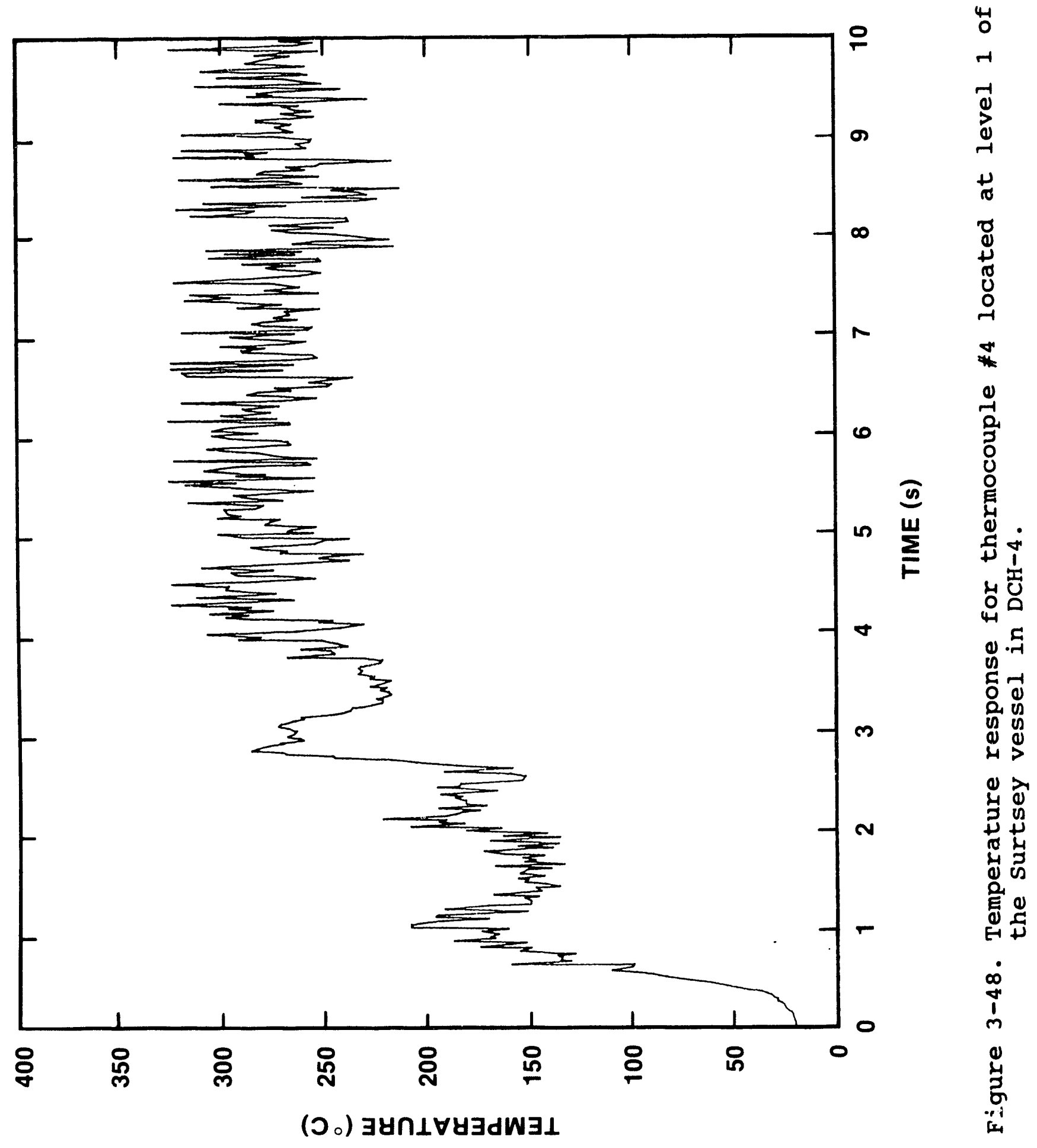




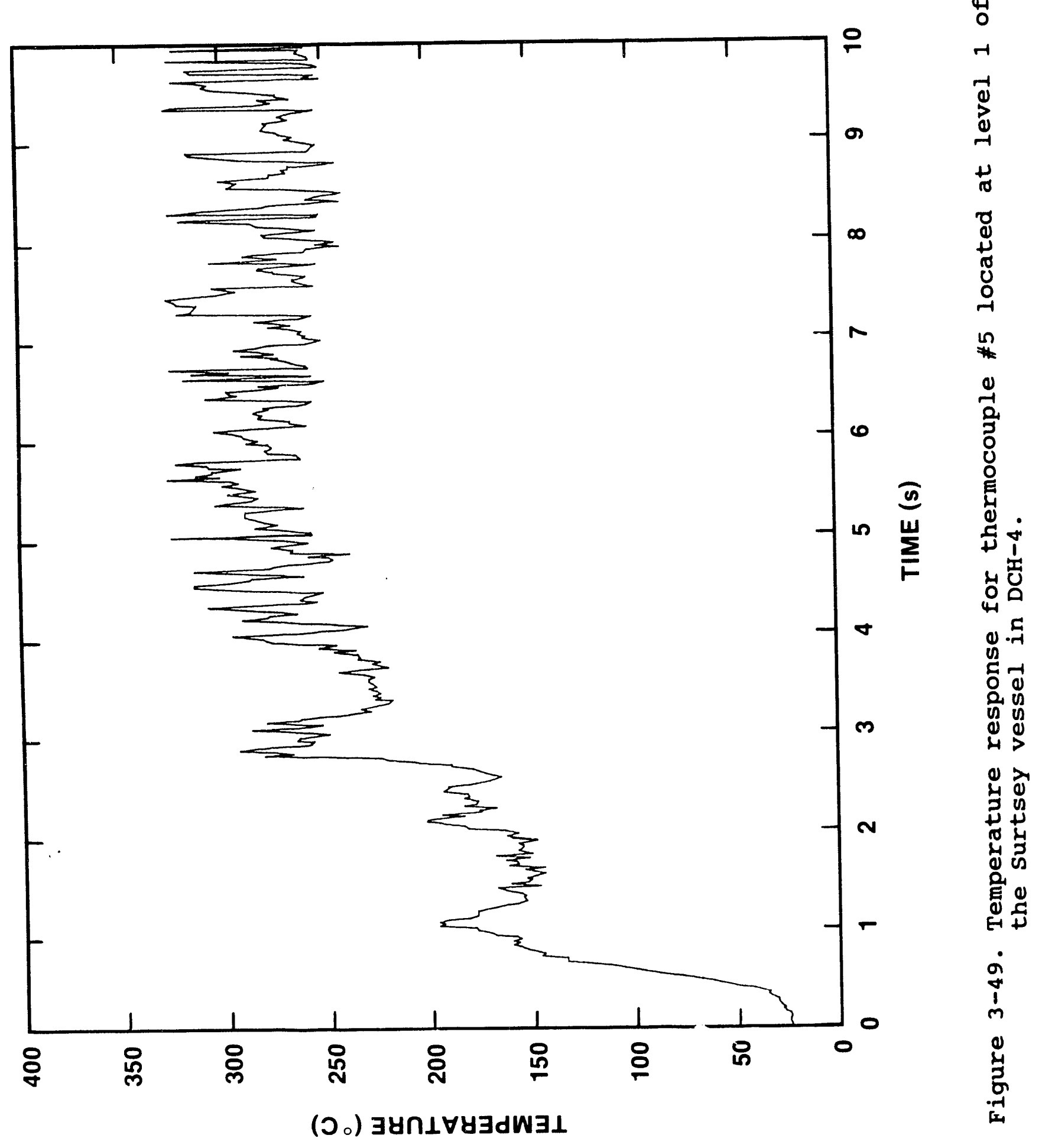




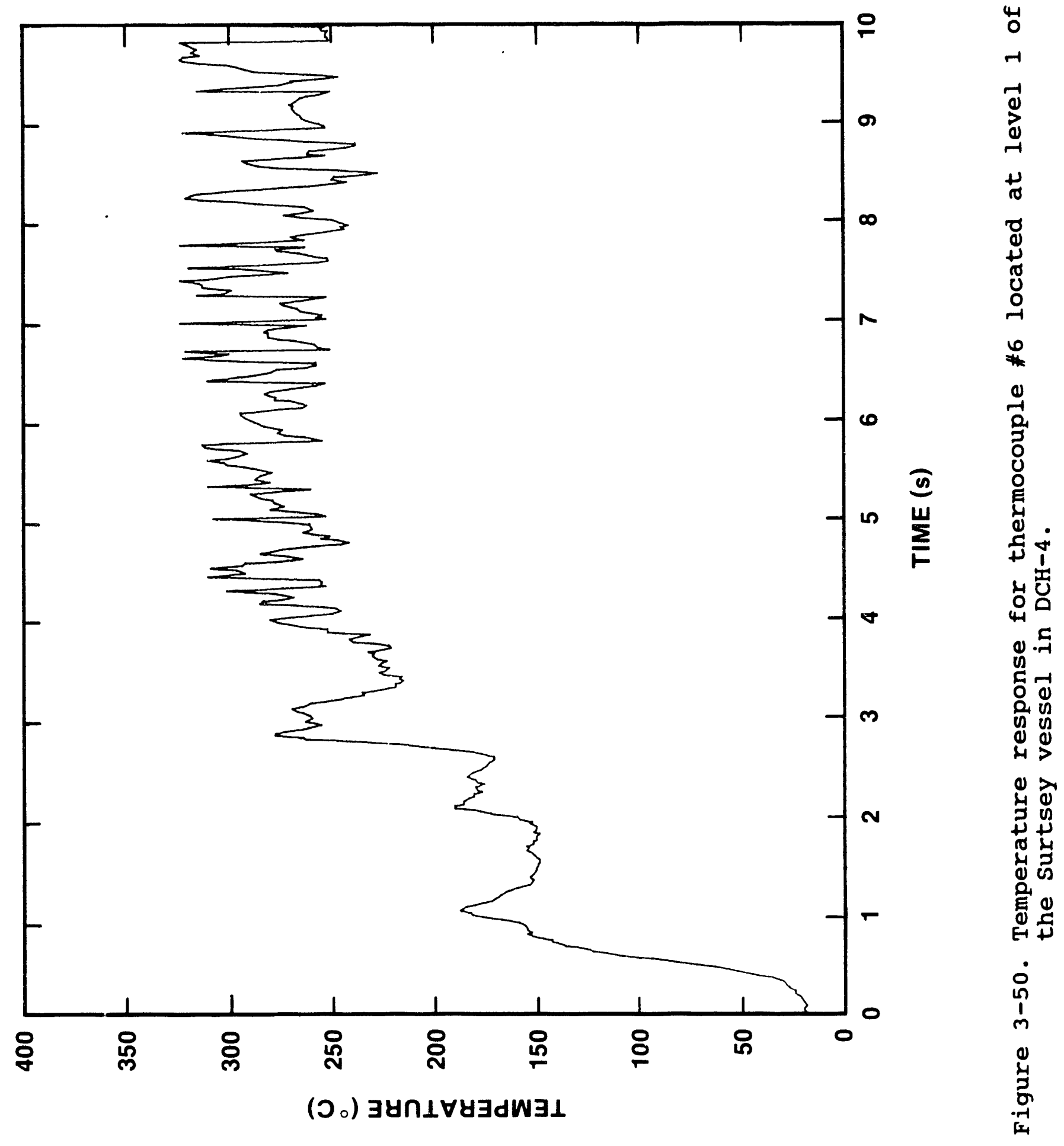




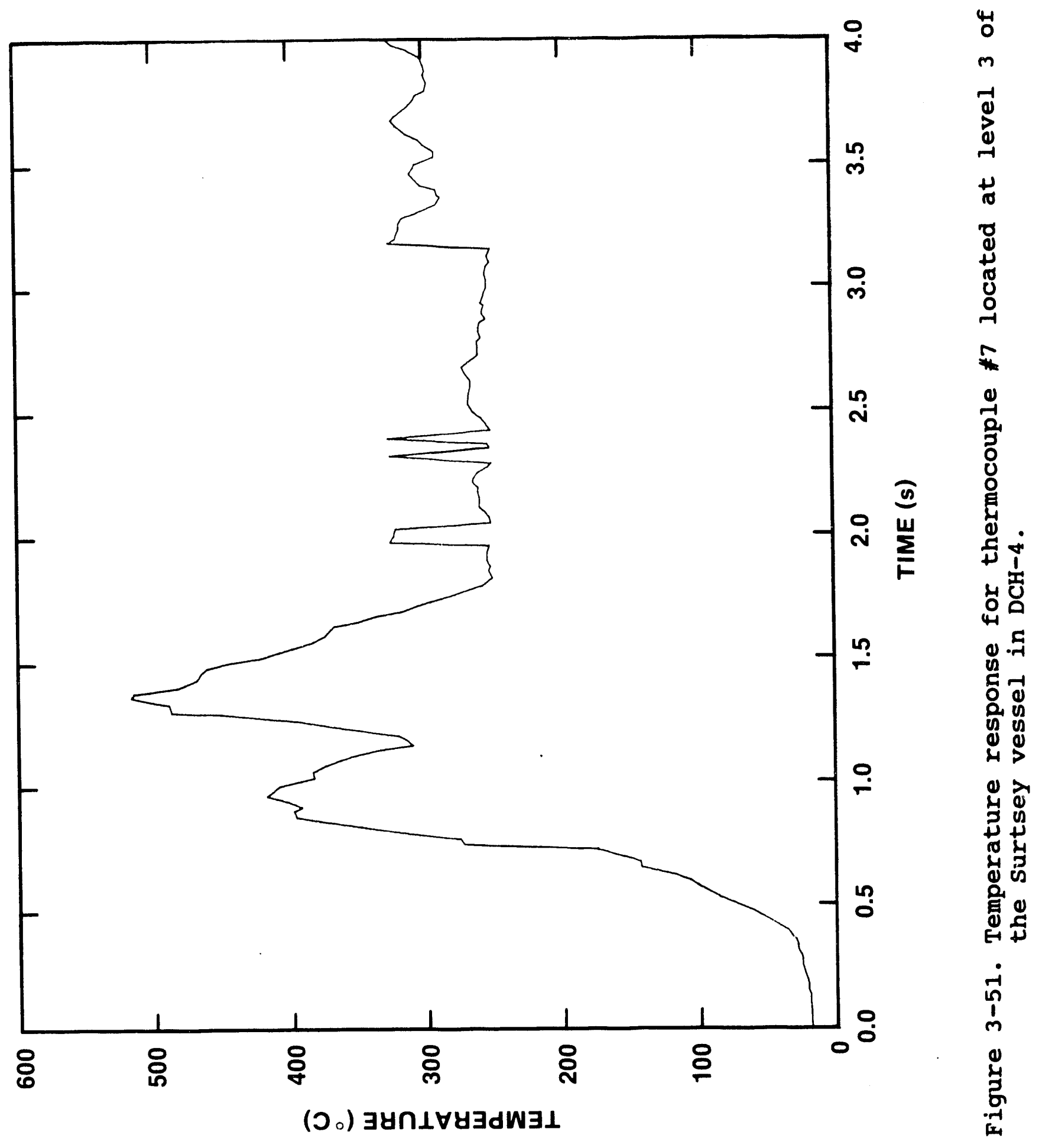




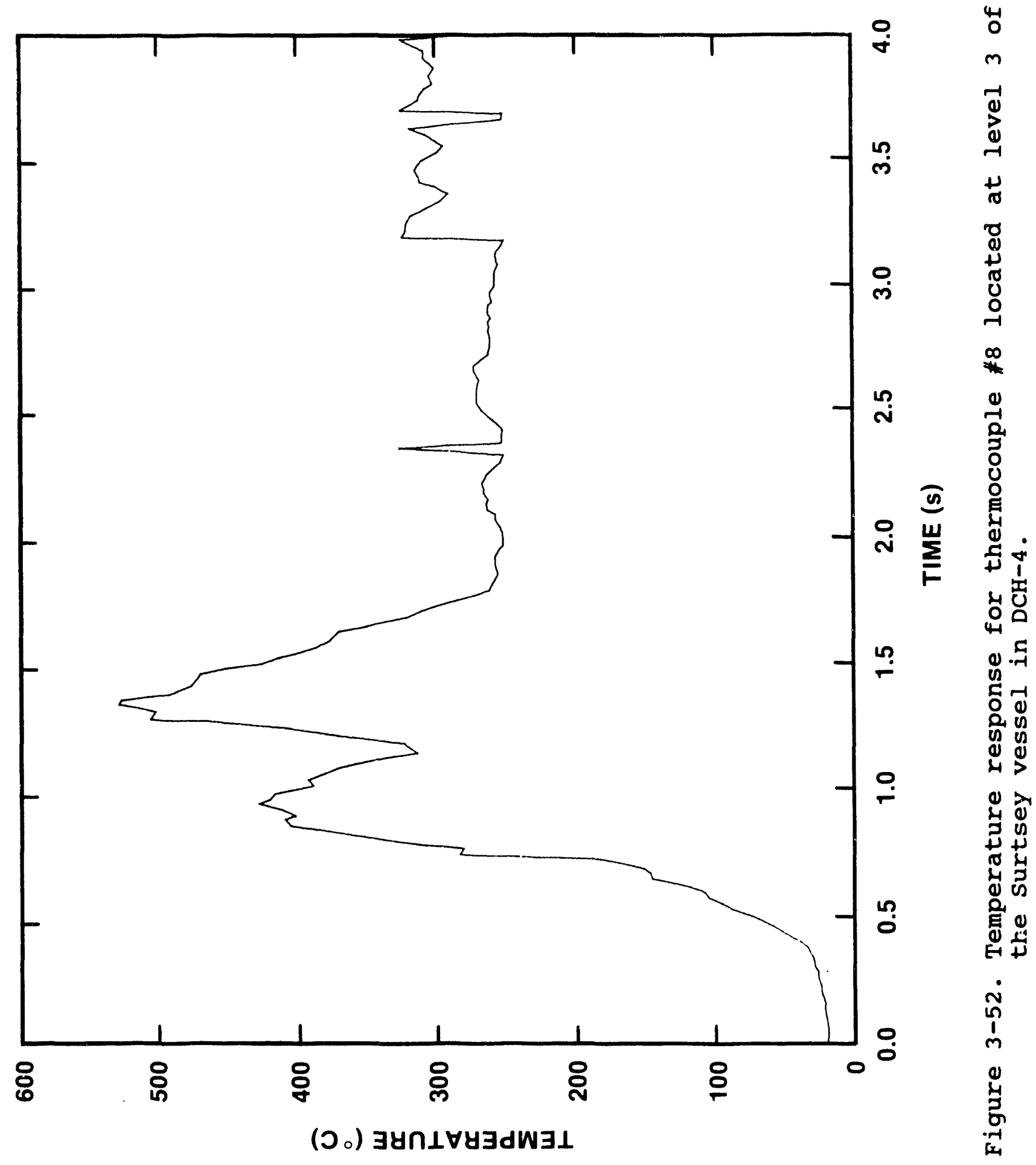




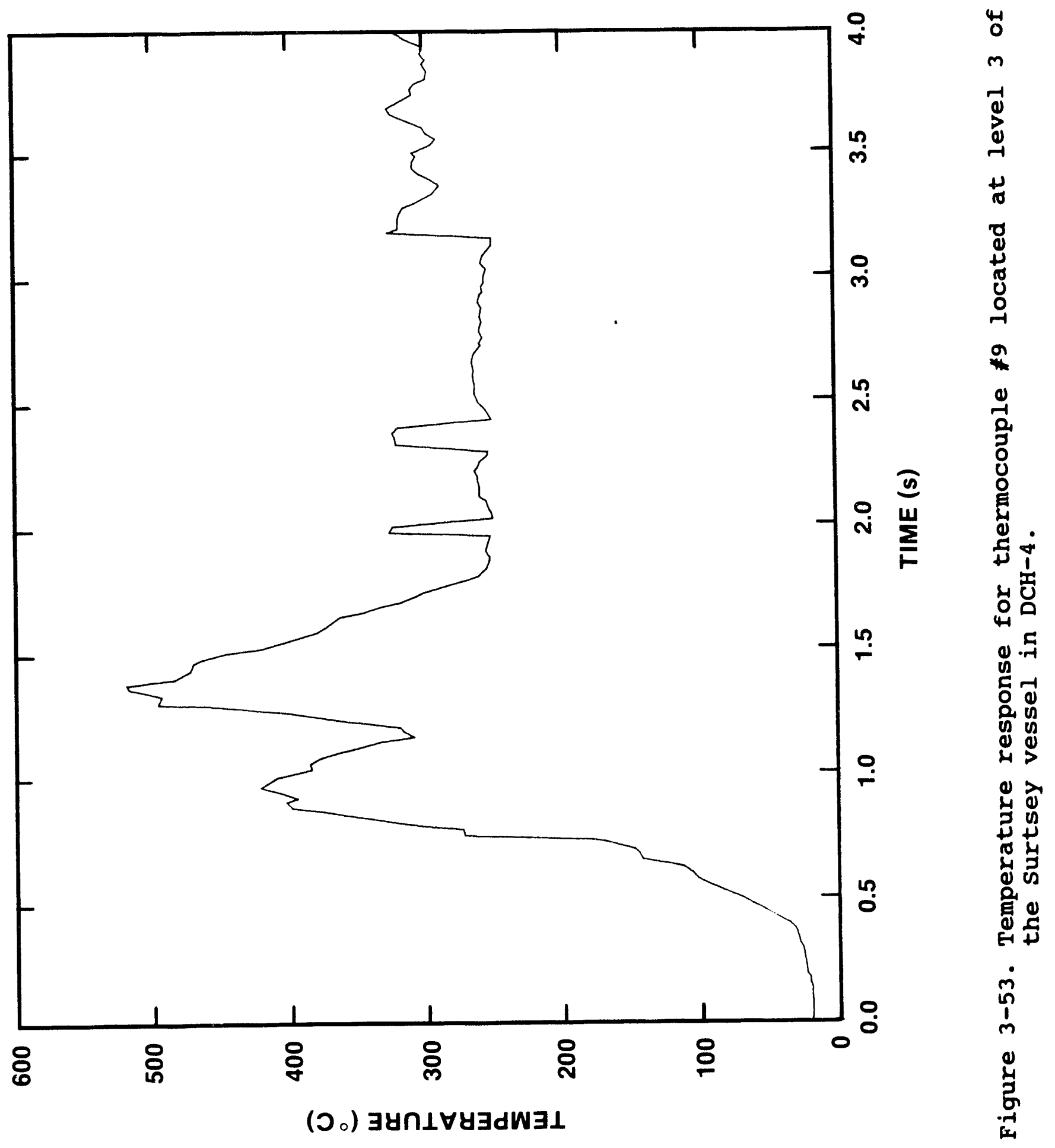




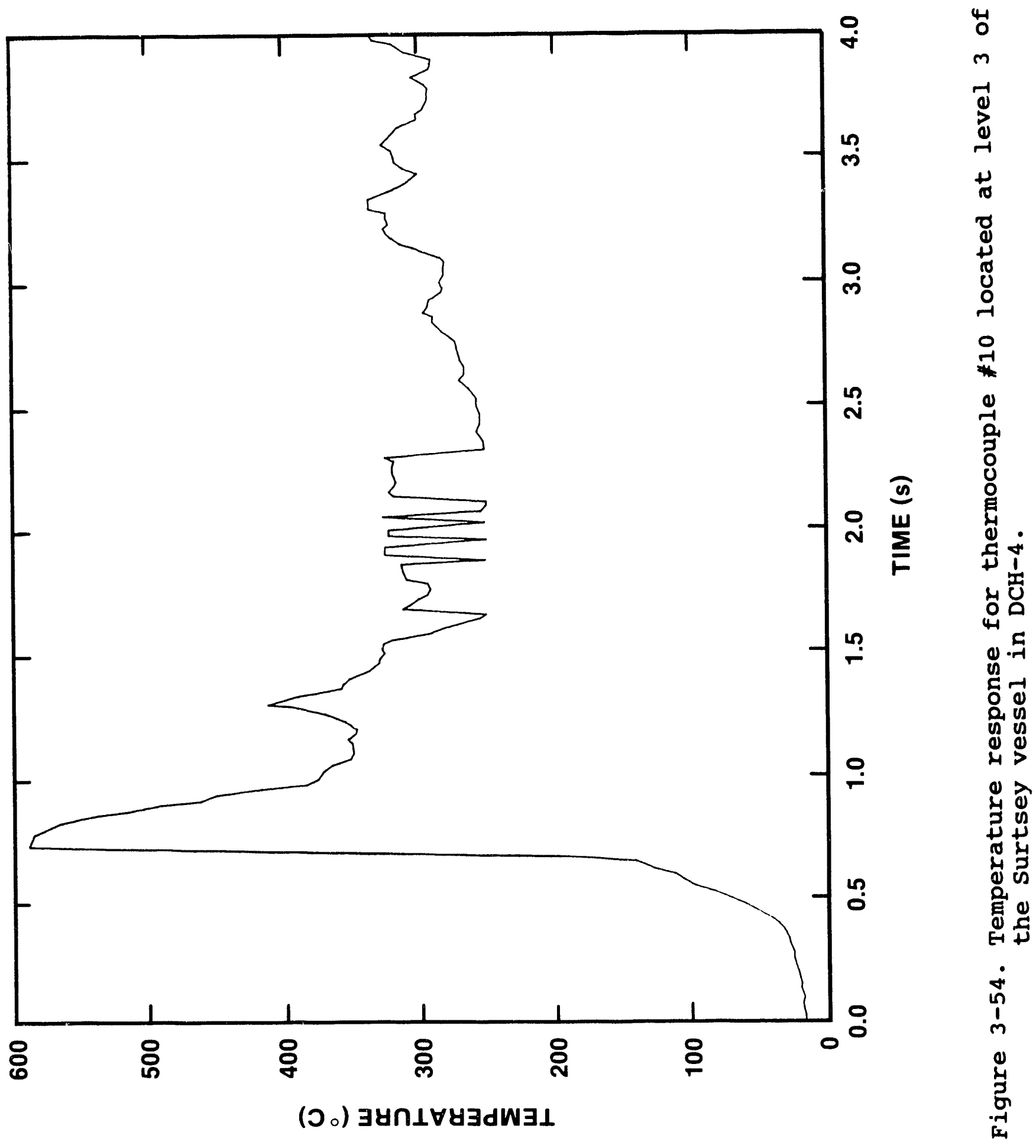




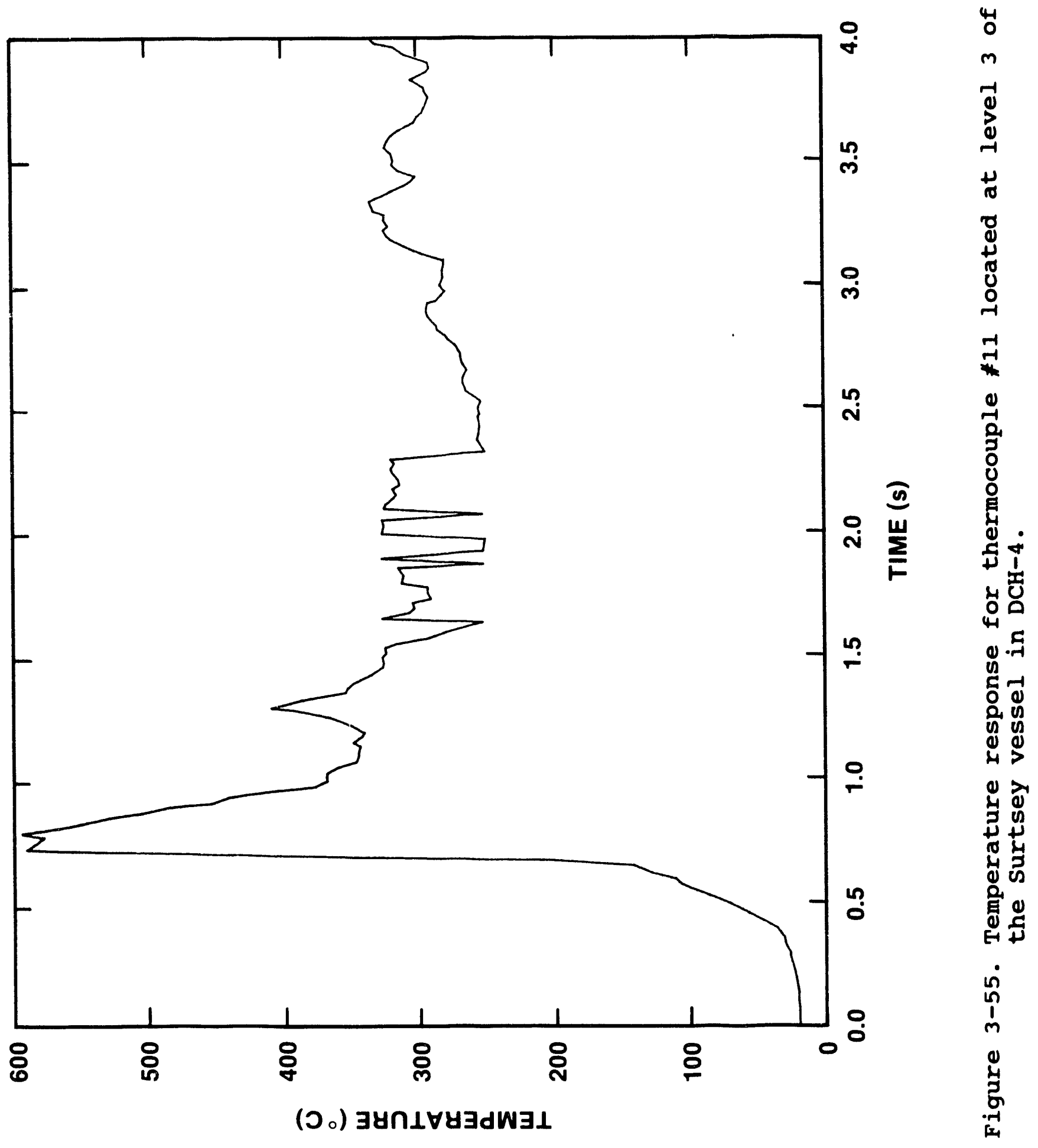




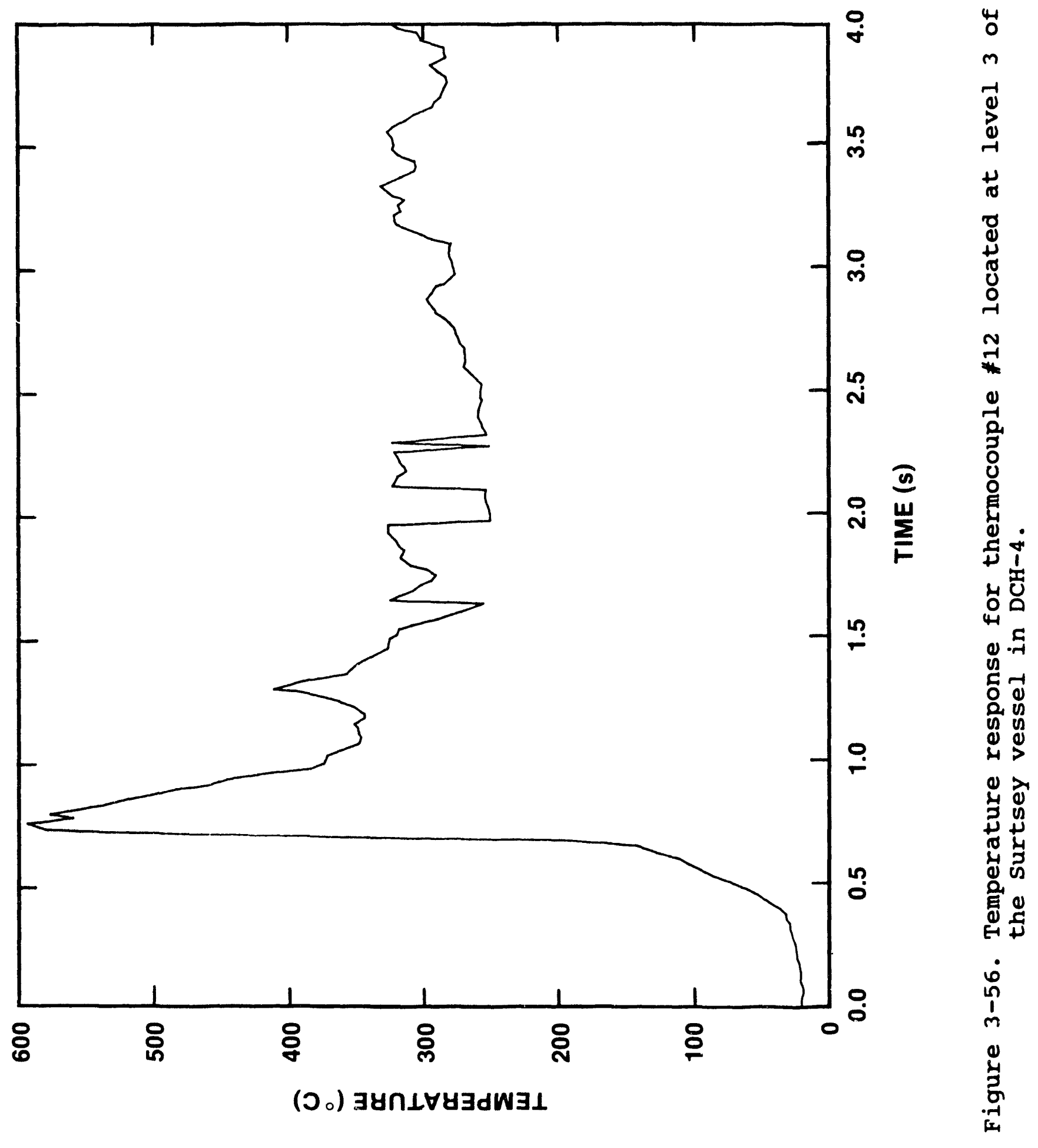




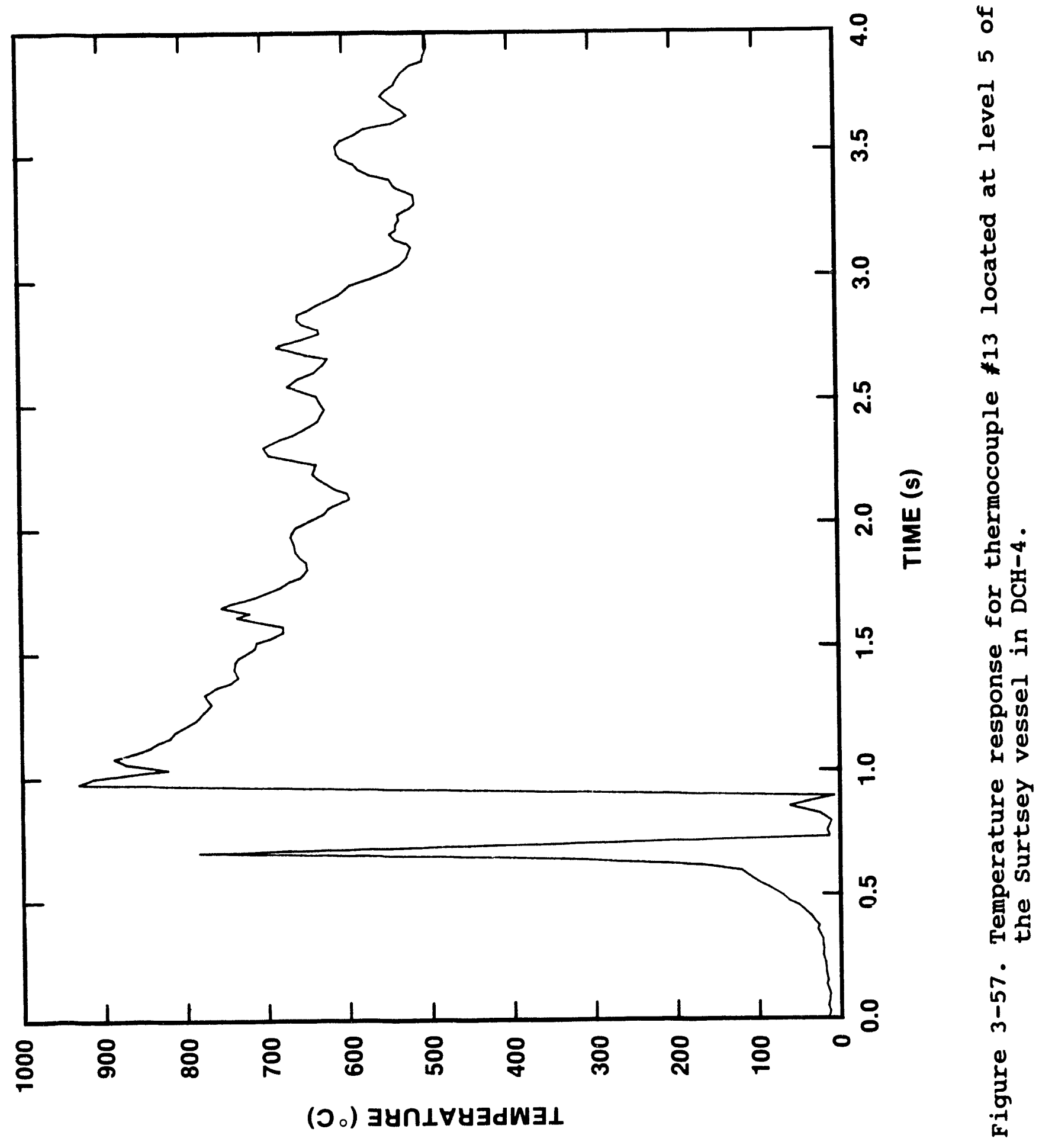




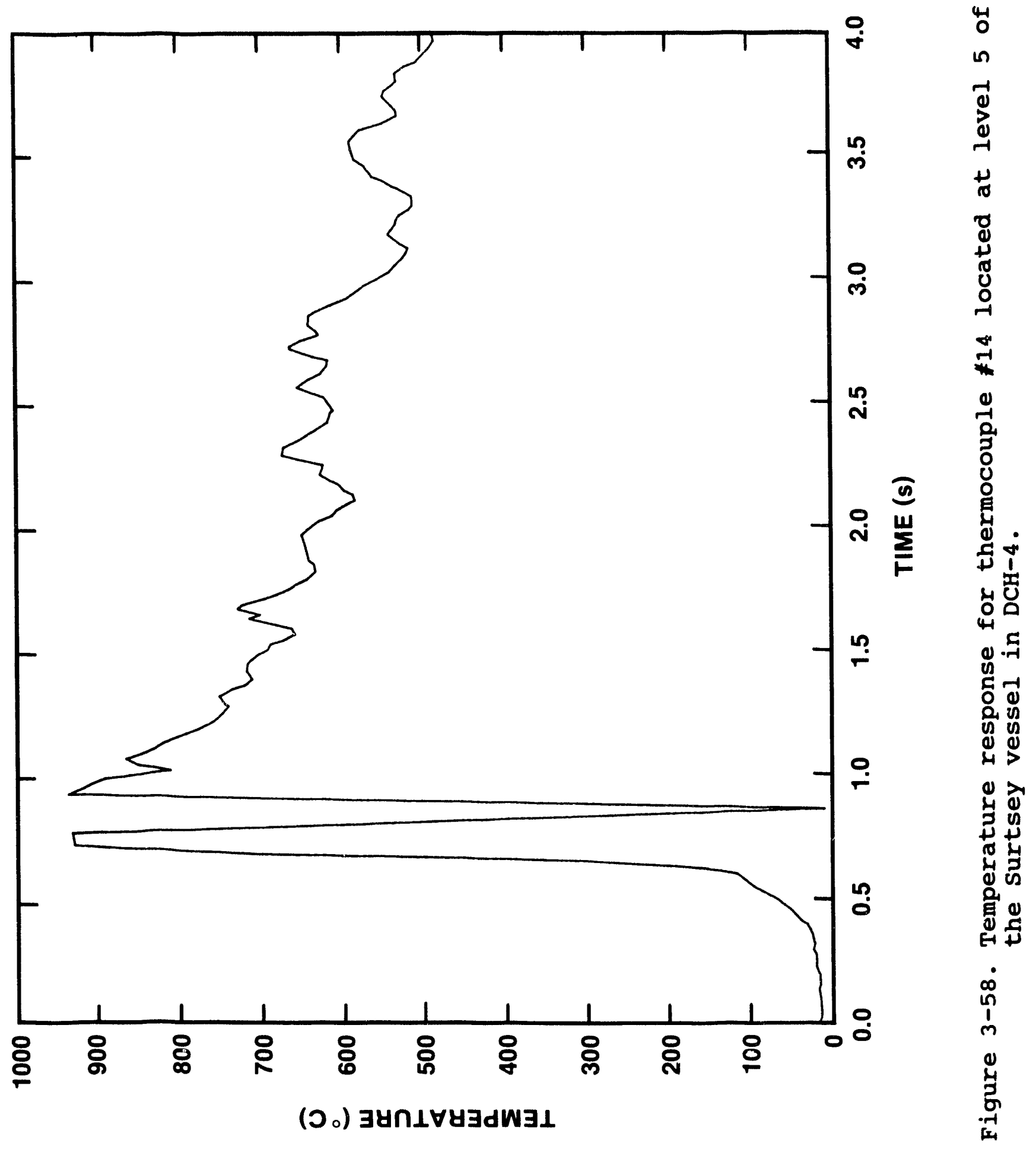




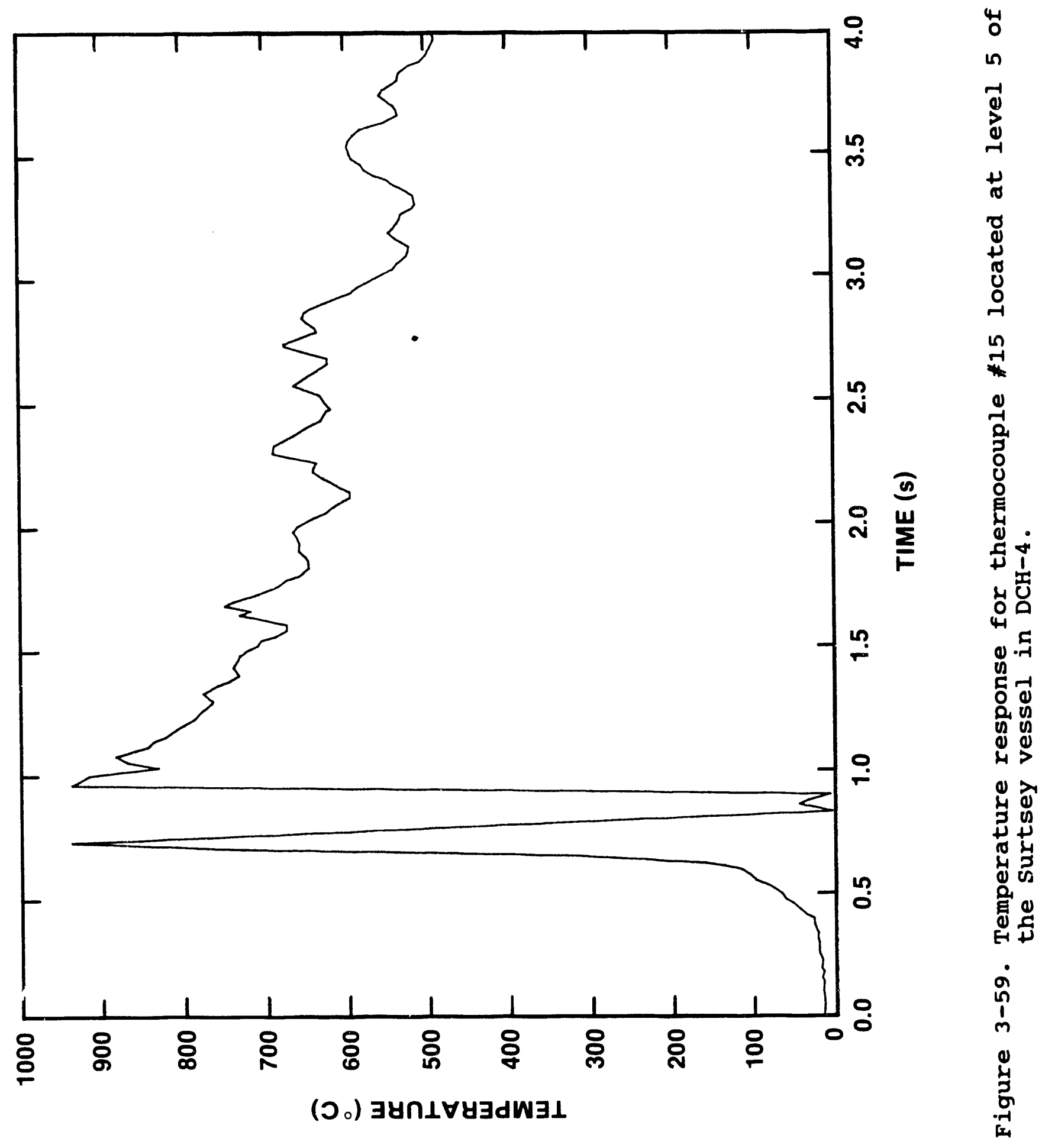




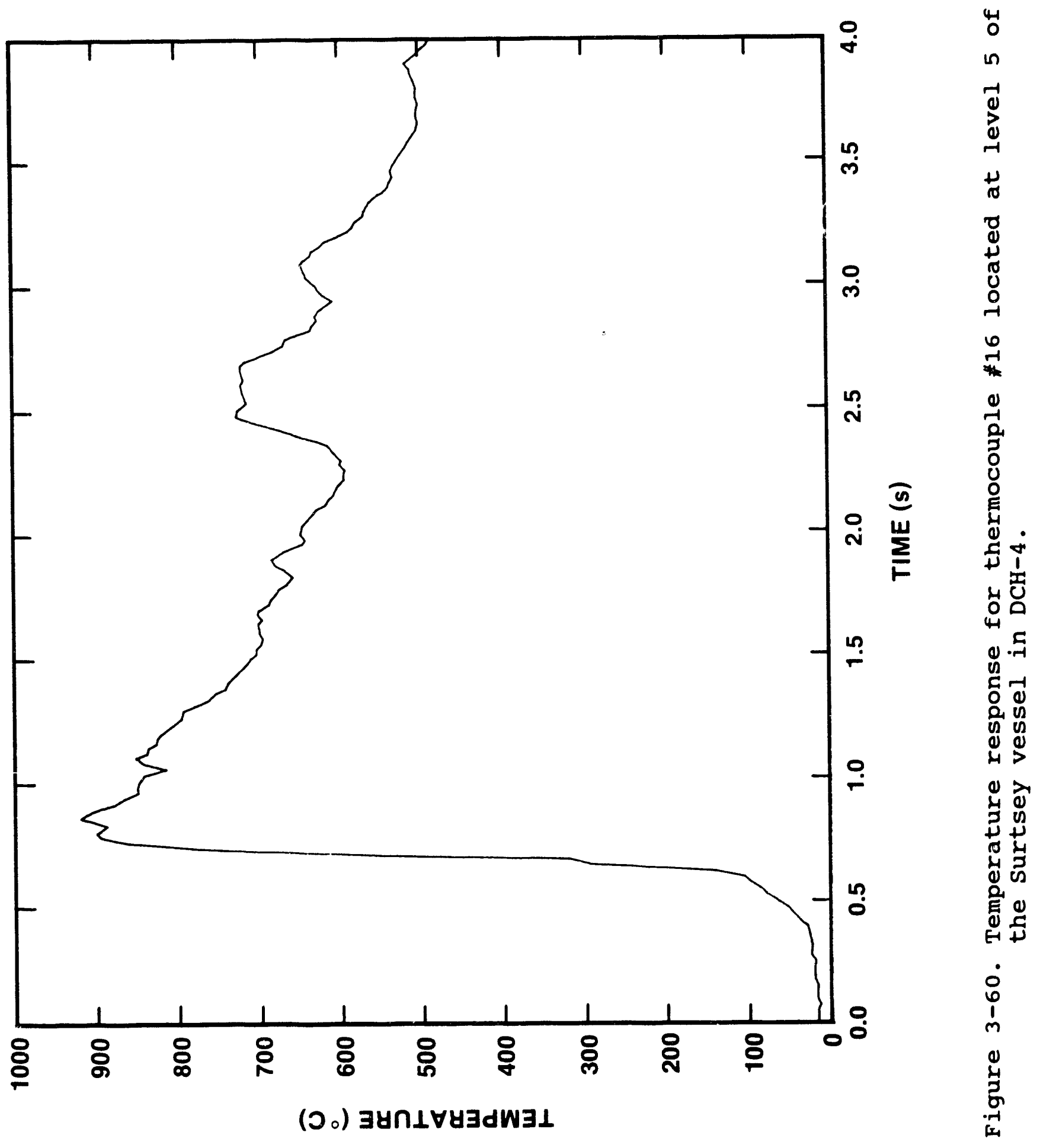




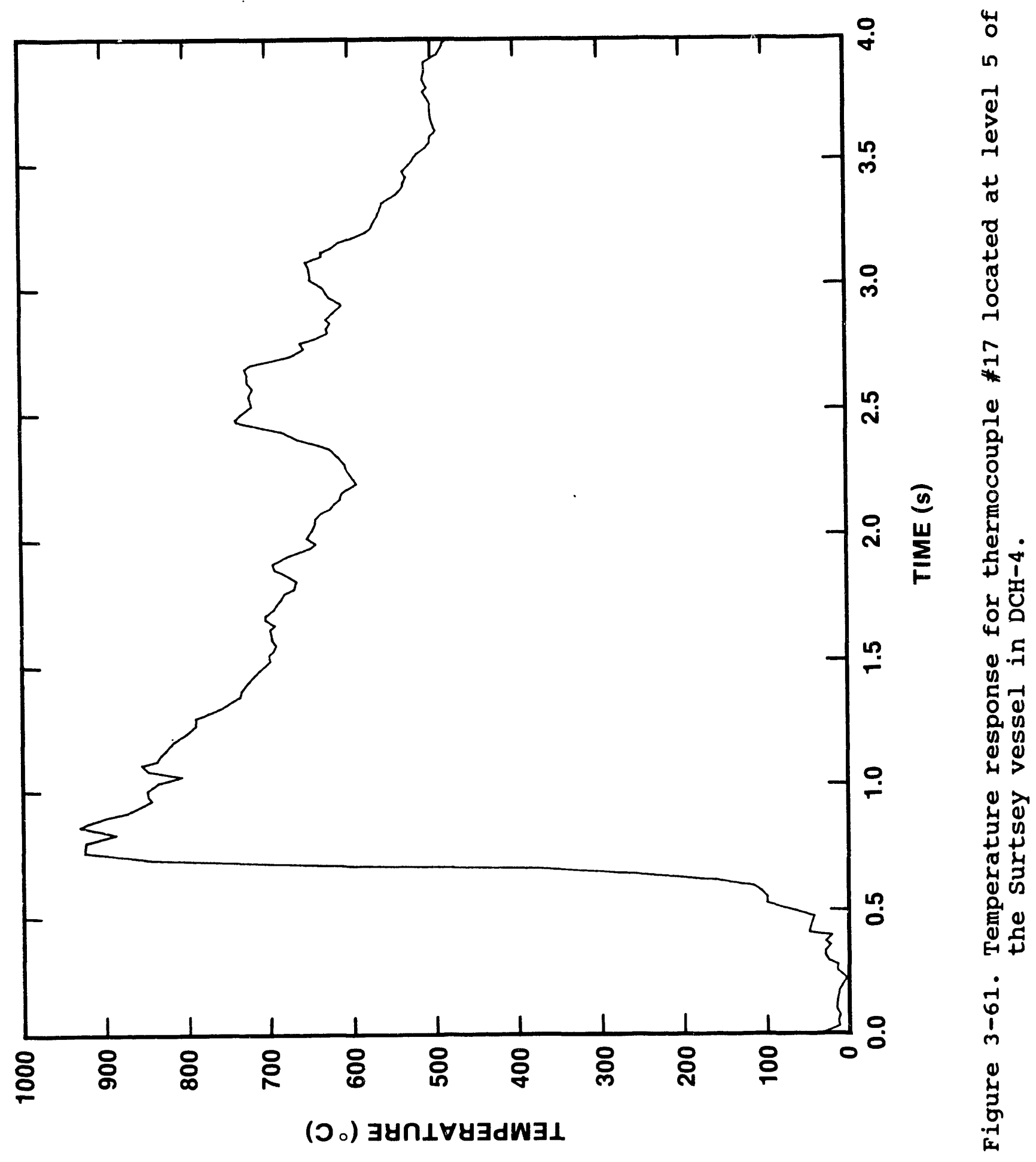




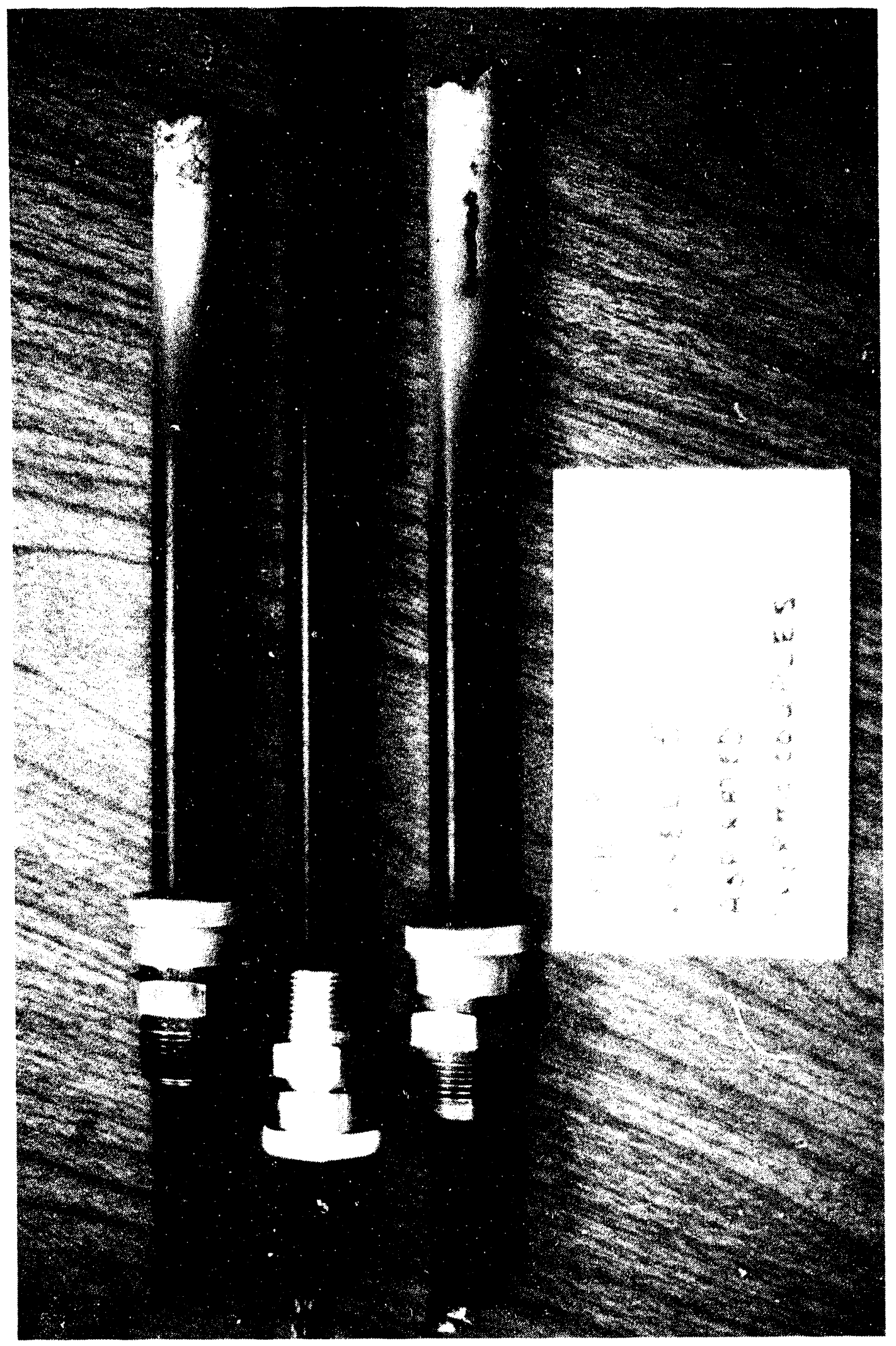

预

d)

近

. 3

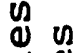

-

도음

E

us

告 $\frac{1}{1}$

돈

용.

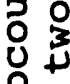

임

보엄

d)

ชृ

$\stackrel{0}{0}$

¿

先

on

on

๑) 움

d I

进要焉

㟧苟. .

ᄃ先

ช.

\%

ơ

먼

O

看

i

v

!

: 


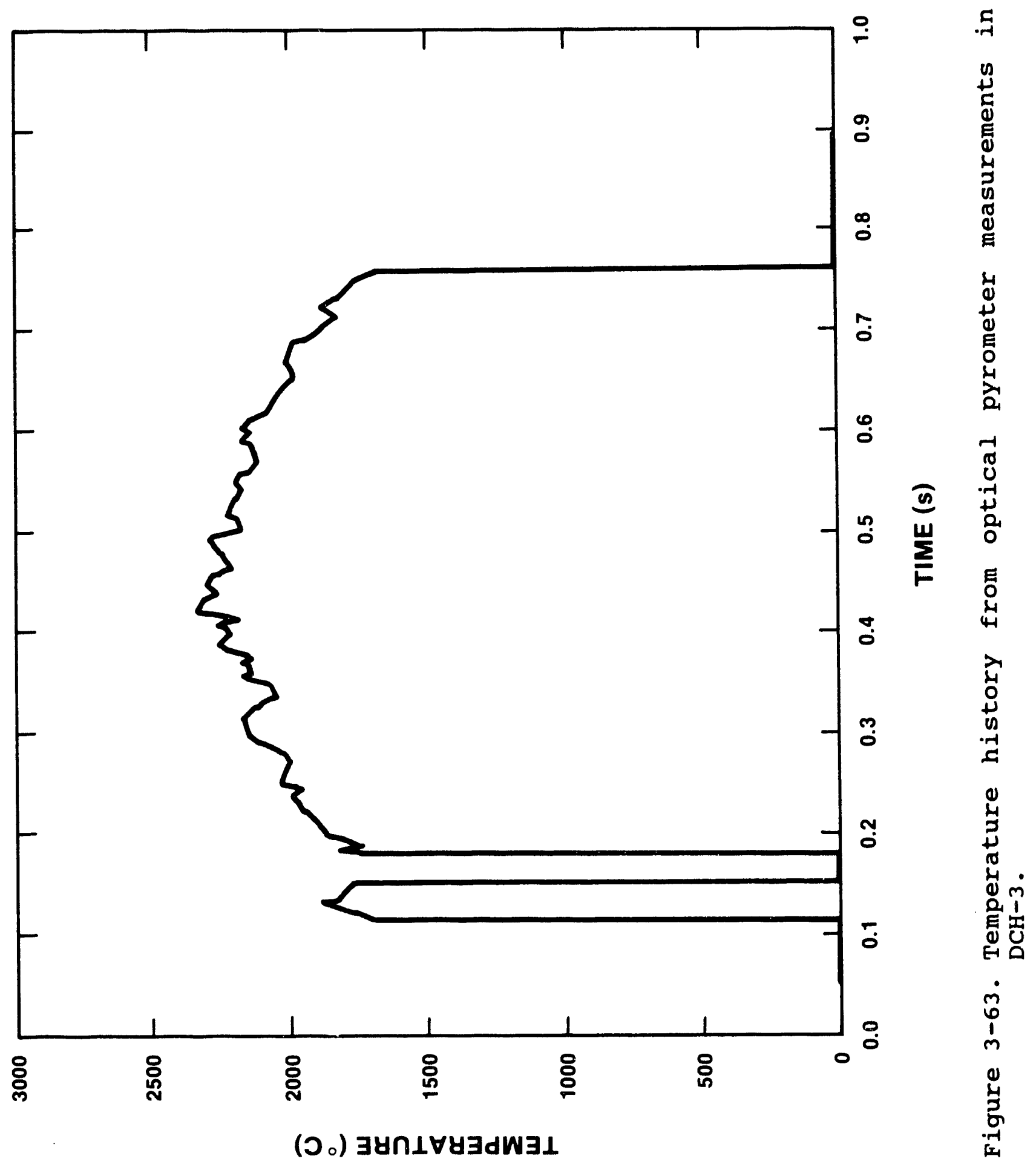




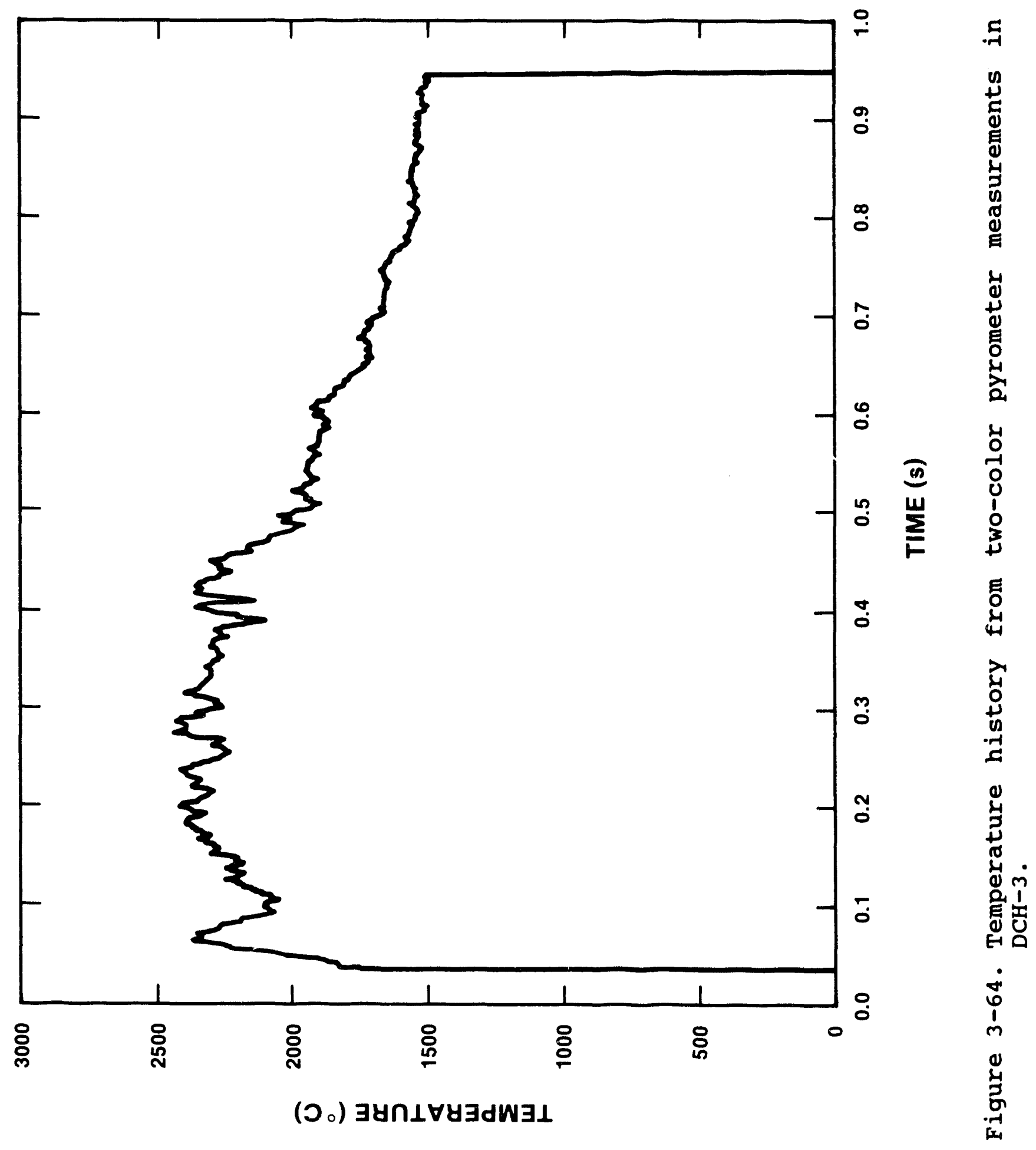




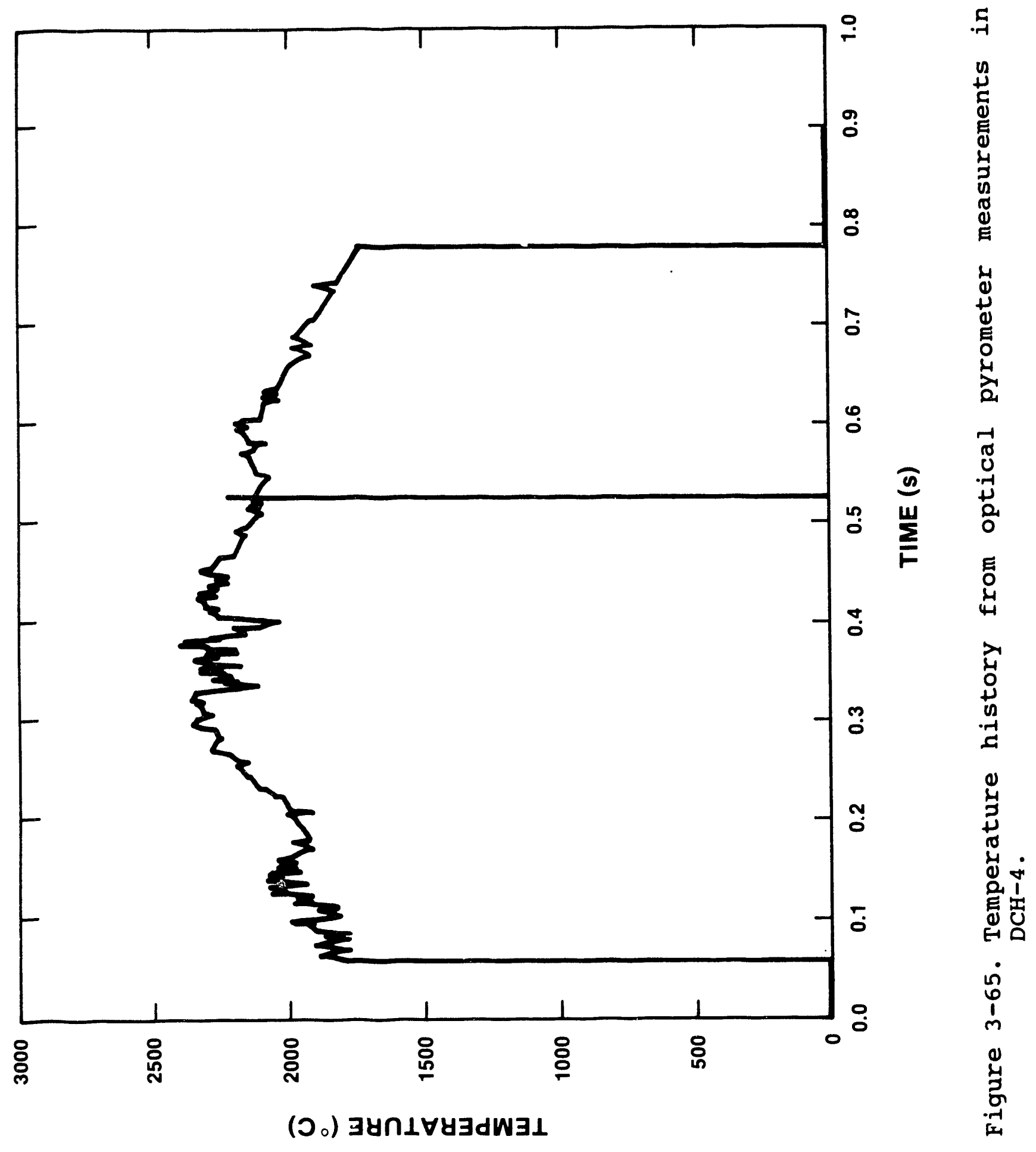




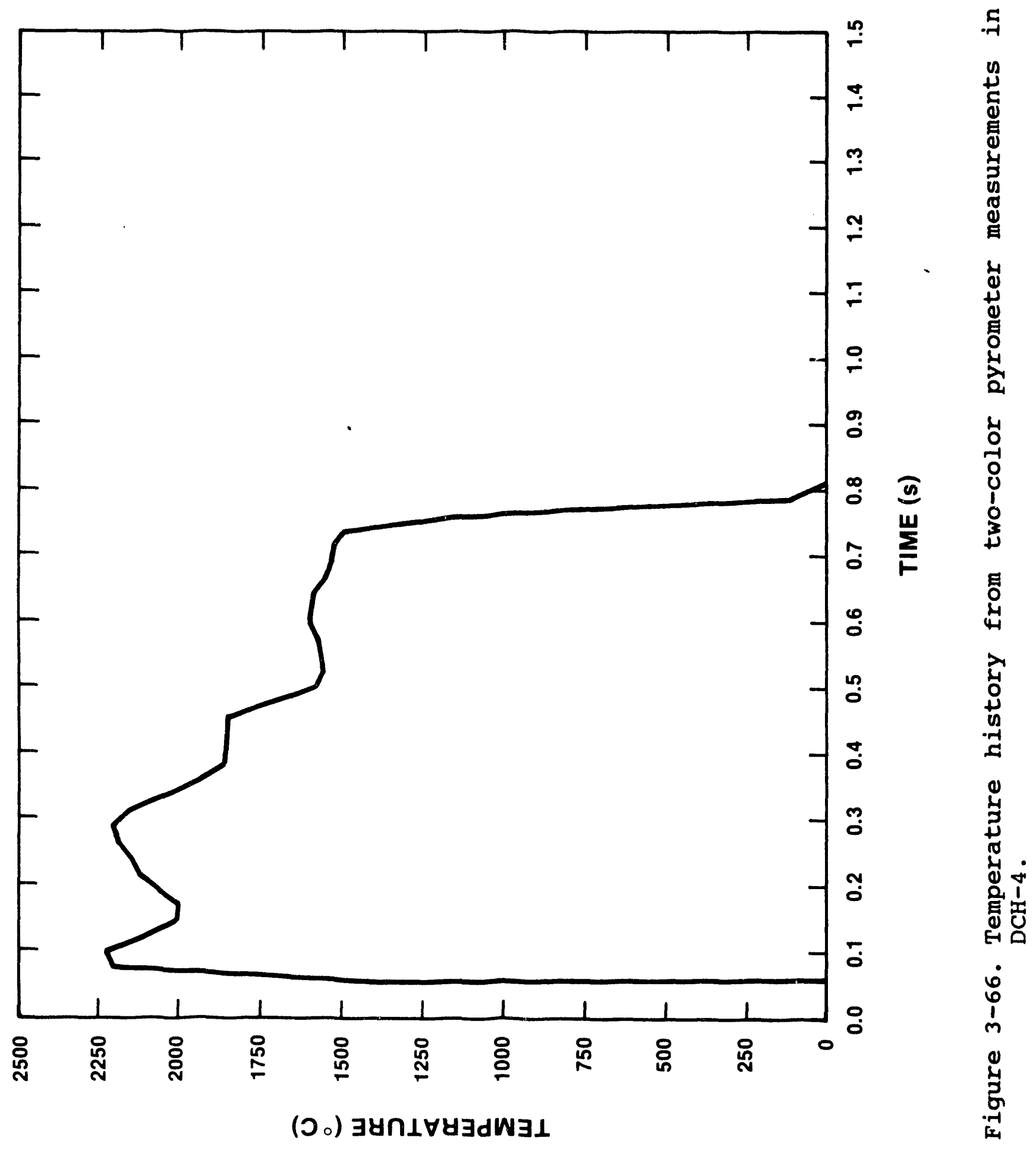




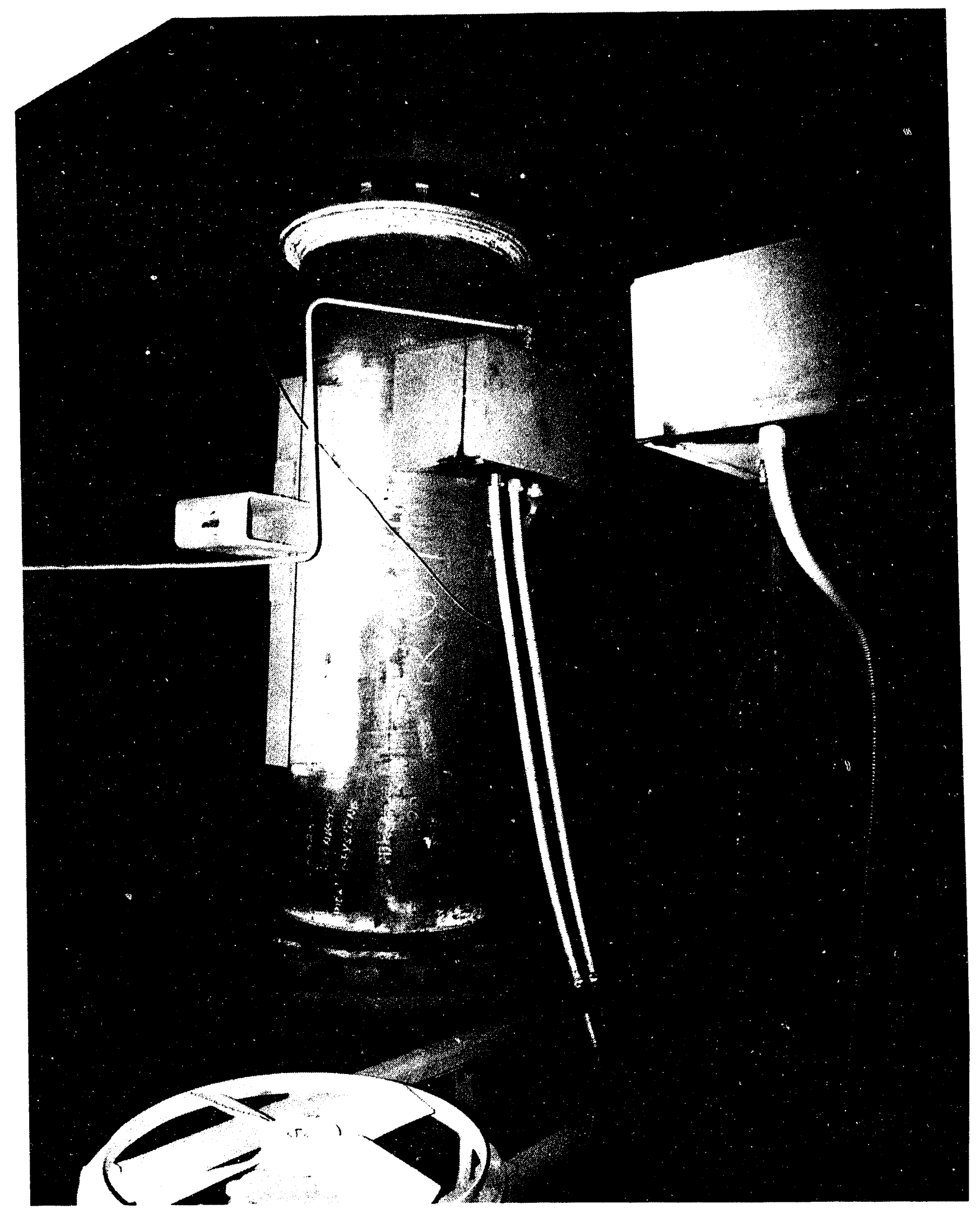

Figure 3-67. Posttest photograph showing an aerosol coating on the melt generator, cavity chute, and a mixing fan after $\mathrm{DCH}^{-3}$. 


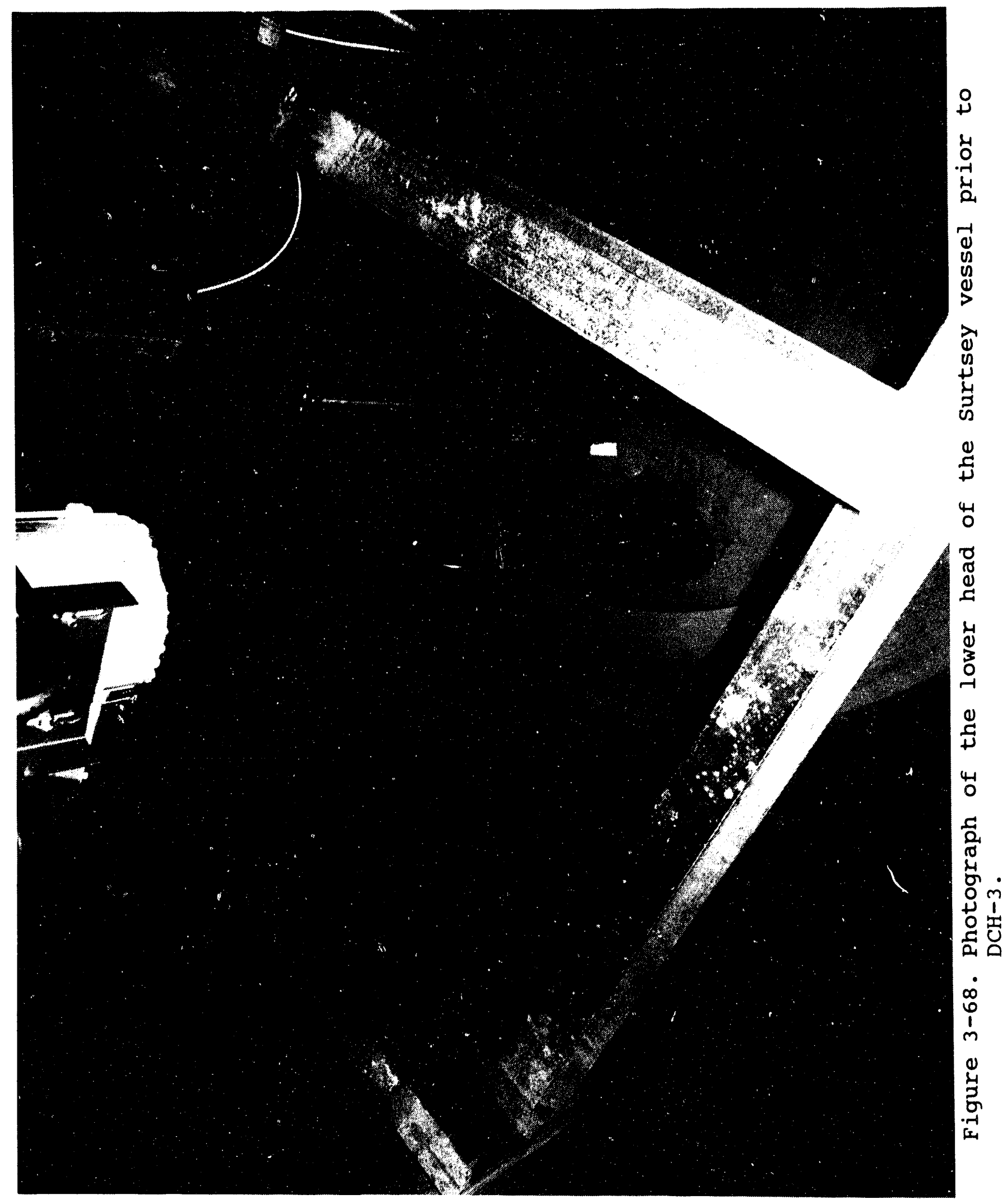




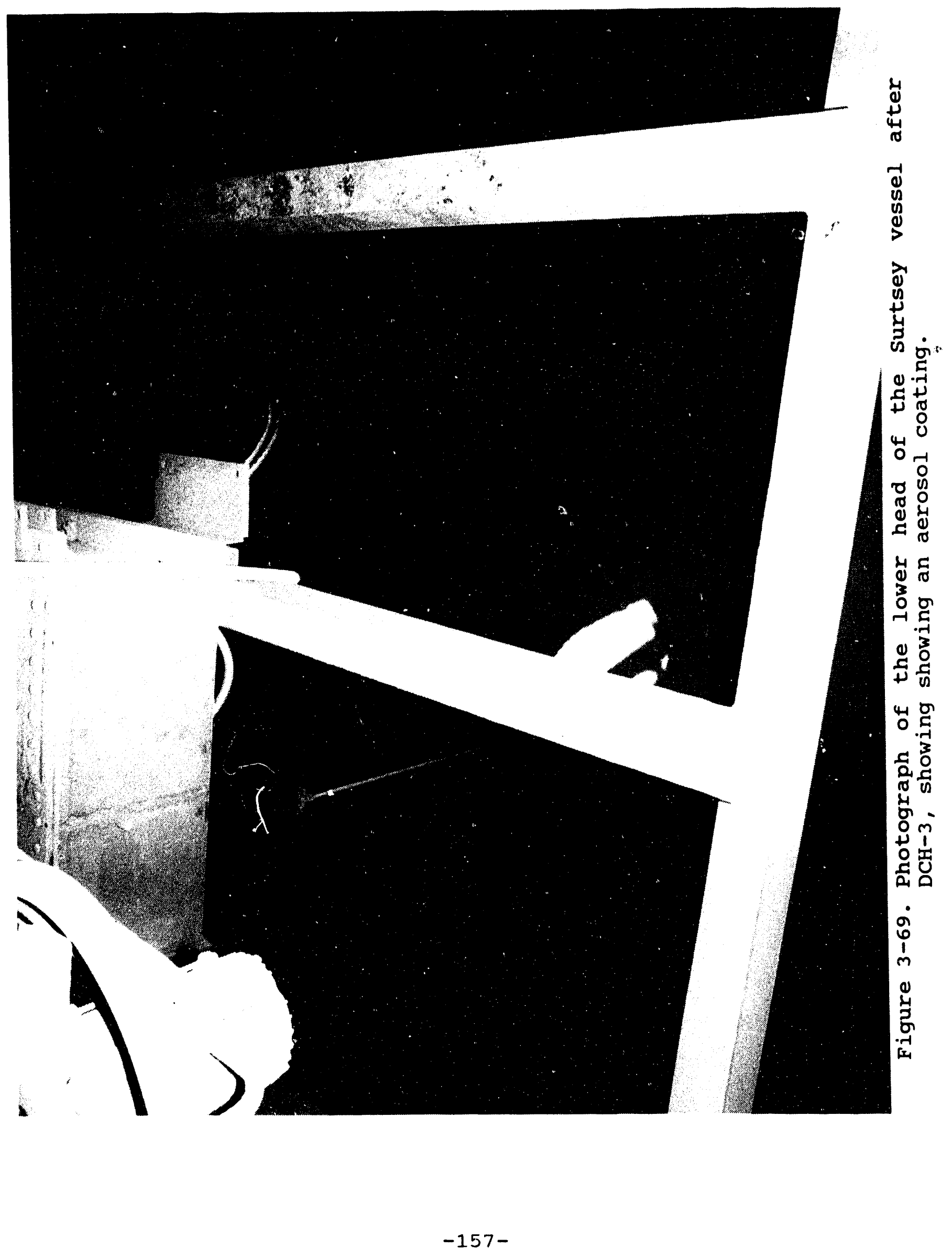




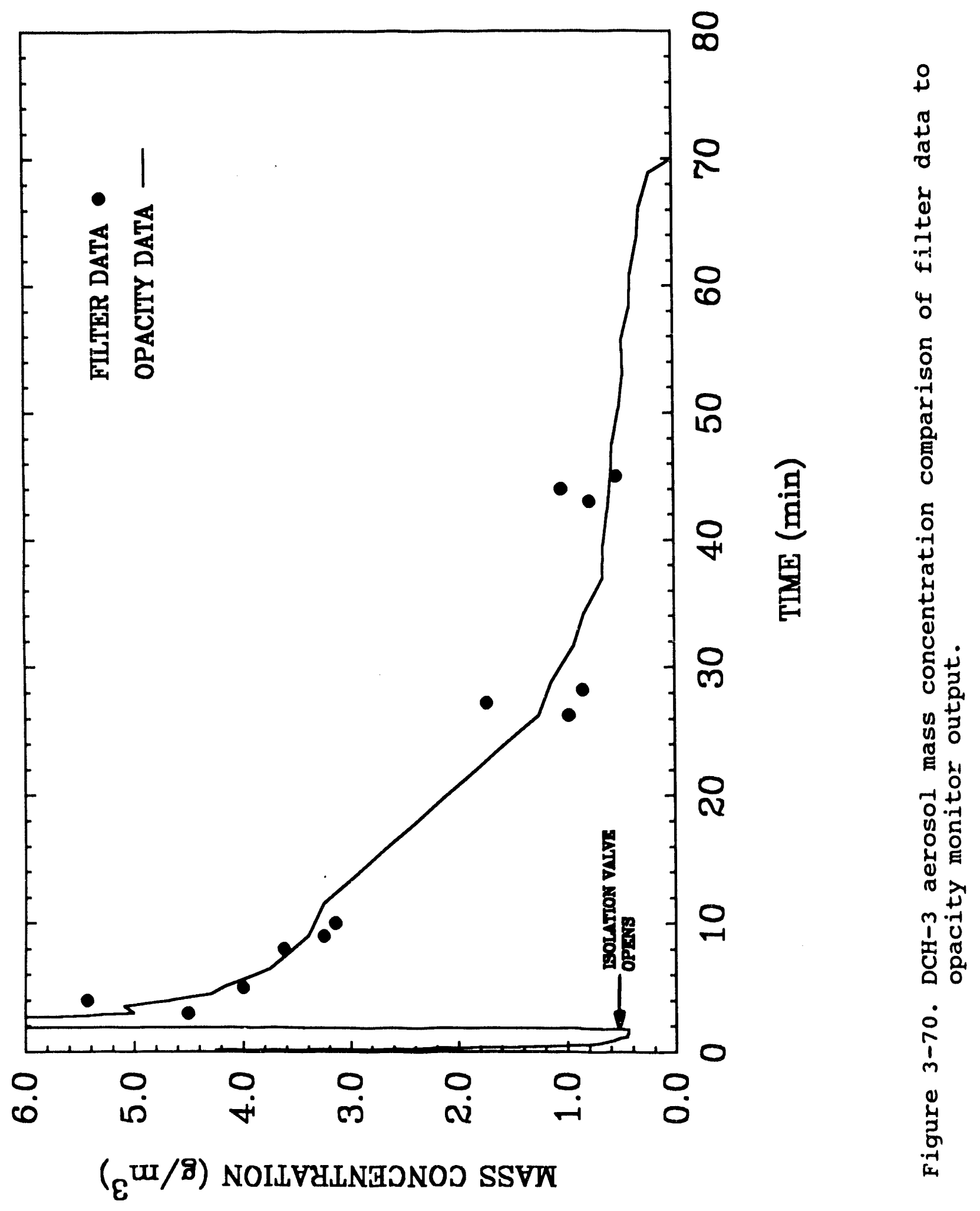



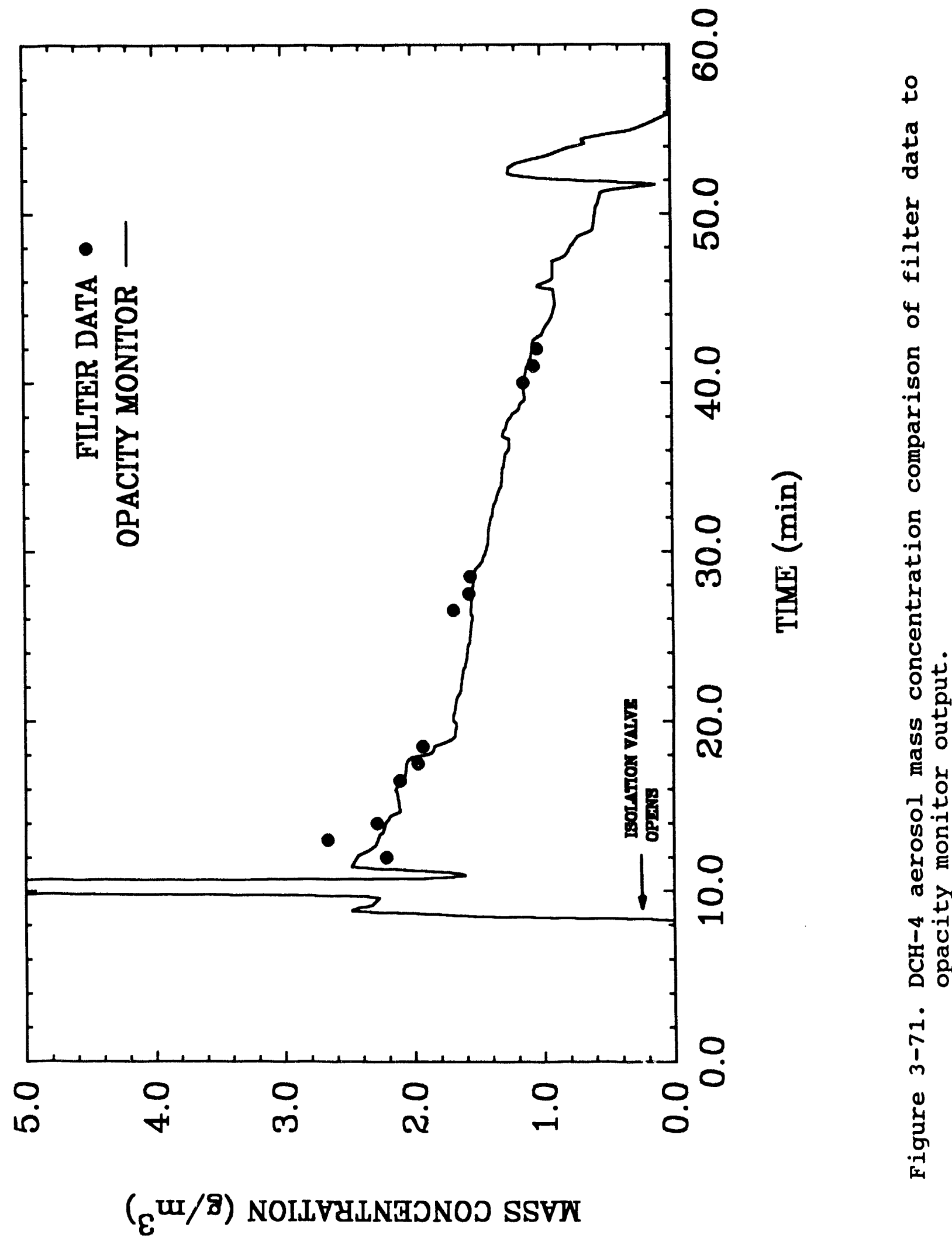


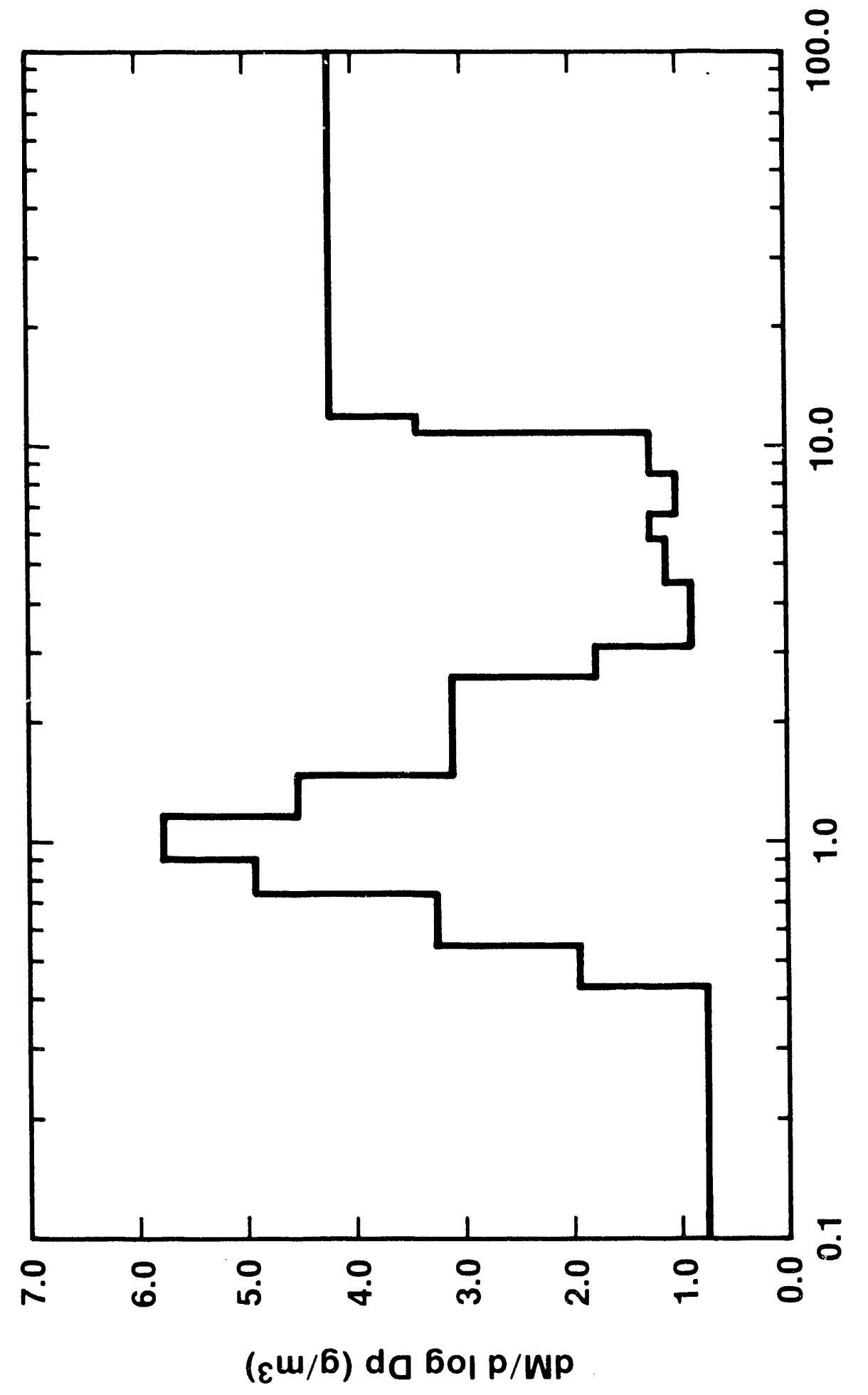

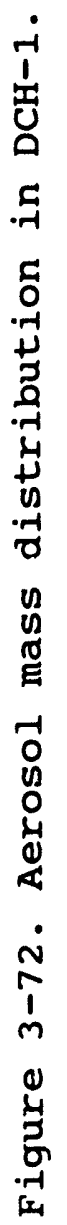




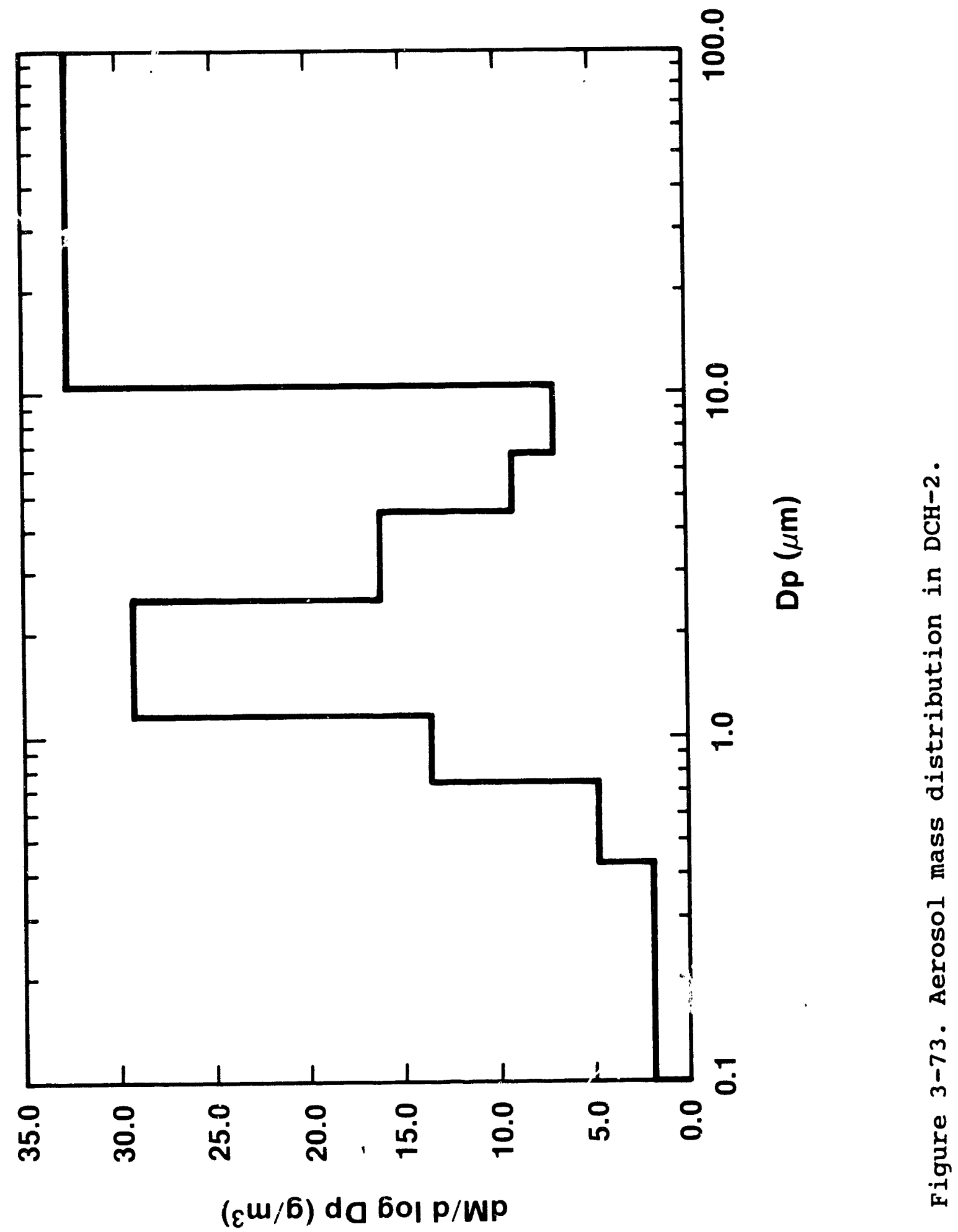




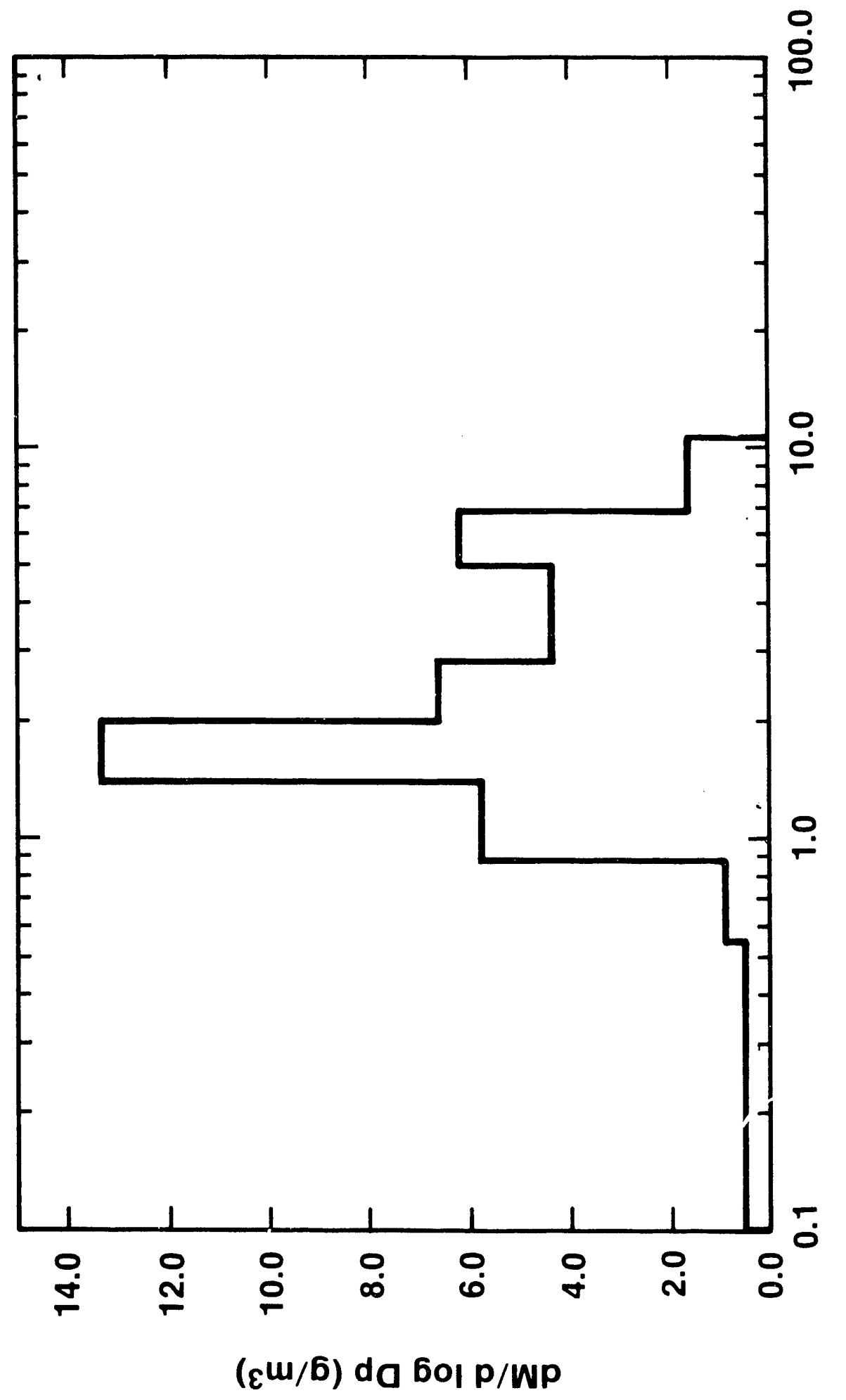

年 


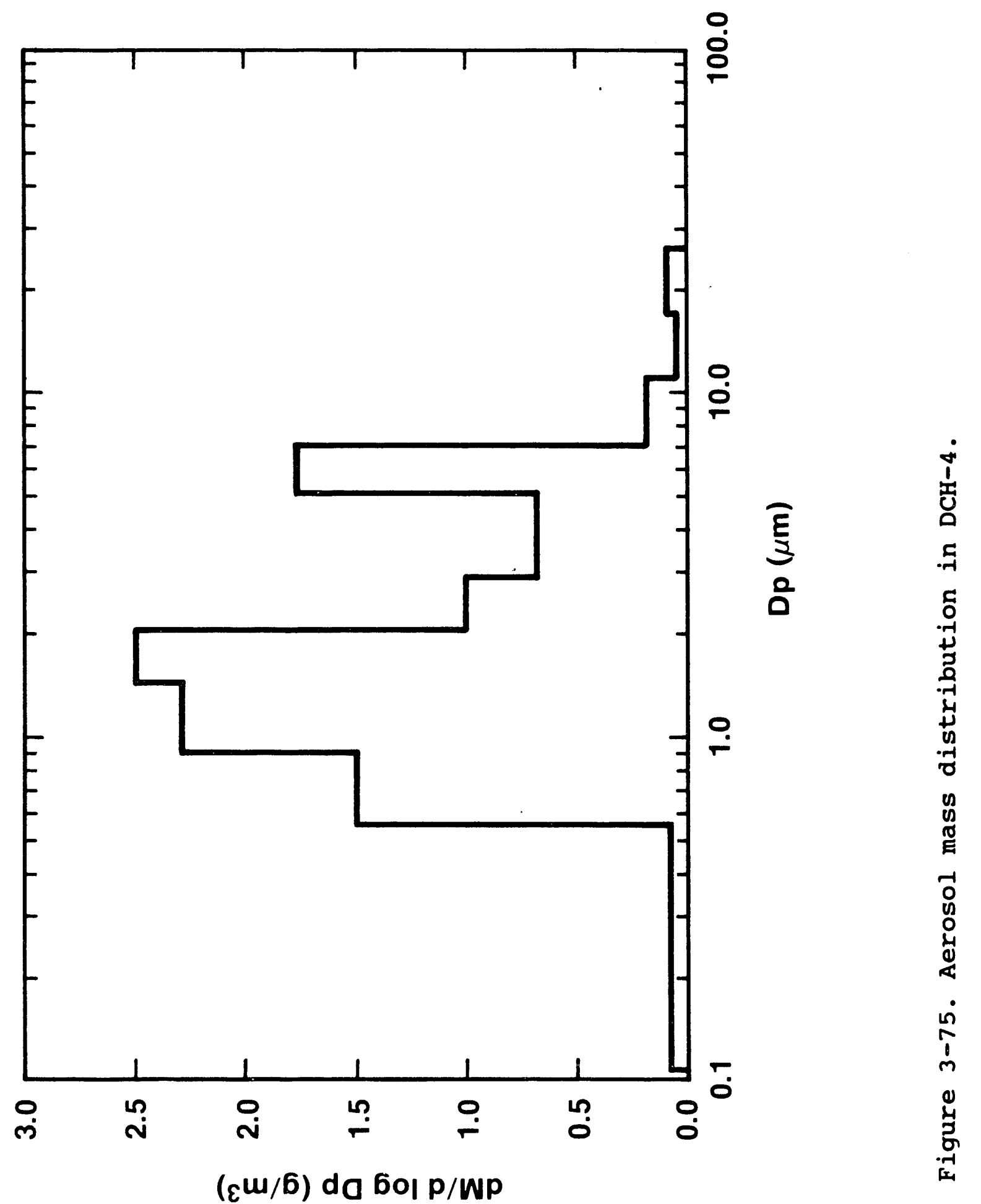




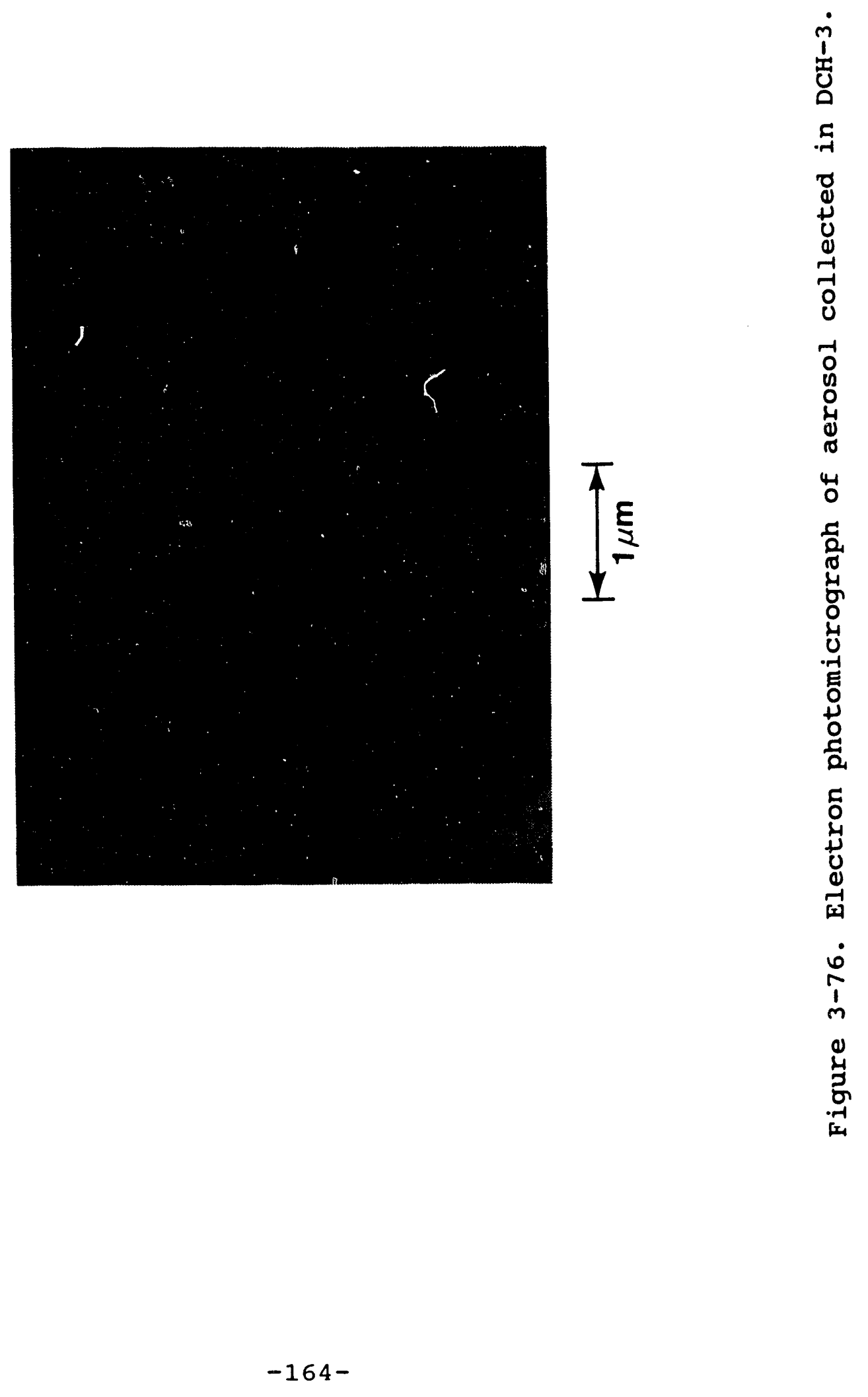




\subsection{ANALYTICAL CALCULATIONS}

The primary objective in developing analytical models is to predict containment response during a light-water reactor (LWR) severe accident in which $\mathrm{DCH}$ is postulated to occur. The Surtsey experiments provided an ideal opportunity to exercise these models as they are implemented into the codes. The primary tool used for accident analysis is a direct heating adaptation of the conTAIN computer code, designated CONTAIN-DCH.

The CONTAIN-DCH code is being developed by sandia National Laboratories, under the sponsorship of the US Nuclear Regulatory Commission (FIN A1198), to provide a systems-level, best-estimate, containment response code. However, CONTAIN-DCH is a lumped-parameter, control-volume code, and this imposes a potentially important limitation on the treatment of material transport and atmosphere physics. In particular, the atmosphere in a given control volume (also called a cell) is assumed to be uniform in temperature and material concentration. In addition, momentum effects are neglected in the treatment of gas flow between interconnected cells. These limitations can be investigated to some extent by nodalizing open volumes into a number of smaller volumes; however, a completely accurate treatment of gas dynamics (e.g., stratification and plume effects) requires a finely resolved (finite-difference) representation of the complete NavierStokes equations. The need to assess the importance of these effects in $\mathrm{DCH}$ events has been a strong motivating force behind the development and application of Kiva-DCH.

Kiva [Amsden et al. 1985] is an advanced thermal hydraulics code which was developed by Los Alamos National Laboratory and the University of California to study the behavior of fuel droplets in internal combustion engines. The code includes models to represent the interaction of droplets with gas and is therefore suited to the investigation of $\mathrm{DCH}$ phenomena.

While Kiva would be too long-running to deal with the complex geometries of reactor containment builàings, it was recognizeả that an improved understanding of the $\mathrm{DCH}$ process could be 
gained by using Kiva to analyze experiments having relatively simple geometries. This, in turn, can make a contribution to our understanding of $\mathrm{DCH}$ and help guide the development of codes like coNTAIN.

It must be emphasized that $\mathrm{Kiva-DCH}$ is intended as an experiment analysis tool and is not suitable for accident analysis. The Kiva-DCH model can only estimate pressures and temperatures for simple geometries (i.e., the surtsey vessel) in well-defined $\mathrm{DCH}$ experiments. The Kiva-DCH code is primarily intended as a tool for tuning the models and/or input used in CONTAIN-DCH.

\subsection{The CONTAIN-DCH Analysis}

The DCH modeling capability in CONTAIN draws from standard containment models and from a suite of $\mathrm{DCH}$ specific models. A high degree of integration exists between the $\mathrm{DCH}$ models and the standard CONTAIN models. This integration is an essential component of the DCH modeling in CONTAIN due to the energetic nature of a $\mathrm{DCH}$ event. The models work together to capture the complex interactions that occurs among the various physical and chemical processes. This integrated approach to DCH modeling is consistent with the spirit of other models in the CONTAIN code.

A few of the more important containment processes associated with DCH phenomenology are intercell flow, two-phase atmosphere and coolant pool thermodynamics, heat transfer to structures, radiation heat transfer, hydrogen transport and combustion, ice condenser behavior, core debris entrainment and transport, and core debris chemical interactions. Dispersed debris is tracked at the cell level, with airborne particles transported by gas flow between cells using a zero slip assumption. The dispersed debris field is allowed to have different characteristics and components in each cell, with one temperature describing the thermodynamic state of the bulk debris field. Debris sources are simultaneously modeled with the flow solver, yielding a coupled solution for the motion of the debris field. 
Chemical and physical interactions between the dispersed debris droplets and the containment atmosphere and structures are also modeled in detail, including zirconium and iron chemical reactions, convection and radiation to the gas, and radiation to surrounding structures. Debris trapping on structures and trapping due to gravitational fallout is also considered, with several parametric or mechanistic models available. Source tables may be entered for high pressure melt ejection, but mechanistic models for initial melt ejection, vessel hole ablation, debris ejection from the vessel, debris entrainment/de-entrainment, and dispersal from the cavity have been implemented.

\subsubsection{CONTAIN-DCH Analysis of DCH-3}

The first analysis of the DCH-3 test with the CONTAIN-DCH code used a single-cell representation of the surtsey configuration and a value of $0.5 \mathrm{~s}^{-1}$ for the trapping fraction, $f_{t r}$. In CONTAIN, the rate at which airborne debris is removed from the cell atmosphere is equal to the product of the trapping fraction and the mass of debris in the cell atmosphere. This resulted in pressure predictions far in excess of the experimental values (Figure 4-1). This poor agreement is attributed, in part, to the trapping rate specified, which does not adequately describe the debris removal rate in the experiment. Additionally, the model as employed does not take into account the limited availability of local oxygen in the debris jet and thermal shielding within the debris-gas-aerosol cloud. These two factors are collectively termed the "cloud effect" and are believed to be important in the $\mathrm{DCH}-3$ and $\mathrm{DCH}-4$ experiments.

Therefore, a second analysis was performed with a three-cell CONTAIN-DCH representation of the surtsey vessel. In the three-cell CONTAIN-DCH model, the surtsey vessel was divided into three cylindrical regions with volumes of $3.5,29.5$, and $70 \mathrm{~m}^{3}$, respectively (Figure 4-2). Cell 1 was a small cell designed to represent the vicinity of the coherent debris jet. Because the debris in this cell was traveling upward during the blowdown, a zero trapping rate was specified. 
Cell 2 modelled the upper 2 meters of the surtsey vessel (Figure 4-2). A trapping fraction of $8.0 \mathrm{~s}^{-1}$ was specified in this cell for the first $0.34 \mathrm{~s}$, to simulate the initial period of debris sticking and film formation on the upper head of the Surtsey vessel. The value of the trapping fraction was based on the estimated time for the debris jet to traverse the cell and impact the upper head of the vessel. As the simulation progressed, the trapping fraction was then changed to a value of $0.5 \mathrm{~s}^{-1}$ at about $2.0 \mathrm{~s}$ into the problem. The negative trapping rate simulated the dripping of previously trapped debris from the upper head of the containment vessel. The dripping was initiated at about 2 seconds into the simulation to induce the second pressure peak observed in the experimental results.

Cell 3 represented the bulk of the vessel volume below the $7 \mathrm{~m}$ level (figure 4-2). The trapping rate in this cell was based on the terminal fall velocity criterion. The cloud effect was captured to some extent by this surtsey representation because debris in cell 1 was not in thermal contact with gas or structures located in Cell 2 and cell 3 .

The results of the CONTAIN-DCH three-cell calculations for the DCH-3 test are also shown in Figure 4-1. The two-peak behavior of the pressure in the experiment is visible in the three-cell calculation.

\subsubsection{Discussion}

The CONTAIN-DCH three-cell calculation for DCH-3 agrees with the experimental data much better than the one-cell calculation. The improvement attained with the three-cell representation indicated the importance of modeling in detail the debris-cloud effects and the interaction of the debris with structures, such as the upper head of the surtsey vessel. This modeling was accomplished by using a large trapping fraction to simulate the impact of the debris jet on the upper head of the surtsey vessel, followed by a negative trapping fraction to simulate the formation and release of drops from the upper head surface. Although the results of the three-cell calculation 
are encouraging, more advanced debris-structure interaction modeling is needed.

\subsection{The Riva-DCH Analysis}

To allow Kiva to be used for the analysis of surtsey DCH experiments, a version of the code known as Kiva-DCH, in which the debris materials and gases used in the surtsey experiments are modeled, has been developed at sandia. In particular, allowance has been made for the chemical and thermal interaction of the debris with the surtsey atmosphere. The new models and the application of Kiva-DCH to the analysis of the surtsey experiments $\mathrm{DCH}-1$ and $\mathrm{DCH}-2$ are described in Marx [1988]. Kiva-DCH is capable of representing gas and debris transport and thermal interactions with greater resolution than CONTAIN-DCH, which is inherently limited by its lumpedparameter control volume framework.

The version of Kiva-DCH used for the present work has been developed from that described in Marx [1988]. The main changes which have been made are as follows:

(a) The chemistry model has been extended to allow for metal oxidation by steam (as well as by oxygen), and to allow chromium metal (in addition to iron) to be treated.

(b) The chemistry and heat transfer models have been enhanced to include a more rigorous treatment of the thermal coupling between the debris and the atmosphere.

(c) The sourced (blowdown) gas was defined in terms of the gas linear velocity. In the current version of Kiva-DCH it can be optionally described in terms of mass flow rate, which is generally more convenient than the earlier method.

(d) The geometry model has been modified to allow debris and gas to be sourced at floor level, as well as from an axially protruding chute. 
(e) Changes have been made to speed up the code.

(f) Some minor coding errors have been corrected.

The Kiva-DCH model includes the hydrodynamic modeling capabilities of $\mathrm{Kiva}$ and is capable of representing the transport of gases and debris with considerable resolution. In particular, gas motion on a multi-dimensional grid is calculated using a finite-difference solution to the Reynoldsaveraged, Navier-stokes equations*. Realistic models for turbulence and debris-gas drag are also included. These capabilities provide a more detailed look at such topics as gas flow, particle transport, debris-structure interactions, and permit a less uncertain estimate of the debris-gas interaction.

In the current version of $\mathrm{Kiva-DCH}$, models for chemistry, heat transfer, and debris/structure interactions are applied to a distribution of particles as they move along a flight path. The models for debris/gas heat transfer and chemical reactions in Kiva-DCH are similar to those implemented in CONTAIN-DCH; however, the dispersed debris in $\mathrm{Kiva-DCH}$ is tracked as a collection of unique computational packets. Heat transfer and chemical reactions between the atmcsphere and the debris are treated separately for each packet within a given hydrodynamic cell. As a result, $\mathrm{Kiva-DCH}$ is capable of predicting local temperature effects and gas-field behavior in considerable detail.

Debris/structure interactions in $\mathrm{Kiva-DCH}$ are modeled by assuming a trapping probability for debris in packets that encounter a surface. The trapping probability, Ptrap, is defined as the probability that a debris packet sticks to a surface and is retained as a film in any one encounter with the

Sweet, D.W. and K.E. Washington, to be published, Further Development of the Kiva-DCH Code for the Analysis of the Transport and Chemical Reaction of Molten Debris in Direct Containment Heating Experiments, SAND90-2535. Sandia National Laboratories, Albuquerque, NM. 
surface. This approach is parametric in nature and requires user input for the value of Ptrap. More detail regarding the models in Kiva-DCH is given in Amsden et al. [1985] and Marx [1988].

\subsubsection{Model Assumptions and Initial Conditions}

In order to accurately model the DCH experiments, Kiva requires information concerning the geometry of the surtsey vessel, the nature of the debris and gas injected into the vessel, how the debris and vessel surfaces interact, and the initial conditions in the vessel at the start of the experiment.

\subsubsection{Geometry}

The Kiva-DCH analysis assumed a 2-D model of the surtsey vessel. The vessel has slightly domed ends and its height and radius cannot be precisely matched in the model; however, pressure transients are sensitive to the debris path length from the chute to the ceiling and to the vessel free volume, and therefore care was taken to accurately reproduce these dimensions in the calculations. Table 4.1 compares the surtsey vessel dimensions with those used in the Kiva-DCH calculation.

When the area of the opening of the exit chute from the cavity in the $\mathrm{DCH}-3$ and $\mathrm{DCH}-4$ experiments was used in $\mathrm{Kiva}-\mathrm{DCH}$ calculations, convergence difficulties were encountered and a larger chute area had to be adopted for the analysis. Sens:tivity studies have shown that results of the code when it converges are very insensitive to the area of the chute opening, so the change should have very little affect on the results of the study.

Table 4.2 gives the spatial mesh used in the Kiva calculations. This is a standard mesh similar to that employed for the analyses described by Marx [1988] and was used for most of the calculations presented here. One calculation for each experiment was repeated with double the number of axial and radial mesh intervals. 
Table 4.1

Comparison of Surtsey Vessel and Kiva Code Model Dimensions

Dimension Vessel Kiva $\underset{\text { model }}{2-D}$ cylinder

$\begin{array}{lcc}\text { Radius } & 1.81 \mathrm{~m} & 1.802 \mathrm{~m} \text { (10 mesh intervals) } \\ \text { Height } & 10.31 \mathrm{~m} & 10.10 \mathrm{~m} \text { (22 mesh intervals) } \\ \begin{array}{l}\text { Debris free } \\ \text { path }\end{array} & \approx 7.4 \mathrm{~m} & 7.40 \mathrm{~m} \text { (16 mesh intervals) } \\ \begin{array}{l}\text { Internal } \\ \text { volume }\end{array} & 103.0 \mathrm{~m}^{3} & 103.0 \mathrm{~m}^{3} \\ \begin{array}{l}\text { Free volume(1) } \\ \begin{array}{l}\text { Area of (2) } \\ \text { chute opening }\end{array}\end{array} & 102.5 \mathrm{~m}^{3} & 102.69 \mathrm{~m}^{3} \\ \end{array}$

Notes:

(1) The model free volume is the internal volume reduced by the volume of the chute. This free volume is believed to be very close to that of the vessel. Details of the volumes of internal structures, such as pipework and beams, which would be needed to assess the precise free volume of the vessel, are not readily available.

(2) Calculations with a chute area equal to that of the square chute used in the experiments proved impractical because of convergence difficulties. The larger chute opening used for earlier studies [Marx 1988] has, therefore, been employed here. sensitivity studies have shown that the calculations are very insensitive to this parameter. 
Table 4.2

Riva-DCH 8patial Mesh

\begin{tabular}{|c|c|c|c|c|}
\hline $\begin{array}{l}\text { Mesh } \\
\text { Point }\end{array}$ & $\begin{array}{r}\text { Radial } \\
(\mathrm{m})\end{array}$ & Mesh & \multicolumn{2}{|c|}{$\underset{\text { (m) }}{\operatorname{Axial} \text { Mesh }}$} \\
\hline 1 & 0.0000 & (center) & 0.0000 & (floor) \\
\hline 2 & 0.1001 & & 0.4500 & \\
\hline 3 & 0.2001 & (chute radius) & 0.9000 & \\
\hline 4 & 0.3002 & & 1.3500 & \\
\hline 5 & 0.4194 & & 1.8000 & \\
\hline 6 & 0.5615 & & 2.2500 & \\
\hline 7 & 0.7309 & & 2.7000 & (chute exit) \\
\hline 8 & 0.9328 & & 3.1625 & \\
\hline 9 & 1.1734 & & 3.6250 & \\
\hline 10 & 1.4602 & & 4.0875 & \\
\hline 11 & 1.8020 & (outer wall) & 4.5500 & \\
\hline 12 & & & 5.0125 & \\
\hline 13 & & & 5.4750 & \\
\hline 14 & & & 5.9375 & \\
\hline 15 & & & 6.4000 & \\
\hline 16 & & & 6.8625 & \\
\hline 17 & & & 7.3250 & \\
\hline 18 & & & 7.7875 & \\
\hline 19 & & & 8.2500 & \\
\hline 20 & & & 8.7125 & \\
\hline 21 & & & 9.1750 & \\
\hline 22 & & & 9.6375 & \\
\hline 23 & & & 10.1000 & (ceiling) \\
\hline
\end{tabular}




\subsubsection{Debris and Gas Injection}

Table 4.3 lists the debris and gas parameters used for the Kiva-DCH analysis.

The lognormal droplet size distribution adopted for the earlier work [Marx 1988] has been retained for the present calculations. Because most of the debris recovered from the DCH-3 and $\mathrm{DCH}-4$ experiments was comprised of sheets of debris that had adhered to surfaces while still molten, rather than individual particles, no new data are available on particle size distribution of airborne debris. sensitivity studies have indicated that the results of the Kiva calculations are fairly insensitive to the debris particle size.

Pyrometer measurements of the debris plume entering surtsey in the $\mathrm{DCH}-3$ and $\mathrm{DCH}-4$ experiments indicated temperatures on the order of $2500^{\circ} \mathrm{K}$. Previously, it was assumed that this surface temperature represented a lower limit for the plume as a whole, and a bulk debris temperature of $2500 \mathrm{~K}$ was chosen for the analysis reported in Marx [1988] (the theoretical temperature of the thermite melt is around $2800 \mathrm{~K}$ ). However, more recent measurements of a disrupted debris jet during the HIPS-10s experiment [Allen et al. 1990] have indicated that there is little variation in temperature within the debris cloud as it emerges from the cavity. A debris temperature of $2300 \mathrm{~K}$ has therefore been assumed for the present analysis. The debris temperature for the $\mathrm{Kiva}-\mathrm{DCH}$ calculations was set to a slightly higher value $(2370 \mathrm{~K})$ to allow the latent heat of fusion of $\mathrm{Al}_{2} \mathrm{O}_{3}$ to be more accurately modeled.

The debris and gas masses injected were set to match those reported for the $\mathrm{DCH}-3$ and $\mathrm{DCH}-4$ experiments. The choice of debris mass is explained in Table 4.4. The extra mass recovered from the experiments was assumed to be composed of eroded $\mathrm{Fe}$ metal and $\mathrm{O}_{2}$ absorbed from the atmosphere by iron oxidation. The amount of oxygen absorbed was an initial estimate that could be revised, but the resulting change in debris specification would be small and would have no significant effect on the results reported here. 
Table 4.3

Debris and Gas Injection Parameters

$\begin{array}{lll}\text { Parameter } & \mathrm{DCH}-3 & \mathrm{DCH}-4\end{array}$

Debris:

Temperature (K)

Injection period (s)

Mass mean debris

particle diameter $(\mu \mathrm{m})$

Initial velocity $(\mathrm{m} / \mathrm{s})$

Mass injected $(\mathrm{kg})$ :

$\begin{array}{ccc}\mathrm{Fe} & 50.5 & 46.5(2) \\ \mathrm{Al}_{2} \mathrm{O}_{3} & \underline{36.3} & \underline{35.3(2)} \\ \text { Total } & 86.8 & 81.8\end{array}$

Blowdown $\mathrm{N}_{2}$ :

Temperature (K)

Injection period (s)

$\mathrm{N}_{2}$ injected (kgmoles) (2)

\section{$2300(2)$}

$0.0-0.65(1,3)$

$550(1)$

$72(1)$

$46.5(2)$

81.8

Notes:

(1) These values were retained from Marx [1988].

(2) These values are appropriate for $\mathrm{DCli}-3$ and $\mathrm{DCH}-4$.

(3) Debris injection was assumed to be at a constant rate. 
Derivation of Debris Data Used for the Analysis

Description

$\frac{\text { Debris Masses }(\mathrm{kg})}{\mathrm{DCH}-3}$

\begin{tabular}{llcc}
\hline $\begin{array}{l}\text { Initial } \\
\text { charge }\end{array}$ & $\begin{array}{l}\mathrm{Al}_{2} \mathrm{O}_{3} \\
\text { Fission product } \\
\text { simulants }\end{array}$ & 34.0 & 34.2 \\
& $\mathrm{Fe}$ & 3.5 & 3.5 \\
& $\begin{array}{l}\text { Subtotal (original } \\
\text { debris) }\end{array}$ & $\underline{42.0}$ & $\underline{42.2}$ \\
& 79.5 & 79.9 \\
Eroded metal, lumped with Fe(1) & $\underline{10.2}$ & $\underline{7.3}$
\end{tabular}

Estimated debris that reached the cavity 89.7 87.2

Composition of debris that reached the cavity (wt. $z$ )

$\mathrm{Fe} \quad 58.2$

56.7

Other (assumed to be $\mathrm{Al}_{2} \mathrm{O}_{3}$ )

Preliminary estimate of

$\mathrm{O}_{2}$ absorbed from atmosphere

$7 \cdot 7$

0.2

Total Recovered Debris Mass

97.4

87.5

Notes:

(1) The extra mass recovered was assumed to be composed of eroded $\mathrm{Fe}$ metal and $\mathrm{O}_{2}$ absorbed from the atmosphere by Fe oxidation. The amount of oxygen absorbed was an initial estimate that could be revised but the resulting change in debris specification would be small and would have no significant effect on the results reported here. 
Table 4.4 (Concluded)

Derivation of Debris Data Used for the Analyses

Description

Debris Masses $(\mathrm{kg})$

$\mathrm{DCH}-3 \quad \mathrm{DCH}-4$

Fraction of debris recovered

from the Surtsey vessel

$97 \%$

$94 \%$

Less $\mathrm{O}_{2}$ from atmosphere

7.7

0.2

Initial mass of debris which entered Surtsey, assumed for analysis

86.8

82.0

Notes:

(1). The extra mass recovered was assumed to be composed of eroded Fe metal and $\mathrm{O}_{2}$ absorbed from the atmosphere by Fe oxidation. The amount of oxygen absorbed was an initial estimate that could be revised but the resulting change in debris specification would be small and would have no significant effect on the results reported here. 
The debris injection period of $0.65 \mathrm{~s}$ was based on calculations with the GASRI,OW code [Pilch and Tarbell 1985]. The injection of the nitrogen blowdown gas was also calculated using GASBLOW, with initial conditions appropriate to $\mathrm{DCH}-3$.

For the $\mathrm{DCH}-4$ analysis, the gas blowdown history for $\mathrm{DCH}-3$ was used but the mass flow rates were linearly scaled to reproduce the somewhat greater mass of blowdown gas in $\mathrm{DCH}-4$.

\subsubsection{Debris-8urface Interactions}

Kiva-DCH includes a parametric model that allows a userspecified fraction, Ptrap, of the debris to be trapped on contact with the side walls or roof of the vessel; the remaining particles ( 1 - Ptrap) bounce from the surfaces. A second option allows a fraction of material trapped on the roof, Pdrip, to drip after a specified time delay [Marx 1988]). Debris that is allowed to bounce from the roof retains radial momentum and therefore has a chance of colliding with the side walls. Debris that drips, on the other hand, falls vertically and is almost certain to reach the floor. Because the final distributions of the debris in the $\mathrm{DCH}-3$ and $\mathrm{DCH}-4$ experiments were known, it was decided to take advantage of the parametric models in Kiva to match these distributions in the calculations by adopting appropriate values of Ptrap and Pdrip.

In the first instance, a high trapping probability (Ptrap) was selected, in line with the analyses in Marx [1988]. The dripping probability was then adjusted to yield the observed debris mass on the floor. Observations during the experiments implied that much of the debris on the floor originated from dripping after a jelay of about $2 \mathrm{~s}$, and the drip delay time was set to $2 \mathrm{~s}$.

Calculations were performed such that most of the debris made its first impact with the roof. As a result less material reached the walls in the calculations than in the experiments. In a second set of calculations, Ptrap was reduced to allow more debris to splash from the roof, which increased the wall loadings to more accruately correspond to the measured values. 
Pdrip was in turn adjusted to maintain the correct debris mass on the floor. In practice, this second method yielded less satisfactory agreement between the calculated and observed pressure histories and it seems likely that the splashing model is not an appropriate way to represent the redistribution of debris from roof to walls.

The values of Ptrap and Pdrip employed in the Kiva-DCH calculations and the calculated and measured distributions of the debris are given in Table 4.5 .

\subsubsection{Initial conditions}

The initial temperature, pressure, and gas composition for the DCH-3 and $\mathrm{DCH}-4$ atmosphere used in the Kiva-DCH calculations are shown in Table 4.6. For $\mathrm{DCH}-3$ the vessel contained dry air, while for $\mathrm{DCH}-4$ the vessel contained argon with some residual air.

\subsubsection{Riva-DCH Results}

The results of the Kiva calculations representing the $\mathrm{DCH}-3$ and DCH-4 experiments are presented below. The effects of altering the kiva trapping and dripping probabilities, the iron oxidation and the debris mass are described.

\subsubsection{Pressure}

Table 4.7 lists the peak pressures calculated by Kiva for the $\mathrm{DCH}-3$ and $\mathrm{DCH}-4$ simulations and compares these values with the experimentally determined values. The effects of altering the assumed trapping and dripping probabilities in the code are shown. The double mesh calculations (44 axial and 20 radial mesh intervals instead of 22 and 10 respectively) gave values closer to measured values. 


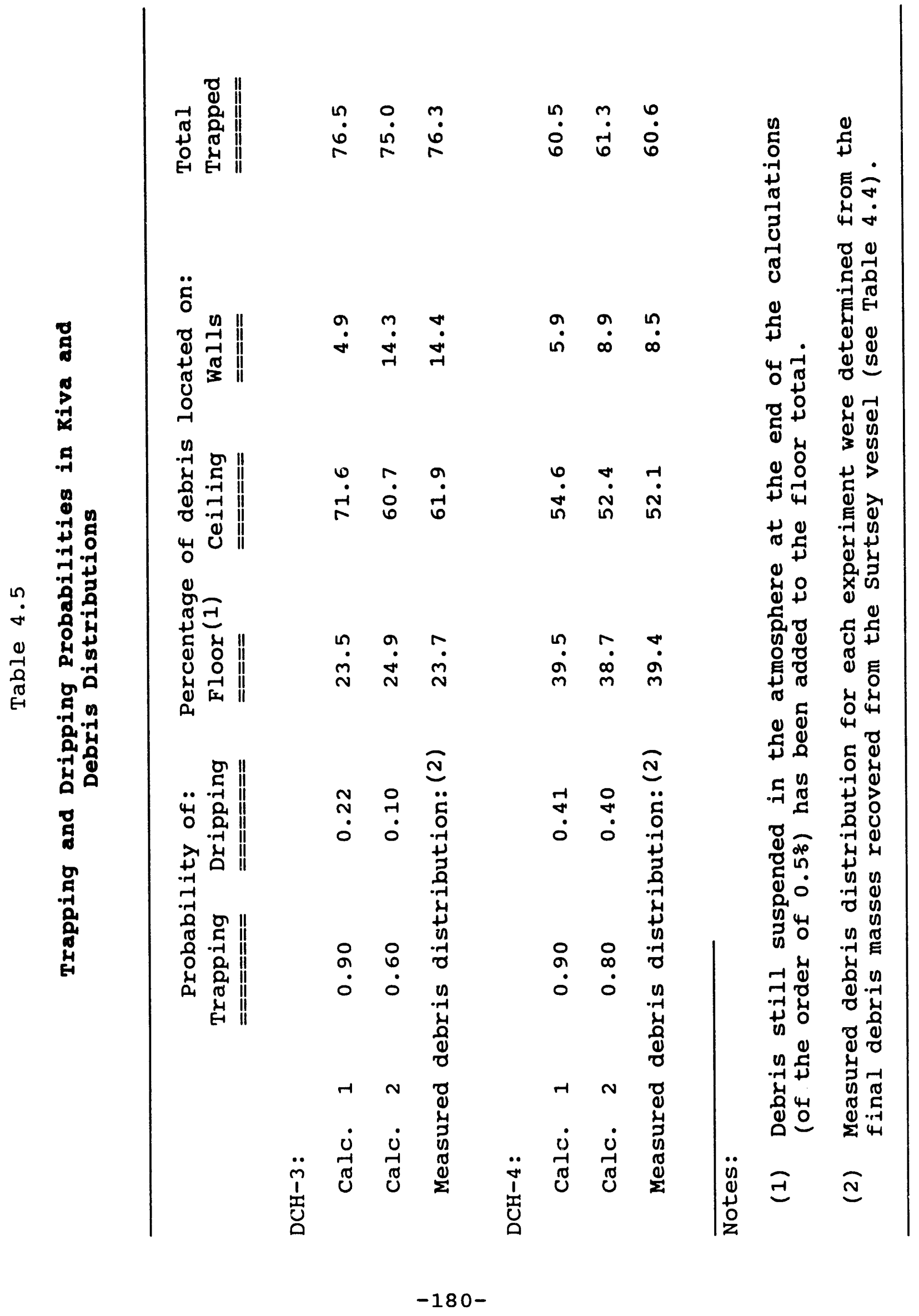


Table 4.6

DCH-3 and DCH-4 Initial Conditions

\begin{tabular}{ccc}
\hline Condition & $\mathrm{DCH}-3$ & $\mathrm{DCH}-4$ \\
\hline Temperature (K) & 295 & 293 \\
Pressure (MPa) & 0.08267 & 0.08267 \\
$\begin{array}{c}\text { Gas Composition } \\
\text { (mole } 8 \text { ) }\end{array}$ & & \\
$\mathrm{N}_{2}$ & 78.12 & 8.85 \\
Or & 20.95 & 1.63 \\
Ar (kgmoles) & 0.93 & 89.52 \\
Total Gas Content & 3.461 & 3.485
\end{tabular}

Notes:

(1) For $\mathrm{DCH}-3$ the composition of dry air from weast and Astle [1980] was assumed, except that the $\mathrm{CO}_{2}(0.03$ percent) was lumped with Ar.

(2) For DCH-4 the initial composition of the atmosphere is that of the final gas sample taken before the test (No. 10-4). Earlier samples gave somewhat higher $\mathrm{N}_{2}$ and $\mathrm{O}_{2}$ readings, implying that the gas lines had not been sufficiently purged. 


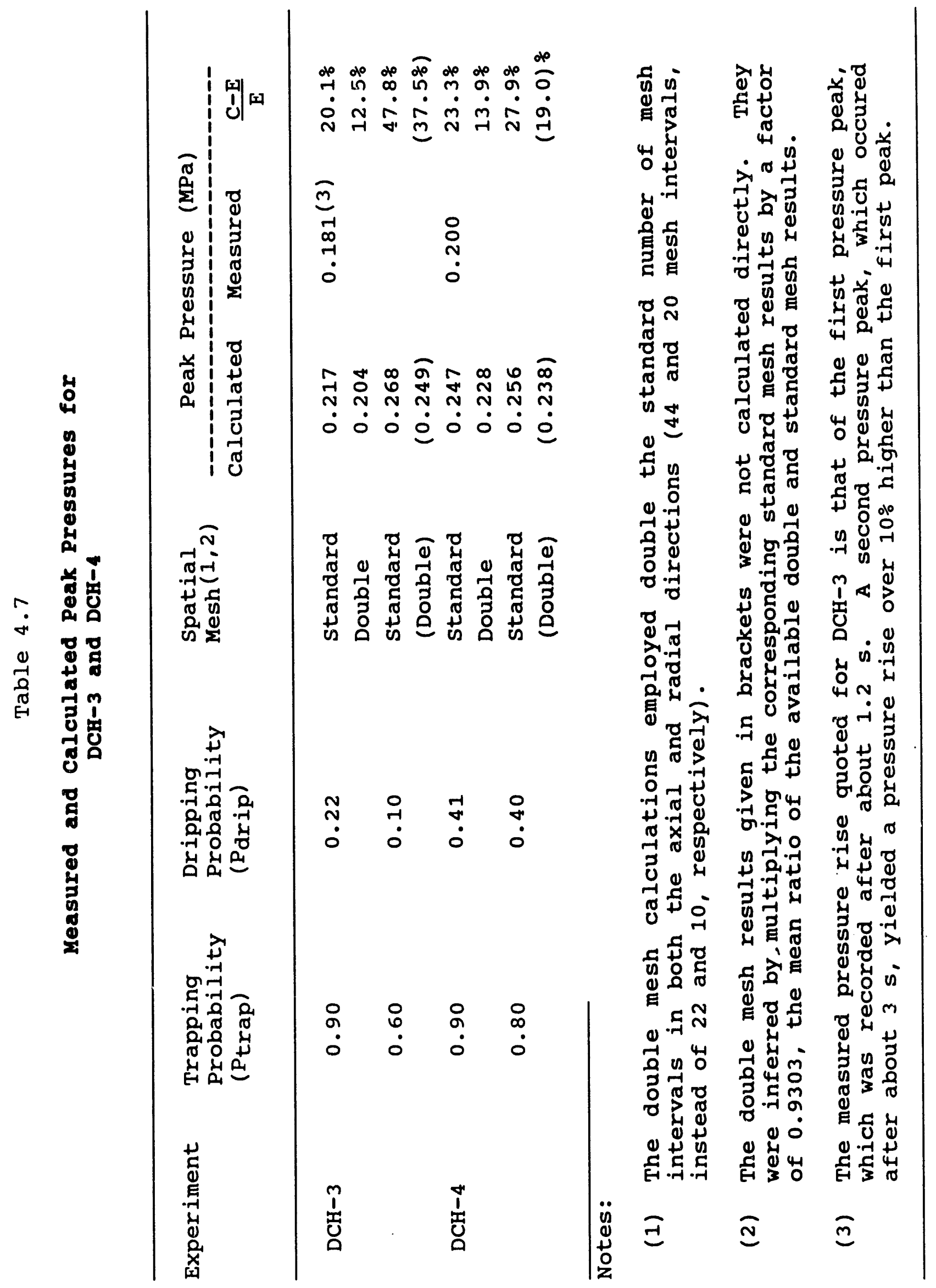


Figure 4-3 compares the Kiva calculations for DCH-3 with Ptrap $=0.90$ and $P_{\text {drip }}=0.22$ with the measured pressure history for the DCH-3 test. Figure 4-3 also provides the comparison of measured pressure against the Kiva calculation when the finer spatial resolution mesh was used. The time zero of the calculation and the experiment have been made to correspond by designating the start of debris ejection as time zero in both figures.

Figure 4-4 compares the DCH-3 Kiva calculation with $P_{\text {trap }}=0.60$ and $P_{\text {drip }}=0.10$ against the measured pressure history for the $\mathrm{DCH}-3$ test. Once again the time zeros have been made to correspond by equating the start of debris ejection.

Figure 4-5 shows the Kiva calculation for DCH-4 with Ptrap $=0.90$ and Pdrip $=0.22$ compared to the measured values of the $\mathrm{DCH}-4$ experiment. Both the standard and double mesh calculations are presented. Figure 4-6 compares the Kiva DCH-4 calculation with $P_{t r a p}=0.80$ and Parip $=0.40$ to the experimental values. As with the $\mathrm{DCH}-3$ results, the time zero of the calculations have been made to correspond to the start of debris ejection.

The calculations with standard spatial mesh and Ptrap $=0.9$ consistently overpredict the initial pressure peak by about 20 percent. For calculations with double the number of mesh intervals, this discrepancy is reduced to about 13 percent. Finer discretization of the grid may result in a more accurute prediction of the peak pressure, however, computational time becomes a factor.

Figures 4-4 to 4-6 show a second pressure peak in the experimental data at about 3.5 seconds. Neither Ptrap/Parip setting for the Kiva calculations resulted in a second rise in pressure. The possible explanations for this are discussed later. 


\subsubsection{Iron Oxidation}

The effect of iron oxidation in the kiva analyses is illustrated in Figures 4-7 to 4-10, where calculated pressure histories with and without iron oxidation are presented.

With Ptrap $=0.9$, (Figure 4-7) Kiva calculates a pressure increment of $0.02 \mathrm{MPa}$ from the iron reaction in $\mathrm{DCH}-3, \mathrm{i} . \mathrm{e}$, an increase in the peak pressure of about 10 percent. The corresponding pressure increment for DCH-4 (Figure 4-8) is of the same order $(0.015 \mathrm{MPa})$ even though the mass of iron calculated to react was only about 20 percent of that for the DCH-3 case.

When the trapping probability for $\mathrm{DCH}-3$ was reduced to 0.6 , (Figure 4-9) the Kiva pressure rise from oxidation was more than doubled, although only about 25 percent more iron reacted. The DCH-4 results with reduced trapping are relatively unchanged (Figure 4-10).

Table 4.8 compares the corresponding kiva peak pressures (with and without oxidation) with pressure rises estimated by bringing the debris and atmosphere to thermal equilibrium. In these simple hand calculations, the iron mass assumed to oxidize has been taken from the corresponding Kiva calculation in each case.

In Table 4.8 the equilibrium pressure rise is estimated from the equilibrium final temperature, $T_{f}$, using the perfect gas law. The equilibrium final gas temperature is estimated from the expression [Marx 1988]:

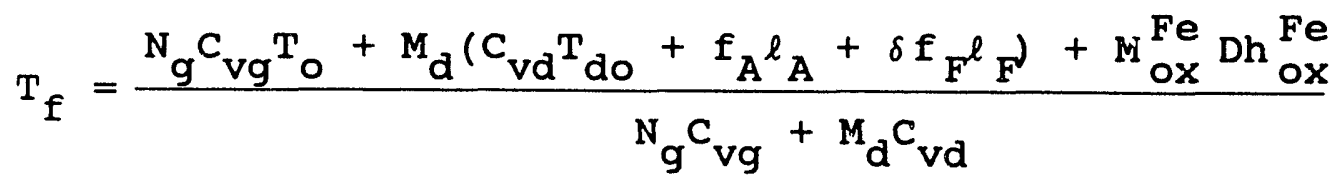

where, 


$$
\begin{aligned}
& \mathrm{N}_{\mathrm{g}} \text { = number of kgmoles of gas in Surtsey (see Table 4.6). } \\
& \begin{array}{l}
C_{v g}=\text { gas specific heat, taken to be } 3 R \text { for } \operatorname{air} \text { and }(3 / 2) R \\
\text { for argon. }
\end{array} \\
& R=\text { universal gas constant } \\
& =8.32 \mathrm{~kJ} / \mathrm{kgmole} \cdot \mathrm{K} \text {. } \\
& \mathrm{C}_{\mathrm{vd}}=\text { debris specific heat }=1.3 \mathrm{~kJ} / \mathrm{kg} \cdot \mathrm{K}[\operatorname{Marx} 1988] \cdot \\
& f_{A}=\begin{array}{l}
\text { mass fraction of } \mathrm{Al}_{2} \mathrm{O}_{3} \text { in debris (taken as } 42.6 \% \\
\text { throughout). }
\end{array} \\
& f_{F}=\text { mass fraction of } F e \text { in debris (taken as } 57.4 \% \\
& \text { throughout). } \\
& l_{\mathrm{A}}=\text { latent heat of fusion of } \mathrm{A}_{2} \mathrm{O}_{3} \text { (m.p. } 2303 \mathrm{~K} \text { ) }= \\
& 1067 \mathrm{~kJ} / \mathrm{kg} \text {. } \\
& \left.l_{F}=\text { latent heat of fusion of Fe metal (m.p. } 1809 \mathrm{~K}\right)= \\
& 246 \mathrm{~kJ} / \mathrm{kg} \text {. } \\
& \delta=\text { delta function } \\
& =0.0 \text { if } \mathrm{T}_{\mathrm{f}}>1809 \mathrm{~K} \text {, } \\
& =1.0 \text { if } T_{f}<1809 \mathrm{~K} \text {. } \\
& \mathrm{T}_{\mathrm{o}}=\text { initial atmosphere temperature (see Table 4.6). } \\
& \mathrm{T}_{\mathrm{do}}=\text { initial debris temperature (see Table 4.3). } \\
& \mathrm{M}_{\mathrm{d}} \text { = debris mass }(\mathrm{kg}) \text {. } \\
& \mathrm{MFe}=\text { mass of iron oxidized (from the corresponding } \\
& \text { ox Kiva calculation) } \\
& \mathrm{Dh} F e \text { = heat released from iron oxidation, assumed } \\
& \text { ox to be } 4870 \mathrm{~kJ} / \mathrm{kg} \text { [Marx 1988]. }
\end{aligned}
$$

The values of $C_{V d}, \ell_{A}$, and $\ell_{F}$ were estimated from the enthalpy tables employed by Kiva-DCH. It should be noted that these simple equilibrium estimates do not allow for the effect of the blowdown of nitrogen or for the effect of heat losses, both of which are modelled by Kiva. 


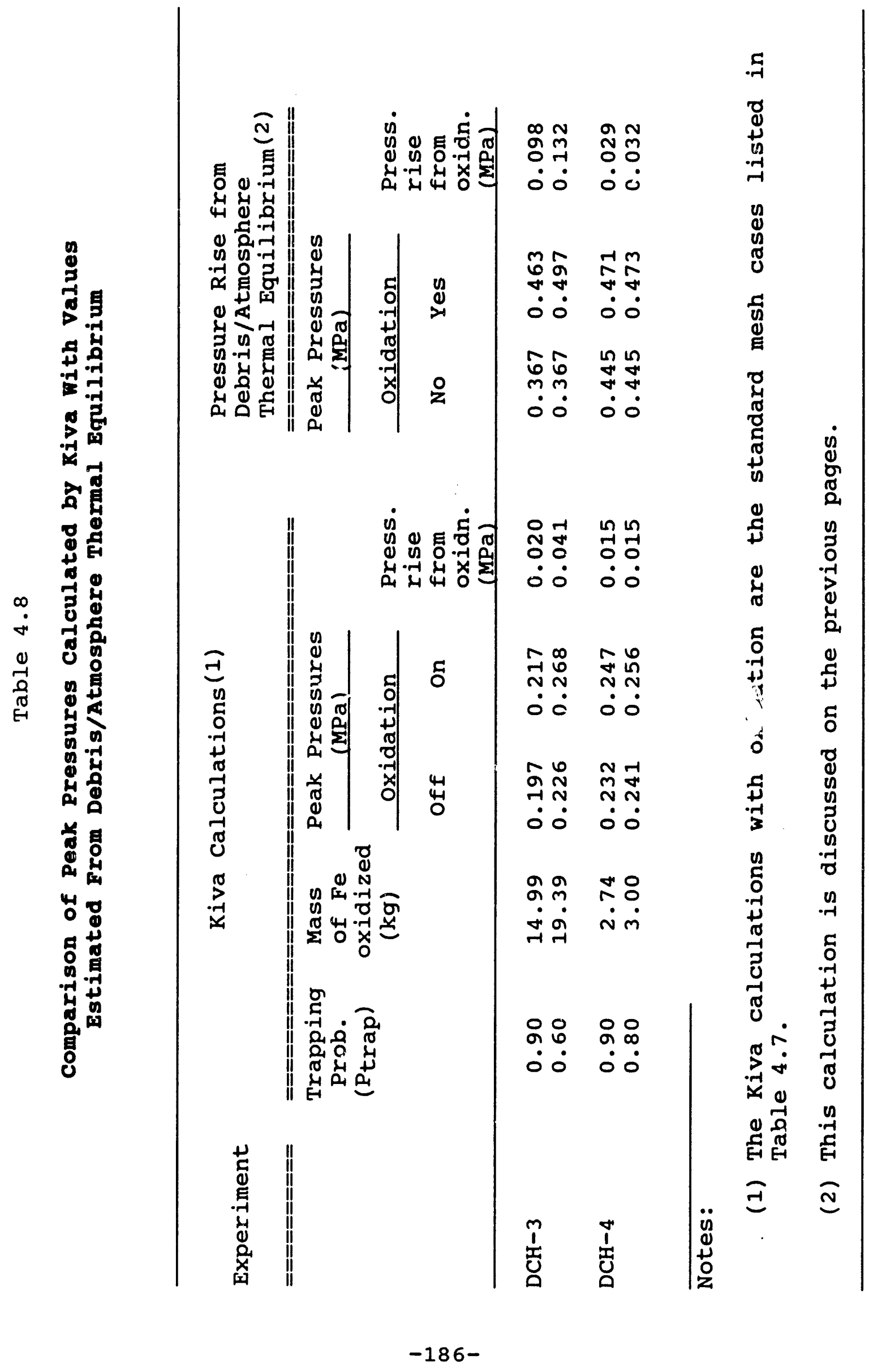


Table 4.9 lists the measured oxygen depletions for the $\mathrm{DCH}-3$ and $\mathrm{DCH}-4$ experiments and compares them with those of the Kiva calculations. The table contains corrections to the experimental values to allow for the oxygen needed to oxidize the carbon monoxide and hydrogen it is estimated burned in the experiments (see section 4.2 .2 .3 ).

The initial and final gas inventories used to derive the data in Table 4.9 were determined as follows:

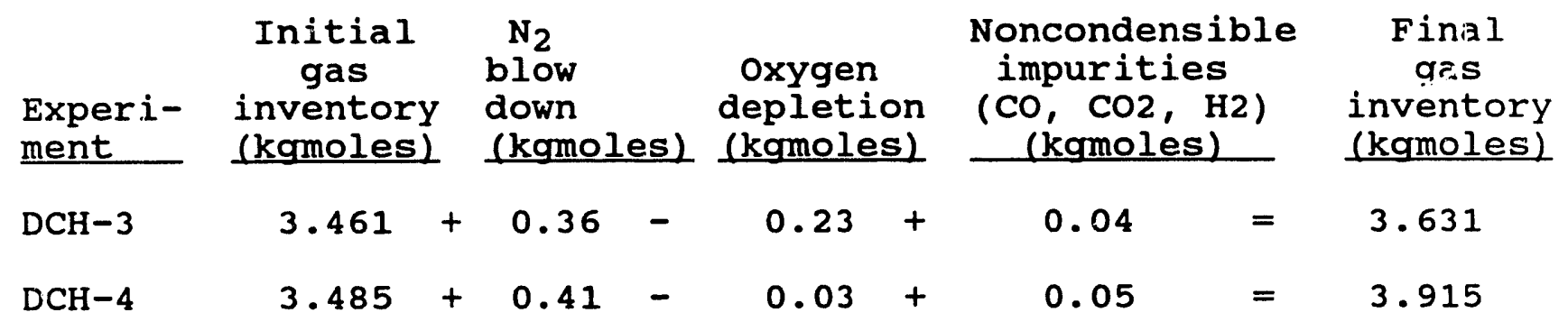

From the gas analysis results described in the next section, the total oxygen depletion may be deduced:

$\underline{\mathrm{DCH}-3}$

Total komoles mole

Before

Test:

3.461

21.38

0.740

$14.00 \quad \underline{0.508}$

3.631

Ater

Test:

oxygen

Depletion

(kgmoles):
DCH-4

Total

kgmoles mole: kgmoles

3.485

1.63

0.0568

3.915

0.71

$\underline{0.0278}$

$\underline{0.029}$

In the calculations above, up to 30 percent less oxygen was used for iron oxidation than in the experiments. However, Kiva was expected to underestimate the oxidation because it does not model the continuing oxidation of debris that was trapped on surfaces. In addition, the experimental values were subject to uncertainties associated with the gas analysis and these uncertainties would affect the comparison. 


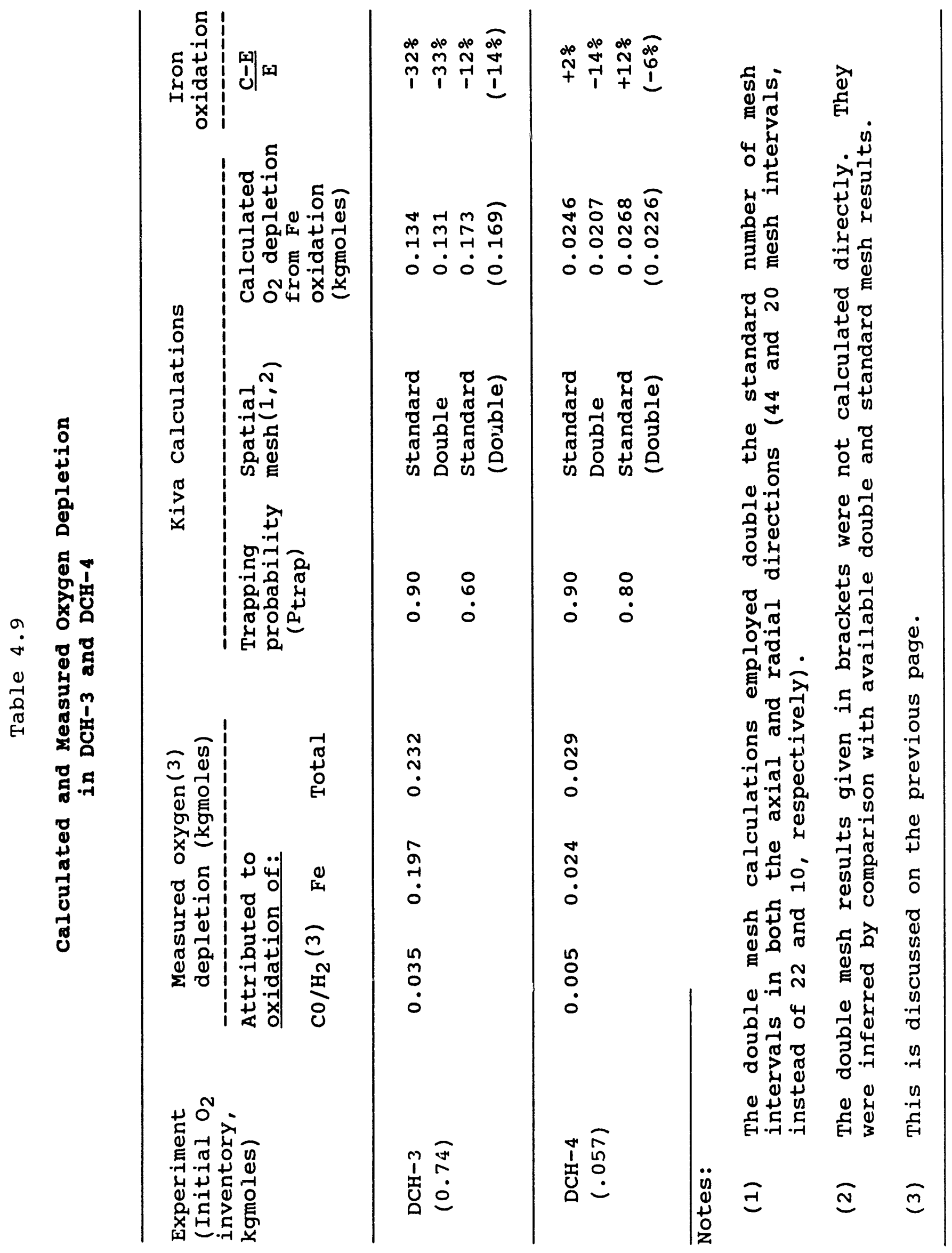




\subsubsection{Gas Analysis}

Table 4.10 gives the measured compositions of the surtsey atmosphere before and after the $\mathrm{DCH}-3$ and $\mathrm{DCH}-4$ tests.

During $\mathrm{DCH}-4$ carbon monoxide and hydrogen were added $(0.60$ and 0.42 molef respectively), while a little carbon dioxide ( 0.15 moleq) was added. After the $\mathrm{DCH}-3$ test, almost no $\mathrm{H}_{2}$ was detected and no $c 0$ was found, but 1.15 moleq of $\mathrm{CO}_{2}$ was detected.

These observations imply that oxides of carbon, hydrogen and perhaps steam $\epsilon$ tered the vessel with the debris during these experiments. Such gases are liberated by reacting thermite and when concrete is ablated by high temperature melts. Because of their close association with reducing metals in the melt, it is assumed that these gases reached the surtsey atmosphere as hot $\mathrm{H}_{2}$ and $\mathrm{CO}$.

In $\mathrm{DCH}-3$, most of the $\mathrm{CO}$ appears to have reacted with the oxygen in the air atmosphere to form $\mathrm{CO}_{2}$ (which was detected) and $\mathrm{H}_{2} \mathrm{O}$ (which was not detectable using the gas analysis methods). In $\mathrm{DCH}-4$, where the atmosphere included only about 1.6 moles $\mathrm{O}_{2}$, only a little of the $\mathrm{CO}$ was oxidized.

It is possible to estimate the amount of $\mathrm{CO}$ and $\mathrm{H}_{2}$ injected during the $\mathrm{DCH}-3$ and $\mathrm{DCH}-4$ experiments. For $\mathrm{DCH}-4$, first consider the moler of carbon oxides at the end of the experiment (see Table 4.10):

End mole? of oxides $=\mathrm{CO}+\mathrm{CO}_{2}-$ background

$$
\begin{aligned}
& =0.60+0.16-0.01 \\
& =0.75
\end{aligned}
$$

where the background molez of oxides is assumed to consist of $\mathrm{CO}_{2}$. If no $\mathrm{CO}_{2}$ was injected with the $\mathrm{CO}$ at the start of the test, it can be concluded that 0.75 mole\% of $c 0$ was injected, of which 0.15 moles was oxidized to $\mathrm{CO}_{2}$. 
Table 4.10

DCH-3 and DCK-4 Experiment Gas samples

\begin{tabular}{|c|c|c|c|c|c|c|c|}
\hline \multirow[t]{2}{*}{ Data } & & \multicolumn{6}{|c|}{ Moles of } \\
\hline & & $\overline{\mathrm{H}_{2}}$ & $\mathbf{N}_{2}$ & $\mathrm{O}_{2}$ & $\mathrm{CO}$ & Ar & $\mathrm{CO}_{2}$ \\
\hline \multicolumn{8}{|l|}{ For $\mathrm{DCH}-3$} \\
\hline $\begin{array}{l}\text { Pretest } \\
\text { Posttest }\end{array}$ & $\overline{-}$ & $\overline{0} .04$ & $\begin{array}{l}77.64 \\
83.89\end{array}$ & $\begin{array}{l}21.38 \\
14.00\end{array}$ & - & $\begin{array}{l}0.95 \\
0.89\end{array}$ & $\begin{array}{l}0.03 \\
1.18\end{array}$ \\
\hline \multicolumn{8}{|l|}{ For $\mathrm{DCH}-4$} \\
\hline $\begin{array}{l}\text { Pretest } \\
\text { Posttest }\end{array}$ & - & $\overline{0.42}$ & $\begin{array}{r}8.85 \\
17.00\end{array}$ & $\begin{array}{l}1.63 \\
0.71\end{array}$ & $\overline{0} .60$ & $\begin{array}{l}89.51 \\
81.11\end{array}$ & $\begin{array}{l}0.01 \\
0.16\end{array}$ \\
\hline
\end{tabular}

Notes:

(1) For $\mathrm{DCH}-3$, the pretest data comprised the mean of all four background samples taken before the test, except that one anomalous $\mathrm{CO}_{2}$ result was rejected. These data were used to estimate the oxygen depletion during the test but the initial composition of the atmosphere for the Kiva analyses was taken to be that for dry air given in weast and Astle [1980] (see Table 4.6). The posttest data were the mean values of the 6 samples taken between 6 and 12 minutes after the test, when a consistent set of readings was obtained.

(2) For DCH-4, the pretest data were the results of the final sample taken before the test. Earlier samples gave significantly higher $\mathrm{N}_{2}$ and $\mathrm{O}_{2}$ readings, indicating that sample lines had not been completely purged. The posttest data comprise the means of 4 of the 5 sets of results taken between 10 and 19 minutes after the test. 
Assuming that $\mathrm{x}$ molef of $\mathrm{H}_{2}$ was oxidized to steam, and that the same proportions of injected $\mathrm{H}_{2}$ and $\mathrm{CO}$ were oxidized,

$$
\begin{aligned}
& -\frac{x}{\text { moleq of } \mathrm{H}_{2}}=\frac{x}{0.42}=\frac{\mathrm{Co}_{2} \text { moleq }}{\mathrm{Co} \mathrm{moleq}_{6}}=\frac{0.15}{0.60} \\
x= & 0.42\left(\frac{0.15}{0.60}\right) \text { moleq } \\
= & 0.105 \text { moleq }
\end{aligned}
$$

This reasoning implies that 0.105 moles of $\mathrm{H}_{2}$ oxidized to steam. The total amount of $\mathrm{H}_{2}$ injected must then be

$$
0.42 \text { moleq }+0.105 \text { moleq }=0.525 \text { moleq } .
$$

It is possible, then, that

$$
0.15 \text { moleq } \mathrm{CO}+0.105 \text { moleq } \mathrm{H}_{2}=0.255 \text { moleq }
$$

of gases were oxidized in $\mathrm{DCH}-4$, which implies that

$$
\frac{0.255 \text { moleq }}{2}=0.1275 \text { mole\% }
$$

of $\mathrm{O}_{2}$ participated in oxidizing $\mathrm{CO}$ and $\mathrm{H}_{2}$.

This analysis can be repeated for $\mathrm{DCH}-3$ :

End moleq of oxides $=\mathrm{CO}+\mathrm{CO}_{2}$ - background

$$
\begin{aligned}
& =0.00+1.18-0.03 \\
& =1.15
\end{aligned}
$$

Therefore 1.15 moleq of $\mathrm{CO}$ was injected in $\mathrm{DCH}-3$, all of which was oxidized.

Steam could not be detected by the mass spectrometer, so the amount present must be estimated. Assuming that the $\mathrm{H}_{2} / \mathrm{CO}$ injection ratio was the same for $\mathrm{DCH}-3$ as for $\mathrm{DCH}-4$, 


$$
\frac{\mathrm{H}_{2}}{\mathrm{CO}_{\mathrm{DCH}-4}}=\frac{\mathrm{H}_{2}}{\mathrm{CO}_{\mathrm{DCH}-3}}=\frac{0.525 \text { molez }}{0.75 \text { molez }}=0.70 \text {, }
$$

then the amount of $\mathrm{H}_{2}$ injected in $\mathrm{DCH}-3$ would be

$$
1.15 \text { molez } \times 0.70=0.805 \text { moleq } .
$$

This yields

$$
0.805 \text { molez }-0.04 \text { moleq }=0.765 \text { moleq }
$$

of $\mathrm{H}_{2}$ which has been oxidized to steam.

Combininc; these results suggests that

$$
1.15 \text { molez }+0.765 \text { molez }=1.915 \text { molez }
$$

of the DCH-3 gases have been oxidized, and that

$$
\frac{1.915 \text { molez }}{2}=0.96 \text { mole\% }
$$

of $\mathrm{O}_{2}$ oxidized $\mathrm{CO}$ and $\mathrm{H}_{2}$.

These estimates of the impurity gases present and of the oxygen consumed in oxidizing them are summarized in Table 4.11, where the quantities of gas are given in kgmoles.

\subsubsection{Debris Mass Variations}

Figure 4-11 illustrates the pressure histories from Kiva calculations based on a DCH-4 case in which the mass of debris has been varied. The base calculation, with $82 \mathrm{~kg}$ of debris, is the DCH-4 calculation in Table 4.7 with $P_{\text {trap }}=0.9$. In the other calculations, the debris mass has been reduced to 60 percent, 30 percent, 10 percent, and 0 percent of $82 \mathrm{~kg}$, but all other data (including the trapping probability and nitrogen blowdown data) have been left unchanged.

Table 4.12 lists the peak pressure rises for the Kiva cases illustrated in Figure $4-11$ and also gives estimates of the 
pressure rises that would result from bringing the debris, blowdown nitrogen, and atmosphere to thermal equilibrium (with no heat losses). These estimates were made using a number of simplifying assumptions: for example, nominal values were used for the gas specific heats and no account was taken of the work done by the blowdown nitrogen in compressing the atmosphere. Nevertheless, it is instructive to compare the estimated pressure rises with those from Kiva.

Table 4.11

Estimated Impurity Gas Qualities for DCH-3 and DCH-4

\begin{tabular}{|c|c|c|c|c|c|c|}
\hline \multirow[t]{4}{*}{ Experiment } & \multicolumn{6}{|c|}{ Gas Quantities } \\
\hline & \multicolumn{4}{|c|}{ Impurity Gases } & \multirow{3}{*}{$\begin{array}{l}\text { Total } \\
\text { impurity } \\
\text { gases } \\
\text { oxidized }\end{array}$} & \multirow{3}{*}{$\begin{array}{l}\text { oxygen } \\
\text { used } \\
\text { to } \\
\text { oxidize } \\
\mathrm{CO}, \mathrm{H}_{2}\end{array}$} \\
\hline & \multicolumn{2}{|c|}{ co } & \multicolumn{2}{|c|}{$\mathrm{H}_{2}$} & & \\
\hline & Injected & $\begin{array}{l}\text { oxidized } \\
\text { to } \mathrm{CO}_{2}\end{array}$ & Injected & $\begin{array}{l}\text { oxidized } \\
\text { to } \mathrm{H}_{2} \mathrm{O}\end{array}$ & & \\
\hline \multicolumn{7}{|l|}{$\mathrm{DCH}-3$} \\
\hline Molez: & 1.15 & 1.15 & 0.805 & 0.765 & 1.915 & 0.96 \\
\hline kgmoles: (1) & 0.042 & 0.042 & 0.029 & 0.028 & 0.070 & 0.035 \\
\hline \multicolumn{7}{|l|}{$\mathrm{DCH}-4$} \\
\hline Molez: & 0.75 & 0.15 & 0.525 & 0.105 & 0.255 & 0.1275 \\
\hline kgmoles: (1) & 0.029 & 0.0059 & 0.021 & 0.00411 & 0.0100 & 0.0050 \\
\hline
\end{tabular}

Notes:

(1) The kgmole quantities are based on the posttest gas inventories of 3.631 and 3.915 kgmoles for $\mathrm{DCH}-3$ and DCH-4, respectively.

The equilibrium pressure rises were estimated by the method described in section 4.2.2.2, Iron oxidation, with the following exceptions: 
(a) The terms $\mathrm{N}_{b} C_{v b} T_{b}$ and $N_{b} C_{v b}$ have been added to the numerator and denominator, respectively, of the expression for the equilibrium temperature, $\mathrm{T}_{\mathrm{f}}$, where:

$\mathrm{N}_{\mathrm{b}}=$ number kgmoles of blowdown nitrogen = 0.41 kgmoles,

$C_{\mathrm{vb}}=\mathrm{N}_{2}$ specific heat, assumed to be $3 \mathrm{R} \mathrm{kJ} / \mathrm{kgmole} \cdot \mathrm{K}$, and

$\mathrm{T}_{\mathrm{b}}=$ blowdown gas temperature $=2000 \mathrm{~K}$.

(b) A simple correction has been made to the final pressure to allow for the volume of nitrogen gas added during blowdown. The iron masses assumed to oxidize in the equilibrium calculations were taken from the corresponding Kiva calculations.

Table 4.12

\section{Comparison of Kiva and simple calculations of Pressure Rise for a Range of Debris Masses with DCH-4 Conditions}

\begin{tabular}{|c|c|c|c|c|c|c|c|c|}
\hline \multirow{4}{*}{$\begin{array}{l}\text { Total } \\
\text { Debris } \\
\text { Mass } \\
\text { (kg) }\end{array}$} & \multirow{4}{*}{$\begin{array}{l}\text { KIVA } \\
\text { Calc. } \\
\text { Peak } \\
\text { Pres- } \\
\text { sure } \\
\text { Rise } \\
\text { (MPa) }\end{array}$} & \multicolumn{5}{|c|}{ Simple Equilibrium Calculations } & \multirow{2}{*}{\multicolumn{2}{|c|}{$\begin{array}{l}\text { Iron Reacted } \\
\text { from Kiva }\end{array}$}} \\
\hline & & \multirow{3}{*}{$\begin{array}{l}\text { Equili- } \\
\text { brium } \\
\text { Temp- } \\
\text { erature } \\
\quad(\mathrm{K})\end{array}$} & \multirow{2}{*}{\multicolumn{4}{|c|}{$\begin{array}{l}\text { Estimated Pressure } \\
\text { Rises (MPa) from: }\end{array}$}} & & \\
\hline & & & & & & & & \\
\hline & & & $\begin{array}{l}\operatorname{Iron}(1) \\
\text { Reaction }\end{array}$ & $\begin{array}{l}\text { Blowdown } \\
\text { Gas }\end{array}$ & $\begin{array}{l}\text { Debris } \\
\text { Stored } \\
\text { Heat }\end{array}$ & Total & $\begin{array}{l}\text { tion of } \\
\text { Total } \\
\text { Iron }\end{array}$ & $(\mathrm{k} . \mathrm{g})$ \\
\hline 82.1 & 0.247 & 1974 & 0.029 & 0.066 & 0.445 & 0.539 & 5.98 & 2.7 \\
\hline 49.3 & 0.228 & 1780 & 0.034 & 0.066 & 0.379 & 0.479 & $8.4 \%$ & 2.4 \\
\hline 24.7 & 0.203 & 1409 & 0.035 & 0.071 & 0.256 & 0.362 & 13.08 & 1.8 \\
\hline 8.2 & 0.167 & 962 & 0.023 & 0.087 & 0.111 & 0.221 & $19.6 \%$ & 0.9 \\
\hline
\end{tabular}

Notes:

(1) Some $\mathrm{Fe}$ oxidation occurs because the Ar atmosphere included 1.6 mole: $\mathrm{O}_{2}$ impurity. 


\subsection{Discussion}

\subsubsection{Pressure Histories}

Figure 4-12 shows the measured pressure histories of the DCH-3 and DCH-4 experiments. Comparing this figure with Figures 4-4 through 4-7, which are Kiva calculations with various trapping and dripping parameters, shows the differences resulting from changing these parameters.

\subsubsection{Initial Pressure Peak}

It has been suggested [Marx 1987] that the peak pressures in the $\mathrm{DCH}-3$ and $\mathrm{DCH}-4$ experiments were comparable partly because the additional energy liberated by chemical reactions in $\mathrm{DCH}-3$ was offset by the lower specific heat of the Ar atmosphere in $\mathrm{DCH}-4(\approx(3 / 2) \mathrm{R}$, compared with $\approx(5 / 2) \mathrm{R}$ to $\approx 3 \mathrm{R}$ for $\mathrm{air})$.

In fact, the initial pressure rise, which reaches a peak after about $1 \mathrm{~s}$, is about 10 percent higher for $\mathrm{DCH}-4$ than for $\mathrm{DCH}-3$. This trend is correctly predicted by the calculations with Ptrap $=0.9$ (Figure 4-13).

The measured pressure rise to the first peak is significantly slower for $\mathrm{DCH}-3$ than for $\mathrm{DCH}-4$ (see Figure 4-12). The calculations for $\mathrm{DCH}-3$ and $\mathrm{DCH}-4$ include all the known differences in boundary conditions, but both predict a pressure rise in line with that for $\mathrm{DCH}-4$. The reason for this observed difference between the experiments is not known at present.

The calculations with standard spatial mesh and Ptrap $=0.9$ consistently overpredict the initial pressure peak by about 20 percent. If calculations with double the number of mesh intervals are considered, thi:s discrepancy is reduced to about 13 percent (Figures $4-3,4-4$, and $4-6$ ). 


\subsubsection{Second Pressure Peak}

The experiments both show a second pressure peak, after about 3 seconds, which is much more pronounced in $\mathrm{DCH}^{-3}$ (see Figure 4-12). The calculations show no second peak. Marx [1988] suggests that the second pressure rise might be explained by debris dripping from the roof of the vessel. Such dripping had been observed in the experiments on an appropriate timescale and Kiva calculations with üripping did show second peaks of the required magnitude. The present kiva calculations also include dripping but the energy transfer from the drops to the atmosphere is much less than before and second pressure peaks are not predicted. This is because:

(a) Larger drops have been assumed $(13.4 \mathrm{~mm}$ diameter compared with $2.5 \mathrm{~mm}$ used previously). The present drop size is a mass-weighted mean of the main and satellite drops expected to form on the roof by Rayleigh-Taylor instability [Pilch 1988; Baker et al. 1988], while the earljer choice of drop size was arbitrary.

(b) Much lower dripping probabilities have been assumed $(0.1$ to 0.4 , compared with 0.5 for the earlier work). These were chosen to reproduce correctly the observed quantities of debris on the floor.

It is of interest to note that only about $22 \mathrm{~kg}$ of debris was recovered from the floor in $\mathrm{DCH}-3$, compared with $32 \mathrm{~kg}$ in $\mathrm{DCH}-4$. This implies less dripping in $\mathrm{DCH}-3$, even though a much larger second pressure peak was observed in that experiment. As a result, the "dripping" hypothesis is not supported by the experimental evidence.

An alternative hypothesis is that the second pressure peaks resulted from the combustion of $\mathrm{CO}$ and $\mathrm{H}_{2}$ in surtsey. It is believed that $\mathrm{CO}$ and $\mathrm{H}_{2}$ were present with the blowdown nitrogen and that some of this gas then combined with oxygen in the vessel. In section 4.2.2.3 the amounts of $\mathrm{CO}$ and $\mathrm{H}_{2}$ which were present and the amounts which oxidized have been estimated from the measured gas compositions. Arguments are now presented to explain the presence of the $\mathrm{CO}$ and $\mathrm{H}_{2}$. 
Experiments with thermite samples taken from the materials used for the $\mathrm{DCH}-3$ and $\mathrm{DCH}-4$ experiments have shown that on the order of 0.0002 to 0.0006 kgmoles of gas are liberated for each $\mathrm{kg}$ of thermite ignited. This gas consists of hydrogen, steam, and oxides of sarbon.

With the $80 \mathrm{~kg}$ of thermite used for DCH-3 and DCH-4, a yield of $0.016-0.048 \mathrm{kgmoles}$ of gas is implied, compared with the totals of $0.07 \mathrm{kgmoles}$ and $0.05 \mathrm{kgmoles}$ that must be accounted for in $\mathrm{DCH}-3$ and $\mathrm{DCH}-4$, respectively. Thus, gases liberated from reacting thermite can account for about one half of the inferred impurity gases. In order to account for the second half of the impurity gases (about 0.03 kgmoles), the ablation of the concrete floor by the melt was considered.

Hydrogen, steam, and oxides of carbon may be liberated when hot melts are poured onto concrete. The scaled zion cavity used in the $\mathrm{DCH}-3$ and $\mathrm{DCH}-4$ experiments was made from common sand/limestone concrete. The total internal surface area of the cavity was $1.735 \mathrm{~m}^{2}$. In experiments in the TURC series [Gronager et al. 1986], metallic melts were poured onto concrete of similar composition and initial ablation rates of $0.6 \mathrm{~mm} / \mathrm{s}$ were observed. Scaled to the total $1.7 \mathrm{~m}^{2}$ area of the zion cavity, the total gas release is $0.03 \mathrm{kgmoles} / \mathrm{mm}$ of concrete ablated.

In practice, significant ablation (perhaps a few $\mathrm{mm}$ ) was observed in the region where the melt impinged on the floor of the cavity, but ablation was much less elsewhere. However, an average ablation depth of $1 \mathrm{~mm}$ over the surface seems possible and this would account for the balance of the gas.

Using the estimates of $\mathrm{CO}$ and $\mathrm{H}_{2}$ determined previously it is possible to determine if the burning of $\mathrm{CO}$ and $\mathrm{H}_{2}$ can account for the second pressure rises by estimating the amount of energy needed for each rise and the amount available from the burning. 
Sweet and Washington* give the oxidation energy of $\mathrm{CO}$ and $\mathrm{H}_{2}$ as

CO: $2.83 \times 10^{8} \mathrm{~J} / \mathrm{kgmole}$

$\mathrm{H}_{2}: 2.86 \times 10^{8} \mathrm{~J} / \mathrm{kgmole}$.

Using the data in Table 4.11 for the number of kgmoles of $c 0$ and $\mathrm{H}_{2}$ oxidized in the experiment, the amount of energy liberated in $\mathrm{DCH}-3$ is found to be

CO: (0.042 kgmoles) $\left(2.83 \times 10^{8} \mathrm{~J} / \mathrm{kgmole}\right)=1.19 \times 10^{4} \mathrm{~kJ}$

$\mathrm{H}_{2}:(0.028 \mathrm{kgmoles})\left(2.86 \times 10^{8} \mathrm{~J} / \mathrm{kgmole}\right)=8.10 \times 10^{3} \mathrm{~kJ}$

Total $\approx 1.99 \times 10^{4} \mathrm{~kJ}$

From the initial and final pressures and temperatures in the Surtsey vessel, and the ideal gas law, the final temperature is

$$
T_{f}=\frac{P_{f}}{P_{i}} T_{i}
$$

In $\mathrm{DCH}-3$ the initial pressure of the chamber was $0.083 \mathrm{MPa}$ and the value of the first peak pressure was $0.181 \mathrm{MPa}$. This is an initial pressure peak of $0.083 \mathrm{MPa}+0.181 \mathrm{MPa}=0.264 \mathrm{MPa}$. $\mathrm{A}$ pressure rise of $0.05 \mathrm{MPa}$ is needed to account for the second pressure peak, giving the final pressure as $0.264 \mathrm{MPa}+$ $0.05 \mathrm{MPa}=0.314 \mathrm{MPa}$. Using $925 \mathrm{~K}$ as the temperature at the initial DCH-3 pressure peak, the ideal gas law gives the final temperature at the second pressure peak as

$$
\mathrm{T}_{\mathrm{f}}=\left(\begin{array}{ll}
0.31 & \mathrm{MPa} \\
\hline 0.26 & \mathrm{MPa}
\end{array}\right) 925 \mathrm{~K}=1103 \mathrm{~K} .
$$

This results in a required temperature rise of $178 \mathrm{~K}$ for the DCH-3 second pressure peak.

* Sweet, D.W. and K.E. Washington, to be published, Further Development of the $\mathrm{Kiva}-\mathrm{DCH}$ Code for the Analysis of the Transport and Chemical Reaction of Molten Debris in Direct Containment Heating Experiments, SAND90-2535. Sandia National Laboratories, Albuquerque, NM. 
For $\mathrm{DCH}-3$, in which the initial environment was air, the atmospheric gas specific heat is considered to be three times the universal gas constant or $3 \times 8.32 \mathrm{~kJ} / \mathrm{kgmole} \cdot \mathrm{K}=24.96$ $\mathrm{kJ} / \mathrm{kgmole} \cdot \mathrm{K}$. Then, with a total atmosphere comprising 3.631 kgmoles after the test (see section 4.2.2.2), it follows that the heat capacity of the atmosphere, $c$, is given by

$$
C=(24.96 \mathrm{~kJ} / \mathrm{kgmole} \mathrm{K})(3.631 \mathrm{kgmole})=90.6 \mathrm{~kJ} / \mathrm{K} \text {. }
$$

Since the temperature rise, $\Delta \mathrm{T}$, needed to account for the second peak is $178 \mathrm{~K}$, it follows that the energy required, $Q$, is

$$
\begin{aligned}
Q & =C \Delta T \\
& =(90.6 \mathrm{~kJ} / \mathrm{K})(178 \mathrm{~K}) \\
& =16100 \mathrm{~kJ} .
\end{aligned}
$$

This result compares favorably with the estimate of the amount of energy released by the oxidation of $\mathrm{CO}$ and $\mathrm{H}_{2}, 19900 \mathrm{~kJ}$.

Following the same line of reasoning for $\mathrm{DCH}-4$ : The amount of energy liberated by the oxidation of $\mathrm{CO}$ and $\mathrm{H}_{2}$ is

CO: (0.0059 kgmoles) $\left(2.83 \times 10^{8} \mathrm{~J} / \mathrm{kgmole}\right)=1670 \mathrm{~kJ}$

$\mathrm{H}_{2}:(0.0041 \mathrm{kgmoles})\left(2.86 \times 10^{8} \mathrm{~J} / \mathrm{kgmole}\right)=1173 \mathrm{~kJ}$

Total $\approx 2800 \mathrm{~kJ}$

The pressure at the initial pressure rise is

$$
0.20 \mathrm{MPa}+0.08 \mathrm{MPa}=0.28 \mathrm{MPa} .
$$

The second pressure peak is $0.016 \mathrm{MPa}$ above this value resulting in a total pressure for the second peak of $0.016 \mathrm{MPa}$ $+0.28 \mathrm{MPa}=0.296 \mathrm{MPa}$. The temperature of the first pressure peak in $\mathrm{DCH}_{-4}$ is of the order of $950 \mathrm{~K}$ and the final temperature is

$$
\mathrm{T}_{\mathrm{f}}=\left(\frac{0.296 \mathrm{MPa}}{0.28 \mathrm{MPa}}\right) 950 \mathrm{~K}=1004 \mathrm{~K}
$$

A temperature rise of $1004 \mathrm{~K}-950 \mathrm{~K}=54 \mathrm{~K}$ results from the second peak. 
The specific heat of argon is $(3 / 2) \mathrm{R}$ or $12.48 \mathrm{~kJ} / \mathrm{kgmole} \cdot \mathrm{K}$. Given the total amount of gas involved (3.915 kgmoles), the energy can be calculated:

$$
\begin{aligned}
Q & =(3.915 \mathrm{kgmoles})(12.48 \mathrm{~kJ} / \mathrm{kgmole} \cdot \mathrm{K})(54 \mathrm{~K}) \\
& =2640 \mathrm{~kJ}
\end{aligned}
$$

This result also compares favorably with the $2800 \mathrm{~kJ}$ released by the oxidation of $\mathrm{CO}$ and $\mathrm{H}_{2}$. Table 4.13 summarizes the results of the above calculations.

This analysis includes a number of simplifying assumptions. For example, heat losses from the atmosphere have been ignored in assessing the additional energy needed to generate the second pressure peak. However, the results show that energies of the orders of magnitude needed to explain the second pressure peaks could have been provided by burns of $\mathrm{CO}$ and $\mathrm{H}_{2}$ in each experiment. These gases would have initially been mixed with the inert blowdown gas, $\mathrm{N}_{2}$, so a delay of a second or so before the burns occurred also seems reasonable.

Although the concentrations of the reacting gases, in particular that of $\mathrm{O}_{2}$ in $\mathrm{DCH}-4$, would have been lower than the usual limits assumed for combustion (about 4 mole\%), it should be noted that the burns would have occurred at a high temperature $(\simeq 1000 \mathrm{~K})$, where few data exist. In addition, the detection of mainly $\mathrm{CO}_{2}$ after $\mathrm{DCH}-3$, contrasting with the presence of mainly $\mathrm{CO}$ following $\mathrm{DCH}-4$, provides strong evidence that gas oxidation did occur in surtsey.

\subsubsection{Iron Oxidation}

In Table 4.8 , the effects of iron oxidation estimated from Kiva and simple equilibrium calculations are compared. The equilibrium results show that the maximum pressure rise per $\mathrm{kg}$ of iron oxidized is significantly more for $\mathrm{DCH}-4$ than for $\mathrm{DCH}-3$, as expected from the atmosphere specific heats. This difference in specific heats is, however, insufficient to explain the Kiva results. 
Most of the remaining difference in the efficiency Kiva predicts for the transfer of chemical energy to the atmosphere is believed to result from a plume, or shielding, effect. In $\mathrm{DCH}-3$, the oxygen concentration is high and iron oxidation is significant throughout the debris cloud. Much of the chemical heat liberated within the cloud is shielded from the atmosphere and remains in the debris when it is trapped on surfaces. When more debris is allowed to splash, more of this energy is released to the atmosphere, resulting in the significantly larger pressure increment noted in section 4.2.2.2.

Table 4.13

Comparison of Gas Oxidation Energy With Energy Required for second Pressure Peak

\begin{tabular}{|c|c|c|c|c|c|c|}
\hline \multirow[t]{2}{*}{$\begin{array}{l}\text { Experi- } \\
\text { ment }\end{array}$} & \multirow[t]{2}{*}{$\begin{array}{l}\text { Quantity } \\
\text { of gas } \\
\text { oxidized } \\
\text { (kgmoles) }\end{array}$} & \multicolumn{2}{|c|}{$\begin{array}{l}\text { Energy release } \\
\text { from gas by } \\
\text { oxidation (kJ) }\end{array}$} & \multirow{2}{*}{$\begin{array}{l}\text { Approx. } \\
\text { pressure } \\
\text { rise } \\
\text { needed } \\
\text { for } \\
\text { second } \\
\text { peak } \\
\text { (MPa) }\end{array}$} & \multirow{2}{*}{$\begin{array}{l}\text { Corres- } \\
\text { ponding } \\
\text { temper- } \\
\text { ature } \\
\text { rise (K) }\end{array}$} & \multirow{2}{*}{$\begin{array}{l}\text { Energy } \\
\text { needed } \\
\text { for secon } \\
\text { pressure } \\
\text { peak (kJ) }\end{array}$} \\
\hline & & $\begin{array}{l}\text { For } \\
\text { each } \\
\text { Gas: }\end{array}$ & Total & & & \\
\hline $\mathrm{DCH}-3$ & $\begin{array}{l}\mathrm{CO}: 0.042 \\
\mathrm{H}_{2}: 0.028\end{array}$ & $\begin{array}{r}11886 \\
8008\end{array}$ & 19900 & 0.05 & 178 & 16100 \\
\hline $\mathrm{DCH}-4$ & $\begin{array}{ll}\mathrm{CO}: & 0.0059 \\
\mathrm{H}_{2}: & 0.0041\end{array}$ & $\begin{array}{l}1670 \\
1173\end{array}$ & $\underline{2800}$ & 0.016 & 57 & $\underline{2640}$ \\
\hline
\end{tabular}

In $\mathrm{DCH}-4$, by contrast, the oxygen concentration is low and the reaction is oxygen-starved where the debris concentration is dense. Relatively nore oxidation occurs therefore where debris is less dense, i.e. at the periphery of the main plume where the heat produced can be transferred more efficiently to the atmosphere and lead to the relatively high pressure rise predicted by Kiva. 


\subsubsection{Oxygen Depletion}

As mentioned earlier, Kiva was expected to underestimate the oxidation occurring because the code does not model the continuing oxidation of debris trapped on the vessel surfaces. The uncertainties in the results of the experimental gas analysis also add to problems with the oxidation estimates, and these uncertainties are difficult to estimate. However, an estimate of likely uncertainties is provided by noting that the initial $\mathrm{O}_{2}$ concentration in the $\mathrm{DCH}-3$ experiment was 21.38 percent. The expected value for an air atmosphere was 20.95 percent. If the difference of 0.43 percent between these values represents an uncertainty which is random between the gas sample analyses before and after the experiment, it would imply an uncertainty in the total $\mathrm{O}_{2}$ depletion as follows:

$$
\begin{aligned}
O_{2} \text { depletion } & =(3.461 *(21.38 \pm 0.43))-(3.631 *(14.00 \pm 0.43)) \\
& =0.740 \pm 0.015-0.508 \pm 0.016 \\
& =0.232 \pm 0.022
\end{aligned}
$$

If a similar uncertainty is assumed for the $\mathrm{Co} / \mathrm{H}_{2}$ concentrations, the $\mathrm{O}_{2}$ depletion from $\mathrm{Fe}$ oxidation would become

$$
(0.232 \pm 0.022-0.035 \pm 0.003)=0.197 \pm 0.022,
$$

or about \pm 11 percent.

A corresponding uncertainty for the DCH-4 case, where the initial $\mathrm{O}_{2}$ concentration is only 1.6 moles, would be much larger.

such uncertainties, coupled with the unquantified excess oxidation expected in the experiments, would make the calculated values of oxygen depletion seem reasonable. 


\subsubsection{Trapping and Dripping Parameters}

When the trapping probability in the calculations is reduced from 0.9 to allow the observed quantities of debris to reach the walls, the differences between the calculated and measured peak pressures become large and the consistent trend between the calculations and the experiments is lost.

The calculated pressure is increased because the extra splashed debris continues to interact with the atmosphere. In particular, the trapping probability for $\mathrm{DCH}-3$ needs to be reduced to 0.6 to yield the observed wall loading. In this case, the pressure rise calculated by a Kiva calculation with fine mesh is nearly 40 percent greater than the observed value.

For DCH-4, a smaller reduction of Ptrap (to 0.8 ) was necessary because less debris reached the walls in this experiment ( $8.7 \%$ compared with 14.68 in $\mathrm{DCH}-3)$. Consequently, with this approach, the peak pressure ralculated for $\mathrm{DCH}-3$ is greater than that for $\mathrm{DCH}-4$, the reverse of the observed trend for the experiments (and for the calculations with $P_{\text {trap }}=0.9$ ).

clearly, adjusting the trapping parameters to match the distribution of the trapped debris yields results which are inconsistent with the observed pressures. By contrast, calculations with $P_{\text {trap }}=0.9$ yielded consistent results for the pressure response but finish with too little debris on the walls (although the total amounts trapped and on the floor are correct).

It seems likely that some mechanism other than splashing is redistributing the debris. For example, once the roof becomes laden with debris, it is possible to envisage droplets being entrained from ripples on the surface, being swept around the dome and redeposited on the walls, without interacting significantly with the atmosphere. 


\subsection{5 sensitivity studies}

The effects of variation in the debris parameters, blowdown gas parameters, and model geometry were studied to investigate the sensitivity of the calculations to these parameters. The results of most of these cases are summarized in Table 4.15.

\subsubsection{Debris sensitivity studies}

Debris Mass. Figure 4-11 illustrates the pressure histories from Kiva calculations based on a $\mathrm{DCH}-4$ case in which the mass of debris has been varied. As the debris mass is increased, the calculated peak pressure approaches a plateau. For example, increasing the debris mass from $49 \mathrm{~kg}$ to $82 \mathrm{~kg}$ only increases the peak pressure by 8 percent. This is believed to be the result of the shielding (or cloud) effect. The atmosphere in the region of the debris approaches an equilibrium balance with the debris, and heat losses decrease limiting further heat transfer and chemical reactions, so that adding more debris has relatively little effect on the pressure.

Table 4.12 includes the peak pressure rises for the Kiva cases illustrated in Figure 4-11 and also gives estimates of the pressure rises which would result from bringing the debris, blowdown nitrogen, and atmosphere to thermal equilibrium (with no heat losses). As noted in section 4.2.2.4, these estimates were made using a number of simplifying assumptions.

For the higher mass cases, the equilibrium pressures are of the order of a factor of 2 greater than the Kiva peak pressures. As the debris mass is increased, the estimated equilibrium pressures also tend to approach a plateau, as the equilibrium temperature gets closer to the debris temperature $(2300 \mathrm{~K})$. However, the equilibrium pressure changes much more with debris mass than the Kiva peak pressures do.

If heat losses in Kiva are taken into account, the differences between the kiva results and the equilibrium estimates are 
reduced somewhat but still remain large. For example, if the radiation heat losses from the atmosphere to the walls [Marx 1988] are turned off, the peak Kiva pressure for an $82 \mathrm{~kg}$ case is increased by about 35 percent, but the equilibrium pressure is still a factor of 1.5 greater than the peak Kiva pressure.

These observations demonstrate that the Kiva peak pressures are insensitive to debris mass because of a cloud effect and not because the debris and atmosphere as a whole are approaching thermal equilibrium.

Debris Temperature. In the Kiva-DCH model, the state of each melt constituent is considered independently. No allowance is made for the change of melting point of materials when solutions are formed, for example, as when $\mathrm{Al}_{2} \mathrm{O}_{3}$ and $\mathrm{FeO}$ are mixed. Furthermore, the latent heat of fusion of each material is smeared over a $100 \mathrm{~K}$ interval. The latent heat of fusion of $\mathrm{Al}_{2} \mathrm{O}_{3}$ (melting point $2309 \mathrm{~K}$ ) is smeared over the range 2300-2400 K, for example.

This effect is illustrated by the Kiva-DCH pressures listed in Table 4.14 for a range of specified initial debris temperatures. The change in calculated pressure is much greater between $2300 \mathrm{~K}$ and $2400 \mathrm{~K}$ where the $\mathrm{Al}_{2} \mathrm{O}_{3}$ latent heat is liberated, than over $100 \mathrm{~K}$ intervals above and below this range. It follows that to allow for the latent heat of $\mathrm{Al}_{2} \mathrm{O}_{3}$ in the analysis, a Kiva-DCH initial debris temperature of $2370 \mathrm{~K}$ is appropriate to represent molten $\mathrm{Al}_{2} \mathrm{O}_{3}$ debris with a physical temperature of around $2300 \mathrm{~K}$. This temperature has been adopted for the Kiva calculations reported here.

Debris specification. Heat transfer from the debris to the atmosphere is directly related to the temperature of the deiris and to the extent to which debris and atmosphere are mixed. This mixing is in part a result of the path length of the debris. Increasing the path length from the chute to the roof by 5 percent (shortening the chute) resulted in a pressure increase of 6 percent; doubling the debris ejection time from $0.65 \mathrm{~s}$ to $1.3 \mathrm{~s}$ while keeping the total mass the same increased the pressure by almost 12 percent (See Table 4.15). 
Table 4.14

\section{sensitivity of DCH-3 and DCH-4 Riva Calculations to Debris Temperature}

\begin{tabular}{|c|c|c|c|c|}
\hline \multirow{2}{*}{$\begin{array}{l}\text { Specified } \\
\text { Debris } \\
\text { Initial } \\
\text { Temper- } \\
\text { ature, } \\
\text { T } \\
\text { (K) }\end{array}$} & \multicolumn{2}{|c|}{$\mathrm{DCH}-3$} & \multicolumn{2}{|l|}{$\mathrm{DCH}-4$} \\
\hline & $\begin{array}{l}\text { Peak } \\
\text { Pressure } \\
\text { Rise, } \\
\text { P(T) } \\
\quad \text { (MPa) }\end{array}$ & $\begin{array}{l}P(T)- \\
P(T-100) \\
\quad(M P a)\end{array}$ & $\begin{array}{l}\text { Peak } \\
\text { Pressure } \\
\text { Rise, } \\
\text { P(T) } \\
\quad \text { (MPa) }\end{array}$ & $\begin{array}{l}P(T)- \\
P(T-100) \\
(M P a)\end{array}$ \\
\hline 2500 & 0.2264 & 0.0049 & 0.2541 & 0.0040 \\
\hline 2400 & 0.2215 & 0.0118 & 0.2501 & 0.0216 \\
\hline 2300 & 0.2097 & 0.0045 & 0.2285 & 0.0040 \\
\hline 2200 & 0.2052 & - & 0.2245 & - \\
\hline
\end{tabular}

on the other hand, if the debris and gas locally approach equilibrium (as argued in the previous section) less sensitivity to parameters such as debris particle size is expected. Increasing the mass mean diameter of the particles from $550 \mu \mathrm{m}$ to $1100 \mu \mathrm{m}$ reduced the peak pressure by 5.5 percent, while halving the initial velocity assumed for the debris (to $36 \mathrm{~m} / \mathrm{s}$ ) reduced the peak pressure by less than 3 percent. Introducing a model to allow for drop-side resistance to heat transfer [Marx 1988] resulted in a pressure decrease of less that 0.5 percent. Turning off radiation heat transfer from debris to gas reduced the peak pressure by less than 4 percent. This does not necessarily mean that this radiation heat transfer is small; rather it implies that convective heat transfer alone is sufficient to bring gas which interacts with the debris close to thermal equilibrium. 
Table 4.15

summary of Riva sensitivity calculations

\begin{tabular}{|c|c|c|}
\hline Parameter & $\begin{array}{l}\text { Change } \\
\text { to } \\
\text { parameter }\end{array}$ & $\begin{array}{l}\text { ange in Peak } \\
\text { essure Rise } \\
\text { lculated } \\
\text { Kiva. }\end{array}$ \\
\hline $\begin{array}{l}\text { Radiation heat transfer } \\
\text { to vessel walls } \\
\text { (see Marx [1988]) }\end{array}$ & Model turned off & $+35 \%$ \\
\hline $\begin{array}{l}\text { Path length of debris } \\
\text { from chute exit to roof }\end{array}$ & $\begin{array}{l}\text { Increased from } \\
7.4 \mathrm{~m} \text { to } 7.8 \mathrm{~m}\end{array}$ & $+6.7 \%$ \\
\hline $\begin{array}{l}\text { Debris ejection } \\
\text { interval }\end{array}$ & $\begin{array}{l}\text { Increased from } \\
0.65 \mathrm{~s} \text { to } 1.3 \mathrm{~s}\end{array}$ & $+11.6 \%$ \\
\hline $\begin{array}{l}\text { Mass mean particle } \\
\text { diameter }\end{array}$ & $\begin{array}{l}\text { Increased from } \\
550 \mu \mathrm{m} \text { to } 1100 \mu \mathrm{m}\end{array}$ & $-5.5 \%$ \\
\hline Debris initial velocity & $\begin{array}{l}\text { Decreased from } \\
72 \mathrm{~m} / \mathrm{s} \text { to } 36 \mathrm{~m} / \mathrm{s}\end{array}$ & $-2.8 \%$ \\
\hline $\begin{array}{l}\text { Drop-side resistance to } \\
\text { heat transfer } \\
\text { [Washington and sweet 1991] }\end{array}$ & Model turned on & $-0.2 \%$ \\
\hline $\begin{array}{l}\text { Radiation heat transfer } \\
\text { from debris to } \\
\text { atmosphere }\end{array}$ & Model turned off & $-3.6 \%$ \\
\hline $\begin{array}{l}\text { Blowdown nitrogen } \\
\text { temperature }\end{array}$ & $\begin{array}{l}\text { Reduced from } \\
2200 \mathrm{~K} \text { to } 1500 \mathrm{~K}\end{array}$ & $-4.8 \%$ \\
\hline
\end{tabular}




\subsubsection{Blowdown Gas}

A Kiva calculation for $\mathrm{DCH}-4$ with no debris but with nitrogen injected at $2000 \mathrm{~K}$ yielded a pressure rise of over $0.1 \mathrm{MPa}$ (Figure 4-11), which is nearly half the pressure rise with debris present. If the temperature of the blowdown gas is reduced by $700 \mathrm{~K}$ in a DCH-4 calculation with $82 \mathrm{~kg}$ of debris present, the peak pressure is reduced by only 5 percent, implying a total contribution to the peak pressure from the gas of not more than 0.05 to $0.06 \mathrm{MPa}$ (the blowdown gas inventory increases the gas mole inventory of the atmosphere by a little over 10 percent). To explain this apparent contradiction, consider the nature of the atmospheres of the experiments.

In the Kiva calculation with no debris, heat is transferred from the hot nitrogen to the argon atmosphere. Because the monatomic argon has a lower specific heat than nitrogen, the resulting temperature and pressure rises are greater than for a nitrogen or air atmosphere. When hot debris is present, the temperature of the nitrogen remains relatively high. Less heat is transferred from the nitrogen to the argon and the influence of the nitrogen on pressure is less than in the absence of debris.

Furthermore, much of the blowdown nitrogen is in intimate contact with the debris but has less than $1 / 10$ of the heat capacity of the debris. Thus the equilibrium temperature between the blowdown nitrogen and debris, which much of the nitrogen will approach, is relatively insensitive to the initial blowdown nitrogen temperature.

Finally, the hot blowdown gas displaces some of the cold vessel gas which would otherwise be heated by the debris, so that less heat is extracted from the debris.

The result of these effects is that, in practice, hot blowdown nitrogen contributes of the order of one quarter of the peak. pressure rise in $\mathrm{DCH}-4$, not of the order of one half as is suggested if nitrogen without debris is injected (refer again to Figure 4-11). 
For DCH-3, the nitrogen blowdown gas and air atmosphere have comparable specific heats so the blowdown gas is expected to contribute somewhat less to the peak pressure than in $\mathrm{DCH}-4$. However, the argument outlined above implies that the relative specific heats of the blowdown gas and atmosphere are much less important in the experiment than if the gases are simply mixed and the blowdown nitrogen is expected to contribute of the order of 20 percent of the pressure rise in $\mathrm{DCH}-3$.

\subsubsection{Geometry}

Spatial mesh. Use of a spatial mesh which is too large will tend to overpredict interaction between the debris and the atmosphere: in the extreme case of a single cell calculation, all the atmosphere can interact with all the debris.

For most of the present calculations, the surtsey vessel was divided into 10 radial and 22 axial mesh intervals. Two calculations apiece for $\mathrm{DCH}-3$ and $\mathrm{DCH}-4$ were repeated with the number of mesh intervals doubled and the calculated peak pressure was reduced an average of 7 percent.

These results confirm that the standard spatial mesh provides sufficient resolution to avoid major errors, but that it is worthwhile taking into account the results of calculations with a double mesh for detailed comparisons with experiments. A finer mesh may give more accurate results, but computational time increases with increasing mesh size.

Chute area. The present analysis employed an area of $0.13 \mathrm{~m}^{2}$ for the mouth of the chute used to inject debris into surtsey, in line with previous work [Marx 1988]. The actual scaled zion chute used in the surtsey experiments had a square section area of $0.058 \mathrm{~m}^{2}$, but calculations with this small chute size proved difficult and expensive to run. Experience has shown that as long as the chute area is small compared with the vessel section, results are insensitive to the chute area because the debris is effectively injected from a point source. 
To illustrate this for the current work, a Kiva calculation was repeated with the chute area reduced from $0.13 \mathrm{~m}^{2}$ to $0.094 \mathrm{~m}^{2}$, half the size of the actual area. This change only increased the peak pressure by just over 1 percent.

\section{4 summary and conclusions}

The Kiva-DCH code has been used to analyze the surtsey DCH-3 and $\mathrm{DCH}-4$ experiments. The main points of this study are:

(1) The Kiva calculations yield reasonable predictions of the initial peak pressures measured in the tests, provided it is assumed that a large fraction (about 90 percent) of the $80 \mathrm{~kg}$ of debris injected in each test becomes trapped on contact with surfaces. With the standard spatial mesh employed for Kiva analyses of surtsey, the peak pressures are overestimated by about 20 percent; for calculations with a mesh having twice the number of axial and radial cells, this difference is reduced to 13 percent.

Table 3.3 lists the trapping fraction in $\mathrm{DCH}-3$ as $\approx 0.74$ and in $\mathrm{DCH}-4$ as $\approx 0.57$. In the Kiva analyses, a trapping fraction of 0.9 had to be assumed to predict peak pressures that were only overestimated by $\approx 20 \%$. This clearly indicates that current models of $\mathrm{DCH}$ phenomena may not be adequate and that further model development and supporting experimental research are needed.

(2) The initial pressure rise of approximately $0.2 \mathrm{MPa}$ measured in $\mathrm{DCH}-4$ was about 10 percent greater than that observed in $\mathrm{DCH}-3$. This difference is reproduced by the Kiva analysis, again providing 90 percent trapping is assumed.

(3) The Kiva-DCH results indicate that chemical heat from oxidation by the air atmosphere in DCH-3 contributed about 10 percent of the initial pressure rise in that 
experiment. A significant quantity of iron was also oxidized during the $\mathrm{DCH}-4$ experiment because the Ar atmosphere was contaminated with air. In this case, the calculations indicated that the chemical heat contributed 6 percent of the pressure rise.

(4) In both experiments, a second pressure peak was measured about 2 seconds after the initial peak. Debris was observed dripping from the ceiling on this timescale and previous studies suggested that this dripping could have caused the second pressure rise. Kiva-DCH includes parametric models to treat debris dripping, and the earlier calculations showed that such dripping could lead to a second pressure peak of appropriate magnitude. Dripping has also been included in the present analysis but a second pressure peak is not predicted because, compared with the earlier work:

(a) The quantities of debris allowed to drip were reduced so that the final debris masses on the floor matched those recovered after the tests.

(b) The size of the drops was increased (from $2.5 \mathrm{~mm}$ to $13 \mathrm{~mm})$, in line with the drop size expected to form by Rayleigh-Taylor instability.

(5) An alternative hypothesis is that the second pressure rise was caused by oxidation of $\mathrm{CO}$ and $\mathrm{H}_{2}$ in surtsey. Such gases would have formed during the thermite reaction and from ablation of the concrete cavity by the melt. Analysis of gas samples from the experiments has confirmed the presence of $\mathrm{CO}, \mathrm{H}_{2}$ and $\mathrm{CO}_{2}$. From these data it has been shown that energies of the order of magnitude needed to account for the second pressure rises could have resulted from $\mathrm{CO} / \mathrm{H}_{2}$ burns.

(6) The Kiva calculations underestimate the oxygen depletion by iron oxidation in $\mathrm{DCH}-3$ by about 30 percent. It is not clear why Kiva underestimates the oxygen depletion. Two possible explanations are that (1) the code does not allow for oxidation of debris after it has become trapped on 
surfaces and (2) there are significant uncertainties in the measured oxygen depletion.

(7) Less debris was trapped on the side wall of surtsey in the calculations than during the experiments $(\sim 5$ percent, compared with $\approx 10$ percent). The calculated wall loadings may be increased to the observed values by reducing the trapping fractions so that more debris splashes from the ceiling, some of which reaches the walls. However, the additional splashed debris interacts with the atmosphere and increases the calculated pressure rise to the extent that the difference between calculated and measured pressure becomes large. This implies that some mechanism other than simple splashing redistributes small quantities of debris from the ceiling to the walls, or perhaps that the splashing model is inadequate.

(8) Sensitivity studies have shown that the calculated pressure rise in surtsey is insensitive to the precise mass of debris injected in $\mathrm{DCH}-3$ and $\mathrm{DCH}-4$. Comparisons with simple equilibrium calculations have shown that this follows because the gas in the vicinity of the debris becomes thermally saturated and not because the atmosphere and debris as a whole come to thermal equilibrium. This phenomenon is known as the "cloud" or "plume" effect. 


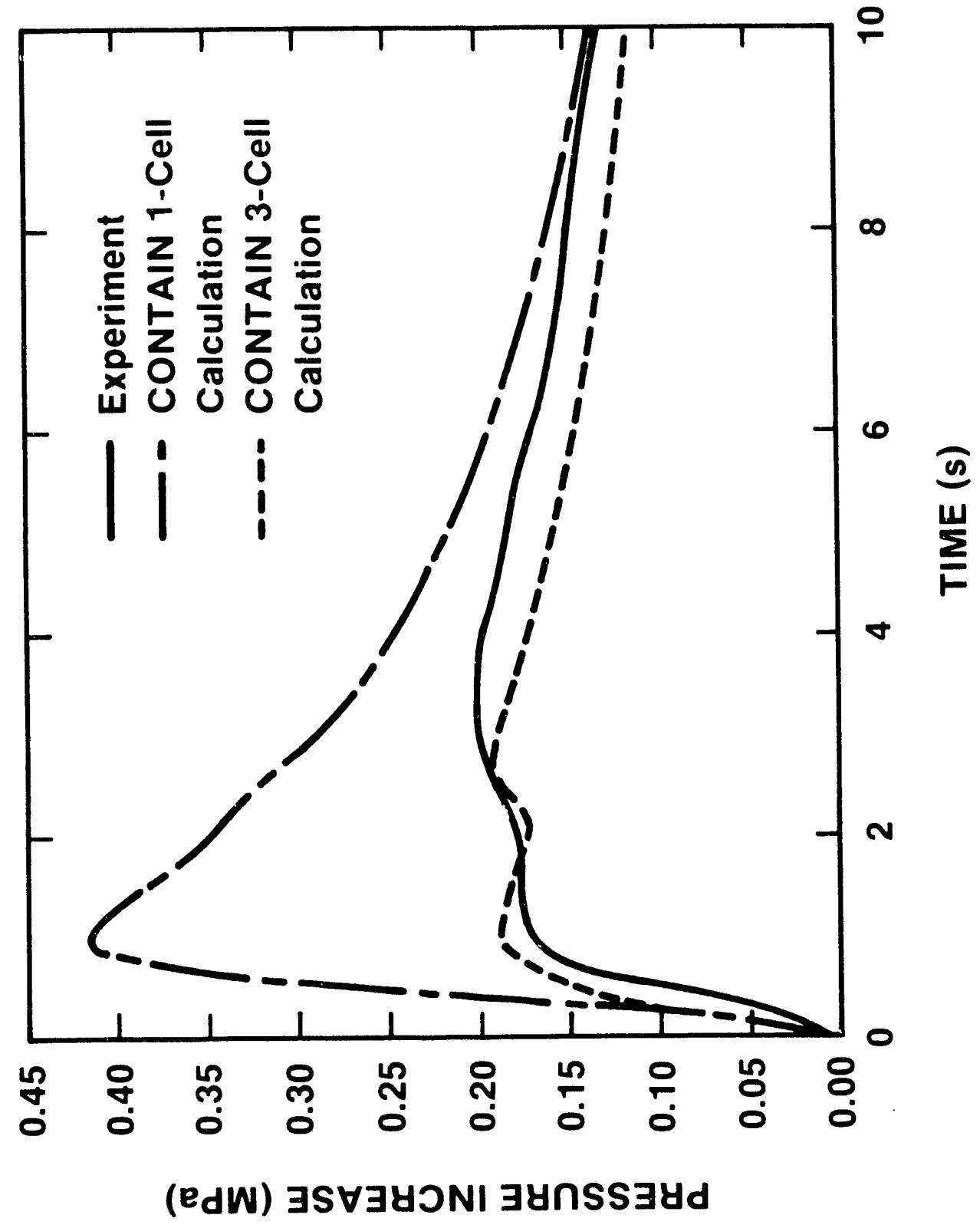

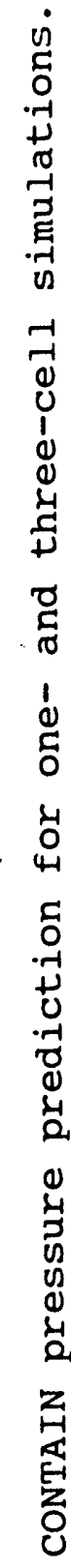

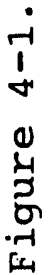




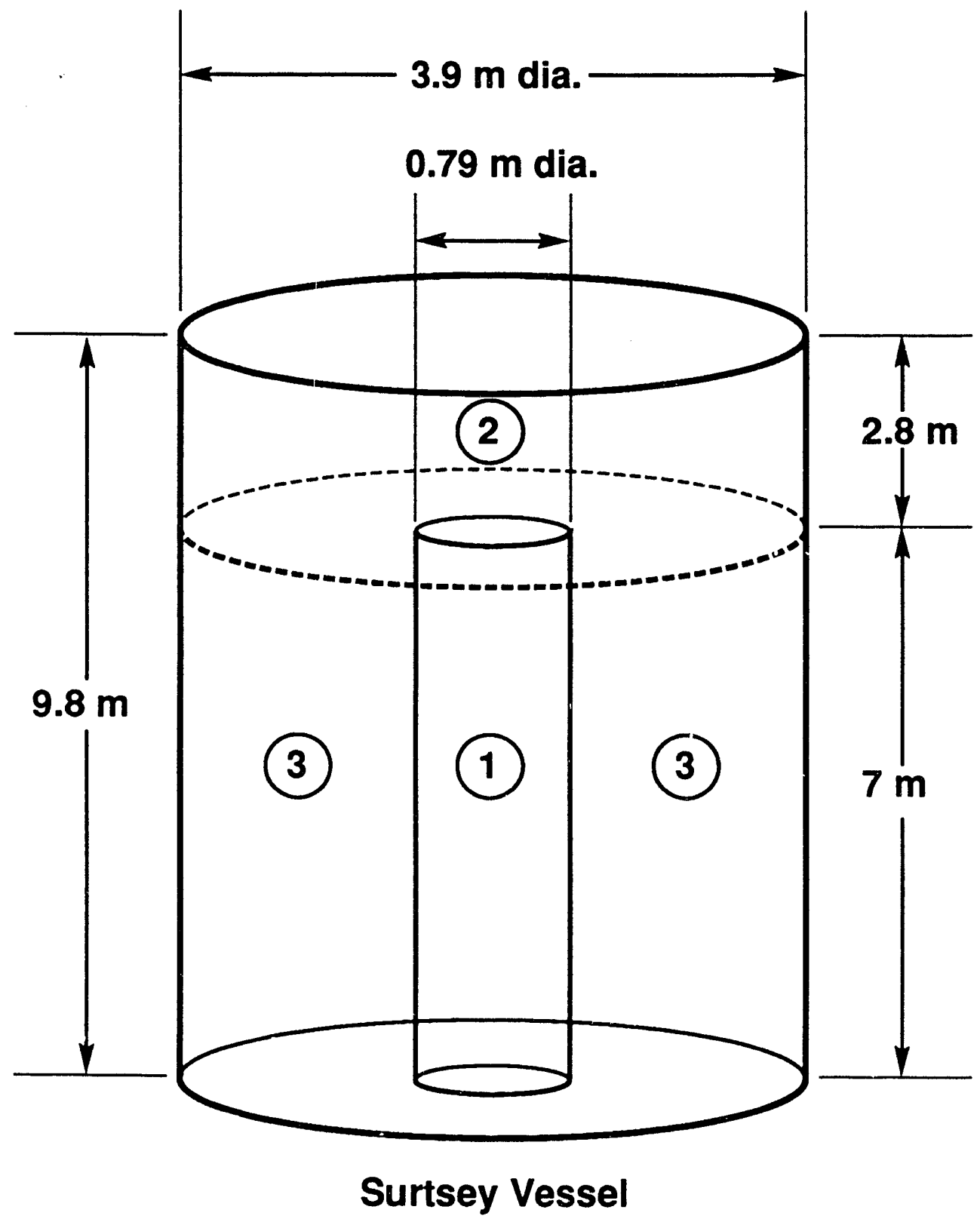

Figure 4-2. Three-cell CONTAIN-DCH representation of the Surtsey vessel. 


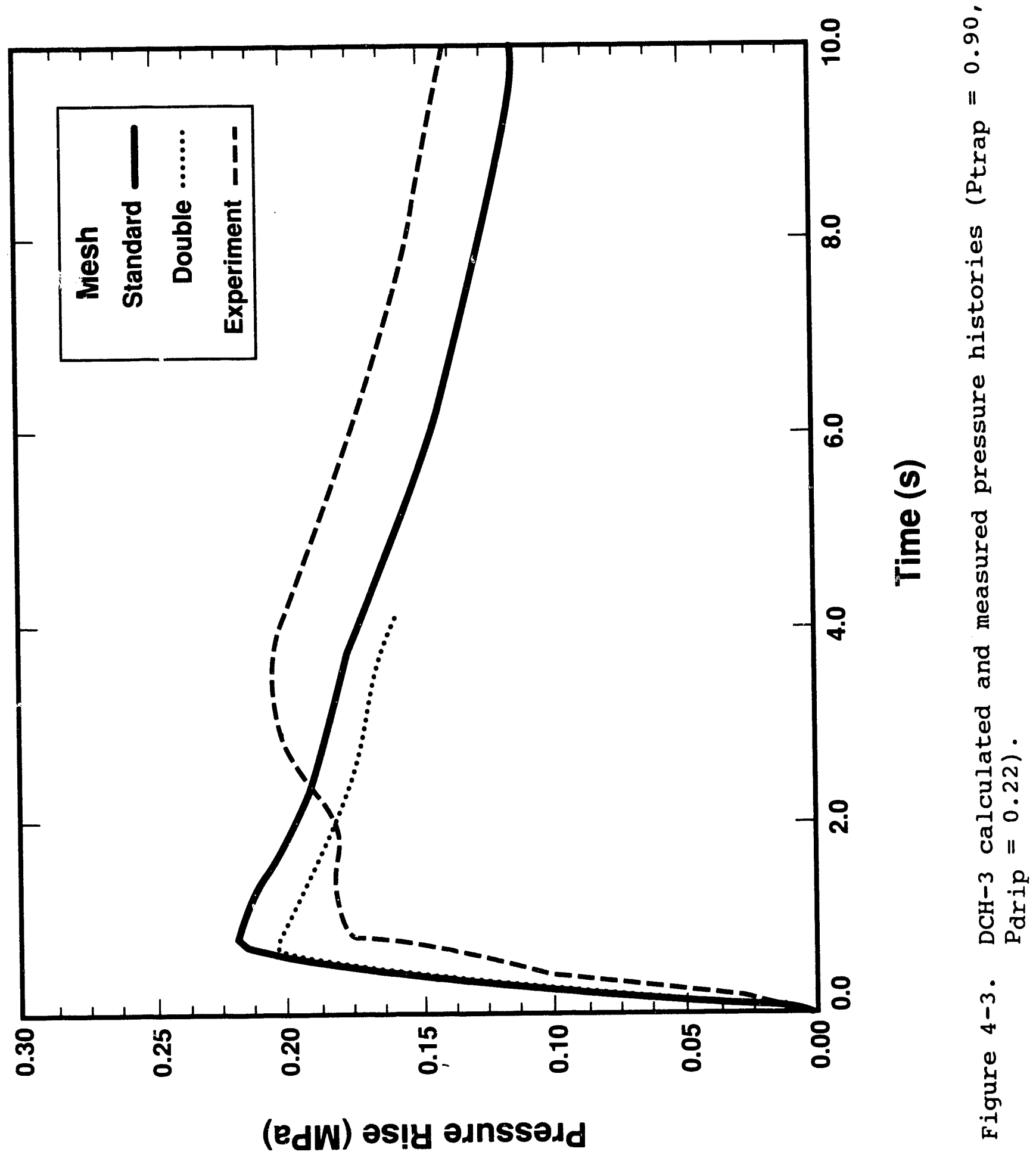




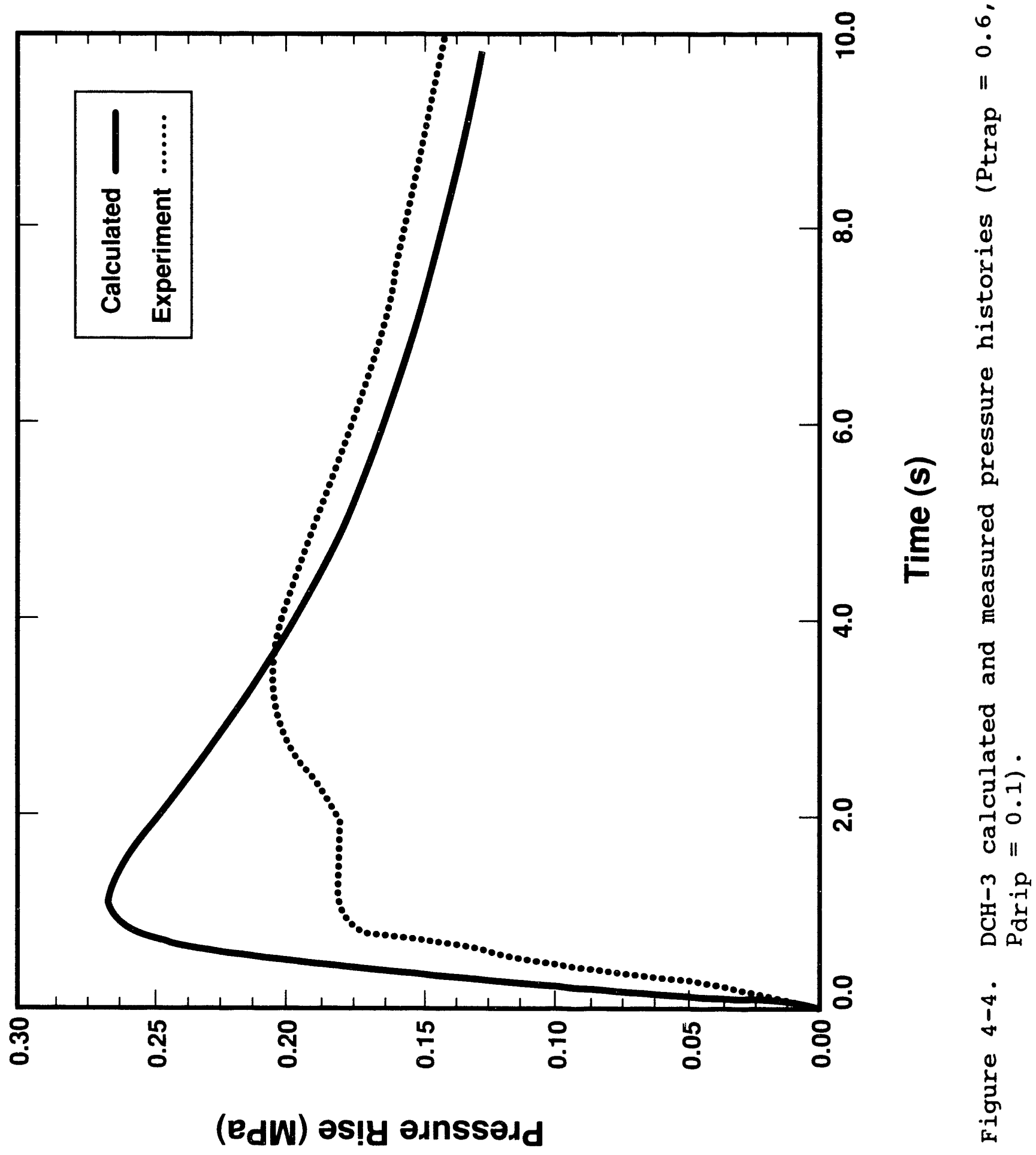




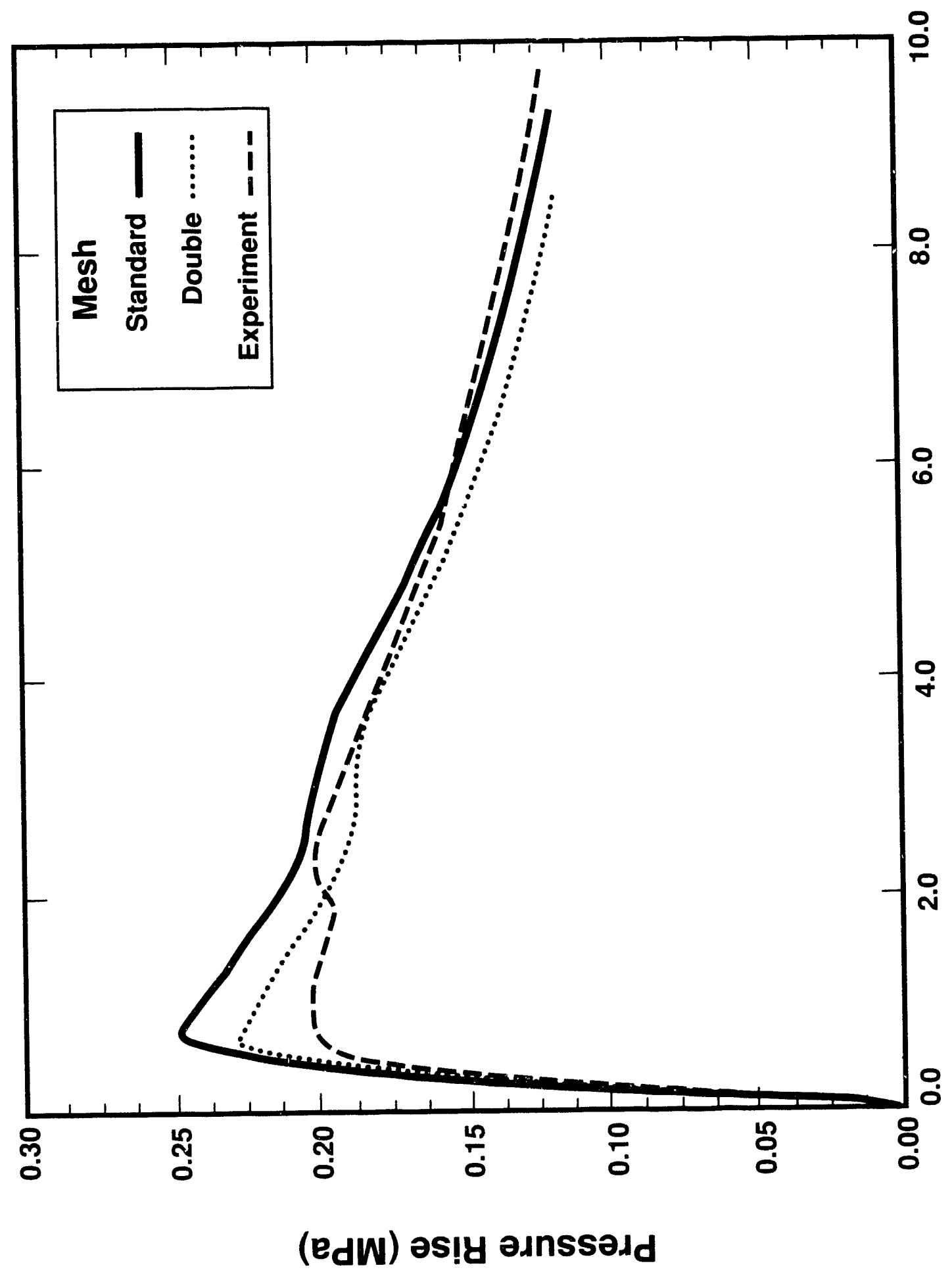

o

II

م

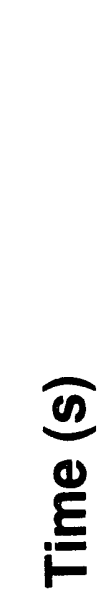

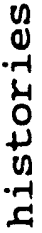

है

$\frac{1}{1}$

4

\%

น్

임

8

$+$

N

U

ช 11

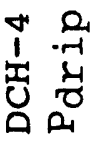

0
1
0
0
2
2
0
01 


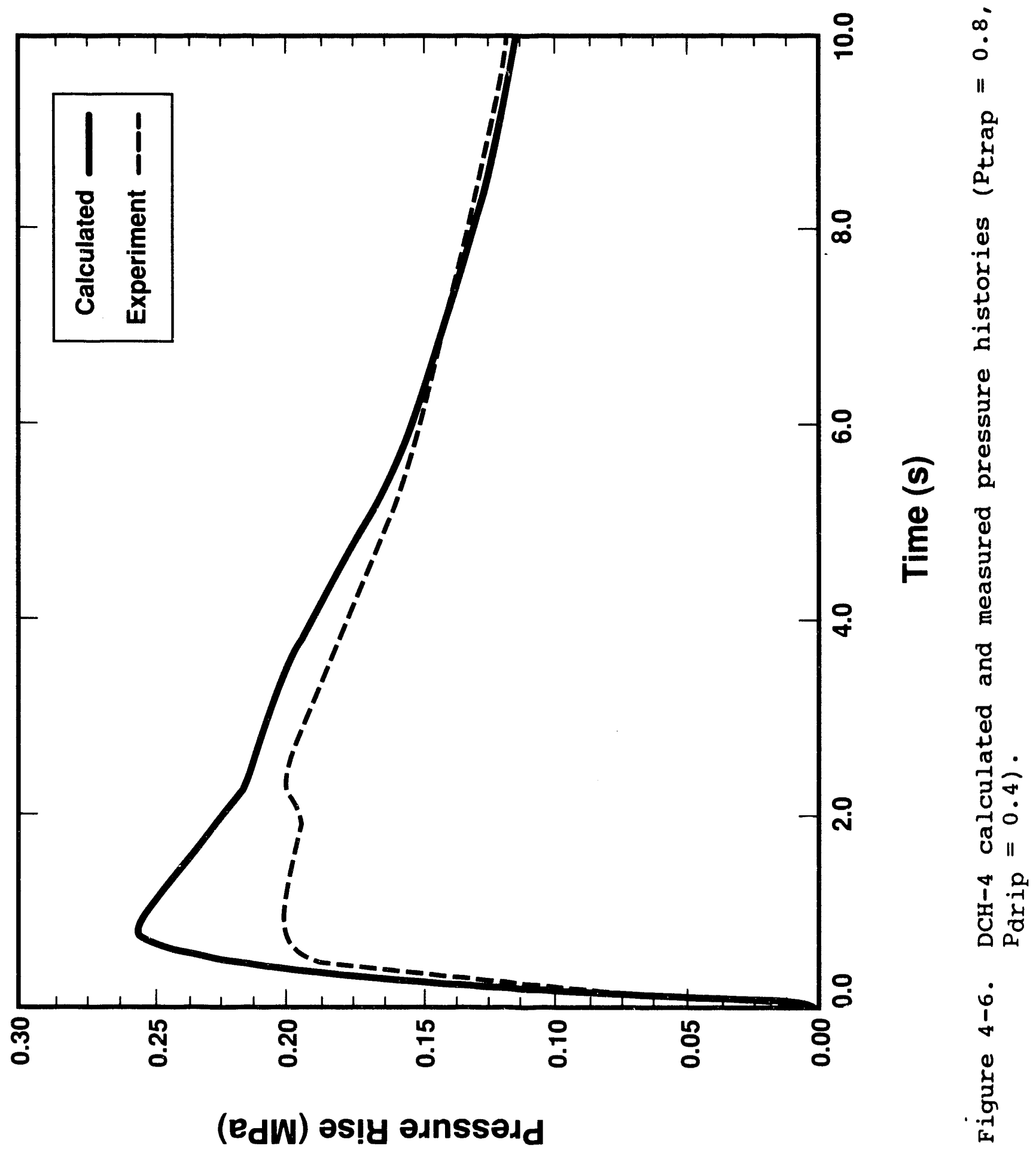




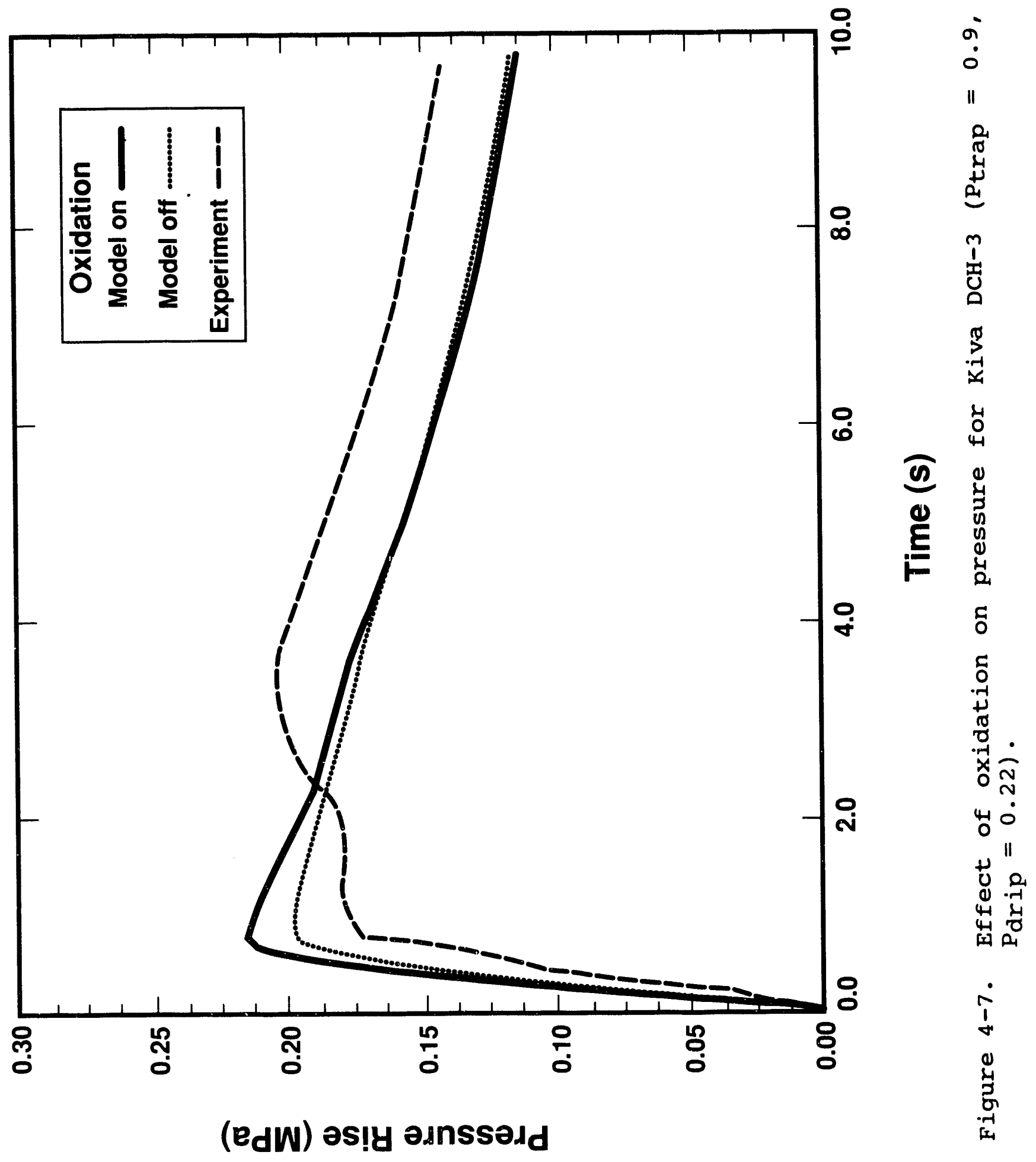




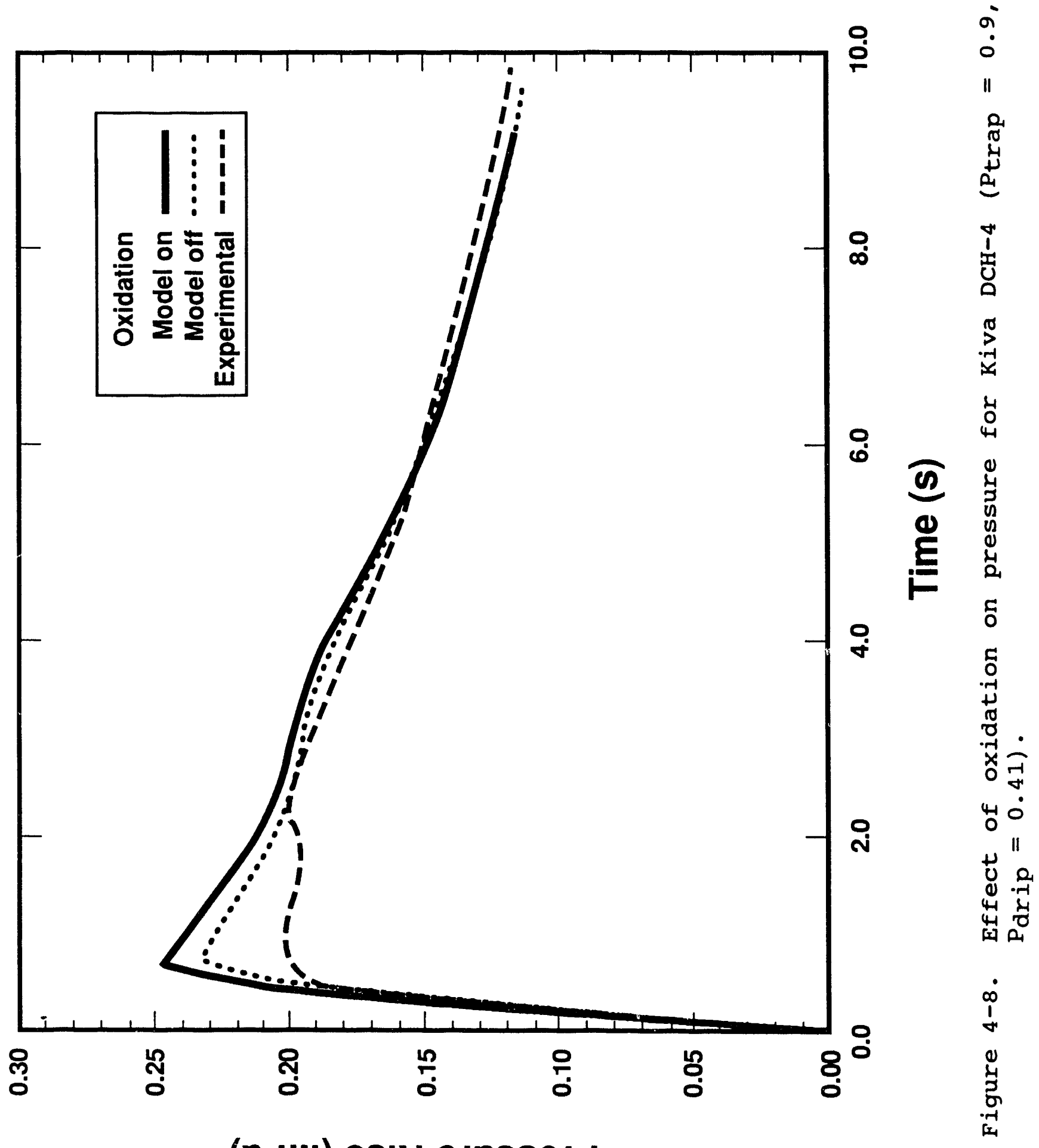

(edW) әs!y ə.tnssəגd 


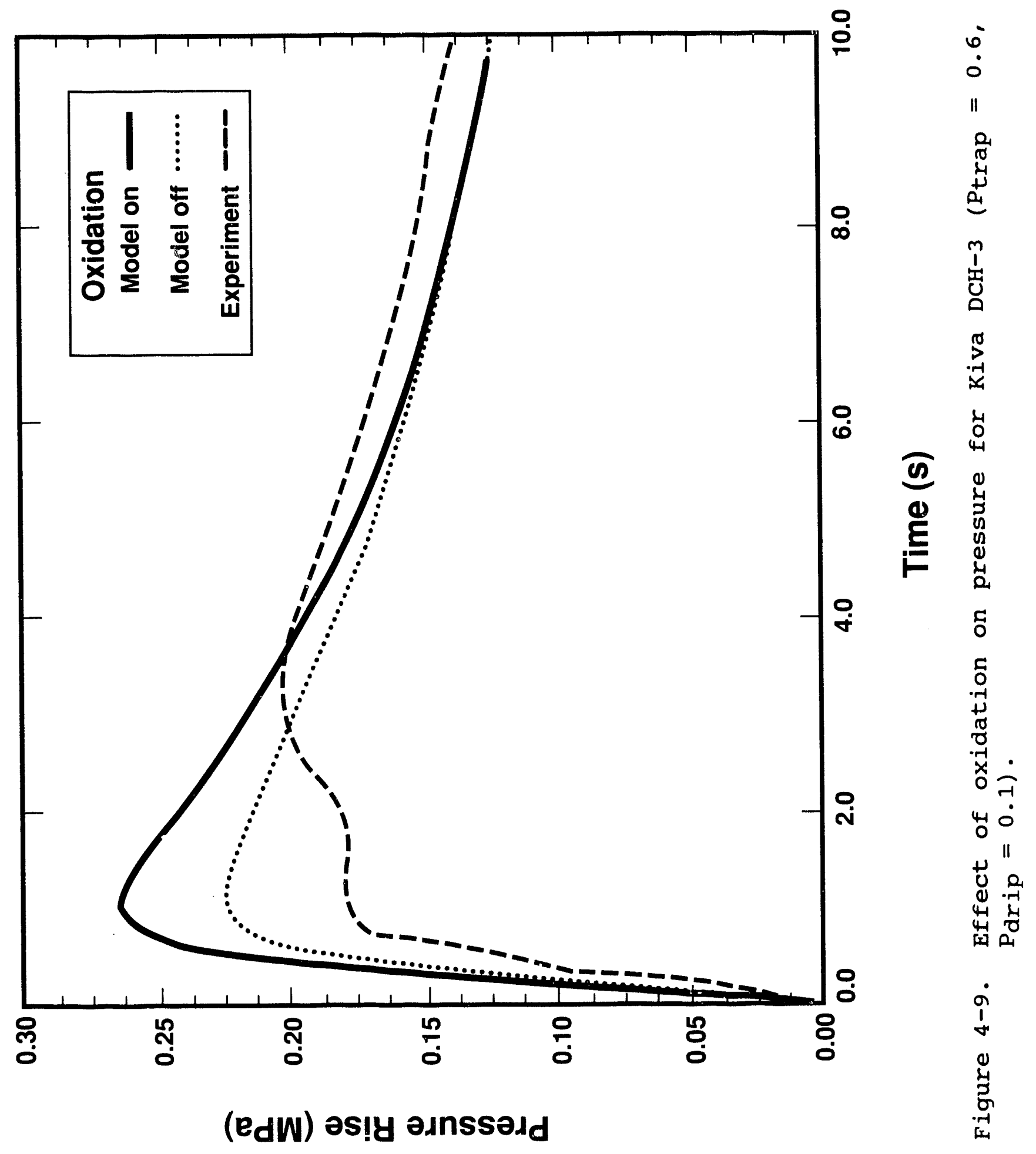




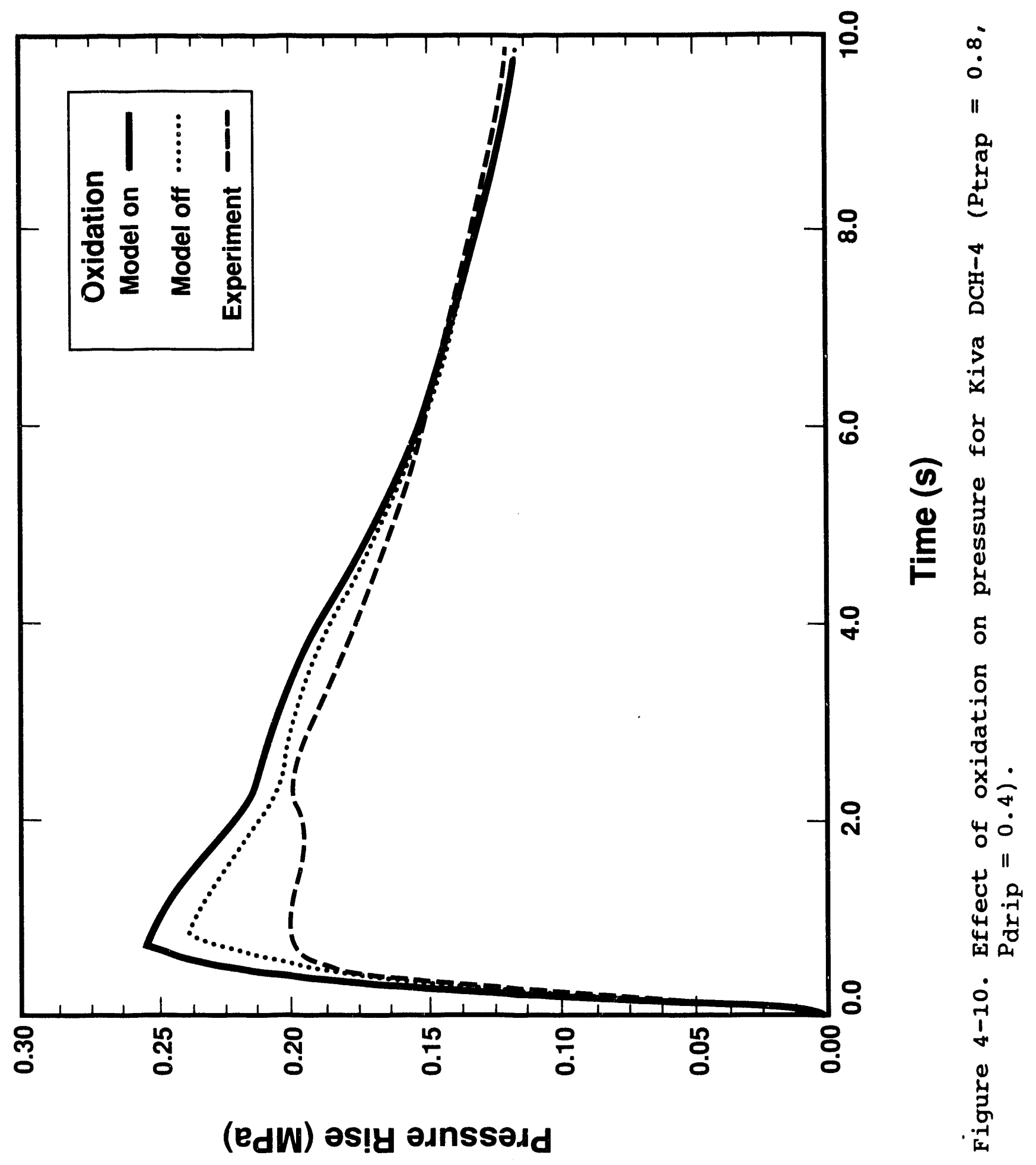




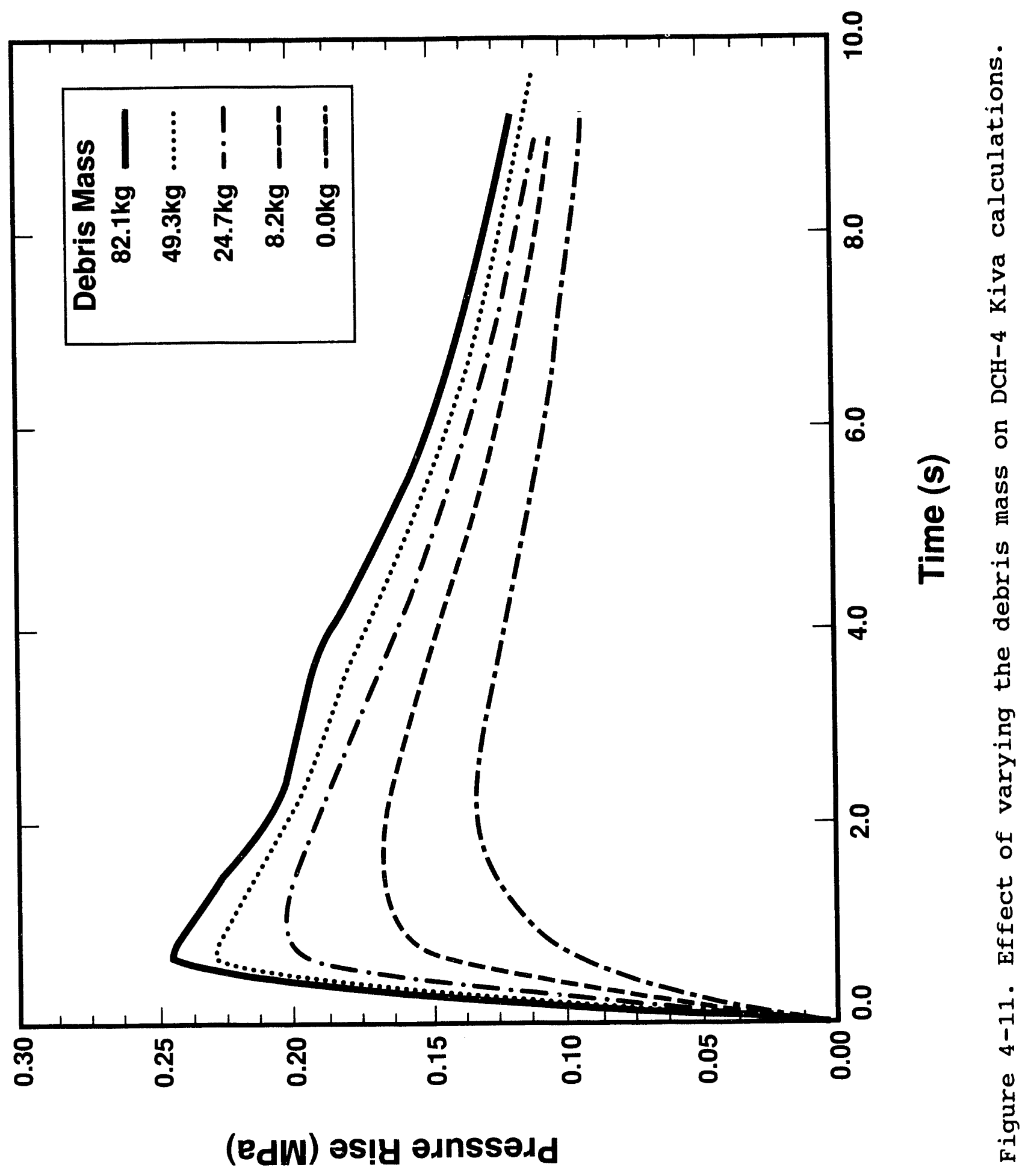




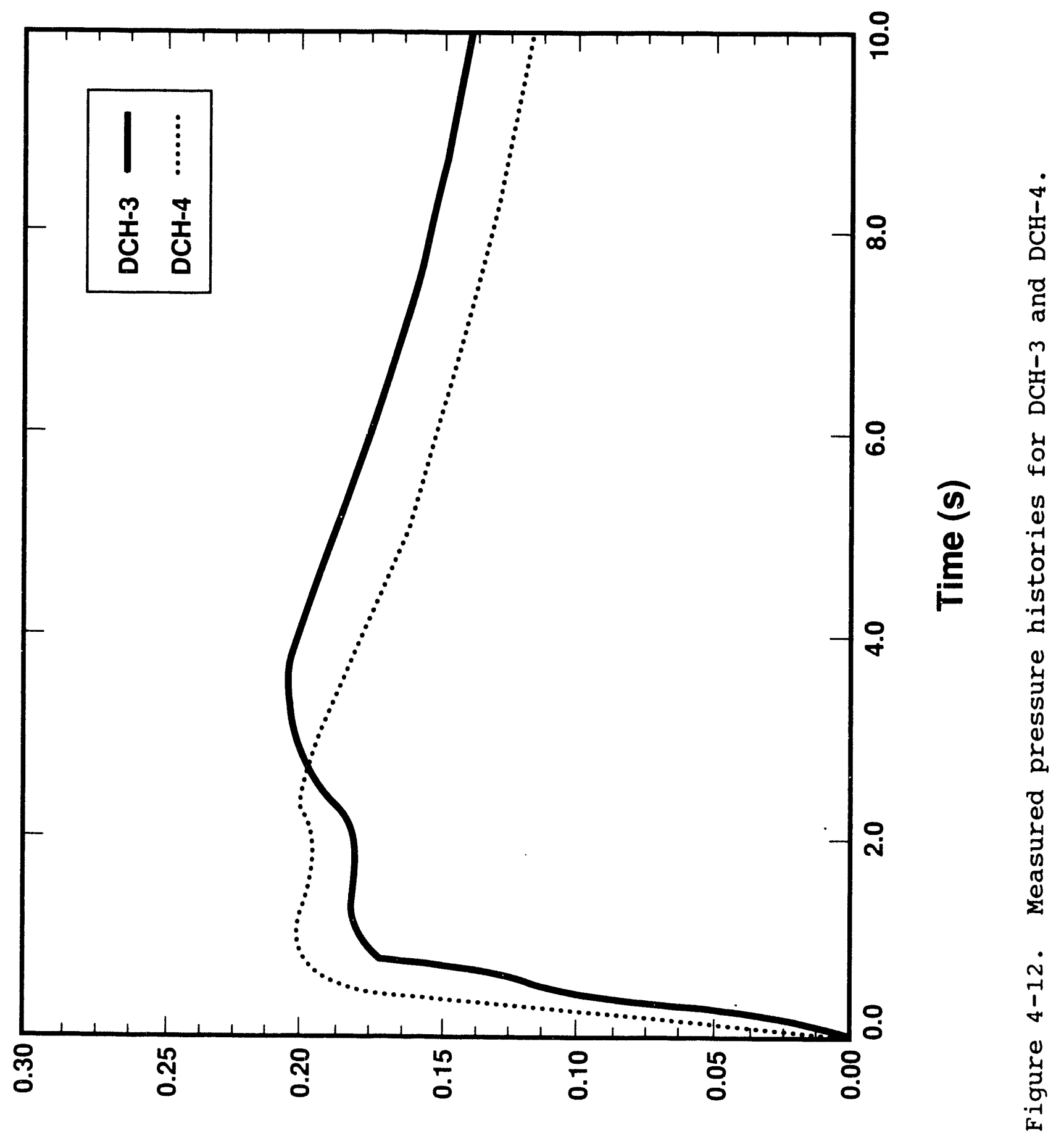

(edW) əs!y ə.tnssəגd 


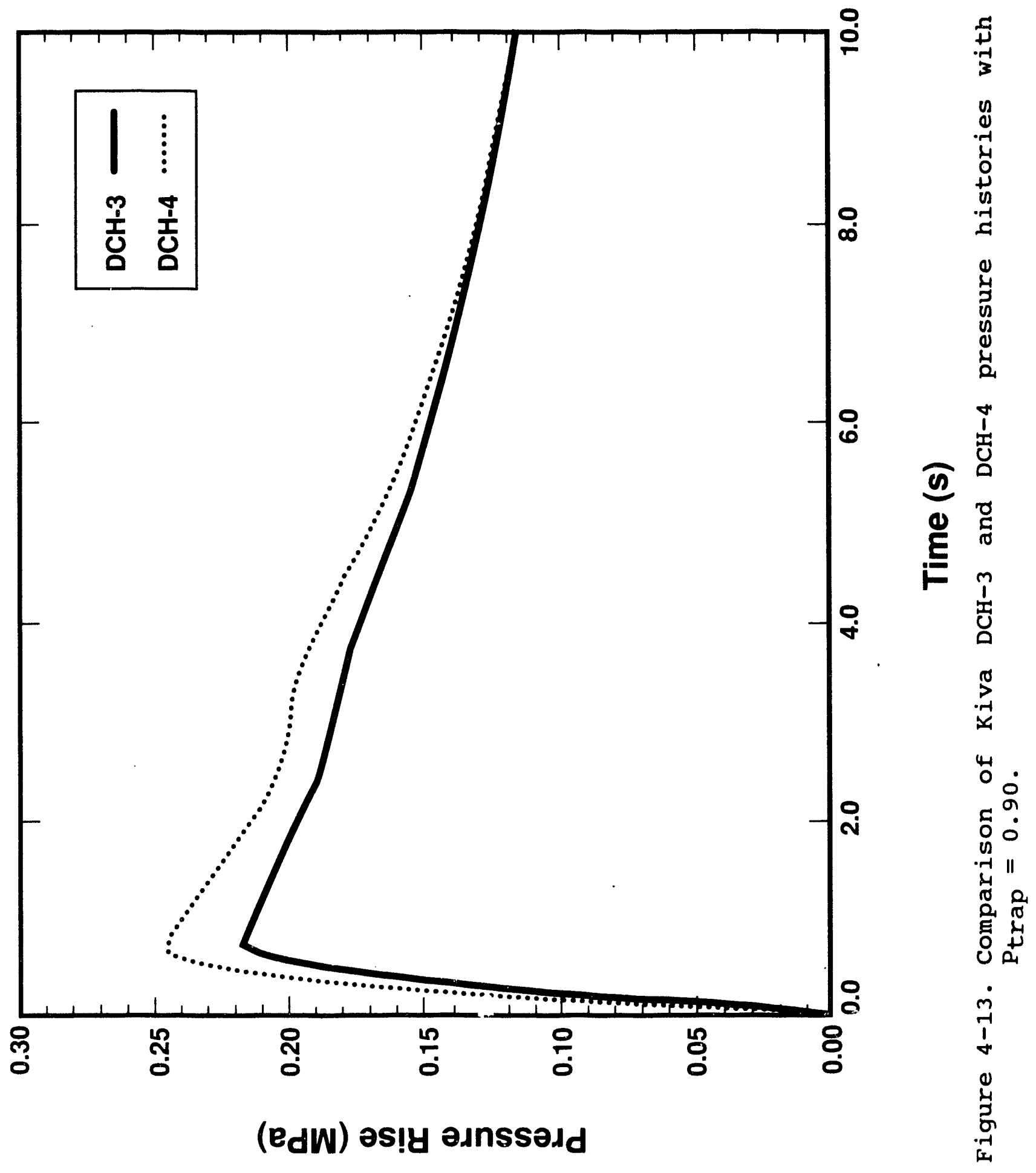


This section discusses comparisons that can be made among the four experiments performed to date in the $D C H$ test series. The focus is on the extent of energy transfer from the debris to the surtsey atmosphere, which is represented by the pressure increase in the vessel.

\subsection{Surtsey Vessel pressure}

The pressure records in Figure 5-1 substantiate the fact that the peak pressures in the large-mass experiments ( $\mathrm{DCH}-2, \mathrm{DCH}-3$, and $\mathrm{DCH}-4$ ) do not scale linearly with mass from the $\mathrm{DCH}-1$ test. Even though the dispersed mass was about eight times greater in the three $80-\mathrm{kg}$ tests, the peak pressure was at most only 2.5 times the $\mathrm{DCH}^{-1}$ value. The implication from the vessel pressure records is that the higher concentration of particles in the debris plume in the larger-mass tests inhibits interaction with the atmosphere. This cloud effect could have resulted in competition between debris particles for local oxygen, thermal shielding of the debris within the cloud, and thermal saturation of the vessel atmosphere. The differences in the measured pressures in the DCH experiments may have been caused by the cloud effect and the interaction of debris with structures in the vessel.

The results of the experiments suggest that heat transfer and chemical reactions occurred primarily at the boundary of the debris plumes. A debris plume can be disrupted by obstructions that induce turbulence and mixing of debris particles with the atmosphere. Thus, obstructions that disrupt the debris cloud may make the energy transfer process more efficient [Pilch et al. 1988], while phenomena that cause the molten particles in the debris cloud to coalesce, such as trapping, may render the energy transfer process less efficient. The results also indicate that the greater total heat capacity of the debris relative to the gas in the $\mathrm{DCH}-2, \mathrm{DCH}-3$, and $\mathrm{DCH}-4$ tests prevents the gas from cooling the debris as effectively as in the $\mathrm{DCH}-1$ experiment. 
The relative fraction of energy imparted by the debris to the atmosphere can be estimated from the pressure records. On this basis, the $\mathrm{DCH}^{-1}$ experiment exchanged the most energy (on a per-mass basis), followed in order by $\mathrm{DCH}-2, \mathrm{DCH}-3$, and $\mathrm{DCH}-4$. Although the lack of oxidation reactions in the $\mathrm{DCH}-4$ experiment suggests a significantly lower energy release, the peak pressures were nearly the same in the $\mathrm{DCH}-3$ and $\mathrm{DCH}-4$ tests. The total heat capacity of air varies from about $3(\mathrm{nR})$ to about (5/2) nR (where $n$ is the total number of moles of gas and $R$ is the universal gas constant) over the temperature range that occurred in the experiment, while the heat capacity of argon is approximately $(3 / 2) \mathrm{nR}$ over the same range. The lower heat capacity of argon caused a larger pressure increase in the vessel for a given energy input. The difference approximately cancels the effect of chemical reactions that occur in air; this explains why the pressure response measured in the $\mathrm{DCH}-1$ test results closely matches the pressure response in the $\mathrm{DCH}-3$ experiment.

The oxygen consumed during each experiment may be used to indicate the extent of the chemical reaction between the debris and the atmosphere. Note that the ranking of tests suggested by the oxygen-consumption results $(i . e ., \mathrm{DCH}-1 \rightarrow \mathrm{DCH}-2 \rightarrow \mathrm{DCH}-3$ $\left.\rightarrow D_{C H}-4\right)$ is the same as that inferred from the pressure records. It is assumed that the lower concentration of debris particles in the $\mathrm{DCH}-1$ test, plus the influence of the aerosol sampling pipe, allowed greater interaction of the debris with the atmosphere and a corresponding increase in oxidation of the debris. The mass of oxygen consumed in the $\mathrm{DCH}-1$ experiment could have completely oxidized the available metallic debris. The gas sample results indicate that the debris was not completely oxidized in the $\mathrm{DCH}-2$ and $\mathrm{DCH}-3$ tests. The specific oxygen consumption (mass $\mathrm{O}_{2}$ per mass debris) was higher in the DCH-2 experiment than in the DCH-3 test, apparently because of the induced mixing caused by the interaction of the debris with the vessel walls. The specific mass of oxygen consumed in the DCH-3 test was less than half of that in the $\mathrm{DCH}-1$ experiment, 0.08 versus 0.18 ( $\mathrm{kg} \mathrm{O} \mathrm{O}_{2} / \mathrm{kg}$ debris). The concentration of particles in the $\mathrm{DCH}-3$ test may have caused a local depletion of oxidant, thus yielding incomplete oxidation of the metal in the debris particles. In addition, in DCH-3, debris may have been trapped on the upper head before complete oxidation had occurred. 


\subsection{Aerosol Generation}

The aerosol collected and analyzed in the four DCH tests had a bimodal size distribution with a mode at $1-2 \mu \mathrm{m}$ and a mode at about $10 \mu \mathrm{m}$ or larger. Inspection of the distributions (Figures 3-72 through 3-75) reveals that most of the mass on the filters came from the 1-2 $\mu \mathrm{m}$ mode. The electron micrograph in Figure 3-76 shows the aerosol in this mode to have the morphology of a vapor condensation aerosol that grew by agglomeration. The mode at $10 \mu \mathrm{m}$ is assumed to have been formed by melt fragmentation.

The composition of the aerosol found on the filters is typically on the order of 40 wt. 8 Fe, 2-4 wt. 8 Al, and about 0.5-2 wt. $\% \mathrm{Ni}, \mathrm{Mo}$, and Mn. The other fission product dopants were present in the aerosol at levels considerably less than 1 wt. o.

The particles in the vapor condensation mode at 1-2 $\mu \mathrm{m}$ had a high persistence in the vessel atmosphere because of their small aerodynamic size. Particles in this size range appeared to be enriched in volatile species.

The metals had higher release fractions than the oxides in each of the tests. The fraction of the aerosol released by fragmentation (FRF) was assumed to be the same for all materials and could not have been larger than the total aerosol release fraction (ARF) in a given test. From Table 3.19 it can be seen that the vaporization release fraction (VRF) is greater than $90 \%$ of the ARF for the metals Fe, Ni, Mo, and Mn. Thus, the 1-2 $\mu \mathrm{m}$ mode came predominantly from the condensation of vapors of the more volatile melt constituents; the aerosol in the mode at 1-2 $\mu \mathrm{m}$ is enriched in the volatile constituents and depressed in the less volatile materials, which were believed to have been present as oxides.

Generally, the release fractions for the elements assumed to have been present as oxides ( $\mathrm{Al}, \mathrm{Ba}, \mathrm{La}, \mathrm{Ce}, \mathrm{Ti}$, and $\mathrm{Nb}$ ) were considerably lower than those for the elements assumed to have 
been present as metals (Fe, $\mathrm{Ni}, \mathrm{Mo}$, and $\mathrm{Mn}$ ). These differences are attributed to the higher volatility of $\mathrm{Fe}, \mathrm{Ni}$, Mn metals, and products of Mo oxidation.

In the experiments with air in the surtsey vesse1 (DCH-1, DCH-2 and $\mathrm{DCH}-3)$, the molybdenum in the ejected melt apparently oxidized to its more volatile oxide form. Release fractions of molybdenum in the $\mathrm{DCH}-1, \mathrm{DCH}-2$, and $\mathrm{DCH}-3$ test were $15 \%, 7 \%$, and 5.5\%, respectively. In the DCH-4 test, the release fraction was an order of magnitude smaller (0.31\%). The DCH tests provide strong evidence of oxidation-driven vaporization from the dispersed debris. This observation provides experimental evidence of the enhanced release of materials having volatile oxides (such as Mo and $\mathrm{Ru}$ ) during pressurized ejection through an oxidizing atmosphere. The enhanced release of some species by vaporization or oxidation-ariven vaporization is of importance in modeling the releases from pressurized melt ejection. The size distribution of this vapor-condensation aerosol would allow it to remain airborne for a long time, which is of particular importance should containment failure occur.

Analyses of the size-segregated aerosol samples taken with the cascade cyclone showed that materials released predominantly by vaporization ( $\mathrm{Fe}, \mathrm{Ni}, \mathrm{Mo}$, and $\mathrm{Mn}$ ) had a relatively constant mass fraction over the entire aerosol size range. Materials considered to have been present as an oxide ( $\mathrm{Al}, \mathrm{Ba}, \mathrm{La}, \mathrm{Nb}$, $\mathrm{Ce}$, and $\mathrm{Ti}$ ) showed a distinct trend toward increasing mass fraction with increasing particle size.

It is interesting to note that while the release fractions declined from a high in the $D C H-1$ test to lower values for the DCH-2 and $\mathrm{DCH}-3$ experiments, the ratios of release fractions (Fe:Ni:Mo:Mn and $\mathrm{Al}: \mathrm{Ba}: \mathrm{La}: \mathrm{Nb}$ ) in each test remained about the same (Table 3.19). This indicates that the relative releases of materials (i.e., release of material $A$ with respect to the release of material B! wre not greatly different, even though the absolute amounts may have differed significantly among tests. 
Comparing all of the aerosol mass concentration results suggests that the $\mathrm{DCH}-1$ and $\mathrm{DCH}-2$ experiments may have produced more aerosolized material than the $\mathrm{DCH}-3$ and $\mathrm{DCH}-4$ experiments. The consistency of the data in the latter two tests, however, is much improved over the former tests. The results from $\mathrm{DCH}-3$ and $\mathrm{DCH}-4$ indicate that the initial aerosol mass is on the order of $0.5-1 \%$ of the initial charge that was relocated into the surtsey vessel. Considering that the $\mathrm{DCH}-1$ and $\mathrm{DCH}-2$ experiments were more efficient in terms of exchanging energy with the atmosphere, it is reasonable to assume that the processes which were responsible for the higher energy transfer efficiency (in particular, debris/gas heat transfer and chemical reactions that were enhanced by mixing of the devris plume with the vessel atmosphere caused by interactions with structures) were also the cause for the increased vapor mass transfer from the debris. The higher amount of melt fragmentation aerosol detected in the $\mathrm{DCH}-1$ and $\mathrm{DCH}-2$ tests is thought to have arisen from the interaction of melt debris with structures.

\subsection{Calculational Results}

The agreement between the $\mathrm{DCH}-1$ data and the CONTAIN-DCH prediction is excellent (Figure 5-2). The good agreement at early times is important because it implies that the chemical reaction rate between debris and the vessel atmosphere and the heat transfer rate from the debris to the gas are adequately modelled in CONTAIN-DCH. There is also good agreement between experiment and prediction well after the end of the debris dispersal period. This is important because it indicates that the rate of energy transfer from the atmosphere gas to the structures is well modeled in CONTAIN-DCH. The good agreement shown in Figure 5-2 also suggests that debris/structure interactions and debris cloud effects played a minor role in the DCH-1 experiment. Thus, the processes that are modeled mechanistically in CONTAIN-DCH dominate the vessel response.

As shown in Figure 4-1, the CONTAIN-DCH three-cell calculation for the $\mathrm{DCH}-3$ test agrees with the data much better than the one-cell results. 14.9 improvement attained with the three-cell representation indicates the importance of modeling in detail 
the debris cloud effects and the interaction of the debris with structures for $\mathrm{DCH}$ experiments.

The pressure response curves in the $\mathrm{DCH}-3$ and $\mathrm{DCH}-4$ experiments exhibited two distinct peaks. The second peak was larger than the first peak for the $\mathrm{DCH}-3$ test (with air in the vessel), while the two peaks were roughly equal in magnitude for the $\mathrm{DCH}-4$ test (with argon in the vessel). originally, it was proposed that dripping from the upper head of the vessel caused the second peak. However, Kiva-DCH calculations with a dropformation model were unable to reproduce the two individual peaks in the pressure response curves for either experiment. An alternative hypothesis is that the second pressure rise was caused by oxidation of $\mathrm{CO}$ and $\mathrm{H}_{2}$ formed during the thermite reaction and from ablation of the concrete cavity by the melt. Analysis of gas samples from the experiments has confirmed the presence of $\mathrm{CO}, \mathrm{H}_{2}$, and $\mathrm{CO}_{2}$. From these data it has been shown that energies of the order of magnitude needed to account for the second pressure rises could have resulted from $\mathrm{CO} / \mathrm{H}_{2}$ combustion. In surtse? DCH experiments conducted after the DCH-4 test (i.e., seven Technology and Development and scoping (TDS) tests and six Limited Flight Path (LFP) tests), in which the surtsey vessel was inerted with argon $\left(<0.05\right.$ mol.o $\left.0_{2}\right)$, a two-peak pressure response was not observed. These tests experienced debris trapping similar to that observed in the DCH tests discussed in this report; however, there was apparently not enough oxygen in the TDS or LFP tests to result in a second peak due to $\mathrm{CO} / \mathrm{H}_{2}$ combustion. This further supports the hypotheses that the second peak is the result of $\mathrm{CO} / \mathrm{H}_{2}$ burning. The first peak, caused primarily by debris/gas heat transfer and metal/oxidation reactions, and the second peak, apparently caused by $\mathrm{CO} / \mathrm{H}_{2}$ combustion, are separated in time by 2 to 3 seconds. Thus these phenomena may not be additive, which may be significant for the peak pressure in the containment.

\subsection{Conclusions}

The DCH experiments in the surtsey test facility demonstrated that direct heating of the vessel atmosphere can occur as a result of the efficient exchange of energy between a hightemperature debris plume and the vessel atmosphere. observations from these experiments can be used to guide the 
development of models in containment response codes, such as CONTAIN-DCH.

The DCH tests indicated that the extent of the energy exchange processes may be affected by the concentration of particles within the debris-gas cloud. It is estimated that the $\mathrm{DCH}-1$ experiment, in which the relocated mass was considerabley smaller than in the other $\mathrm{DCH}$ experiments, showed nearly complete exchange of the debris energy with the atmosphere. This resulted in a pressure increase of almost $0.1 \mathrm{MPa}$ from the $10 \mathrm{~kg}$ of debris ejected into the vessel.

CONTAIN-DCH predictions of the $\mathrm{DCH}-1$ test are in excellent agreement with the experimental results. This good agreement is attributed to the fact that debris-structure interactions and debris cloud effects played a minor role in the DCH-1 experiment, thereby allowing the processes that are modeled mechanistically in CONTAIN-DCH to dominate the vessel response. Kiva-DCH predictions also agree well with the $D C H-1$ results, which primarily serve to validate the new debris-field models in the code.

The DCH-2 experiment showed that debris striking a steel surface caused a significant disruption of the debris-gas stream. Particles impacting on the surface can bounce, skid, fragment, or freeze to form a film. Over $70 \%$ of the recovered debris in $\mathrm{DCH}-2$ was found adhered to the sides and top head of the vessel. The retention of this material and the lack of thorough mixing of the debris with the vessel atmosphere resulted in a relatively small pressure increase compared to that obtained from linear scaling of the $\mathrm{DCH}-1$ experiment.

The DCH-3 experiment was performed in the same geometry as the DCH-1 test except with a larger melt mass. Over $60 \%$ of the debris was found adhered to the upper head of the surtsey vessel. Accurate simulation of the $\mathrm{DCH}-3$ test by the Kiva-DCH code required a trapping model to describe the observed behavior. The best agreement between experiment and calculation was obtained using a trapping probability of 0.9 combined with the drop-formation model. The high trapping 
fraction may have compensated for the poor mixing between the debris cloud and gas in the vessel (i.e., the cloud effect).

The film record shows that some of the material initially retained on the top head flowed together to form drops that fell through the vessel well after the rest of the debris had settled. The drops may have contributed to a second pressure peak in the vessel at about 2 to $3 \mathrm{~s}$ after the first peak, but the drop-formation model was unable to totally account for the second peak. The second peak may have been the result of the combustion of $\mathrm{CO}$ and $\mathrm{H}_{2}$ formed by the thermite reaction and by concrete ablation.

A Surtsey three-cell representation was used in the CONTAIN-DCH calculation of the $\mathrm{DCH}-3$ test. As in the Kiva-DCH prediction, the complex debris-structure interactions seen in the experiment were simulated using a rapid trapping fraction and a parametric drop-formation model. Although the results using this approach agreed well qualitatively with the experiment, more advanced debris-structure interactions modeling is needed.

The DCH-4 experiment used an argon atmosphere to suppress chemical oxidation of the debris. The pressure increase measured was similar to that observed in the DCH-3 test performed in an air atmosphere. The pressure loss from the lack of chemical energy release was compensated by the lower heat capacity of argon relative to air.

The data from the four $\mathrm{DCH}$ experiments provided valuable insight into understanding $\mathrm{DCH}$ and related phenomena. The tests also provided a data base for the validation of certain aspects of the DCH version of the cONTAIN accident analysis code. Caution should be taken in any direct translation or scaling of the results to full-scale accident conditions. For example, debris-structure interactions or debris cloud effects may not mitigate pressurization of a full containment building to the same degree as they did in the $\mathrm{DCH}-3$ and $\mathrm{DCH}-4$ experiments. Rather, these experiments show that these effects may be important, and that the physical processes involved need to be well-modeled in accident analysis codes that treat HPME and $\mathrm{DCH}$. 


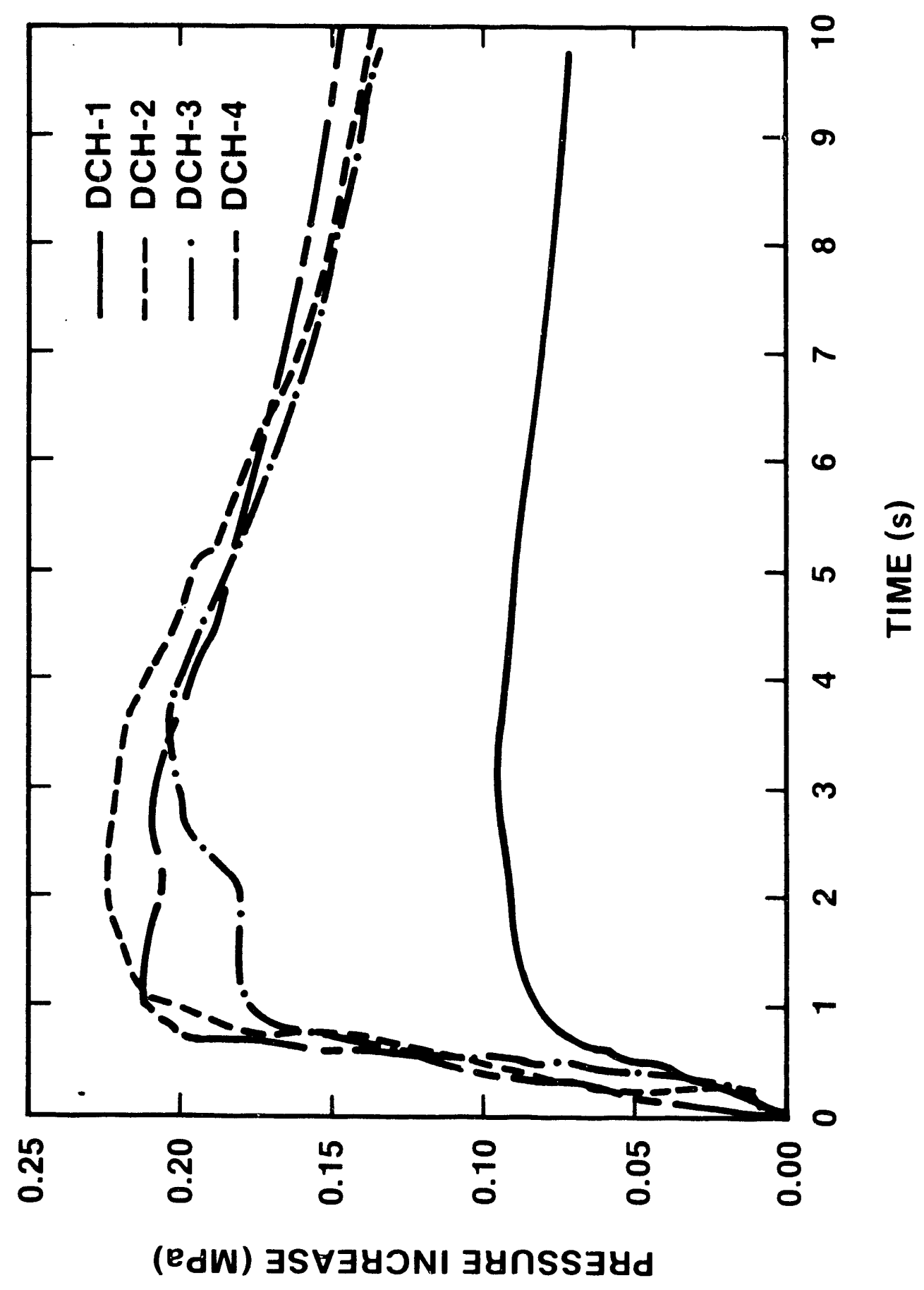

Uू

í 


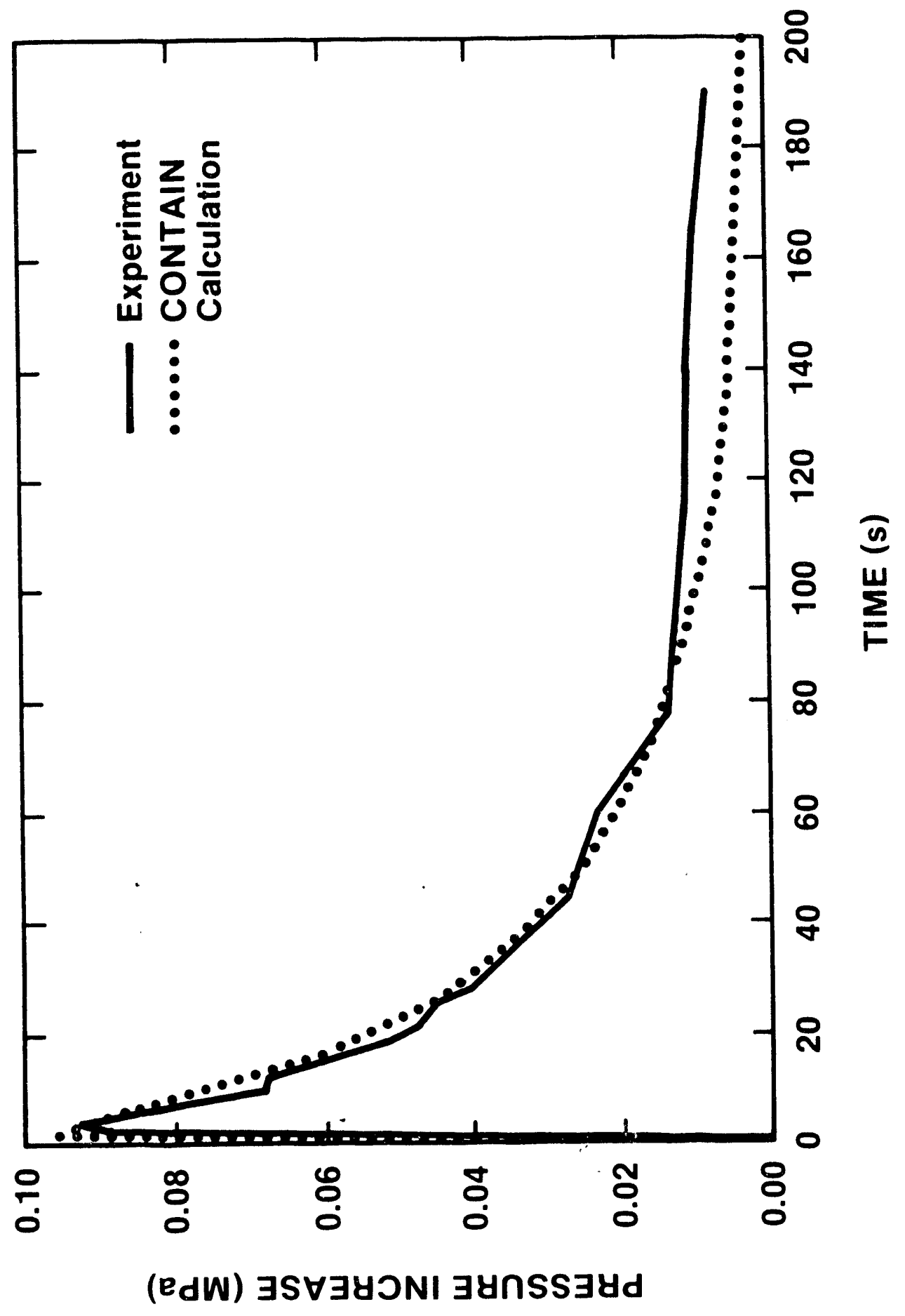

언

D

.0

㟔

焉

岁

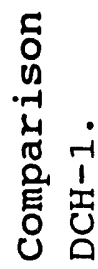

$\dot{i}$ 


\subsection{REFERENCES}

Allen, M.D. et al., 1990, A Demonstration Experiment of SteamDriven, High-Pressure Melt Ejection: The HIPS-10s Test, NUREG/CR-5373, SAND89-1135, Sandia National Laboratories, Albuquerque, NM.

Amsden, A.A. et al., 1985, Kiva: A Computer Program for Twoand Three-Dimensional Fluid Flows with Chemical Reactions and Fuel Sprays, LA-10245-MS, Los Alamos National Laboratory, Los Alamos, NM.

Baker, L. Jr. et al., October 1988, "Droplet structure Interactions in Direct Containment Heating," presented at the ANS/ENS International Conference, Washington DC.

Bergeron, K.D., and D.C. Williams, 1985, "CONTAIN Calculations of Containment Loading of Dry PWRs," Nuclear Engineering and Design, 90: 153-159.

Bergeron, K.D. et al., 1987, "Development and Application of the Interim Direct Heating Model for the CONTAIN Computer Code," SAND86-1989C, presented at the Fourteenth water Reactor Safety Information Meeting, Gaithersburg, MD.

Berry, X.E., 1967, "Cloud Droplet Growth by Collection," J. Atmospheric Science, 24: 688 .

Brockmann, J.E., and W.W. Tarbell, 1984, "Aerosol Source Term in High Pressure Melt Ejection," Nuclear Science and Engineering, 88: 342-356.

Brockmann, J.E. and D.J. Rader, 1989, The Response of the Aerodynamic Particle sizer to Nonspherical Particles and Use in Experimental Determination of Dynamic Shape Factor, NUREG/CR-5454, SAND89-2040, Sandia National Laboratories, Albuquerque, NM.

Brockmann, J.E., and D.J. Rader, 1990, "APS Response to Nonspherical Particles and Experimental Determination of Dynamic Shape Factor," Aerosol Science and Technology, 13: $162-172$. 
Clift, R. et al., 1978, Bubbles, Drops, and Particles, Academic Press, New York, NY.

Frid, W., 1988, Behavior of a Corium Jet in High Pressure Melt Ejection from a Reactor Pressure Vessel, NUREG/CR-4508, SAND85-1726, Sandia National Laboratories, Albuquerque, NM.

Fuchs, N.A., 1964, The Mechanics of Aerosols, Pergamon Press, New York, NY.

Gronager, A.J. et al., 1986, TURC1: Large Scale Metallic Meltconcrete Interaction Experiments and Analysis, NUREG/CR-4420, SAND85-0707, Sandia National Laboratories, Albuquerque, NM.

Marx, K.D., 1988, A Model for the Transport and Chemical Reaction of Molten Debris in Direct Containment Heating Experiments, NUREG/CR-5120, SAND88-8213, Sandia National Laboratories, Albuquerque, NM.

Marx, K.D., 1989, "A Computer Model for the Transport and Chemical Reaction of Debris in Direct Containment Heating Experiments," Nuclear Science and Engineering: 102, 391-407.

Murata, K.K. et al., 1989, User's Manual for CONTAIN 1.1: A Computer code for severe Nuclear Reactor Accident Containment Analysis, NUREG/CR-5026, SAND87-2309, Sandia National Laboratories, Albuquerque, NM.

Nichols, R.T., and W.W. Tarbell, October 1988, "Low Pressure Debris Dispersal from Scaled Reactor Cavities," presented at the ANS/ENS International Conference, Washington DC.

NRC, NUREG-75-014, 1975, Reactor Safety Study - An Assessment of Accident Risks in U.S. Commercial Nuclear Power Plants. WASH-1400 Nuclear Regulatory Commission, Washington DC.

NRC, NUREG-1079, 1985, Estimates of Early Containment Loads from Core Melt Accidents, Nuclear Regulatory Commission, Washington DC. 
NRC, NUREG-1265, 1987, Uncertainty Papers on Severe Accident Source Terms, Nuclear Regulatory Commission, Washington DC.

NRC, SECY-88-147, 1988, Integration Plan for Closure of severe Accident Issues, Nuclear Regulatory Commission, Washington DC.

NRC, NUREG-1150, 1989, Severe Accident Risk Assessment: An Assessment of Five U.S. Nuclear Power Plants, Volumes 1-2, Summary Report, Second Draft for Peer Review, Sandia National Laboratories, Albuquerque, NM.

Pilch, M. and W.W. Tarbell, 1985, High Pressure Ejection of Melt From a Reactor Pressure Vessel: The Discharge Phase, NUREG/CR-4383, SAND85-0012, Sandia National Laboratories, Albuquerque, NM.

Pilch, M., and W.W. Tarbell, 1986, Preliminary Calculations on Direct Heating of a Containment Atmosphere by Airborne Core Debris, NUREG/CR-4455, SAND85-2439, Sandia National Laboratories, Albuquerque, NM.

Pilch, M., April 25-29, 1988, "Lower Head Failure and Instrument Tube Ejection During Severe Reactor Accidents," presented at the Severe Accident Research Program Partners Review Meeting, Albuquerque, NM.

Pilch, M. et al., 1988, The Influence of Selected containment Structures on Debris Dispersal and Transport Following High Pressure Melt Ejection From the Reactor Vessel, NUREG/CR-4914, SAND87-0940, Sandia National Laboratories, Albuquerque, NM.

Powers, D.A. et al., 1983, "The Role of Ex Vessel Interactions in Determining the Severe Reactor Accident Source Term for Fission Products," Proceedings of the International Meeting on Light Water Reactor Severe Accident Evaluation, Cambridge, MA.

Silberberg, M. et al., 1986, Reassessment of the Technical Basis for Estimating Source Terms, NUREG-0956, Nuclear Regulatory Commission, Washington DC. 
Tarbell, w.w. et al., 1984, High-Pressure Melt streaming (HIPS) Program Plan, NUREG/CR-3025, SAND82-2477, Sandia National Laboratories, Albuquerque, NM.

Tarbell, w.w. et al., 1986, Pressurized Melt Ejection Into Scaled Reactor Cavities, NUREG/CR-4512, SAND86-0153, Sandia National Laboratories, Albuquerque, NM.

Tarbell, w.w. et al., 1987, Results From the DCH-1 Experiment, NUREG/CR-4871, SAND86-2483, Sandia National Laboratories, Albuquerque, NM.

Tarbell, w.w. et al., 1988a, DCH-2: Results from the second Experiment Performed in the Surtsey Direct Heating Test Facility, NUREG/CR-4917, SAND87-0976, Sandia National Laboratories, Albuquerque, NM.

Tarbell, w.w. et al., March 21-25, 1988b, "Research on Direct Containment Heating and Pressurized Melt Expulsion from the Reactor Coolant System," presented at the IAEA/OECD Nuclear Energy Agency International symposium on Severe Accidents in Nuclear Power Plants, SAND88-0717C, Sorrento, Italy.

Tarbell, W.W., April 25-29, 1988c, "Debris Dispersal Threshold for Pressurized Melt Ejection Accident Sequences," presented at the Severe Accident Research Program Partners Review Meeting, Albuquerque, NM.

Tarbell, w.W. et al., October 3-7, 1988d, "Direct Containment Heating: Surtsey Test Results and Models," NUCSAFE 88 , ENS/ANS Topical Meeting on Thermal Reactor Safety, Avignon, France.

Tarbell, W.W. et al., October 1988e, "Direct Containment Heating and Aerosol Generation During High Pressure Melt Expulsion Experiments," SAND88-1504C, presented at the ANS/ENS International Conference, Washington DC.

Tarbell, w.W. et al., October 17-20, 1988f, "Direct Containment Heating: Surtsey Test Results and Models," presented at the Severe Accident Research Program Partners Review Meeting, Bethesda, MD. 
Tarbell, W.W. et al., October 24-27, 1988g, "High-Pressure Melt Ejection and Direct containment Heating Research," SAND88-2977C, presented at the 16th water Reactor Safety Information Meeting, Gaithersburg, MD.

Tutu, N.K. et al., 1988, Debris Dispersal from Reactor Cavities During High-pressure Melt Ejection Accident Scenarios, NUREG/CR-5146, BNL-NUREG-52147, Brookhaven National. Laboratory, Upton, NY.

Weast, R.C., and M.J. Astle, 1980, CRC Handbook of Chemistry and Physics, 61 edition, CRC Press, Inc., Boca Raton, FL.

Whitby, K.T. et al., 1972, "The Aerosol Size Distribution of Los Angeles Smog," J. Colloid Interface Science, 39: 177-204.

Williams, D.C. et al., 1987, Containment Loads Due to Direct Containment Heating and Associated Hydrogen Behavior: Analysis and calculations with the conTAIN code, NUREG/CR-4896, SAND87-0633, Sandia National Laboratories, Albuquerque, NM.

Yamano, N., and J.E. Brockmann, 1989, Aerosol Sampling and Transport Efficiency Calculation (ASTEC) and Application to surtsey/DCH Aerosol Sampling system, NUREG/CR-5252, SAND88-144, Sandia National Laboratories, Albuquerque, NM.

ZPSS, 1981, zion Probabilistic safety study, Commonwealth Edison Co., Chicago, IL. 
U. S. Nuclear Regulatory Commission (8) office of Nuclear Regulatory Research

Attn: C. Tinkler, NLN-344 (1)

M. Cunningham, NLS-372

F. Eltawila, NLN-344

G. Marino, NLS-007

J. Mitchell, NLS-314

B. Sheron, NLS-007

T. Walker, NLN-344

R. W. Wright, NLN-344

Washington, D.C. 20555

U. S. Nuclear Regulatory Commission (2) Office of Nuclear Reactor Regulation

Attn: R. Barrett, 10E4

W. Lyon, $8 \mathrm{E} 23$

Washington, D.C. 20555

U. S. Nuclear Regulatory Commission

NRC/RES

Attn:

E. Beckjord, NLS-007

B. Hardin, NLS-169

T. Lee, NLN-353

R. Meyer, NLS-007

Z. Rosztoczy, NLS-007

C. Ryder, NLS-372

T. Speis, NLS-007

Washington, D.C. 20555

U. S. Department of Energy (2)

Albuquerque operations office

Attn: C. E. Garcia, Director

For: C. B. Quinn

P. O. Box 5400

R. L. Holton

Albuquerque, NM 87185

Electric Power Research Institute (4)

Attn: F. Rahn

R. Ritzman

W. Lowenstein

R. Sehgal

3412 Hillview Avenue

Palo Alto, CA 94303 
Brookhaven National Laboratory (6)

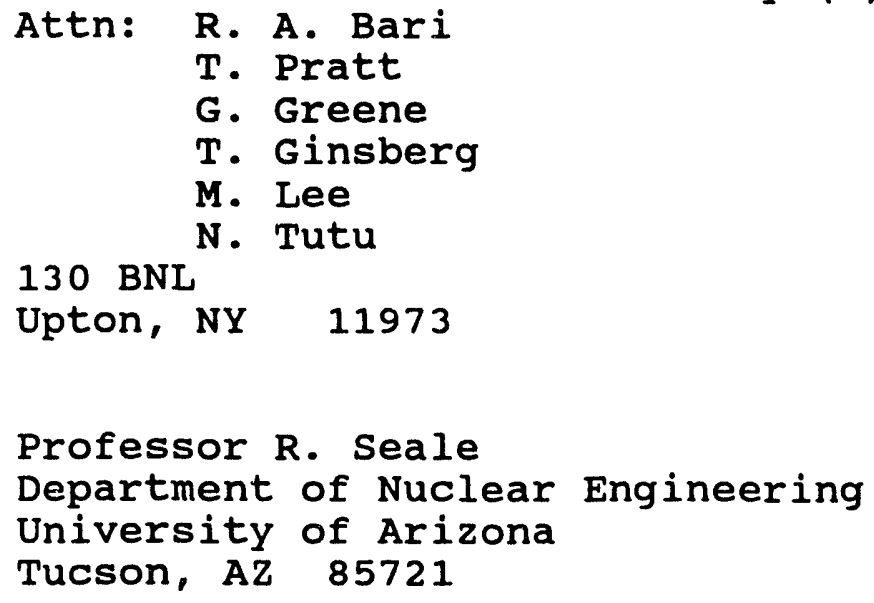

Oak Ridge National Laboratory

Attn: T. Kress

P. O. BoX $Y$

Oak Ridge, TN 37830

Argonne National Laboratory (8)

Attn: J. Rest

C. Johnson

L. Baker, Jr.

D. Cho

B. Spencer

K. Leong

J. Fink

V. Novick

9700 S. Cass Avenue

Argonne, IL 60439

Cathy Anderson

Nuclear Safety Oversight Commission 1133 15th Street, NW

Room 307

Washington, D.C. 20005

Battelle Columbus Laboratory

(4)

Attn: C. Alexander

P. Cybulskis

R. Denning

J. Gieseke

505 King Avenue

Columbus, OH 43201 
U. S. Department of Energy

office of Nuclear Safety Coordination

Attn: R. W. Barber

Washington, D.C. 20545

Department of Energy

Scientific and Tech. Info. Center

P. O. Box 62

Oak Ridge, TN 37831

Fauske and Associates, Inc. (2)

Attn: R. Henry

M. Plys

16 W070 West $83 \mathrm{rd}$ street

Burr Ridge, IL 60952

Los Alamos National Laboratories

Attn: M. Stevenson

P.O. Box 1663

Los Alamos, NM $8754 \mathrm{~s}$

UCLA (3)

Nuclear Energy Laboratory

Attn: I. Catton

D. Okrent

W. Kastenberg

405 Hilgaard Avenue

Los Angeles, CA 90024

University of Wisconsin

Nuclear Engineering Department

Attn: M. L. Corradini

1500 Johnson Drive

Madison, WI 53706

EG\&G Idaho

Willow Creek Building, $\mathrm{W}-3$

Attn: R. Hobbins

P. O. Box 1625

Idaho Falls, ID 83415

Battelle Pacific Northwest Laboratory

Attn: M. Freshley

P. O. Box 999

Richland, WA 99352 
w. Stratton

2 Acoma Lane

Los Alamos, NM 87544

Wang Lu

TVA

400 Commerce, W9C157-CK

Knoxville, TN 37902

Peter Bieniarz

Risk Management Associates

2309 Dietz Farm Road, NW

Albuquerque, NM 87107

J. E. Antill

Berkeley Nuclear Laboratory

Berkeley GL 139PB

Gloucestershire, England

UNITED KINGDOM

W. G. Cunliffe

Bldg. 396

British Nuclear Fuels, Ltd.

Springfield Works

Salwick, Preston

Lancashire, England

UNITED KINGDOM

Professor Agustin Alonso

E.T.S. Ingenieros Industriales

Jost Gutierrez Abascal, 2

28006 Madrid

SPAIN

Dr. Alfonso Perez

Departmento de Seguridad Nuclear

Junta de Energia Nuclear

Avenida Complutense, 22

Madrid - 3

SPAIN

Gesellschaft fur Reaktorsicherheit (GRS)

Postfach 101650

Glockengrasse 2

5000 Koeln 1

FEDERAL REPUBLIC Of GERMANY 
Kraftwerk Union

Attn: Dr. M. Peehs

Hammerbacher Strasse 1214

Postfach 3220

D-8520 Erlangen 2

FEDERAL REPUBLIC Of GERMANY

UKAEA (9)

Attn: R. Potter 209/A32

A. Nichols $102 / A 50$

B. Bowsher 105A/A50

J. Mitchell 01/A50

B. Morris 216/A32

P. Smith $215 /$ A32

D. Sweet

S. Kinnersly $203 / \mathrm{A} 32$

D. Williams $210 / \mathrm{A} 32$

Winfrith, Dorchester

Dorset DT2 8DH

UNITED KINGDOM

Nucleare e della Protezione Sanitaria (DISP) (2)

Attn: Mr. Manilia

Mr. G. Petrangeli

Ente Nazionnle Energie Alternative (ENEA)

Viale Regina Margherita, 125

Casella Postale M. 2358

I-00100 Roma A. D.

ITALY

Dr. K. J. Brinkman

Reactor Centrum Nederland

1755 ZG Petten

THE NETHERLANDS

Kernforschungszentrum Karlsruhe (2)

Attn: H. Alsmeyer

H. Rininsland

Postfach 3640

75 Karlsruhe

FEDERAL REPUBLIC Of GERMANY

Mr. H. Bairiot, Chief

Department LWR Fuel

Belgonucleaire

Rue de Champde Mars. 25

B-1050 Brussels

BELGIUM 
Japan Atomic Energy Research Institute

Attn: K. Sato

Fukoku Seimei Bldg.

2-2-2, Uchisaiwai-cho, Chiyoda-ku, Tokyo

100

JAPAN

Japan Atomic Energy Research Institute

Tokai Research Establishment

Attn: Dr. S. Matsuura, Deputy Director General

Tokai-mura, Naka-gun, Ibaraki-ken

319-11

JAPAN

Japan Atomic Energy Research Institute

Department of Fuel safety Resarch

Attn: Dr. M. Ichikawa, Director

Tokai-mura, Naka-gun, Ibaraki-ken

319-11

JAPAN

Japan Atomic Energy Research Institute

Reactor Accident Laboratory

Attn: Dr. T. Fujishiro, Head

Tokai-mura, Naka-gun, Ibaraki-ken

319-11

JAPAN

Japan Atomic Energy Institute (20)

Severe Accident Research Laboratory

Attn: Dr. K. Soda, Head

N. Yamano

M. Kajimoto

Tokai-mura, Naka-gun, Ibaraki-ken

319-11

JAPAN

P. Fehrenback

Atomic Energy Canada, Ltd.

Chalk River, ontario

CANADA KOJ IJO

UKAEA (2)

Attn: A. Taig

M. Haynes

Safety and Reliauility Directorate

Wigshaw Lane

Culcheth

Warrington WA3 4NE

Chesire

UNITED KINGDOM 
J. R. Mathews

Aere Harwell

Didcot

Oxfordshire OX11 ORA

UNITED KINGDOM

UKAEA Culham Laboratory (3)

Attn: N. J. Brealey E5.152

B. D. Turland E5.157

Abingdon

F. Briscoe

Oxfordshire OX14 3DB

UNITED KINGDOM

H. J. Teague (3)

UKAEA

Safety and Reliability Directorate

Wigshaw Lane

Culcheth

Warrington, WA3 $4 \mathrm{NE}$

UNITED KINGDOM

M. Jankowski

IAEA

Division of Nuclear Reactor Safety

Wagranesrstrasse 5

P. O. Box 100

A/1400 Vienna

AUSTRIA

Statens Karnkraftinspektion

(2)

Attn: L. Hammer

W. Frid

P. O. Box 27106

S-10252 stockholm

SWEDEN

Studvik Energiteknik $A B$

Attn: K. Johansson

S-611 82 Nykoping

SWEDEN

Atomic Energy Canada Ltd. (2)

Attn: H. Rosinger

D. Wren

Pinawa, Manitoba

CANADA ROE 1 LO

Korea Adv Energy Research Inst

Attn: H. R. Jun

P. O. Box 7

Daeduk-Danji

Choong-ĩam

KOREA 
Institute of Nuclear Energy Research Attn: Sen-I Chang

P. O. Box 3

Lungtan

Taiwan 325

REPUBLIC OF CHINA

Juan Bagues

Consejo de Seguridad Nuckan

SOR Angela de la Cruz No 3

Madrid 28056

SPAIN

UKAEA

Reactor Development Division

Attn: T. Butland

Winfrith, Dorchester

Dorset DT2 8DH

UNITED KINGDOM

Ms. C. Lecomte

CEN FAR

60-68 Av. du G. Leclerc - B.P. 6

92265 Fontenay aux Roses cedex

France

Dr. A. Meyer-Heine

CEN Cadarache

13108 Saint Paul lez Durance

France

Dr. A. Tattegrain

CEN Cadarache

13108 Saint Paul lez Durance

France

Dr. G. Hache

CEN Cadarache

13108 Saint Paul lez Durance

France 
1810 D. W. Schaeffer

2514 W. W. Tarbell

3141 S. A. Landenberger (5)

3145 Document Processing

for DOE-OSTI (8)

3151 G. L. Esch

6321 B. D. Zak

6400 D. J. McCloskey

6410 D. A. Dahlgren

6412 A. L. Camp

6415 R. M. Cranwell

6418 R. K. Cole

6418 J. E. Kelly

6420 W. B. Gauster

6422 D. A. Powers (2)

6422 M. D. Allen (5)

6422 F. E. Arellano

6422 N. Bixler

6422 R. Blose

6422 J. E. Brockmann

6422 R. M. Elrick

6422 E. R. Copus

6422 T. Heames

6422 D. A. Lucero

6422 M. Pilch (5)

6422 R. T. Nichols

6423 K. O. Reil

6425 D. R. Bradley

6429 K. E. Washington

6429 F. Gelbard

6429 D. C. Williams

6473 W. A. Von Riesemann

8524 J. A. Wackerly 

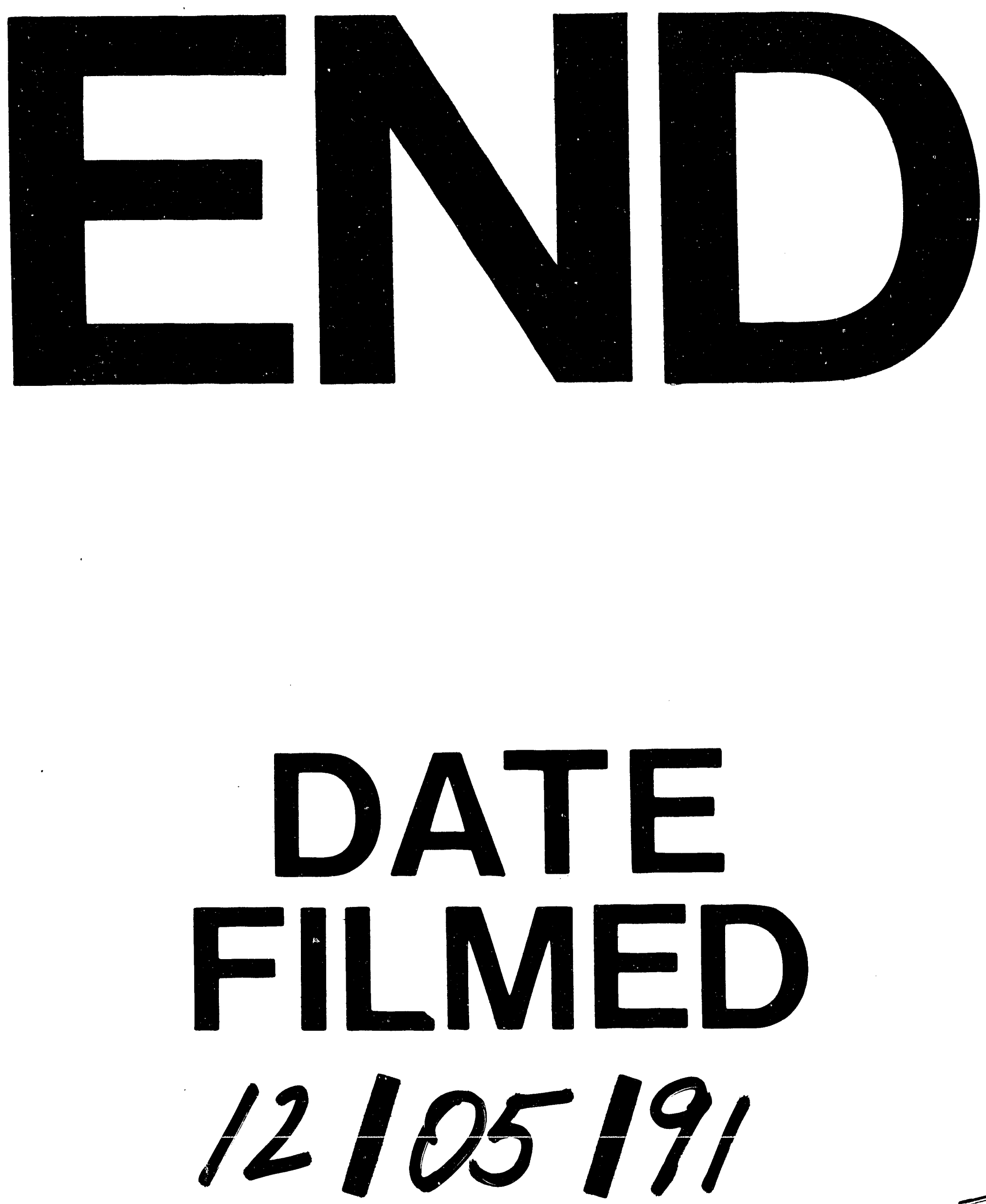

I 
